\author{
UNIVERSIDADE DE SÃO PAULO \\ FACULDADE DE ZOOTECNIA E ENGENHARIA DE ALIMENTOS
}

LEANDRO FÉLIX DEMUNER

Ajuste de curvas de crescimento e deposição de nutrientes em linhagens de frangos de corte com análise econômica

PIRASSUNUNGA

2016 
LEANDRO FÉLIX DEMUNER

Ajuste de curvas de crescimento e deposição de nutrientes em linhagens de frangos de corte com análise econômica

"Versão corrigida"

Tese apresentada à Faculdade de Zootecnia e Engenharia de Alimentos da Universidade de São Paulo, como parte dos requisitos para a obtenção do Titulo de Doutor em Ciências.

Área de Concentração: Qualidade e Produtividade Animal.

Orientador: Prof. Dr Douglas Emygdio de Faria

PIRASSUNUNGA 
Ficha catalográfica elaborada pelo

Serviço de Biblioteca e Informação, FZEA/USP, com os dados fornecidos pelo autor

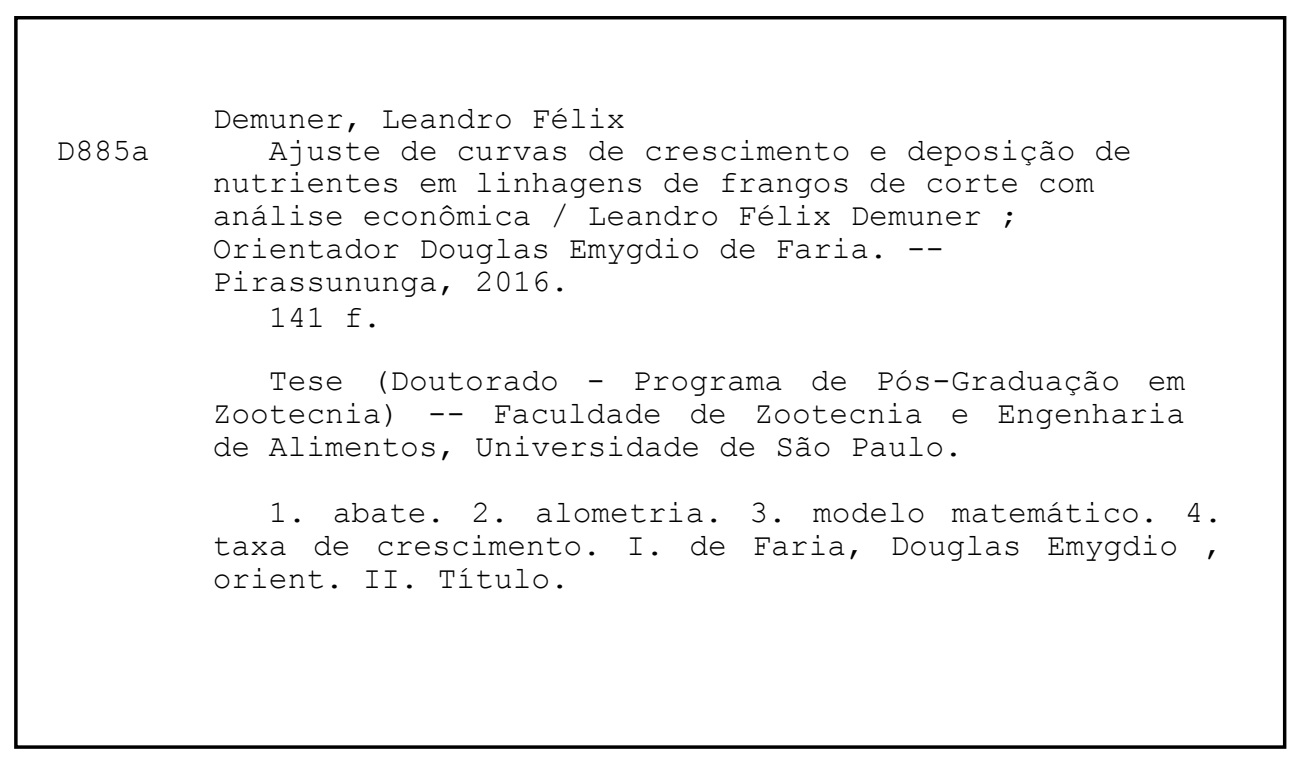

Permitida a cópia total ou parcial deste documento, desde que citada a fonte - o autor 


\title{
Ajuste de curvas de crescimento e deposição de nutrientes em linhagens de frangos de corte com análise econômica
}

\author{
Tese apresentada à Faculdade de \\ Zootecnia e Engenharia de Alimentos da \\ Universidade de São Paulo, como parte \\ dos requisitos para obtenção do Título \\ de Doutor em Ciências. \\ Área de Concentração: Qualidade e \\ Produtividade Animal \\ Orientador: Prof. Dr Douglas Emygdio de \\ Faria
}

\section{Data da aprovação: 24/08/2016}

Banca Examinadora:

Prof. Dr. Douglas Emygdio de Faria - Presidente da Banca Examinadora Faculdade de Zootecnia e Engenharia de Alimentos, Universidade de São Paulo, Pirassununga.

Prof. Dr. César Gonçalves de Lima - Faculdade de Zootecnia e Engenharia de Alimentos, Universidade de São Paulo, Pirassununga.

Profa. Dra. Cristiane Gonçalves Titto - Faculdade de Zootecnia e Engenharia de Alimentos, Universidade de São Paulo, Pirassununga.

Prof. Dr. José Fernando Machado Menten - Escola Superior de Agricultura "Luiz de Queiroz", Universidade de São Paulo, Piracicaba.

Prof.Dr. Manoel Garcia Neto - Faculdade de Medicina Veterinária, Universidade Estadual Paulista Júlio de Mesquita Filho, Araçatuba. 


\section{DEDICATÓRIA}

Ao grande Deus, por me conceder a vida;

Aos meus pais, Pedro Leone Demuner e Ângela Lucia Lago Loures, pois sempre me guiaram pelo caminho do bem;

Aos meus irmãos, pela vivência e cumplicidade;

A todos os professores, pelos ensinamentos dentro e fora da sala de aula;

A todos meus amigos que me ajudaram direta e indiretamente na minha trajetória de vida até aqui.

"Você é a média das cinco pessoas com que mais passa tempo."

Jim Rohn 


\section{AGRADECIMENTOS}

À Faculdade de Zootecnia e Engenharia de Alimentos, Campus de Pirassununga - USP, pela oportunidade oferecida para a realização deste curso.

À Coordenação de Aperfeiçoamento de Pessoal de Nível Superior (CAPES) pelo oferecimento da bolsa de estudos.

Ao Prof. Dr. Douglas Emygdio de Faria pela oportunidade de ser seu orientado, estagiário do Programa de Aperfeiçoamento do Ensino (PAE) e pelos ensinamentos, dedicação e paciência.

Ao Prof. Dr. Daniel Emygdio de Faria Filho por sua valiosa contribuição nas análises estatísticas, conselhos na redação, apoio e amizade.

Ao Prof. Dr. César Gonçalves de Lima agradeço por ter sido, por duas vezes, meu supervisor no PAE, além disso, sou muito grato por todo ensinamento, colaboração nas análises estatísticas, amizade e paciência.

A Professora Catarina Abdalla Gomide pelos conselhos nas análises bromatológicas.

Aos membros da banca pelas correções e observações que foram bem proveitosas na redação desta tese.

Aos professores da UFES, José Geraldo de Vargas Junior e Walter Amaral Barboza, que fizeram parte da minha formação como Zootecnista e também aos eternos amigos pela convivência desta época e sempre: Ana Paula Januário, Bruno Scottá, Déborah Rodrigues, Pedro Laino e Victor Massini.

Aos funcionários do Laboratório de Avicultura Vanessa de Souza Nakagi, Cibele Padro Zinni e Cláudio da Silva pela amizade, dedicação, competência e profissionalismo. 
Aos funcionários da biblioteca que contribuíram com grandiosas observações quanto à normalização da tese.

Aos funcionários do matadouro-escola, confinamento e fábrica de ração, que contribuíram para a realização prática deste trabalho sem medir esforços.

Aos colegas de Laboratório Amanda Caniatto, Julian Muñoz, Vinicius Caetano, Amanda Lapa, Ana Paula agradeço por toda ajuda e contribuição neste trabalho, assim como todos os momentos divertidos. Também aos estagiários do laboratório, Kauan Oliveira, Mariana Palhares, Renan Silva agradeço pela contribuição na parte prática do experimento desde a chegada dos pintinhos até corte de penas.

Ao grupo de amigos mais divertido e animado de Pirassununga, Diana Suckeveris, Fernanda Cavalari, Jairo Azevedo, Kazuo Yokobatabe, Lina Rodrigues, Lucas Arantes, Thiago Almeida, Yuri Natividade e em especial, Elayna Maciel e Isabela Menezes, pela companhia de todas as horas e pela grande amizade construída em todo esse período, agradeço a todos pelos momentos de Farras.

Aos irmãos de Republica (Família) Só-Kanela, Paulo Bravo (Mindinho), Leonardo Capeletto (Diabo), Victor Antonialli (Bocó), Samuel Oliveira (Bucefálo), Henrique Silva (Biba), Bruno Viana (Chico), Mickaël Boillon (Francês maldito), Felipe Leão (Batata), Lucas Ruela (Ruela), Vitor Nonino (Marica), João Fracaro (Mutuca), Lucas Marques (Aranha), Gabriel Ferreira (Flehmen), Rodrigo Guerra (Cunheta), Gabriel Araujo (Marpa), Mateus Crispim (Calango), Davi Lima (Jacú), meus sinceros agradecimentos por toda convivência, respeito e amizade construída durante esse período que permaneci na casa.

Àqueles que não foram citados aqui, mas de alguma forma contribuíram para a realização deste trabalho, direta ou indiretamente, meus sinceros agradecimentos. 


\section{RESUMO}

DEMUNER, L. F Ajuste de curvas de crescimento e deposição de nutrientes em linhagens de frangos de corte com análise econômica. 2016, 141p. Tese (Doutorado) - Faculdade de Zootecnia e Engenharia de Alimentos, Universidade de São Paulo, 2016.

O estudo foi conduzido para estimar os parâmetros, avaliar e comparar os ajustes de curvas de crescimento corporal e dos componentes corporais físicos e químicos, de linhagens de frangos de corte sexados. Foram utilizados 1848 pintinhos de um dia de idade distribuídos em delineamento inteiramente casualizado com tratamentos em esquema fatorial hierárquico com os fatores: Sexo (Macho e Fêmea) e Linhagens (Cobb 500, Ross 308 e Hubbard Flex) dentro de cada sexo, totalizando seis tratamentos com seis repetições de 50 aves cada. A dieta experimental atendeu à necessidade nutricional para cada sexo. No primeiro dia foram abatidos oito animais de cada linhagem e sexo, obtendo o peso inicial dos componentes físicos e químicos e semanalmente as aves e rações de cada boxe foram pesadas para obter os dados de consumo de ração e peso corporal. De acordo com o peso médio de cada boxe foram feitos abates semanais, de dois a três animais ( $24 \mathrm{~h}$ de jejum), sendo obtidos os pesos: corporal em jejum, corporal em jejum depenado, penas, carcaça, peito, coxa, sobrecoxa, asa, coração, fígado e moela. Outras duas aves (a partir do peso médio do boxe) em jejum foram foram selecionadas para o estudo de deposição dos nutrientes sobre o peso corporal em jejum depenado e de penas, tendo amostras destas características sido processadas, homogeneizadas e analisadas para matéria seca, nitrogênio, extrato etéreo e cinzas. Os parâmetros médios das curvas foram estimados, assim como os coeficientes alométricos e utilizados os critérios estatísticos de qualidade de ajuste (coeficiente de determinação, coeficiente de determinação ajustado, Critério de informação de Akaike e Critério de informação Bayesiano de Schwarz) para selecionar o modelo mais adequado. Também foi realizada a análise técnica (conversão alimentar) e econômica (margem bruta de comercialização - MB) a partir de estimativas de pesos corporais e de consumo de ração do melhor modelo selecionado, nos pesos e idade de abate predeterminados. A curva de Gompertz e a equação de alometria em função da proteína corporal foram selecionadas para estimar os valores individuais 
dos pesos de cada boxe e avaliar os efeitos de sexo e de linhagem em cada sexo. Os coeficientes alométricos foram heterogônicos negativos para a deposição de água corporal e órgãos; e heterogônicos positivos para cinzas, gordura corporal, carcaça e cortes da carcaça. Os machos tiveram maior desenvolvimento corporal e dos componentes com maior precocidade, exceto para gordura corporal. Macho Cobb 500 apresentou peso superior de peito; macho Hubbard maior deposição de proteína corporal, sendo mais eficiente tecnicamente e Ross 308 , macho e fêmea, foram mais precoces para crescimento corporal e para a maior parte dos componentes. $\mathrm{Na}$ análise econômica utilizando o modelo Gompertz observou-se que machos apresentaram melhor conversão alimentar e MB do que fêmeas e Ross 308 , apesar de ter comportamento superior em crescimento e precocidade, não foi tão eficiente tecnicamente e/ou economicamente quanto às linhagens Cobb $500 \mathrm{e}$ Hubbard Flex nas últimas pesagens.

Palavras-Chave: abate, alometria, modelo matemático, taxa de crescimento 


\begin{abstract}
DEMUNER, L. F Growth curves adjustment and nutrient deposition in broilers strains with economic analysis. 2016, 141p. Thesis (Doctorate)- Faculdade de Zootecnia e Engenharia de Alimentos, Universidade de São Paulo, 2016.
\end{abstract}

The study was conducted to estimate the parameters, evaluate and compare the adjustments of body growth curves and the physical and chemical body components, lines of sexed broilers. 1848 day-old chicks in a completely randomized design in a factorial design with treatments in hierarchical factorial design with the factors: sex (male and female) and strains (Cobb 500, Ross 308 and Hubbard Flex) within each sex, a total of six treatments with six replicates of 50 birds each. The experimental diet attended the nutritional requirement for each sex. On the first day, eight animals of each strain and sex were slaughtered, obtaining the initial weight of the physical and chemical components and weekly birds and every boxing feeds were weighed for the feed intake data and body weight. According to the mean weight of each pen were made weekly slaughter, two or three animals (24 h of fasting) were obtained, weights: Body fasting, body fasting plucking, feathers, carcass, chest, thigh, drumstick, wing, heart, liver and gizzard. Other two birds (from average body weight) fasted were used to study deposition of nutrients on body weight plucking fasting and feathers, and samples of these characteristics were processed, homogenized and analyzed for dry matter, nitrogen, extract ethereal and ashes. The average curve parameters were estimated, as well as the allometric coefficients and used statistical criteria for goodness of fit (coefficient of determination, adjusted determination coefficient, Akaike information criterion and Bayesian information criterion of Schwarz) to select the most appropriate model. It was also carried out technical analysis (feed conversion) and economic (gross margin trading - GM) from body weights estimates and feed intake of the best model selected, the weight and age of predetermined slaughter. The Gompertz curve and the allometry equation as a function of body protein were selected to estimate individual values of each pen weights and evaluate the effects of sex and strain of each sex. The allometric coefficients were negative heterogônic for the deposition of body water and organs; and positive heterogônic for ashes, body fat, carcass and carcass cuts. Males had earlier higher body development and their components, except for body fat. Male 
Cobb 500 showed a higher weight breast and thigh, male Hubbard had greater deposition of body protein being more efficient and technically Ross 308 , male and female, were earlier for body growth and most of their components. In the economic analysis using the Gompertz model it was observed that males had better feed conversion and GM than females and Ross strain 308, despite having higher growth and precocity, it was not as efficient technically and / or economically as the Cobb 500 and Hubbard Flex.

Males had higher body development and components begin earlier, except for body fat. Male Cobb 500 showed superior weight breast; Male Hubbard had greater deposition of body protein being more efficient and technically Ross 308 , male and female, were earlier for body growth and most of the components. In the economic analysis using the Gompertz model was observed that males had better feed conversion and MB than females and Ross strain 308, that despite having superior behavior on growth and earliness, this last line was not as efficient technically and / or economically as the lines Cobb 500 and Hubbard Flex in the last weighing.

Keywords: Allometry, growth rate, mathematical model, slaughter 


\section{LISTA DE FIGURAS}

Figura 1 - Variação dos valores dos parâmetros no modelo de Richards reparametrizado 36

Figura 2 - Alometria entre o peso proteico corporal e o peso da carcaça de frangos machos.

Figura 3 - Valores de temperatura e umidade relativa do aviário durante o experimento

Figura 4- Ajustes dos modelos de crescimento sobre as características de consumo de ração $(C R-1)$ e peso corporal $(P C-2)$ de frangos de corte machos (-) e fêmeas (- - -). .56

Figura 5- Ajustes dos modelos de crescimento sobre as características de PC de frangos de corte em jejum e depenado (PCJD- 1) e das penas (2) de machos (-) e fêmeas (- - -).

Figura 6- Ajustes dos modelos de crescimento sobre as características de carcaça (1) e peito (2) de frangos de corte machos (-) e fêmeas (- - -) .58

Figura 7 - Ajustes dos modelos de crescimento sobre as características de coxa (1) e sobrecoxa (2) para frangos de corte machos (-) e fêmeas (- - -).

Figura 8 - Ajustes dos modelos de crescimento sobre as características de asa (1) e moela (2) para frangos de corte machos (-) e fêmeas (- - -).

Figura 9 - Ajustes dos modelos de crescimento sobre as características de coração (1) e fígado (2) para frangos de corte machos (-) e fêmeas (- - -) .

Figura 10 - Curvas e taxas de consumo de ração (1) e crescimento corporal (2) em linhagens Cobb $500(\mathrm{C})$, Ross $308(\mathrm{R})$, Hubbard Flex (H), machos (a) e fêmeas (b), segundo modelo de Gompertz*.

Figura 11 - Curvas e taxa de crescimento do peso corporal em jejum de 24 horas (PCJ - 1) e depenado (PCJD - 2) em linhagens Cobb 500 (C), Ross 308 (R), Hubbard Flex $(\mathrm{H})$, machos (a) e fêmeas (b), segundo modelo de Gompertz* .77

Figura 12 - Curvas e taxas de deposição de agua (1) e proteína (2) no peso corporal em jejum de 24 horas e depenado (PCJD) em linhagens Cobb 500 (C), Ross 308 $(R)$, Hubbard Flex $(H)$, machos (a) e fêmeas $(b)$, segundo modelo de Gompertz*...82 Figura 13 - Curvas e taxas de deposição de gordura (1) e cinzas (2) no peso corporal em jejum de 24 horas depenado (PCJD) em linhagens Cobb 500 (C), Ross 
$308(R)$, Hubbard Flex $(H)$, machos (a) e fêmeas (b), segundo modelo de Gompertz

Figura 14 - Curvas e taxas de crescimento de penas em linhagens Cobb 500 (C), Ross $308(\mathrm{R})$, Hubbard Flex $(\mathrm{H})$, machos e fêmeas, segundo modelo de Gompertz*

Figura 15 - Curvas e taxas de deposição de água (1) e proteína bruta (2) nas penas em linhagens Cobb $500(\mathrm{C})$, Ross $308(\mathrm{R})$, Hubbard Flex $(\mathrm{H})$, machos (a) e fêmeas (b), segundo modelo de Gompertz*

Figura 16 - Curvas e taxas de deposição de gordura nas penas em linhagens Cobb $500(\mathrm{C})$, Ross $308(\mathrm{R})$, Hubbard Flex $(\mathrm{H})$, machos e fêmeas, segundo modelo de Gompertz* 92

Figura 17 - Curvas e taxas de crescimento do peso da carcaça em linhagens Cobb $500(\mathrm{C})$, Ross $308(\mathrm{R})$, Hubbard Flex $(\mathrm{H})$, machos e fêmeas, segundo modelo de Gompertz*

Figura 18 - Curvas e taxa de crescimento do peso do peito em linhagens Cobb 500 (C), Ross $308(R)$, Hubbard Flex $(H)$, machos e fêmeas, segundo modelo de Gompertz* .97

Figura 19 - Curva e taxa de crescimento do peso de coxa em linhagens Cobb 500 (C), Ross $308(R)$, Hubbard Flex $(H)$, machos e fêmeas, segundo modelo de Gompertz 101

Figura 20 - Curvas e taxa de crescimento do peso de sobrecoxa em linhagens Cobb $500(\mathrm{C})$, Ross $308(\mathrm{R})$, Hubbard Flex $(\mathrm{H})$, machos e fêmeas, segundo modelo de Gompertz*

Figura 21 - Curvas e taxa de crescimento do peso de asa em linhagens Cobb 500 $(C)$, Ross $308(R)$, Hubbard Flex $(H)$, machos e fêmeas, segundo modelo de Gompertz* 106

Figura 22 - Curvas e taxas de crescimento de coração em linhagens Cobb 500 (C), Ross $308(R)$, Hubbard Flex $(H)$, machos e fêmeas, segundo modelo de Gompertz*

Figura 23 - Curvas e taxas de crescimento do fígado em linhagens Cobb 500 (C), Ross $308(R)$, Hubbard Flex $(H)$, machos e fêmeas, segundo modelo de Gompertz* 
Figura 24 - Curvas e taxas de crescimento da moela em linhagens Cobb 500 (C), Ross $308(R)$, Hubbard Flex $(H)$, machos e fêmeas, segundo modelo de Gompertz* 117

Figura 25 - Conversão alimentar estimada a partir do modelo de Gompertz de acordo com as predeterminações de peso e idade para linhagens e sexo de frangos de corte 122 Figura 26 - Margem bruta estimada a partir do modelo de Gompertz de acordo com as predeterminações de peso e idade para linhagens e sexo de frangos de corte.122 


\section{LISTA DE TABELAS}

Tabela 1 - Composição percentual e valores calculados das dietas experimentais de frangos de corte

Tabela 2 - Modelos de crescimento e respectivas taxas máximas (TM) e pontos de inflexões (PI)

Tabela 3 - Preços médio para os ingredientes das rações experimentais e do frango para corte

Tabela 4 - Avaliação do ajuste médio de modelos matemáticos (com 3 e 4 parâmetros) das características avaliadas de frangos machos (M) e fêmeas (F), através do coeficiente de determinação (R2) ajustado $\left(R^{2}{ }_{\text {aj }}\right)$ e pelos critérios de informação de Akaike (AIC) e Bayesiano de Schwarz (BIC) .55

Tabela 5 - Estimativas dos parâmetros $(\mathrm{a}, \mathrm{b}, \mathrm{k} \text { e } \mathrm{m})^{1}$ dos modelos matemáticos não ponderados (NP) e ponderados $(P)$ em características $(C)$ avaliadas de frangos machos $(M)$ e fêmeas $(F)$

Tabela 6 - Avaliação do ajuste médio da equação alométrica das características avaliadas de frangos machos $(M)$ e fêmeas $(F)$, através do coeficiente de determinação ajustado $\left(R^{2}{ }_{a j}\right)$ e pelos critérios de informação de Akaike $(A I C)$ e Bayesiano de

Schwarz

$(\mathrm{BIC})^{*}$ contínua

Tabela 7 - Estimativas médias e erros-padrões dos parâmetros (a, b e k), taxa máxima de consumo de ração ou crescimento (TM CR/C) e idade de inflexão (Ti) do modelo de Gompertz sobre o consumo de ração e peso corporal de frangos machos (M) e fêmeas (F) das linhagens Cobb 500(C), Ross 308 (R) e Hubbard Flex (H)....70 Tabela 8 - Média semanal do ganho de peso corporal (PC) e consumo de ração (CR) diário de frangos machos $(\mathrm{M})$ e fêmeas $(F)$ das linhagens Cobb $500(\mathrm{C})$, Ross 308 $(\mathrm{R})$ e Hubbard Flex $(\mathrm{H})$, segundo modelo de Gompertz

Tabela 9 - Médias e erros-padrões das estimativas dos parâmetros (a, b e k), taxa máxima de crescimento (TMC) e idade de inflexão (Ti) da curva de Gompertz sobre o peso corporal de frangos em jejum de 24 horas (PCJ) e depenados (PCJD), em machos (M) e fêmeas (F), das linhagens Cobb 500 (C), Ross 308 (R) e Hubbard Flex (H)

Tabela 10 - Média semanal de ganho diário de peso corporal após jejum de 24 horas (PCJ) e peso corporal depenado em jejum de 24 horas (PCJD) de frangos 
machos (M) e fêmeas (F) das linhagens Cobb 500 (C), Ross 308 (R) e Hubbard Flex $(\mathrm{H})$, segundo modelo de Gompertz

Tabela 11 - Médias e erros-padrões das estimativas dos parâmetros (a, b e k), taxa máxima de deposição (TMD) e idade de inflexão (Ti) da curva de Gompertz sobre nutrientes depositados (água, proteína bruta, gordura e cinzas) no corpo em jejum de 24 horas e depenado (PCJD) de frangos machos (M) e fêmeas (F) das linhagens Cobb 500 (C), Ross 308 (R) e Hubbard Flex (H) .79

Tabela 12 - Média semanal de ganho de peso médio dos nutrientes (água, proteína bruta, gordura e cinzas) depositados no peso corporal em jejum de 24 horas e depenado $(\mathrm{g})$ de frangos machos $(\mathrm{M})$ e fêmeas $(\mathrm{F})$ das linhagens Cobb $500(\mathrm{C})$, Ross $308(\mathrm{R})$ e Hubbard Flex $(\mathrm{H})$, segundo modelo de Gompertz Tabela 13 - Médias e erros-padrões do intercepto $(\alpha)$, coeficiente de regressão $(\beta)$ e coeficiente de determinação $\left(R^{2}\right)$ das equações alométricas de água, gordura e cinzas em função da proteína corporal de frangos machos $(M)$ e fêmeas $(F)$ das linhagens Cobb $500(\mathrm{C})$, Ross 308 (R) e Hubbard Flex (H) .86 Tabela 14 - Médias e erros-padrões das estimativas dos parâmetros (a, b e k), taxa máxima de crescimento ou deposição (TMC/D) e idade de inflexão (Ti) da curva de Gompertz sobre o peso e nutrientes depositados (água, proteína bruta (PB), gordura e cinzas) das penas de frangos machos (M) e fêmeas $(F)$ das linhagens Cobb 500 (C), Ross 308 (R) e Hubbard Flex (H). 88 Tabela 15 - Média da deposição diária de nutrientes (água, proteína bruta e gordura) de penas de frangos machos (M) e fêmeas (F) das linhagens Cobb 500 (C), Ross $308(\mathrm{R})$ e Hubbard Flex $(\mathrm{H})$, em intervalos de 7 dias, segundo o modelo de Gompertz. .89

Tabela 16 - Médias e erros-padrões das estimativas dos parâmetros (a, b e k), taxa máxima de crescimento (TMC) e da idade de inflexão (Ti) do modelo de Gompertz sobre a carcaça e componentes físicos da carcaça de frangos machos ( $M)$ e fêmeas (F) das linhagens Cobb 500 (C), Ross 308 (R) e Hubbard Flex (H) .......................93 Tabela 17 - Média de ganho diário de peso de carcaça (g) de frangos machos (M) e fêmeas (F) das linhagens Cobb 500 (C), Ross 308 (R) e Hubbard Flex (H), em intervalos de 7 dias, segundo modelo de Gompertz 93 Tabela 18 - Médias e erros-padrões das estimativas dos parâmetros (a, b e k), taxa máxima de crescimento (TMC) e da idade de inflexão (Ti) do modelo de Gompertz 
sobre o peso do peito de frangos machos (M) e fêmeas (F) das linhagens Cobb 500 (C), Ross 308 (R) e Hubbard Flex (H).

Tabela 19 - Média semanal de ganho diário de peso de peito $(\mathrm{g})$ de frangos machos (M) e fêmeas (F) das linhagens Cobb 500 (C), Ross $308(\mathrm{R})$ e Hubbard Flex (H), segundo modelo de Gompertz .96

Tabela 20 - Médias e erros-padrões das estimativas dos parâmetros ( $a$, b e k), taxa máxima de crescimento (TMC) e da idade de inflexão (Ti) do modelo de Gompertz sobre o peso de coxa de frangos machos (M) e fêmeas (F) das linhagens Cobb 500 (C), Ross 308 (R) e Hubbard Flex $(\mathrm{H})$.

Tabela 21 - Média de ganho diário de peso de coxa (g) de frangos machos (M) e fêmeas (F) das linhagens Cobb 500 (C), Ross $308(R)$ e Hubbard Flex (H), em intervalos de 7 dias, segundo modelo de Gompertz 100

Tabela 22 - Médias e erros-padrões das estimativas dos parâmetros ( $a$, b e k), taxa máxima de crescimento (TMC) e da idade de inflexão (Ti) do modelo de Gompertz sobre o peso de sobrecoxa de frangos machos $(M)$ e fêmeas $(F)$ das linhagens Cobb 500 (C), Ross $308(\mathrm{R})$ e Hubbard Flex (H).... 102

Tabela 23 - Média de ganho diário de peso de sobrecoxa $(\mathrm{g})$ de frangos machos (M) e fêmeas (F) das linhagens Cobb $500(\mathrm{C})$, Ross $308(\mathrm{R})$ e Hubbard Flex (H), em intervalos de 7 dias, segundo modelo de Gompertz 103 Tabela 24 - Médias e erros-padrões das estimativas dos parâmetros (a, b e k), (Ti) taxa máxima de crescimento (TMC) e da idade de inflexão (Ti) do modelo de Gompertz sobre os peso da asa de frangos machos $(M)$ e fêmeas $(F)$ das linhagens Cobb 500 (C), Ross 308 (R) e Hubbard Flex (H) 105 Tabela 25 - Média de ganho diário de peso de asa (g) de frangos machos (M) e fêmeas (F) das linhagens Cobb 500 (C), Ross $308(R)$ e Hubbard Flex (H), em intervalos de 7 dias, segundo modelo de Gompertz 105 Tabela 26 - Médias e erros-padrões das estimativas do intercepto ( $\alpha$ ) e coeficiente de regressão $(\beta)$ alométrico de peso de carcaça, peito, coxa, sobrecoxa e asa em função do peso proteína bruta $(P B)$ corporal de frangos machos $(M)$ e fêmeas $(F)$ das linhagens Cobb $500(\mathrm{C})$, Ross $308(\mathrm{R})$ e Hubbard Flex $(\mathrm{H})^{*}$ 108 Tabela 27 - Médias e erros-padrões das estimativas dos parâmetros (a, b e k), taxa máxima de crescimento (TMC) e da idade de inflexão (Ti) do modelo de Gompertz sobre o coração de frangos machos $(M)$ e fêmeas $(F)$ das linhagens Cobb $500(C)$, Ross 308 (R) e Hubbard Flex (H) 
Tabela 28 - Média de ganho diário de peso de coração $(\mathrm{g})$ de frangos machos (M) e fêmeas $(F)$ das linhagens Cobb $500(C)$, Ross $308(R)$ e Hubbard Flex $(H)$, em intervalos de 7 dias, segundo modelo de Gompertz 110 Tabela 29 - Médias e erros-padrões das estimativas dos parâmetros (a, b e k), taxa máxima de crescimento (TMC) e da idade de inflexão (Ti) do modelo de Gompertz sobre o fígado de frangos machos $(M)$ e fêmeas $(F)$ das linhagens Cobb 500 (C), Ross $308(\mathrm{R})$ e Hubbard Flex $(\mathrm{H})$. 113

Tabela 30 - Média de ganho diário de peso de fígado (g) de frangos machos (M) e fêmeas $(F)$ das linhagens Cobb $500(C)$, Ross $308(R)$ e Hubbard Flex $(H)$, em intervalos de 7 dias, segundo modelo de Gompertz 113 Tabela 31 - Médias e erros-padrões das estimativas dos parâmetros (a, b e k), taxa máxima de crescimento (TMC) e da idade de inflexão (Ti) do modelo de Gompertz sobre a moela de frangos machos (M) e fêmeas (F) das linhagens Cobb 500 (C), Ross 308 (R) e Hubbard Flex $(\mathrm{H})$. 116

Tabela 32 - Média de ganho diário de peso de moela ( $\mathrm{g}$ ) de frangos machos (M) e fêmeas $(F)$ das linhagens Cobb $500(C)$, Ross $308(R)$ e Hubbard Flex $(H)$, em intervalos de 7 dias, segundo modelo de Gompertz 116 Tabela 33 - Médias e erros-padrões das estimativas do intercepto $(\alpha)$ e coeficiente de regressão $(\beta)$ das equações alométricas de peso de coração em função do peso proteico corporal de frangos machos $(\mathrm{M})$ e fêmeas $(F)$ das linhagens Cobb $500(C)$, Ross $308(\mathrm{R})$ e Hubbard Flex $(\mathrm{H})^{*}$ 119

Tabela 34 - Médias de idade ou peso de abate, conversão alimentar (CA) e margem bruta (MB) de comercialização em linhagens e sexo de frangos de corte de acordo com as predeterminações de abate (1350 g, $2350 \mathrm{~g}$ e com 45 dias de idade), utilizando o modelo de Gompertz para estimar o peso corporal em jejum (PCJ) e o consumo de ração. 121 


\section{LISTA DE ABREVIATURAS, SÍMBOLOS E SIGLAS}

\begin{tabular}{|c|c|}
\hline$\alpha$ & Intercepto \\
\hline$\beta$ & Coeficiente alométrico \\
\hline $\boldsymbol{\mu}$ & Taxa relativa de crescimento \\
\hline${ }^{\circ} \mathrm{C}$ & Graus Celsius \\
\hline$\varepsilon$ & Erro experimental \\
\hline $\mathbf{a}$ & Peso à maturidade \\
\hline ABPA & Associação Brasileira de Proteína Animal \\
\hline AIC & Akaike Information Criterion \\
\hline ANOVA & Análise de variância \\
\hline b & Constante de integração \\
\hline BEEP & Broiler Economics for Energy and Protein \\
\hline BIC & Bayesian of Schwarz Information Criterion \\
\hline C & Cobb 500 \\
\hline CÇ & Carcaça \\
\hline CDi & Custo da dieta pelo frango "i"no período "t" \\
\hline CEP & Comitê de Ética em Pesquisa \\
\hline COR & Coração \\
\hline CR & Consumo de Ração \\
\hline $\mathbf{C X}$ & Coxa \\
\hline $\mathbf{H}$ & Hubbard Flex \\
\hline EAT & Eficiência Alimentar Total \\
\hline EFG & Emmans Fischer Gous \\
\hline $\mathbf{F}$ & Fêmea \\
\hline FG & Fígado \\
\hline g & Grama \\
\hline GPTi & Ganho de Peso Total \\
\hline IBGE & Instituto Brasileiro de Geografia e Estatística \\
\hline IEA & Instituto de Economia Agrícola \\
\hline INPC & Índice Nacional de Preços ao Consumidor \\
\hline k & Taxa de maturidade \\
\hline Kcal & Quilocaloria \\
\hline
\end{tabular}




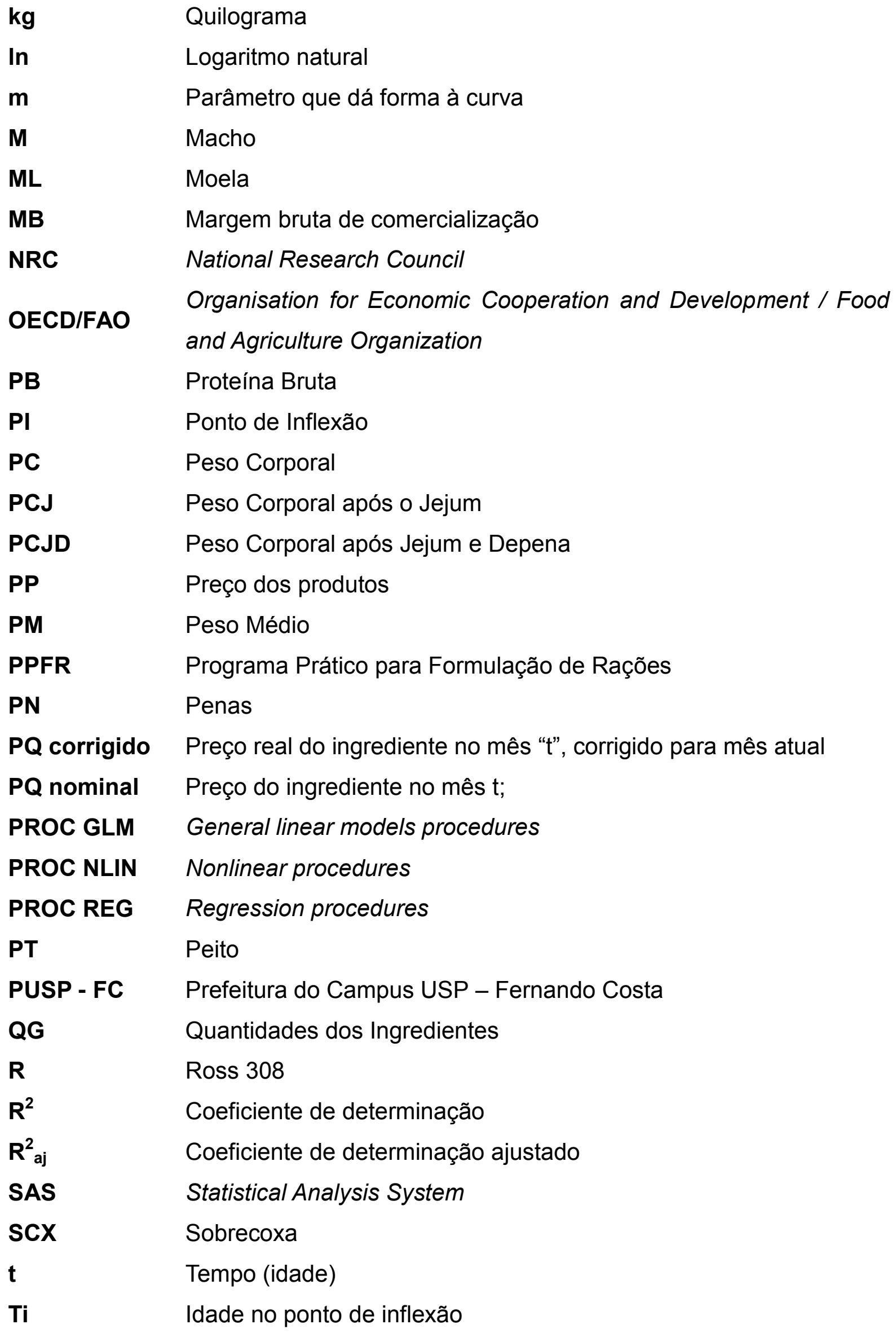


TMC

USDA

$Y_{\mathrm{i}}$

$\mathbf{Y}_{\mathbf{t}}$
Taxa máxima de crescimento

United State Department of Agriculture

Peso da variável no ponto de inflexão

Peso da variável observado na idade " $\mathrm{t}$ " 


\section{SUMÁRIO}

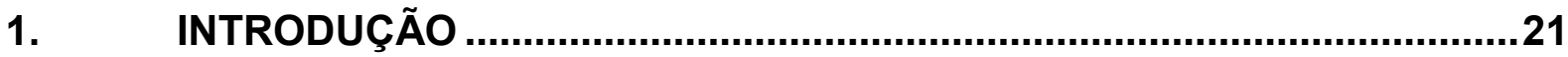

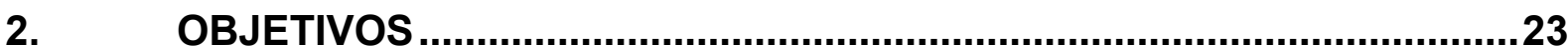

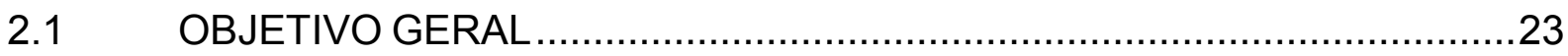

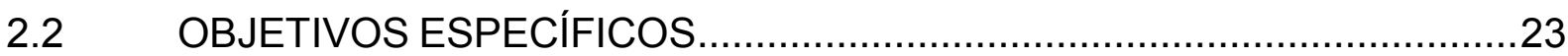

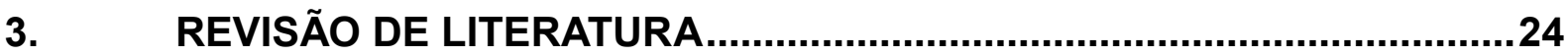

3.1 BREVE HISTÓRICO DA AVICULTURA NO BRASIL ..............................24

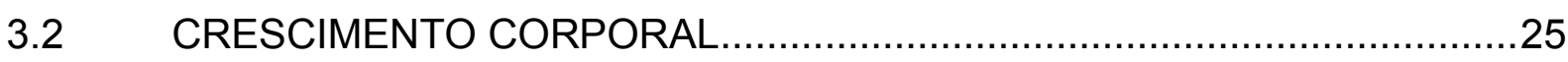

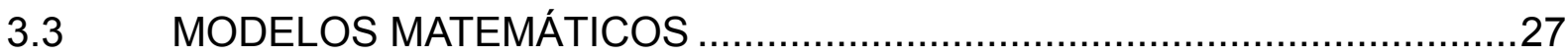

3.3.1 Descrição dos modelos de crescimento ...............................................28

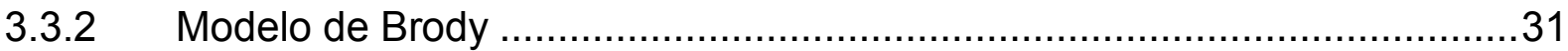

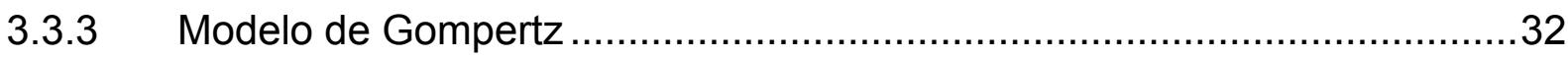

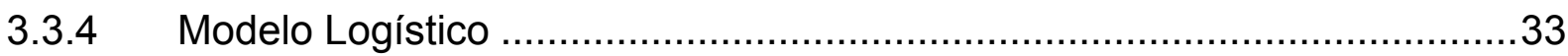

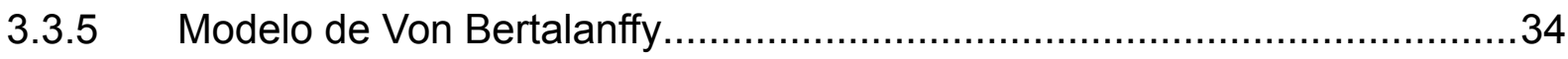

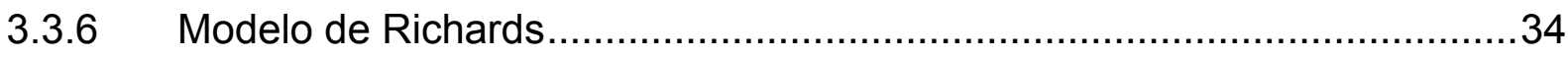

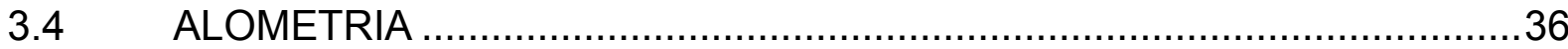

3.5 IMPORTÂNCIA ECONÔMICA DOS MODELOS MATEMÁTICOS ...............40

4. MATERIAL E MÉTODOS

4.1 AVES, DELINEAMENTO EXPERIMENTAL E INSTALAÇÕES ..................43

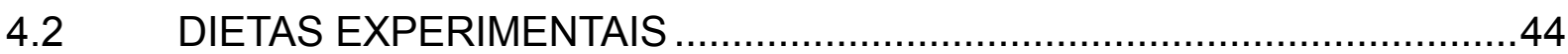

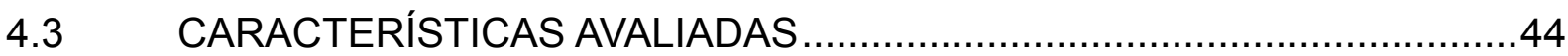

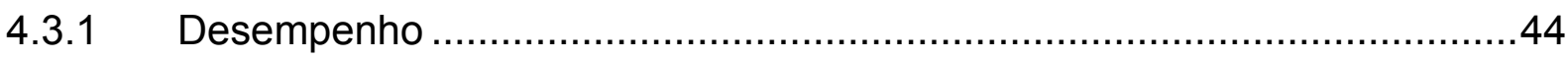

4.3.2 Componentes físicos e químicos ............................................................ 46

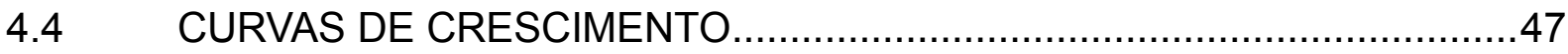

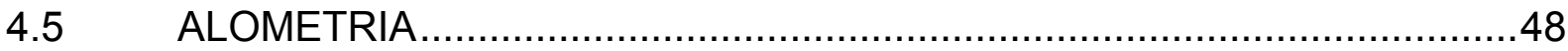

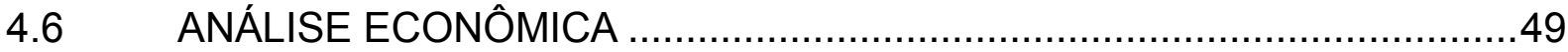

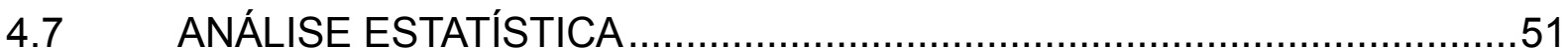

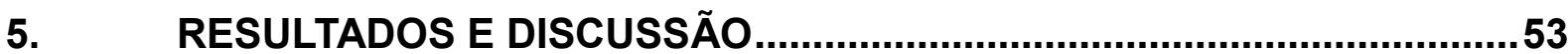

5.1 CONVERGÊNCIA E QUALIDADE DO AJUSTE DE CURVAS DE CRESCIMENTO EM DIFERENTES LINHAGENS DE FRANGOS DE CORTE ........53 
5.2 EQUAÇÕES ALOMETRICAS.

5.3 AVALIAÇÃO DOS PARÂMETROS ESTIMADOS DO CONSUMO DE RAÇÃO, CRESCIMENTO CORPORAL, COMPONENTES FÍSICOS E DEPOSIÇÃO DE NUTRIENTES CORPORAIS .69

5.3.1 Consumo de ração e crescimento corporal ...........................................70

5.3.2 Crescimento e deposição de nutrientes sobre o peso corporal das aves em jejum (PCJ) e depenadas (PCJD) e das penas ...................................................

5.3.2.1 Crescimento, deposição dos nutrientes no PCJD e alometria .....................76

5.3.2.2 Crescimento e deposição dos nutrientes sobre as penas ...........................86

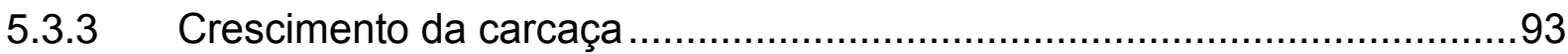

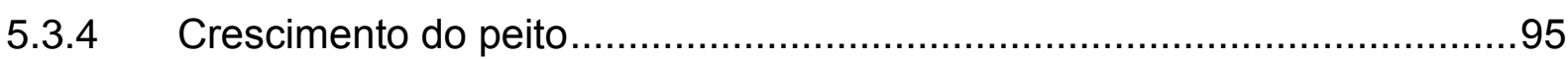

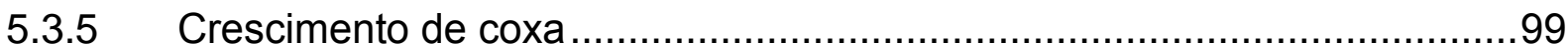

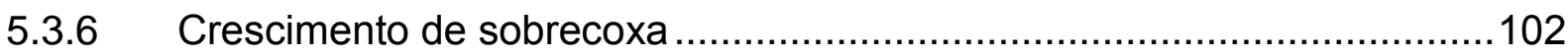

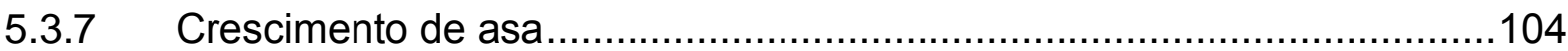

5.3.8 Alometria da carcaça e componentes da carcaça em função da proteína

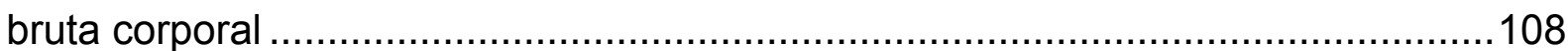

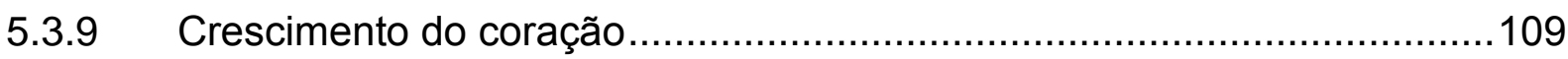

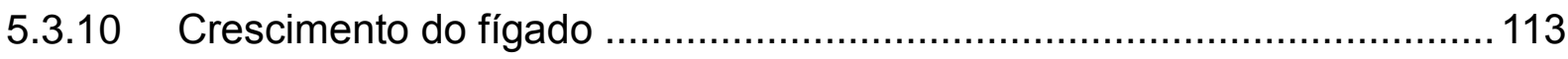

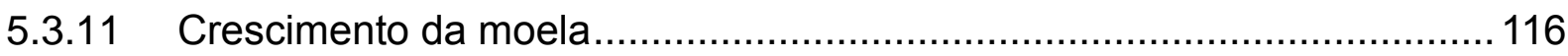

5.3.12 Alometria dos órgãos em função da proteína bruta corporal ..................... 119

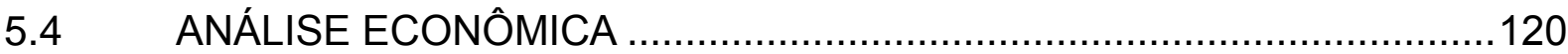

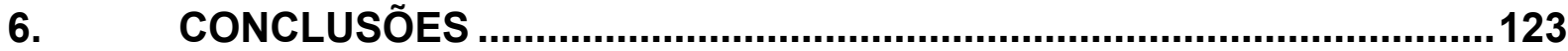

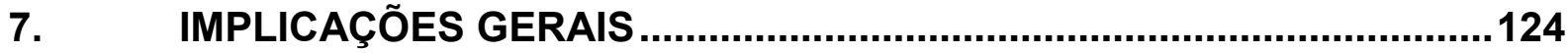

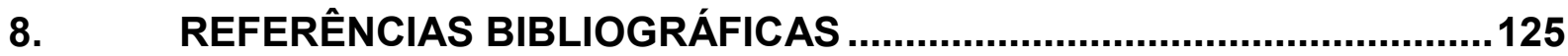

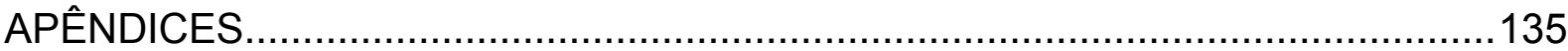




\section{INTRODUÇÃO}

A produção de carnes cresceu cerca de $300 \%$ nos últimos 50 anos devido a crescente melhoria nas práticas de manejo, melhoramento genético realizado na seleção de animais com maior rendimento, e no aprimoramento da alimentação animal. Aliado ao aumento da produção de carnes está o aumento no consumo de carnes, segundo a Organisation For Economic Cooperation And Development / Food And Agriculture Organization (OECD/FAO, 2012).

Dentre a produção de proteína animal chama atenção os registros para a produção de carne de frango no triênio de 2011/2013 pela OCDE/FAO, sendo previsto aumento de $13 \%$ para carne bovina, $15 \%$ para carne suína e $25 \%$ para a carne de aves numa década. De acordo com essa previsão, em 2023 a avicultura terá um papel fundamental com $53 \%$ do crescimento previsto na produção de carne para alimentação do mundo (OECD/FAO, 2014). Segundo o relatório de 2014 da Associação Brasileira de Proteína Animal (ABPA, 2015), os Estados Unidos (17.254.000 de toneladas) e China (13.000.000 de toneladas) foram os maiores produtores de carne de frango e em 2015, conforme a United States Department Of Agriculture (USDA, 2015) o Brasil (13.146.000 de toneladas) ultrapassou o volume produzido pela China (13.025.000 toneladas), passando a ser o segundo maior produtor e o maior exportador mundial de carne de frango com consumo interno anual de 43,25 kg por pessoa (ABPA, 2015).

É possível perceber que o Brasil tem grande potencial neste setor em relação a outros países e este avanço está associado às expressivas evoluções técnicas e científicas na cadeia produtiva do frango de corte. Com isso, gradativamente, efetivou-se a conquista dos mercados interno e externo, superando os diversos concorrentes na oferta de proteína animal.

$\mathrm{O}$ atual sucesso no melhoramento genético nas aves ao longo das últimas décadas tem causado mudanças na curva de crescimento destas, aumentando a eficiência alimentar para máxima expressão do seu potencial genético. Assim, o frango contemporâneo é abatido cada vez mais precoce, com melhorias significativas no crescimento e rendimento de carcaça, particularmente no rendimento de carne de peito, disponibilizando aves com diferentes curvas de 
crescimento e composições corporais, e essas diferenças alteram as exigências nutricionais das aves.

Para medir o potencial de crescimento, em geral, pesquisadores têm usado modelos matemáticos que descrevem várias características de padrões de desenvolvimento das aves. Tais estudos envolvem medidas repetidas no tempo em que as unidades experimentais, representando os diferentes tratamentos (sexo, raça, doses), são analisadas ao longo de diversas condições de avaliação (FREITAS, 2005). Dentre essas análises, na produção animal destacam-se os ajustes das curvas de crescimento, que relacionam os pesos (corporal ou de componentes do corpo) e as idades dos animais, por meio de modelos não lineares.

A partir desses modelos, que caracterizam o crescimento do animal e/ou de partes destes, através de medidas repetidas e do consumo de ração, é possível a tomada de decisão sobre procedimentos nutricionais e de gestão, para otimizar o lucro ou diminuir o prejuízo. 


\section{OBJETIVOS}

\subsection{OBJETIVO GERAL}

Este estudo tem como objetivo a escolha do modelo, através das equações de crescimento e comparar o desenvolvimento corporal e dos componentes físicos e químicos do corpo de machos e de fêmeas das linhagens de frango de corte Cobb 500, Ross 308 e Hubbard Flex.

\subsection{OBJETIVOS ESPECÍFICOS}

Ajustar curvas de crescimento e estimar o crescimento corporal, da carcaça, dos cortes, das penas e consumo de ração para comparação das linhagens comerciais de frango de corte machos e fêmeas.

Estimar o aumento dos componentes químicos (água, cinzas, lipídios e proteína) do corpo usando curvas de crescimento e as relações alométricas que existem entre os diferentes componentes do corpo de linhagens comerciais de frango de corte machos e fêmeas.

Comparar o rendimento econômico das linhagens e sexo, visando à melhor idade de comercialização do frango vivo. 


\section{REVISÃO DE LITERATURA}

\subsection{BREVE HISTÓRICO DA AVICULTURA NO BRASIL}

Existem mais de 300 raças de galinhas domésticas (Gallus domesticus) em todo o mundo, podendo ser distinguidas em três grupos diferentes: raças puras para fins comerciais, raças híbridas que resultam de cruzamentos e raças locais ou nacionais. As principais raças utilizadas como reprodutoras para frangos de corte são a Cornish Branca, Plymouth Rock Branca, New Hampshire e Sussex (FIGUEIREDO, 2003).

No Brasil, entre os anos de 1900 a 1930, as aves eram criadas soltas sem finalidade zootécnica ou interesse econômico, sendo o inicio do ciclo de modernização da economia. Em 1937, foram importadas para o Sul do Brasil as primeiras matrizes do Japão, os quais foram utilizadas para o melhoramento genético junto com matrizes Leghorn (ABPA, 2011). Assim as características fenotípicas relacionadas à estética das aves passaram a ser selecionadas pelos produtores (SILVA; NAKANO, 1998).

Com o decorrer dos anos novas técnicas de produção e a genética deram uma impulsionada na avicultura e a partir da década de 50 foram iniciados os trabalhos pioneiros destinados à obtenção de aves poedeiras comerciais no Instituto de Pesquisa e Experimentação Agropecuária de Centro-Sul. Inclusive, iniciados nesta época os cruzamentos de aves de raça (Cornish Branca, New Hampshire e Plymouth Rock Branca) destinados à produção de carne. Concomitantemente, a granja Guanabara, se preocupava com o melhoramento genético de aves para cortes (EUCLIDES CUNHA, 1999; SILVA, 2009).

Assim sendo, a criação e abate das aves aumentaram entre os anos 50 e 60, colaborando para um novo ciclo de modernas técnicas, e a partir dos anos 60 surgiram as marcas especiais dos produtores, suplantando com as raças de dupla aptidão, com dois tipos de aves comerciais: para cortes e para postura; Além disso, as importações dos EUA de linhagens de corte e postura, contribuíram, ainda mais, com o desenvolvimento do setor. Relatos mostram que as melhores linhagens de corte, da época, atingiam $1,6 \mathrm{~kg}$ com 64 dias e para postura chegavam a cerca de 220 ovos, em 14 meses de produção (ABPA, 2011). 
Nesta mesma época outras instituições brasileiras iniciaram novas pesquisas genéticas na avicultura: a Escola Superior de Agricultura "Luiz de Queiroz" (ESALQ) nos anos 60; a Universidade Federal de Viçosa, no final de 1970; e dai em diante outras instituições como Instituto de Zootecnia em Nova Odessa; a Universidade Federal de Pelotas (UFPel), Universidade Federal de Santa Maria (UFSM) e mais tarde a EMBRAPA também contribuíram para as pesquisas com aves (COELHO et al., 2008; EUCLIDES CUNHA, 1999; SILVA, 2009). Entretanto, com a estagnação dos programas de melhoramento nos anos 90 e a redução dos investimentos governamentais devido à abertura do mercado pela globalização, as multinacionais intensificaram o processo do melhoramento de raças e originaram linhagens específicas com características próprias chamada de raças híbridas e são muito comuns, apresentando maior produtividade do que as raças puras (MADEIRA et al., 2006).

O mercado mundial de genética avícola impõe intensa competição, tornando o mercado dinâmico e com fortes barreiras à entrada de novos concorrentes, sendo inviável investir nesta área, que demanda grandes investimentos para manter as atividades de pesquisa e desenvolvimento (MARTINELLI, 2009). Dessa forma, existem algumas empresas que monopolizam o mercado mundial na área da genética avícola com seus híbridos: Ross, Cobb Vantress, Hybro, Isa Vedette, MPK, Arbor Acres, Avian, Shaver e Hubbard; sendo os híbridos comerciais de frangos de corte nacionais: Embrapa 021, S-54 e Chester (FIGUEIREDO, 2003). Todos os cruzamentos para obter as linhagens atuais de frango de corte são realizados no Brasil (ABPA, 2011) e as empresas Aviagen Internacional (Erich Wesjohann GroupAlemanha) e Cobb-Vantress (Tyson - EUA) possuem maior parte do mercado internacional e nacional de genética avícola (COELHO et al., 2008; SOUZA ALVES, 2003).

\subsection{CRESCIMENTO CORPORAL}

De acordo com Gous (2007) o crescimento é normalmente acompanhado por uma sequência ordenada de mudanças na maturação e envolve a deposição de proteína e aumento em comprimento e diâmetro, e não apenas um aumento de peso. As fases iniciais de crescimento ocorrem principalmente através do processo de aumento do número de células (hiperplasia), enquanto que as etapas posteriores 
são o resultado, principalmente do aumento no tamanho da célula (hipertrofia), embora este modifique com os diferentes tecidos e espécies.

O crescimento animal pode ser definido como o aumento do tamanho e ganho de peso. Na verdade, essa afirmação não está totalmente correta, pois uma ave adulta não deveria ganhar peso. O crescimento é observado pelo aumento da proteína corporal excluindo a deposição de gordura do ganho de peso, sendo observada esta fase na ave jovem. Entretanto, na ave adulta também ocorre deposição de gordura, mas a taxa relativa de síntese proteica é maior na ave jovem, enquanto que a taxa relativa de deposição de gordura é maior na ave mais velha. $O$ crescimento dos diferentes tecidos ocorre inicialmente no tecido nervoso seguido do ósseo, muscular e adiposo (GONZALES; SARTORI, 2002).

O estudo do aumento dos músculos é fundamental para o conhecimento dos processos de crescimento corporal, porque quanto maior a produção de músculos, maior a produção de carne e, para que o desenvolvimento muscular ocorra de forma adequada, há necessidade de boa sustentação, proporcionada pela estrutura óssea. Dessa forma, o desenvolvimento dos ossos e músculos deve estar associado, para que ocorra bom crescimento do animal, com boa sustentação e bom aumento muscular (MARCATO et al., 2009).

O comportamento característico de crescimento é perfeitamente sincronizado para cada sistema, isto é, o acumulo de tecido ósseo é mais rápido do que o do tecido muscular que, por sua vez, é mais rápido do que o do tecido adiposo, distinguindo-se por uma maior ou menor taxa específica de crescimento do animal (GONZALES; SARTORI, 2002). Através desta sequência, observa-se o destino final dos nutrientes no corpo do animal, sendo assim importante conhecer o peso e/ou idade em que a taxa de crescimento corporal diminui e a maior parte dos nutrientes é enviada para o tecido adiposo, devido ao aumento da demanda de gasto energético (LAWRENCE; FOWLER, 1997).

O crescimento do frango pode ser descrito através de uma curva sigmoide, com uma fase de desenvolvimento exponencial inicial, uma fase intermediária ou transitória, e uma fase final da inibição do crescimento, que consiste de uma redução gradual da taxa de crescimento após um aumento assintótico no peso corporal (AGUILAR; FRIEDLI; CANAS, 1983). 


\subsection{MODELOS MATEMÁTICOS}

Modelagem matemática é definida como o uso de equações para descrever ou simular processos em um sistema (DUMAS; DIJKSTRA; FRANCE, 2008). A maioria dos modelos empregados em experimentação avícola é do tipo modelo linear, uma vez que as análises estatísticas são executadas de forma mais fácil. Entretanto, muitos fenômenos biológicos são mais bem descritos por modelos nãolineares como os modelos que descrevem o crescimento das aves (RONDÓN; MURAKAMI; SAKAGUTIL, 2002). Segundo Baldwin (1995), os modelos matemáticos ainda podem ser classificados como: estáticos ou dinâmicos; determinísticos ou estocásticos; e como empíricos ou mecanísticos (ou mecanicista).

Nos modelos dinâmicos os parâmetros podem variar no tempo, deste modo o tempo age como uma variável independente. Os modelos estáticos descrevem o fenômeno em determinado momento ou instante, assim o tempo não é um parâmetro para esse modelo. Os modelos empregados nas determinações de exigências nutricionais para uma idade específica (NRC, 1994) podem ser classificados como estáticos, enquanto que as curvas de crescimento são exemplos de modelos dinâmicos (THORNLEY; FRANCE, 2007).

Modelos determinísticos são aqueles que só têm uma única resposta e expressa o valor médio da população fazendo predições para quantidades (THORNLEY; FRANCE, 2007), enquanto que nos modelos estocásticos (ou probabilísticos), que do grego significa stokhastikos, ou seja, "capaz de adivinhar" (BROWN; ROTHERY, 1993), as possíveis respostas dependem de uma distribuição de probabilidade, sendo modelos de difícil construção e avaliação (THORNLEY; FRANCE, 2007).

Os modelos empíricos são baseados apenas em correlações ou associações entre duas ou mais variáveis, sem levar em consideração os mecanismos que controlam o fenômeno, por exemplo, descrever as respostas de desempenho de um sistema utilizando equações matemáticas sem nenhuma interpretação biológica dos parâmetros e sem restrições dos princípios científicos. Por outro lado, os modelos mecanísticos tentam explicar ou descrever os mecanismos envolvidos, baseando-se nas leis da física, química, bioquímica e etc, proporcionando um grau de entendimento ou explicação de um problema que está modelando (RONDÓN; MURAKAMI; SAKAGUTIL, 2002). 


\subsubsection{Descrição dos modelos de crescimento}

Cada tipo de animal possui uma curva de crescimento, a qual deve ser observada em condições ideais ou não limitantes. Diferentes linhagens e sexos podem diferir em vários aspectos, como peso à maturidade, composição e taxas de deposição dos nutrientes corporais, pois estes aspectos afetam as características da curva de crescimento. Para tais avaliações, existe a necessidade da utilização de modelos matemáticos, que expressem com maior precisão o crescimento das aves em função da idade para fins de pesquisa e de programas de alimentação (GOUS et al., 1999) sob condições não limitantes (EMMANS, 1987).

Prever o crescimento das aves identificando a taxa máxima de crescimento é um fator muito importante que contribui para a rentabilidade na criação destas. O desconhecimento das curvas de crescimento e parâmetros produtivos de interesse econômico tem limitado a implementação de melhores programas de criação de animais que aumentam a produtividade, por isso é importante usar essas ferramentas em sistemas de produção animal (MARTíNEZ et al., 2010).

Há funções que descrevem o crescimento da ave desde a idade zero $(\mathrm{t}=0)$ até a idade adulta e um resumo matemático é fornecido sobre os dados que em termos gerais pode ser escrito como uma única eq. (1) e a representação matemática do crescimento relativo é descrita pela eq. (2):

$$
\begin{gathered}
Y_{t}=f(t) \\
d Y / d t=\mu Y
\end{gathered}
$$

\section{Em que:}

$Y_{t}$ é o valor observado de uma característica no tempo " $t$ ";

$\mathrm{f}(\mathrm{t})$ é a representação da função de crescimento que é função do tempo "t";

$\mu$ é a taxa relativa de crescimento.

A taxa relativa de crescimento não depende apenas da proporção do peso do animal, mas também da eficiência ou velocidade com que este animal ganha peso (FRANCE; DIJKSTRA; DHANOA, 1996). Assim, esta equação (1) tem muitas expressões e os parâmetros do modelo são estimados a partir das observações. Os modelos têm sido amplamente estudados em varias áreas, incluindo na produção 
animal, que indicam que tais funções de crescimento necessitam de cuidados na escolha do melhor modelo ajustado para o conjunto de dados (KOYA; GOSHU, 2013).

A fim de estimar os valores dos parâmetros na equação de crescimento é necessário criar as aves de linhagens ou raças semelhantes ao seu potencial e aferir o seu peso em intervalos regulares de tempo, durante o período de crescimento (GOUS, 1990; MARTIN; BRADFORD; GOUS, 1994).

Tradicionalmente, as funções matemáticas chamadas "funções de crescimento" e relacionam o peso corporal com a idade da ave ou consumo acumulado de ração. Elas também podem ser usadas para determinar a eficiência de utilização de nutrientes, que é a razão da relação entre peso corporal e consumo de ração acumulado, e como as funções de resposta para prever a energia diariamente e as necessidades dietéticas de proteína para a manutenção e crescimento (FRANCE et al., 1989). A função de crescimento deve descrever bem o comportamento dos dados e conter parâmetros biologicamente e fisicamente significativos (FRANCE; DIJKSTRA; DHANOA, 1996).

Entre as várias aplicações das curvas de crescimento na produção animal, destacam-se: a) resumir em poucos parâmetros, as características de crescimento da população, pois os parâmetros dos principais modelos não-lineares utilizados possuem interpretabilidade biológica; b) avaliar o perfil de respostas de tratamentos ao longo tempo; c) estudar as iterações de respostas dos tratamentos com o tempo; d) identificar em uma população os animais mais pesados em idades mais jovens; o que pode ser feito avaliando-se a relação entre o parâmetro "k" das curvas de crescimento, que expressam a taxa de declínio na taxa de crescimento relativo, e o parâmetro "a", que é peso limite do animal ou peso assintótico; e) obter as variâncias entre e dentro de indivíduos que são de grande interesse nas avaliações genéticas (FREITAS, 2005).

Funções de crescimento podem ser classificadas em três categorias: 1) aquelas que descrevem comportamento com rendimento decrescente (por exemplo, monomolecular); 2) o comportamento sigmoide com um ponto fixo de inflexão (por exemplo, logístico, Gompertz e Von Bertalanffy); 3) e comportamento sigmoide com um ponto de inflexão flexível (por exemplo, Richards, López, Weibull) (THORNLEY; FRANCE, 2007). As funções flexíveis são frequentemente modelos mais completos 
que envolvem modelos mais simples para os valores particulares de certos parâmetros adicionais (KUHI et al. 2010).

Freitas et al. (1984) compararam entre si modelos de regressões polinomiais e os modelos Gompertz, logístico, Richards e Von Bertalanffy para ajustar dados peso-idade de frangos e frangas do nascimento até 68 dias de idade, e concluíram que o modelo Gompertz e o logístico proporcionaram os resultados mais adequados para o crescimento.

Freitas (2005) discutiu as propriedades de cinco modelos não lineares considerando o ajuste de curvas de crescimento para algumas espécies animais dentre estes os frangos de corte. Estes autores verificaram que as duas formas de Gompertz (modelos alternativos), o logístico e ainda o Von Bertalanffy apresentaram bom ajuste para o frango de corte. Quanto aos pesos iniciais, ambos os modelos Gompertz e Von Bertalanffy subestimaram os pesos iniciais até 12 dias de idade, enquanto o logístico superestimou até oito dias. Para as idades intermediárias, os cinco modelos proporcionaram bons ajustes, mas todos subestimaram os pesos a partir de 65 dias de idade.

Kuhi et al. (2010) verificaram em revisão sobre funções matemáticas para análise de crescimento em aves, que um ponto fixo de inflexão pode ser uma limitação para as equações como os modelos de Gompertz e logístico e em muitos casos, quatro parâmetros na equação com um ponto de inflexão flexível se ajustam melhor os dados de crescimento. Estes autores citam que em alguns casos, podem ocorrer problemas de otimização das equações, como a de Richards, mas é necessária considerar que cada caso tem sua particularidade, sendo que a equação de López ou Morgon tem sido frequentemente demonstrada ser uma função matemática adequada para análise do perfil de crescimento em aves. Para descrever o crescimento em relação ao consumo alimentar acumulado, bem como a taxa de retenção em relação o consumo diário, cujos dados geralmente não exibem um ponto de inflexão, o monomolecular apareceria como uma função de escolha.

Goliomytis, Panopoulou e Rogdakis (2003) estudaram o crescimento de frangos de corte contemporâneos, por meio do modelo de Richards para o peso corporal e partes importantes da carcaça do frango e obtiveram informações importantes sobre o potencial de crescimento do frango melhorado geneticamente. Scheuermann et al. (2003) ajustaram a curva de Gompertz para o peso corporal e o peso de peito das linhagens e sexos de frango de corte comerciais e compararam 
com a densidade de fibra muscular e também encontraram informações importantes para o crescimento e para as variações genéticas relacionadas com o gênero da ave.

Nesta revisão observa-se que para frangos corte os modelos mais utilizados para descrever o crescimento são Gompertz, Logístico, Von Bertalanffy, Brody e Richards (FREITAS 1984; GOLIOMYTIS; PANOPOULOU; ROGDAKIS, 2003; KUHI et al., 2010; MORAIS et al., 2015).

\subsubsection{Modelo de Brody}

O modelo de Brody (1945) foi desenvolvido a partir da curva monomolecular, a partir do trabalho de Spliman e colegas no USDA como uma forma de lei dos rendimentos decrescentes para descrever o peso vivo de um animal em função do seu consumo de alimentos. A função monomolecular em conjunto com a exponencial explica o padrão de crescimento em forma de "S" ao longo do tempo e descreve o de modo "auto-acelerado" (exponencial) antes e "auto-inibitórios" (monomolecular) após a idade da puberdade do animal (THORNLEY; FRANCE, 2007). Assim, as taxas de crescimento diminuem à medida que aumenta o peso e a idade. Este modelo foi proposto para descrever o peso corporal após o ponto de inflexão. Neste modelo o parâmetro "m" assume o valor 1,0 (um). A maioria dos trabalhos que utilizam este modelo considera o nascimento como o ponto de inflexão, podendo assim ser usado para descrever o crescimento pós-natal (PAZ et al. 2004). Esta função pode ser descrita pela seguinte eq. (3):

$$
\mathrm{Y}=\mathrm{a}(1-\mathrm{b} \exp (-\mathrm{kt}))^{1}
$$

Em que:

"Y" é a medição correspondente (de peso) no tempo t (dias);

"a" é o peso adulto ( $\mathrm{kg}$ ou g);

"b" é uma constante de integração, relacionada aos pesos iniciais do animal até a idade adulta do animal, não possui interpretação bem definida;

"k" é um parâmetro da velocidade (kg/dia por kg);

"exp" = 2,71828 (base do logaritimo neperiano). 


\subsubsection{Modelo de Gompertz}

Esta função foi desenvolvida por um matemático inglês, Benjamin Gompertz, para o cálculo das taxas de mortalidade em seres humanos (GOMPERTZ, 1825). Sendo que Winsor (1932) foi um dos primeiro a propor o uso da Gompertz em ciência animal, indicando alguns dos seus usos e limitações. $O$ autor comenta que se pode esperar um bom ajuste ao aplicar esta curva aos dados de crescimento que apresentam ponto de inflexão em sua parte inicial de aproximadamente 35 a $40 \%$ do crescimento total. A função de Gompertz é definida como (eq.4):

$$
\mathrm{Y}=\mathrm{a}(\exp (-\mathrm{b} \exp (-\mathrm{kt})))
$$

Em que:

"Y" é a medição correspondente (de peso) no tempo t (dias);

"a" é o peso adulto ( $\mathrm{kg}$ ou g);

"b" é uma constante de integração, relacionada aos pesos iniciais do animal até a idade adulta do animal, não possui interpretação bem definida;

"k" é um parâmetro da velocidade ( $\mathrm{kg} /$ dia por $\mathrm{kg}$ );

"exp" = 2,71828 (base do logaritimo neperiano).

A função de Gompertz descreve o comportamento sigmoidal suave para o desenvolvimento de frangos desde o nascimento até a sua maturidade, sendo que a eficiência do desenvolvimento decai de acordo com o tempo. Esta função indica um crescimento mais rápido no início, mas uma aproximação mais lenta para uma assíntota do que a logística (THORNLEY; FRANCE, 2007).

Esse modelo tem sido empregado na obtenção de parâmetros da curva de crescimento de aves e no estudo das exigências nutricionais durante o crescimento (BRACCINI NETO, 1996; DANISMAN; GOUS, 2013; FREITAS et al., 1984; GOUS et al., 1999; HANCOOK et al., 1995; SAKOMURA et al., 2005).

Martínez et al. (2010) mostraram em detalhes a construção dos parâmetros derivados da função de Gompertz e que fornecem informações importantes sobre o fenômeno biológico que está sendo modelado. Esses parâmetros são: taxa de crescimento, assíntotas, ponto de inflexão, taxa máxima de ganho de peso, valor 
delta, taxa de crescimento relativo, taxa de maturidade sexual e o grau de maturidade absoluta.

\subsubsection{Modelo Logístico}

Este modelo foi primeiramente proposto e nomeado por Verhulst (1838) para expressar a lei do crescimento de populações humanas. O desenvolvimento corporal fundamenta-se em três suposições: 1) é proporcional ao peso; 2) é proporcional ao substrato (quantidade de alimento); e é um processo irreversível (THORNLEY; FRANCE, 2007). Segundo Dumas, Dijkstra e France (2008), este modelo foi aplicado primeiro por Robertson (1908) no estudo sobre autocatálise em plantas e subsequentemente introduzido na produção animal por Pearl (1925).

O modelo da eq. (5) apresenta uma curva simétrica em relação ao ponto de inflexão, que pode alcançar $50 \%$ do valor assintótico e aproxima-se, em seu segundo trecho, à função de Brody, porém, em seu primeiro trecho aproxima-se a uma função exponencial de taxa relativa de crescimento constante, em outras palavras, este modelo considera a velocidade de crescimento proporcional ao crescimento efetuado e ao crescimento que fica por efetuar.

Varias parametrizações tem sido propostas para este modelo como, por exemplo, a indicada por $\operatorname{Nelder}^{1}$ (1961, p. 89-110 apud PAZ et al., 2004, p. 1419) que comprovou em estudos pioneiros que o modelo Logístico foi mais apropriado para descrever o crescimento dos animais e que comumente descrito como na eq. (6).

$$
\begin{aligned}
& \mathrm{Y}=\mathrm{a}(1+\mathrm{b} \exp (-\mathrm{kt}))^{-1} \\
& \mathrm{Y}=\mathrm{a}(1+\exp (-\mathrm{kt}))^{-\mathrm{m}}
\end{aligned}
$$

em que:

"Y" é a medição correspondente (de peso) no tempo t (dias);

"a" é o peso adulto (kg ou g);

"b" é uma constante de integração, relacionada aos pesos iniciais do animal até a idade adulta do animal, valor fixado $=1$ na eq. (6), não possui interpretação bem definida;

\footnotetext{
${ }^{1}$ NELDER, J.A. The fitting of a generalization of the logistic curve. Biometrics, v.17, p.89-110, 1961
} 
"k" é um parâmetro da velocidade (kg/dia por kg);

"exp" = 2,71828 (base do logaritimo neperiano);

m é o parâmetro de inflexão.

A equação Logística utilizada refere-se à forma logística generalizada (Nelder, 1961) que permite um ponto de inflexão variável.

\subsubsection{Modelo de Von Bertalanffy}

O biólogo australiano Ludwing Von Bertalanffy (1938) descreveu em sua equação (7) o crescimento dos peixes, no qual o ganho de peso se apresenta como resultado do processo anabólico e a perda de peso como produto do catabolismo, conforme a lei de alometria, ou seja, que o ganho de peso é proporcional à área de superfície do organismo, assim a taxa desse processo pode ser expressa em função do peso corporal (VON BERTALANFFY, 1957).

$$
\mathrm{Y}=\mathrm{a}(1-\mathrm{b} \exp (-\mathrm{kt}))^{3}
$$

em que:

"Y" é a medição correspondente (de peso) no tempo t (dias);

"a" é o peso adulto (kg ou g);

"b" é uma constante de integração, relacionada aos pesos iniciais do animal até a idade adulta do animal, não possui interpretação bem definida;

"k" é um parâmetro da velocidade (kg/dia por kg);

"exp" = 2,71828 (base do logaritimo neperiano);

\subsubsection{Modelo de Richards}

A função de Richards (1959) possui quatro parâmetros, porém com ponto de inflexão variável, sendo considerado por vários pesquisadores como o modelo de crescimento mais completo sendo definido por (eq. 8):

$$
\mathrm{Y}=\mathrm{a}(1-\mathrm{b} \exp (-\mathrm{kt}))^{\mathrm{m}}
$$

em que: 
"Y" é a medição correspondente (de peso) no tempo t (dias);

"a" é o peso adulto (kg ou g);

"b" é uma constante de integração, relacionada aos pesos iniciais do animal até a idade adulta do animal, não possui interpretação bem definida;

"k" é um parâmetro da velocidade ( $\mathrm{kg} /$ dia por $\mathrm{kg}$ );

"exp" = 2,71828 (base do logaritimo neperiano);

"m" é o parâmetro do ponto de inflexão.

A importância desse modelo está no ponto de inflexão, dependente do parâmetro $\mathrm{m}$, que deve ser estimado para cada análise, para que possa ser feita uma melhor interpretação biológica. Assim, assumindo o ponto de inflexão $(\mathrm{m}) \mathrm{da}$ equação de Richards igual a $1(m=1)$, obtém-se o modelo de Brody; quando $m=3$, o modelo Von Bertalanffy; se $\mathrm{m} \rightarrow 1$, o modelo de Gompertz; e se b = 1, o modelo Logístico generalizado. Percebe-se, então, que os primeiros modelos são casos especiais do modelo Richards, que possui quatro parâmetros. Entretanto, existe dificuldade em se ajustar esta eq. (8) devido a não convergência do processo iterativo, causado principalmente pela alta correlação negativa entre "b" e "m" (BROWN; FITZHUGH; CARTWRIGHT, 1976, p.810-818 apud PAZ et al., 2004, p. 1419) ${ }^{2}$.

A variação de qualquer um dos parâmetros na função de crescimento causa uma mudança na trajetória da curva, como mostrada no modelo de Richards na Figura 1. Com isso, valores diferentes do parâmetro "a" obtêm-se distintos pontos de assíntota do peso corporal. Mudanças em "b" alteram o crescimento relacionando o peso inicial do animal até a idade adulta. A variação em "k" faz com que a curva se arraste ao longo do eixo da idade, no caso, valores superiores de "k" concentram o crescimento em torno do ponto de inflexão, ocasionando um crescimento inicial e final mais lento, do contrário, valor menor de "k" faz com que o crescimento seja mais distribuído ao longo do tempo.

\footnotetext{
2 BROWN, J.E.; FITZHUGH JR., H.A.; CARTWRIGHT, T.C.A. A comparision of nonlinear models for describing weight-age relationships in cattle. Journal Animal Science, v.42, p.810-818, 1976.
} 
Figura 1 - Variação dos valores dos parâmetros no modelo de Richards reparametrizado

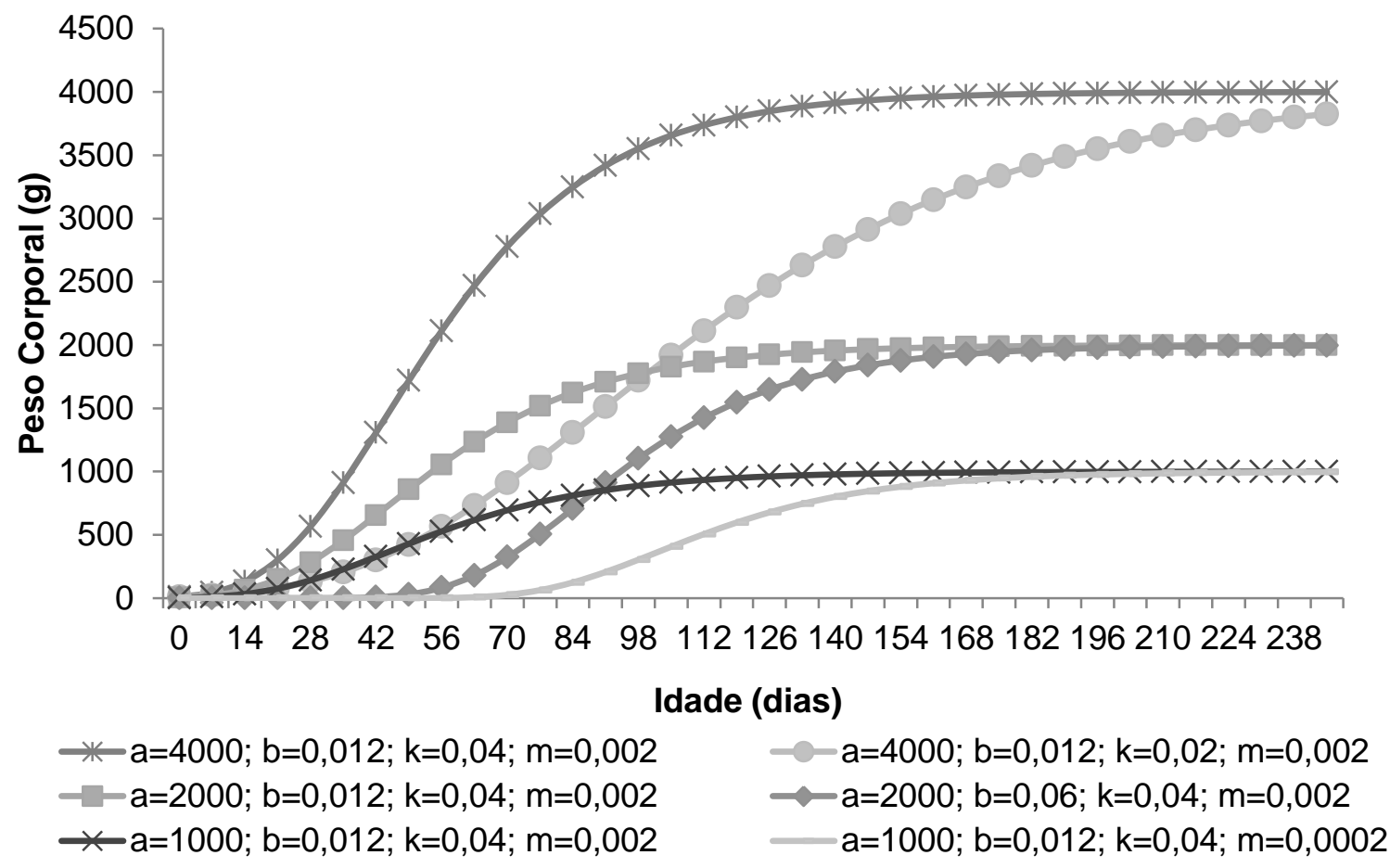

Fonte: Própria autoria.

\subsection{ALOMETRIA}

Alometria em biologia significa, a escala não-isométrica e também é conhecida como Alloios que é derivado do grego "diferente". O termo alometria é usado para descrever o desenvolvimento morfológico das espécies, e baseia-se na relação entre o tamanho de um organismo, e o tamanho de qualquer parte do organismo (SCHMIDT-NIELSEN, 1984).

Existem vários tipos de organismos vivos na terra e cada um possui um tamanho, caracterizado pela massa corporal, a partir de princípios físicos, químicos e biológicos. À medida que o corpo aumenta, a razão entre superfície e o volume diminui. Nos animais pequenos, a área da superfície é suficientemente grande se comparada ao volume, de tal forma que a troca de gases, alimentos e detritos pode ser realizada somente por processos de difusão. Para animais grandes as distâncias tornam-se largas e a difusão mostra-se ineficiente. Deste modo, o transporte por convecção apresenta-se indispensável. Isso levou ao desenvolvimento de sistemas circulatórios celômicos e vasculares sanguíneos (BARBOSA, 2007). 
Galileu foi um dos primeiros a considerar a alometria, observando que o diâmetro dos ossos dos vertebrados deveria crescer mais rápido do que seu comprimento para que a tensão de compressão não aumentasse mais rápido com a massa. (SCHMIDT-NIELSEN, 1984).

Relações alométricas foram encontradas em várias circunstâncias (BROWN; WEST; ENQUIST, 2000; WEST; BROWN, 2004), e que têm de ser explicadas com graus variados de sucesso, muitas vezes, como resultado de restrições físicas. A equação alométrica pode ser representada graficamente num sistema de eixos cartesianos, com o tamanho do corpo sobre o eixo $\mathrm{X}$ e o tamanho do componente no eixo Y. Alometria permite aos cientistas estudar as funções biológicas, por exemplo, mais energia é consumida por um elefante, mas um rato provavelmente consome mais energia quando é medido como uma função do seu peso corporal do rato. A equação (9) alométrica é geralmente indicada como:

$$
Y=\alpha X^{\beta} \varepsilon_{i}
$$

Em que:

"Y" = peso do componente físico (cortes comerciais) ou químico (lipídio, água ou cinzas) observado;

"X" = peso corporal observado ou proteína corporal;

" $\alpha$ " e " $\beta$ " = coeficientes.

Huxley (1924) propôs o uso da equação (9) para descrever a taxa de crescimento diferencial entre quelas (pinças) e partes do corpo de caranguejoviolinista (Uca). O autor ainda supôs que o valor de " $\beta$ " adere à Lei de Superfície, em que existe uma relação de escala entre a taxa metabólica basal e a massa corporal, sendo esta igual a dois terços, mais tarde conhecido como alometria (HUXLEY; TEISSIER, 1936). Nem todas as comparações alométricas são lineares, no entanto, quando as variáveis são plotadas em coordenadas logarítmicas (natural), o resultado é uma linha reta, em que o expoente " $\beta$ " representa a inclinação da regressão (SCHMIDT-NIELSEN, 1984).

Assim, esta função tem definido um ponto de início ou peso inicial, o qual pode ser interpretado como o peso ganho durante a incubação, tendo uma massa positiva no tempo zero. A principal desvantagem do uso desta função é que não 
possui um platô ou mesmo uma diminuição no crescimento como observado em varias espécies (RICKLEFS; STARCK, 1998).

$\mathrm{Na}$ equação (10), o valor de " $\beta$ " para os diferentes componentes do corpo pode ser heterogônico (maior ou menor) ou isogônico (igual) que a unidade. Sempre que $b<1$ a proporção entre a variável dependente diminui à medida que aumenta $a$ variável independente, ou seja, com o desenvolvimento corpo (X), normalmente, ocorre uma diminuição na deposição de água corporal $(Y)$. Quando b =1, como no caso da proteína do corpo, a relação é constante, e a proporção aumenta quando b $>1$, como no caso da gordura corporal.

A eq. (10) que compensa a uma função não linear é:

$$
\ln Y=\ln \alpha+\beta \ln X+\varepsilon_{i}
$$

Em que:

In = logaritmo na base natural;

$\mathrm{Y}=$ peso do componente físico (cortes comerciais) ou químico (lipídio, agua ou cinzas) observado;

$X=$ peso corporal observado ou proteína corporal;

$\alpha$ e $\beta=$ coeficientes;

$\varepsilon i=$ erro multiplicativo.

Previsões precisas do crescimento de componentes corporais podem ser obtidas para aves em crescimento em condições não limitantes, medindo o peso destes componentes, proteína corporal, a intervalos regulares de tempo durante todo o período de crescimento (GOUS, 1986; GOUS et al., 1990). Segundo, Emmans e Fisher ${ }^{3}$ (1986, p. 9-39 apud Danisman, 2009, p. 8) a equação de Gompertz é ajustada aos pesos corporais de proteína de modo que as estimativas precisas do tamanho adulto e da taxa de amadurecimento do genótipo são conseguidas, e as estimativas de crescimento dos componentes químicos e físicos do corpo podem ser obtidas a partir do componente proteico usando as relações alométricas que existem entre os diferentes componentes do corpo em relação a este componente (Figura 2).

\footnotetext{
${ }^{3}$ Emmans, G.C.; Fisher, C. Problems in nutritional theory. In: Nutrient Requirements of Poultry and Nutritional Research. (Eds.) Fisher C. and Boorman K.N., Butterworths, Oxford, p. 9-39, 1986.
} 
Figura 2 - Alometria entre o peso proteico corporal e o peso da carcaça de frangos machos

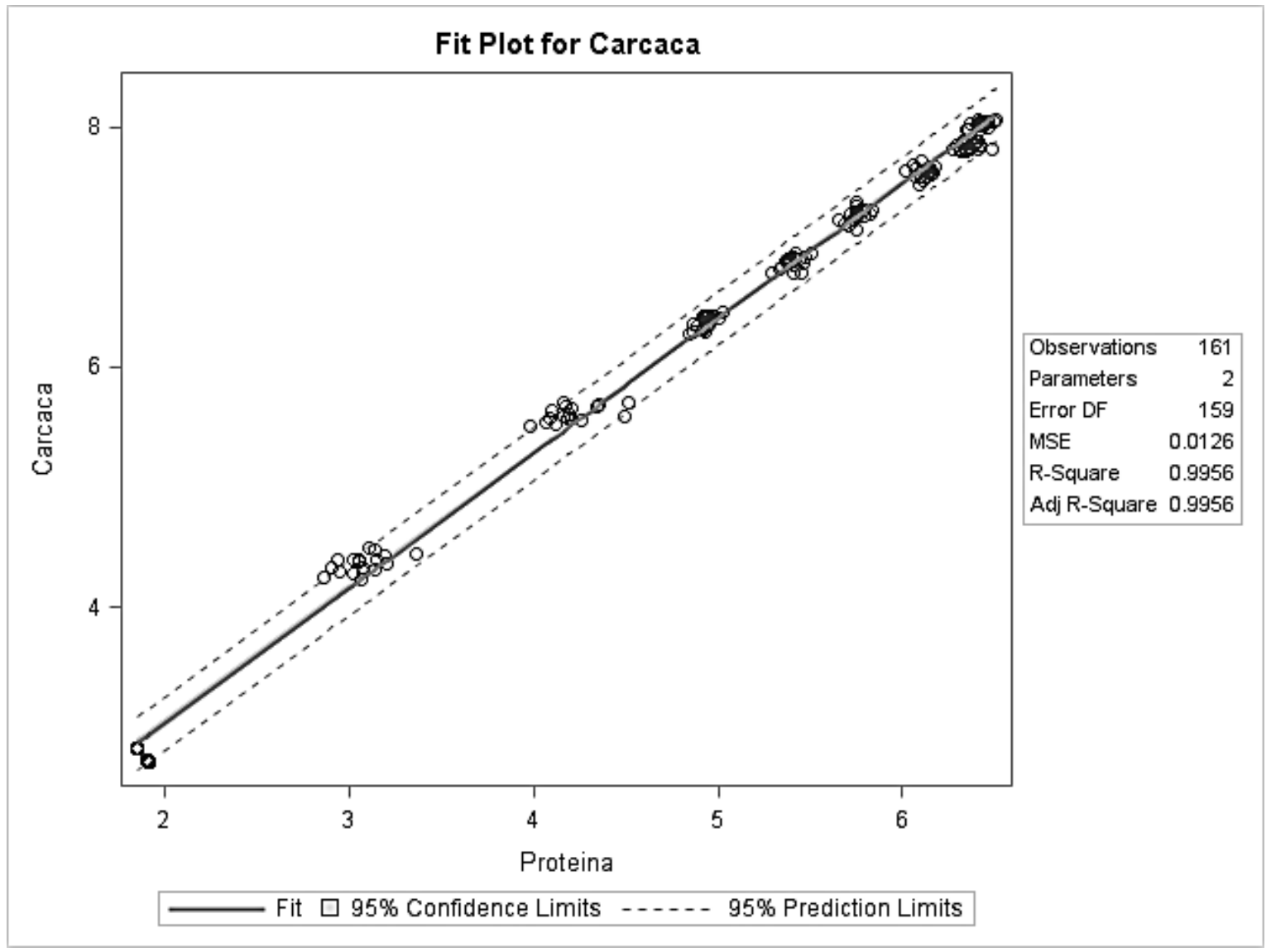

Fonte: Própria autoria.

A maioria dos componentes do corpo e do potencial de crescimento, exceto penas, pode estar simplesmente relacionada com o peso de proteína corporal (GOUS, 1999). Podendo então, o crescimento da proteína ser previsto utilizando a função de crescimento Gompertz e de acordo com o critério acima, o acúmulo de água, cinza e de lipídios pode ser derivado a partir dos pesos de proteína, e em seguida adicionando os pesos de todos estes componentes em cada dia do período de desenvolvimento do animal, sendo possível prever a taxa de crescimento de todo o corpo livre de penas.

Todos os componentes físicos do frango, exceto penas, têm a mesma taxa de maturação para a proteína corporal. Assim, as taxas de crescimento destes componentes podem também serem previstas da mesma forma que os componentes (GOUS, 1999). Estas relações são úteis para a compreensão das mudanças que ocorrem no corpo da ave à medida que ela cresce, mas são particularmente interessantes, na previsão dos pesos dos vários componentes durante o crescimento, e ao fazer comparações entre os genótipos (GOUS, 2007). 
Segundo Danisman e Gous (2011), os componentes que tem a mesma taxa de maturação podem ser dimensionados alometricamente.

De acordo com Emmans e Fisher (1986, p. 9-39 apud Danisman 2009, p.8), para estimar os parâmetros da curva e da taxa de crescimento da ave pode-se utilizar o crescimento do corpo, livre de penas como um todo; predizendo separadamente, o crescimento dos quatro componentes químicos do corpo livre de penas (água, cinza, lipídio, proteína e uma pequena quantidade de carboidratos); ou ainda, prever o crescimento de um destes componentes e presumir os outros em relação a este componente.

\subsection{IMPORTÂNCIA ECONÔMICA DOS MODELOS MATEMÁTICOS}

Os nutricionistas de aves precisam tomar decisões a respeito da utilização dos alimentos para formulação da ração, seguindo uma matriz nutricional desejada para cada fase de vida da ave, para obter o maior potencial de crescimento do genótipo e gênero utilizado na produção de frangos de corte. Segundo GOUS (2004), tais decisões devem se basear em princípios biológicos e econômicos, pois o desempenho da ave depende do consumo de ração, crescimento e composição da carcaça e se houver qualquer mudança na composição da dieta é provável que tenham consequências econômicas.

A avicultura mundial está sujeita a custos voláteis sobre os insumos, preços de venda dos produtos e oscilações quanto à demanda do consumo dos produtos das aves. Com isso, a indústria avícola tende a ser competitiva, sempre buscando maior eficiência sobre a produção, seja ela melhorando as linhagens já existentes de acordo com mercado consumidor, e/ou utilizando alimentos alternativos para baratear a ração, aumentando a rentabilidade do processo (OVIEDO-RONDÓN, 2010).

Métodos matematicamente sofisticados para a formulação de dietas e rações apareceram na década de 1960, juntamente com o desenvolvimento de computadores e o aumento do número de fontes de nutrientes disponíveis (DUMAS; DIJKSTRA; FRANCE, 2008). A formulação de ração tornou-se popular utilizando softwares de programação linear de custo mínimo que viabilizou a melhor combinação de ingredientes, de acordo com as exigências nutricionais dos animais, permitindo uma análise rápida do custo econômico e nutricional da inclusão de um 
ingrediente na ração. No entanto, estes programas assumem que cada ingrediente fornece o mesmo retorno econômico marginal, e que os retornos biológicos de produção são constantes não garantindo o melhor benefício econômico (OVIEDORONDÓN, 2010).

Com o propósito de predizer de forma mais precisa as exigências de energia e nutrientes para aves, os modelos de crescimento, tem sido utilizado para comparar os resultados de experimentação empírica (OVIEDO-RONDÓN; FRITTS; WALDROUP, 2002). O primeiro modelo elaborado com sucesso na produção animal foi para suínos de Edinburgh, que trouxe modificações para modelos já existentes e para pesquisas direcionadas a preencher as lacunas de nossos conhecimentos de aspectos críticos da teoria incorporada nestes modelos (GOUS, 2007).

As curvas de crescimento são utilizadas para avaliar os tratamentos, durante o período de crescimento, que tem um efeito acumulativo sobre o desenvolvimento dos animais. Além disso, elas ajudam a visualizar quando um dos componentes do tratamento (como uma dieta no programa de alimentação) pode ser alterado para melhorar o desempenho estimando o peso vivo e o consumo de ração em idades em que os dados não foram coletados, o que é importante para a análise econômica. Por razões econômicas, é importante que os modelos não superestimem as necessidades nutricionais para apoiar o nível de ganho estabelecido (OVIEDO-RONDÓN; FRITTS; WALDROUP, 2002). Porém, é importante destacar que nenhum modelo é perfeito, mas aqueles modelos mecanísticos podem ser melhorados à medida que se identificam os processos fisiológicos e metabólicos (OVIEDO-RONDÓN, 2010).

As aplicações modernas da teoria da maximização do lucro devem incluir a idade das aves como uma importante variável. Isto porque o peso corporal e o consumo de alimento são correlacionados no tempo, embora a relação não seja necessariamente linear (PESTI; MILLER, 1997).

Atualmente existem vários modelos para estimar o crescimento e a lucratividade da criação de frangos, a partir de diferentes situações como exemplificado por Oviedo-Rondón (2010): o BEEP (Broiler Economics for Energy and Protein) que permite observar as respostas a aminoácidos (proteína balanceada) e níveis de energia; Modelo EFG, que reúne um modelo de crescimento de frangos, um otimizador, e um programa de formulação num pacote que permite analisar uma grande variedade de situações de mercado e produção; OmniPro® II 
que utiliza a média dos dados de desempenho de campo das diferentes linhagens ou cruzamentos genéticos ou dados de crescimento de determinada situação. Este é um modelo dinâmico, semi-empírico e determinístico que ajusta as concentrações das dietas ou os programas de alimentação e requisitos para maximizar lucro; A planilha eletrônica PPFR (Programa Prático para Formulação de Rações) que é utilizada para formulação de rações para várias categorias de animais e também para formulação de suplementos vitamínicos e minerais, segundo o modelo linear (dietas de custo mínimo) e não linear (dietas de lucro máximo) (GARCIA-NETO, 2015). 


\section{MATERIAL E MÉTODOS}

Este trabalho experimental foi conduzido de acordo com diretrizes brasileiras, baseado na Lei Federal $n^{0} 11.794$ de 08 de outubro de 2008 e aprovados pela Comissão no Uso de Animais - CEUA/FZEA/USP, processo número 14.1.148.74.7. O experimento foi realizado no Laboratório de Avicultura do Departamento de Zootecnia da Faculdade de Zootecnia e Engenharia de Alimentos (FZEA-USP), Campus Fernando Costa com localização geográfica $21^{\circ} 59^{\circ}$ de latitude sul e $47^{\circ} 26^{\circ}$ de longitude oeste e altitude média de 635 metros.

\subsection{AVES, DELINEAMENTO EXPERIMENTAL E INSTALAÇÕES}

Os ovos para incubação foram adquiridos de lotes de matrizes de 40-50 semanas de idade das linhagens Cobb 500, Ross 308 e Hubbard Flex. Foram utilizados 1848 pintinhos de um dia, sendo 308 pintinhos de cada linhagem e sexo. No primeiro dia de vida oito pintinhos de cada linhagem e sexo foram utilizados para as medições de carcaça e cortes da carcaça. Os pintinhos foram vacinados contra a doença de Marek e separados por sexo no incubatório e vacinados contra doença de New Castle e Gumboro, aos 7 dias via ocular.

O experimento iniciou em aviário experimental de $5 \mathrm{~m} \times 32 \mathrm{~m}$ de piso de concreto com pé direito de 2,5m contendo duas salas com 20 boxes/cada medindo $2,47 \mathrm{~m}^{2} /$ boxe, onde foram alojados 50 pintinhos de um dia em cada boxe, distribuídos em seis tratamentos: macho Cobb 500; fêmea Cobb 500; macho Ross 308; fêmea Ross 308; macho Hubbard Flex; fêmea Hubbard Flex utilizando o delineamento inteiramente casualizado contendo seis repetições por tratamento, totalizando 36 unidades experimentais.

Foi utilizada cama de maravalha nova em boxe com bebedouros do tipo nipple e comedouros tubulares de acordo com as diferentes fases de criação. Para o aquecimento das aves, foram instaladas lâmpadas (infravermelha de $250 \mathrm{~W}$ ) e campânulas a gás nos corredores, na fase inicial de desenvolvimento. O programa de luz adotado foi de $23 \mathrm{~h}$ de luz/ $1 \mathrm{~h}$ de escuro por dia, com uso de timer. Diariamente a temperatura do ar e a umidade relativa foram registradas em cinco em cinco minutos, utilizando data logger, Hobo® (Onset, Bourne, Massachusetts) (Figura 1). 
Figura 3 - Valores de temperatura e umidade relativa do aviário durante o experimento
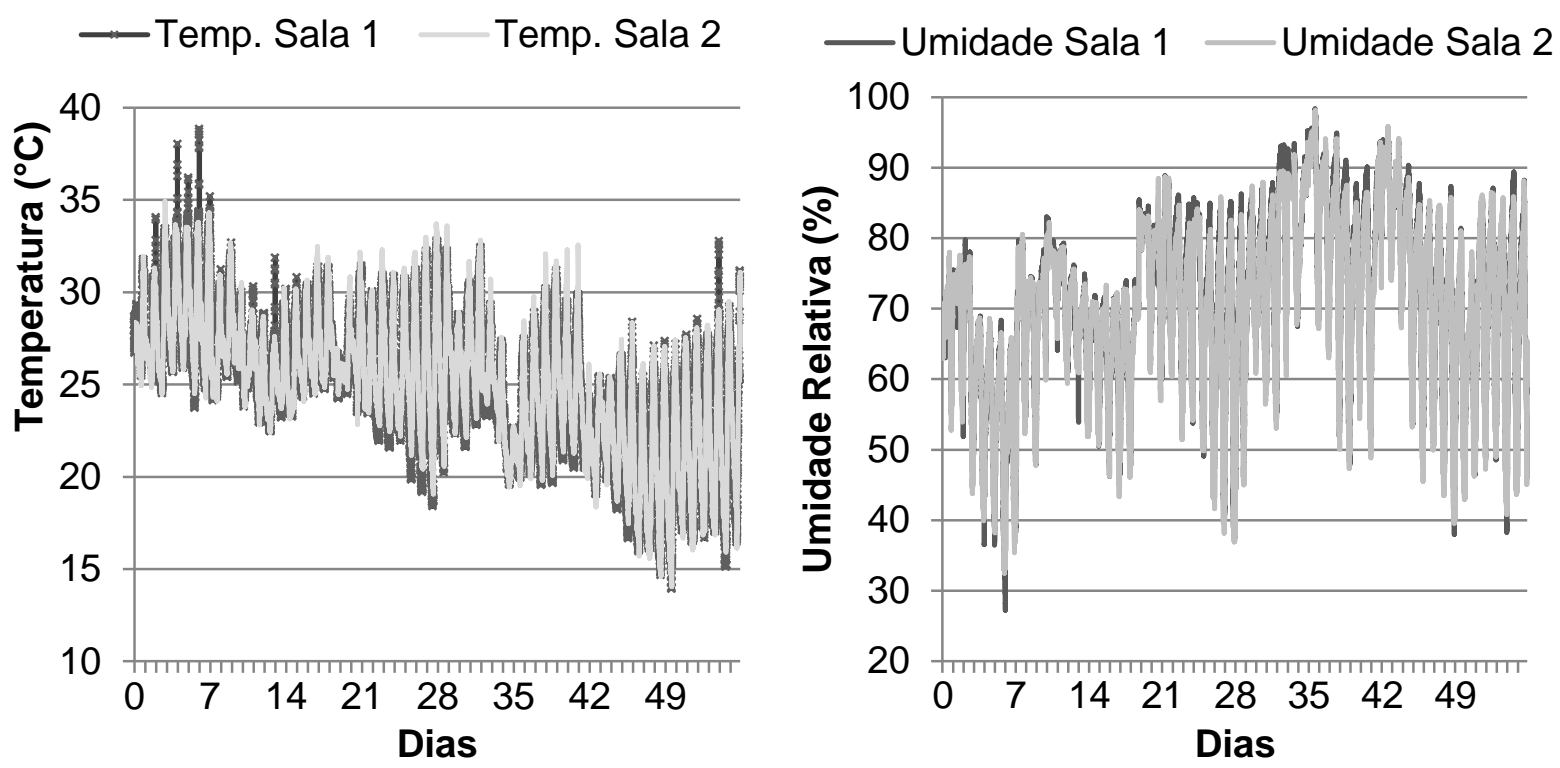

Fonte: Própria autoria.

\subsection{DIETAS EXPERIMENTAIS}

As dietas foram formuladas à base de milho e farelo de soja atendendo as recomendações para frangos de corte fêmeas e machos, com desempenho superior propostas por Rostagno et al. (2011). Estas dietas, apresentadas na Tabela 1, foram fornecidas nas seguintes fases de 1 a 7 dias (Pré-inicial), 8 a 21 dias (Inicial), 22 a 35 dias (Crescimento I), 36 a 42 dias (Crescimento II) e 43 a 56 dias (Final).

\subsection{CARACTERÍSTICAS AVALIADAS}

\subsubsection{Desempenho}

Com o intuito de obter os dados das variáveis usados nos ajustes das curvas de crescimento, semanalmente as aves e as rações de cada boxe (unidade experimental) foram pesadas para obter os valores do peso médio corporal (PC) e consumo de ração $(\mathrm{CR})$. O CR foi calculado pela diferença entre o total de ração fornecida e as sobras de cada boxe (unidade experimental), semanalmente, e dividida pelo número de "aves corrigido", considerando assim a mortalidade para retificar o número de aves. (SAKOMURA; ROSTAGNO, 2007). 
Tabela 1 - Composição percentual e valores calculados das dietas experimentais de frangos de corte

\begin{tabular}{|c|c|c|c|c|c|c|c|c|c|c|}
\hline \multicolumn{11}{|c|}{ COMPOSIÇÃO PERCENTUAL } \\
\hline Fases & \multicolumn{2}{|c|}{$\begin{array}{l}\text { Pré-inicial } \\
\text { (1-7 dias) }\end{array}$} & \multicolumn{2}{|c|}{$\begin{array}{c}\text { Inicial } \\
\text { (8-21 dias) }\end{array}$} & \multicolumn{2}{|c|}{$\begin{array}{c}\text { Crescimento I } \\
\text { (22-35 dias) }\end{array}$} & \multicolumn{2}{|c|}{$\begin{array}{c}\text { Crescimento II } \\
\text { (36-42 dias) }\end{array}$} & \multicolumn{2}{|c|}{$\begin{array}{c}\text { Final } \\
\text { (43-56 dias) }\end{array}$} \\
\hline Ingredientes (\%) & Macho & Fêmea & Macho & Fêmea & Macho & Fêmea & Macho & Fêmea & Macho & Fêmea \\
\hline Milho $(7,88 \%)$ & 53,59 & 55,09 & 57,62 & 56,13 & 59,15 & 61,45 & 63,44 & 65,63 & 65,31 & 67,29 \\
\hline Farelo de Soja (45\%) & 38,94 & 37,58 & 34,90 & 36,07 & 32,49 & 31,05 & 28,61 & 27,41 & 26,57 & 25,70 \\
\hline Óleo de soja & 2,903 & 2,639 & 3,441 & 3,723 & 4,622 & 4,140 & 4,522 & 4,072 & 4,900 & 4,457 \\
\hline Fosfato Bicálcico & 1,904 & 1,915 & 1,539 & 1,557 & 1,335 & 1,172 & 1,124 & 1,084 & 1,018 & 0,806 \\
\hline Calcário Calc & 0,911 & 0,911 & 0,935 & 0,944 & 0,888 & 0,877 & 0,794 & 0,625 & 0,745 & 0,659 \\
\hline Sal comum & 0,508 & 0,507 & 0,457 & 0,483 & 0,458 & 0,445 & 0,445 & 0,419 & 0,432 & 0,407 \\
\hline L-Lisina HCL & 0,286 & 0,349 & 0,252 & 0,237 & 0,237 & 0,184 & 0,264 & 0,134 & 0,257 & 0,095 \\
\hline Metionina ( & 0,426 & 0,453 & 0,360 & 0,364 & 0,342 & 0,230 & 0,318 & 0,215 & 0,291 & 0,171 \\
\hline L-Treonina & 0,116 & 0,146 & 0,085 & 0,081 & 0,072 & 0,037 & 0,076 & 0,000 & 0,067 & 0,000 \\
\hline Suplemento* & $0,400^{1}$ & $0,400^{1}$ & $0,400^{2}$ & $0,400^{2}$ & $0,400^{3}$ & $0,400^{3}$ & $0,400^{3}$ & $0,400^{3}$ & $0,400^{4}$ & $0,400^{4}$ \\
\hline Antiox & 0,013 & 0,013 & 0,013 & 0,013 & 0,013 & 0,013 & 0,013 & 0,013 & 0,013 & 0,013 \\
\hline Total & 100 & 100 & 100 & 100 & 100 & 100 & 100 & 100 & 100 & 100 \\
\hline \multicolumn{11}{|c|}{ ENERGIA E NUTRIENTES (\%) } \\
\hline $\mathrm{l} / \mathrm{kg})$ & 2960 & 2960 & 3050 & 3050 & 3150 & 3150 & 3200 & 3200 & 3250 & 3250 \\
\hline PB & 22,40 & 22,00 & 21,20 & 20,80 & 19,80 & 19,20 & 18,40 & 17,80 & 17,60 & 17,10 \\
\hline Lisin & 1,324 & 1,341 & 1,217 & 1,201 & 1,131 & 1,057 & 1,060 & 0,933 & 1,006 & 0,862 \\
\hline Metionina+cisti & 0,953 & 0,965 & 0,876 & 0,864 & 0,826 & 0,722 & 0,774 & 0,681 & 0,734 & 0,629 \\
\hline Metionina dig. & 0,652 & 0,670 & 0,588 & 0,581 & 0,555 & 0,456 & 0,519 & 0,430 & 0,489 & 0,386 \\
\hline Treor & 0,861 & 0,871 & 0,791 & 0,780 & 0,735 & 0,687 & 0,689 & 0,608 & 0,654 & 0,585 \\
\hline Triptofano dig. & 0,253 & 0,246 & 0,237 & 0,231 & 0,218 & 0,211 & 0,198 & 0,192 & 0,187 & 0,183 \\
\hline Arginina dig. & 1,417 & 1,379 & 1,334 & 1,302 & 1,231 & 1,193 & 1,226 & 1,092 & 1,065 & 1,044 \\
\hline Valina dig. & 0,944 & 0,922 & 0,896 & 0,878 & 0,835 & 0,815 & 0,773 & 0,757 & 0,739 & 0,728 \\
\hline Leucina dig. & 1,725 & 1,695 & 1,656 & 1,632 & 1,569 & 1,544 & 1,484 & 1,465 & 1,435 & 1,426 \\
\hline Isoleucina dig. & 0,876 & 0,854 & 0,828 & 0,808 & 0,766 & 0,744 & 0,702 & 0,684 & 0,667 & 0,655 \\
\hline Cálcio & 0,920 & 0,920 & 0,841 & 0,831 & 0,758 & 0,711 & 0,663 & 0,587 & 0,614 & 0,528 \\
\hline Fósforo disp. & 0,470 & 0,470 & 0,401 & 0,396 & 0,354 & 0,322 & 0,309 & 0,274 & 0,286 & 0,246 \\
\hline Potássio & 0,868 & 0,848 & 0,823 & 0,806 & 0,766 & 0,747 & 0,708 & 0,692 & 0,676 & 0,667 \\
\hline Sódio & 0,220 & 0,220 & 0,210 & 0,200 & 0,200 & 0,195 & 0,195 & 0,185 & 0,190 & 0,180 \\
\hline Cloro & 0,354 & 0,354 & 0,339 & 0,325 & 0,325 & 0,317 & 0,318 & 0,303 & 0,310 & 0,296 \\
\hline 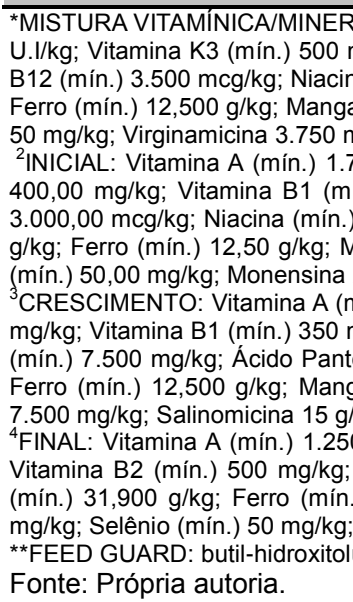 & $\begin{array}{l}\text { gar } \\
\mathrm{g} / \mathrm{kg} \\
50 . \mathrm{C}\end{array}$ & $\begin{array}{l}; \text { Halqui } \\
.000 \mathrm{U} \\
\text { minna B } \\
\text { in.) } 2.7\end{array}$ & $\begin{array}{l}0 \mathrm{~g} / \mathrm{kg} ; \mathrm{Z} \\
7.500,00 \\
; \text { Vitami } \\
\text { inn.) } 1.00 \\
\mathrm{ng} / \mathrm{kg} ; A\end{array}$ & 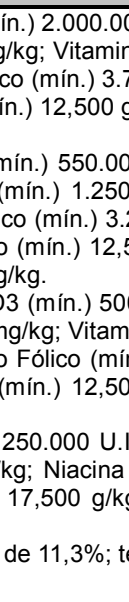 & 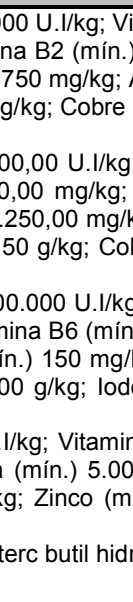 & $\begin{array}{l}500 \\
\mathrm{Col} \\
\mathrm{min} \\
\mathrm{E}(\mathrm{n} \\
\mathrm{mg} / \mathrm{k}\end{array}$ & $\begin{array}{l}\text { Vita } \\
\text { n.) }\end{array}$ & $\begin{array}{l}\text { g/kg; } \\
\text { nio ( } \\
\text { Vitan } \\
\text { ico ( }\end{array}$ & ina & $\begin{array}{l}600 \mathrm{~g} / \mathrm{kg} ; \\
\text { nio (min.) } \\
3 \text { (min.) } \\
12 \text { (min.) } \\
\text { in.) } 82.01 \\
; ; \text { Selênio } \\
\text { min.) } 400 \\
\text {; Niacina } \\
950 \text { g/kg; } \\
\text { Halquinol } \\
0 \text { mg/kg; } \\
\text { g; Colina } \\
\text { min) } 300\end{array}$ \\
\hline
\end{tabular}




\subsubsection{Componentes físicos e químicos}

Durante a chegada dos pintinhos, foram selecionados aleatoriamente para abate oito de cada linhagem e sexo, sendo seis aves para obtenção dos pesos dos componentes físicos e duas aves para os componentes químicos do corpo de cada tratamento. Da primeira semana (sete dias de idade) até a quinta semana (35 dias de idade) foram selecionadas três aves por boxe para obtenção dos pesos dos componentes físicos e de duas aves para os componentes químicos do corpo. $\mathrm{Na}$ sexta semana (42 dias de idade) até a oitava semana (56 dias de idade) foram selecionadas duas aves por boxe para obtenção dos pesos dos componentes físicos e duas aves para os componentes químicos do corpo.

Após a seleção e identificação as aves selecionadas foram separadas para jejum de 24 horas recebendo apenas água à vontade. Após o jejum as aves foram pesadas e levadas para o Matadouro-Escola da Prefeitura do Campus de USP "Fernando Costa" (PUSP-FC) para obtenção dos componentes físicos da ave. O abate foi por eletrocussão para evitar a perda de sangue (GOUS et al., 1999) e em seguida as aves foram escaldadas, depenadas, evisceradas, feito a pesagem das aves depenadas e posterior separação dos cortes em balança com precisão digital $(0,01 \mathrm{~g})$, que consistiram em: Cabeça+pescoço+pés, asa, peito, coxa, sobrecoxa, osso do peito+dorso+pele. A carcaça foi calculada a partir da soma dos cortes, com exceção da cabeça+pescoço+pés. O peso das penas foi calculado a partir da diferença entre o peso corporal após jejum e peso corporal após depena. Os órgãos foram separados e identificados no momento da evisceração para posterior pesagem do coração, fígado e moela.

As aves para amostras dos componentes químicos foram congeladas para posteriormente serem descongeladas, autoclavadas e trituradas em liquidificador industrial. Foi utilizado liofilizador (LIOBRAS, São Carlos, São Paulo) por 48 horas ou secagem completa, obtendo o teor de água das amostras trituradas (GOUS et al. 1999). Em seguida, as amostras liofilizadas foram novamente trituradas em mixer e submetidas à análise dos demais componentes químicos (proteína bruta, gordura, cinzas).

Após coleta total das penas estas foram congeladas e posteriormente descongeladas, lavadas, secas em estufa à $55^{\circ} \mathrm{C}$ por período aproximado de 48 horas e esfriadas à temperatura ambiente (DAHLKE, 2005). Em seguida, foi 
realizado o corte com tesoura e trituração em processador de parte das penas coletadas para melhor homogeneização das amostras de penas e levadas ao laboratório para análises dos componentes químicos (proteína bruta, gordura, cinzas). Para obtenção da matéria seca das penas foi utilizado estufa à $105^{\circ} \mathrm{C}$ por 48 horas, conforme a metodologia descrita por Silva \& Queiroz (2002).

As análises de proteína bruta foram realizadas no laboratório QualiLeite/FMVZ/USP utilizando o aparelho rapid $N$ cube (ELEMENTAR, Hanau, Alemanhã) através do método de DUMAS com rápida determinação do nitrogênio (N) utilizando no máximo $250 \mathrm{mg}$ da amostra para cada análise. No laboratório de Bromatologia/FZEA/USP foi realizada a extração de gordura das amostras liofilizadas utilizado o extrator de Soxhlet e as análises de matéria mineral (cinzas) através da queima das amostras em mufla (SILVA \& QUEIROZ, 2002).

\subsection{CURVAS DE CRESCIMENTO}

Para melhor explicar o comportamento das características avaliadas em função do tempo foram ajustados aos dados cinco curvas de crescimento com interpretação biológica mostrada na Tabela 2, assim como, algumas propriedades associadas aos modelos, tais como taxa máxima (crescimento, consumo ou deposição) (TCM) e ponto de inflexão (PI).

Tabela 2 - Modelos de crescimento e respectivas taxas máximas (TM) e pontos de inflexões (PI)

\begin{tabular}{|c|c|c|c|}
\hline Modelos & Equações $^{1}\left(\mathbf{y}_{\mathbf{t}}=\right)$ & $\operatorname{TM}\left(\mathbf{d}_{\mathbf{y}_{\mathrm{t}}} / \mathbf{d}_{\mathbf{t}}\right)$ & $P I\left(y_{i} ; T i\right)$ \\
\hline Gompertz & $a \exp (b \exp ((-k t)))$ & $b_{k y} \exp (-k t)$ & $0,368 \mathrm{a} ; \ln (\mathrm{b}) / \mathrm{k}$ \\
\hline Logístico 1 & $a(1+b \exp ((-k t)))^{(-1)}$ & $\frac{3 \mathrm{ky}_{\mathrm{t}} \exp ((-\mathrm{kt}))}{((1-\exp ((-\mathrm{kt}))))}$ & $1 / 2 \mathrm{a} ; \ln (\mathrm{b}) / \mathrm{k}$ \\
\hline Logístico 2 & $a(1+\exp ((-k t)))^{(-m)}$ & $\frac{\mathrm{mky}_{t} \exp ((-\mathrm{kt}))}{((1+\exp ((-\mathrm{kt}))))}$ & $\begin{array}{l}\mathrm{a}(\mathrm{m} /(\mathrm{m}+1))^{\mathrm{m}} \\
\ln (\mathrm{m}) / \mathrm{k}\end{array}$ \\
\hline Brody & $a(1-b \exp (-k t))$ & $\frac{\left(\mathrm{ky}_{t}(\mathrm{~b} \exp (-\mathrm{kt}))\right)}{(1-\exp (-\mathrm{kt}))}$ & Não possui \\
\hline $\begin{array}{c}\text { Von } \\
\text { Bertalanffy }\end{array}$ & $a(1-b \exp ((-k t)))^{3}$ & $\frac{\left.\left(3 \mathrm{k} y_{t} \exp (-\mathrm{kt})\right)\right)}{(1-\exp (-\mathrm{kt}))}$ & $0,269 a ; \ln (3 b) / k$ \\
\hline Richards $^{2}$ & $a(1 \pm b \exp ((-k t)))^{(-1 / n)}$ & $\frac{\mathrm{nk} y_{t}(\mathrm{~b} \exp (-\mathrm{kt}))}{((1-\mathrm{b} \exp (-\mathrm{kt}))}$ & $\begin{array}{c}\mathrm{a}(\mathrm{n}+1)^{(-1 / \mathrm{n})} \\
(-1) /(\mathrm{k}[\ln (\mathrm{n} / \mathrm{b})])\end{array}$ \\
\hline
\end{tabular}


A taxa máxima (TM) estima o incremento no peso no ponto de inflexão ( $\mathrm{PI})$, que ocorre quando o ganho de peso do corpo, parte do corpo ou para o consumo de ração é máximo, sofrendo uma mudança na forma da curva, passando a função de uma forma crescente (côncava) para uma forma decrescente (convexa). Cada modelo possui um ponto de inflexão, exceto o caso particular do modelo de Brody que não possui uma forma algébrica do ponto de inflexão, sendo o próprio peso ao nascimento o seu ponto de inflexão, comumente utilizado para descrever o crescimento pós-natal ou a fase de auto-inibição do crescimento (FREITAS, 2005).

\subsection{ALOMETRIA}

O crescimento alométrico dos componentes químicos (água, proteína bruta, gordura e cinzas) e físicos (penas, cortes e órgãos) em relação ao peso corporal e proteico foi realizado através da equação exponencial (SCHMIDT-NIELSEN, 1984), definida como $Y=\alpha X^{\beta}$ (eq. 9), transformada logaritmicamente numa reta linear simples (eq. 10):

$$
\ln Y_{i}=\ln \alpha+\beta \ln X_{i}+\ln \varepsilon_{i}
$$

Em que:

In = logaritmo na base natural;

"Y” = peso do componente físico (cortes comerciais) ou químico (lipídio, agua ou cinzas) observado;

" $\mathrm{X}_{\mathrm{i}}$ " = peso corporal observado ou proteína corporal;

$\alpha$ a intercepção do logaritmo da regressão linear sobre $Y$ e $\beta$;

" $\beta$ " o coeficiente de crescimento relativo ou coeficiente de alometria.

$\varepsilon_{i} \circ$ erro multiplicativo.

Na equação anterior (eq.10), o valor de $\beta$ para os diferentes componentes do corpo pode ser heterogônico (maior ou menor), sempre que $1>\beta<1$ e quando $\beta=$ 1, a relação é constante ou isogônico (igual). 


\subsection{ANÁLISE ECONÔMICA}

Com o intuito de analisar a produção de frangos de corte em função das respostas do consumo de ração oriundas dos dados observados e estimados, foi realizada análise econômica através do peso-idades do frango observado e estimado. Segundo informações sobre a produção de frango no Brasil (AVISITE, 2016) os principais pesos e dia em que os frangos são abatidos são de 1350 g, 2350 g e o peso aos 45 dias de idade, mostrando que o mercado externo (frangos grillers) demanda a produção interna de aves com peso menor (próximo de $1350 \mathrm{~g}$ ) do que o mercado consumidor interno que prefere aves mais pesadas (próximo de 2350g) levando a produção de frangos aos 45 dias.

Para determinar as estimativas de peso para a idade de abate determinada foram calculados, através da equação de Gompertz, os parâmetros da equação utilizando dados de PCJ e para obter o dia do abate de acordo com o peso determinado para o abate foram utilizados os mesmos parâmetros na eq. (11) a seguir:

$$
t=-\ln \left(\ln \left(a / y_{(t)}\right) / b\right) / k
$$

Em que:

$\mathrm{t}=$ Idade (dias) do PCJ determinado;

In = logaritmo neperiano;

$a=P C J$ à maturidade $(\mathrm{g})$;

$\mathrm{y}_{(\mathrm{t})}=$ PCJ determinado $(\mathrm{g})$;

$\mathrm{b}=$ Constante de integração;

$\mathrm{k}=$ Taxa de maturidade.

Para analisar a eficiência econômica foram considerados os preços dos fatores (custo da dieta) e do produto (frango vivo). A margem bruta de comercialização (MBi) foi obtida através do seguinte cálculo (eq. 12):

$$
\mathrm{MBi}=\mathrm{EAT}_{\mathrm{i}} \times\left(\mathrm{PC}_{\mathrm{i}} / \mathrm{CD}_{\mathrm{i}}\right)
$$

Em que:

- $P C_{i}$ que representa o preço do quilo (em $\mathrm{R} \$ / \mathrm{kg}$ ) do produto (frango vivo) i; 
- $C D_{i}$ o custo da dieta (em $R \$ / k g$ ) consumida pelo frango i no período $X$ do experimento, obtido em função da sua composição e dos preços dos ingredientes;

- EAT $\mathrm{i}$ que representa a eficiência alimentar total, ou seja, ganho de peso total (GPTi) (g) e consumo de ração total (CRTi) (g) obtidos pelos resultados da estimativa do modelo no período $X$ dos frangos de corte.

O preço do frango, milho, farelo de soja, óleo de soja, sal comum da ração foram encontrados na base de dados do Instituto de Economia Agrícola (IEA, 2016), de forma a se obter preços históricos representativos desses produtos no período de dez anos (dezembro de 2005 até dezembro de 2015). Os preços nominais foram corrigidos pelo Índice Nacional de Preços ao Consumidor do Instituto Brasileiro de Geografia e Estatística ((INPC/IBGE, 2016), de acordo com o método usual, apresentado por Hoffmann (1991) na eq.(13):

$$
P Q_{(\text {corrigido, } t)}=P Q_{(\text {nominal, } t)} \times\left(\text { INPC }_{\text {dez/2015 }} / \mathrm{INCP}_{\mathrm{t}}\right)
$$

Sendo:

- PQ corrigido,t o preço real do ingrediente no mês $t$, corrigido para dezembro de 2015;

- PQ nominal,t o preço do ingrediente no mês t;

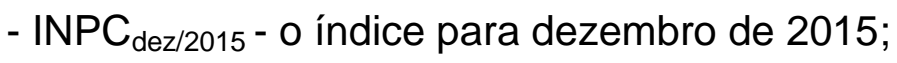

- INPC $\mathrm{t}$ o índice para o mês t.

Os preços para os demais ingredientes da ração foram levantados e assim obtido o custo da dieta (CD), que é composto pelo somatório dos produtos entre as quantidades de cada um dos ingredientes (QG) pelos seus respectivos preços (PG) como mostrado na eq. (14):

$$
C D=\Sigma(Q G \times P G)
$$

A quantidade de cada ingrediente $(Q G)$ foi previamente definida por ocasião da formulação das dietas para macho e fêmea com mudanças nutricionais para cada fase de crescimento do animal, sendo assim feito o custo das dietas através do consumo de ração para cada período estudado. O fundamento para a utilização da MBi como parâmetro para a avaliação da eficiência econômica pode ser encontrado em Gameiro (2009) e Trevisan et al. (2014). O preço médio para cada ingrediente das rações e do frango vivo está demostrados na Tabela 3. 
Tabela 3 - Preços médio para os ingredientes das rações experimentais e do frango para corte

\begin{tabular}{|c|c|c|}
\hline \multicolumn{2}{|c|}{ Ingredientes/Produto } & $\begin{array}{c}\text { Preço médio } \\
(\mathrm{R} \$ / \mathrm{kq})\end{array}$ \\
\hline \multicolumn{2}{|l|}{ Frango para corte $^{1}$} & 2,43 \\
\hline \multicolumn{2}{|l|}{ Milho grão $(7,88 \%)^{1}$} & 0,55 \\
\hline \multicolumn{2}{|l|}{ Farelo de Soja $(45 \%)^{*} 1$} & 1,17 \\
\hline \multicolumn{2}{|l|}{ Óleo de soja ${ }^{1}$} & 5,13 \\
\hline \multicolumn{2}{|l|}{ Sal comum $^{1}$} & 0,34 \\
\hline \multicolumn{2}{|l|}{ Fosfato Bicálcico ${ }^{2}$} & 2,26 \\
\hline \multicolumn{2}{|l|}{ Calcário Calcítico ${ }^{2}$} & 0,14 \\
\hline \multicolumn{2}{|l|}{ L-Lisina $\mathrm{HCL}^{2}$} & 6,02 \\
\hline \multicolumn{2}{|l|}{ Metionina (MHA) ${ }^{2}$} & 21,92 \\
\hline \multicolumn{2}{|l|}{ L-Treonina $^{2}$} & 9,20 \\
\hline \multirow{4}{*}{ Mistura vitamínica/mineral ${ }^{3}$} & Pré - Inicial & 13,99 \\
\hline & Inicial & 14,96 \\
\hline & Crescimento & 11,75 \\
\hline & Final & 5,93 \\
\hline \multicolumn{2}{|l|}{ Antioxidante $^{2}$} & 10,36 \\
\hline \multicolumn{3}{|c|}{$\begin{array}{l}\text { *Preço do farelo de soja }(47 / 48 \%) \text {; } \\
\text { 'Fonte: IEA-APTA (dezembro de } 2005 \text { - agosto de 2016); } \\
\text { 2 Fonte: Preço do produto levantado junto aos fornecedores da região no de fevereiro de } 2016 \text { e corrigido para } \\
\text { inflação do mês de agosto de } 2016 \text {. }\end{array}$} \\
\hline
\end{tabular}

\subsection{ANÁLISE ESTATÍSTICA}

Para melhor explicar o comportamento das características do consumo de ração $(C R)$, peso corporal $(P C)$, peso corporal em jejum e depenado (PCJD), penas, carcaça (CAR), peito (PT), coxa (CX), sobrecoxa (SCX), asa, coração, fígado, moela e componentes químicos em função do tempo foram ajustados curvas, separadamente para cada sexo e linhagem dentro de cada sexo, utilizando-se o procedimento NLIN do SAS ${ }^{\circledR} 9.3$ (SAS Institute Inc, Cary, NC) que estimou os parâmetros para modelos não lineares por processo iterativo de Gauss-Newton modificado, desenvolvido por Hartley (1961). O desempenho dos modelos foi avaliado com relação ao coeficiente de determinação $\left(R^{2}\right)$, coeficiente de determinação ajustado ( $R^{2}$ aj), Critério de informação de Akaike (AIC) (AKAIKE, 1974) e Critério de informação Bayesiano de Schwarz (BIC) (SAWA, 1978).

Sabendo que convergência é a capacidade dos algoritmos matemáticos em resolver o problema de estimativa de parâmetros não-linear (ZUIDHOF, 2005), sendo necessário atribuir valores iniciais às estimativas dos parâmetros dos modelos e por 
um processo iterativo calcula-se a soma dos quadrados do erro e obtém-se um conjunto de estimativas, passo a passo, chegando numa convergência com soma mínima dos quadrados do erro e estimativas atualizadas (SARMENTO et al, 2006).

Depois da escolha do melhor modelo de crescimento foram estimados os parâmetros das equações $(a, b, k)$ individualmente para cada boxe (unidade experimental). Em seguida, foi realizada a análise de variância (ANOVA) usando o procedimento GLM do SAS ${ }^{\circledR} 9.3$ (SAS Institute Inc, Cary, NC), sendo as médias comparadas pelo teste $F(5 \%)$ quando necessário utilizou-se o teste de TukeyKramer, com exceção do parâmetro "b", que é uma constante de integração e não possui interpretação biológica.

Para os coeficientes alométricos " $\beta$ " e os valores de " $\alpha$ ", foi realizada análise da regressão usando o PROC REG do SAS ${ }^{\circledR} 9.3$ (SAS Institute Inc, Cary, NC) e foi usado o teste Tukey-Kramer para comparar as médias dos tratamentos sempre que necessário para o coeficiente alometrico $(\beta)$.

$\mathrm{Na}$ análise econômica os valores de MBC foram submetidos à ANOVA e o teste Tukey-Kramer para comparar as médias dos tratamentos sempre que necessário.

Em todos os casos verificou-se a presença de outliers e as pressuposições de normalidade para a ANOVA adotando delineamento inteiramente casualizado em que os tratamentos consistiram de efeitos de sexo e aninhamento de três linhagens dentro de sexo, considerando o modelo com dois critérios de classificação hierárquica, devido ao uso de uma ração para cada sexo, conforme equação (15) a seguir:

$$
y_{i j k}=\mu+S_{i}+L_{j(i)}+e_{(i j) k}
$$

em que:

$y_{i j k}=$ observação em cada repetição, com $i=1,2$ (macho e fêmea); $j=1,2,3$ (Cobb 500, Ross 308 e Hubbard) e k = 1, 2, 3, 4, 5 e 6 repetição;

$\mu=$ constante comum a todas as observações;

$S_{i}=$ efeito do sexo $i$

$\mathrm{L}_{j(i)}=$ efeito da linhagem $(j)$ dentro do sexo $(i)$;

$e_{(i j) k}=$ erro associado a cada observação, aninhado sob os níveis de sexo e linhagem. 


\section{RESULTADOS E DISCUSSÃO}

\subsection{CONVERGÊNCIA E QUALIDADE DO AJUSTE DE CURVAS DE CRESCIMENTO EM DIFERENTES LINHAGENS DE FRANGOS DE CORTE}

Foi realizada uma regressão linear simples dos dados de peso corporal (PC) médio de cada boxe (unidade experimental) de cada idade contra o respectivo PC médio da amostra retirada semanalmente do boxe com a finalidade de observar a representatividade das amostras selecionadas do PC da população experimental (GOUS, 1999). Deste modo, foi obtido coeficiente de regressão de $0,9975\left(R^{2}=\right.$ 99,56\%) (Apêndice A), podendo afirmar que as amostras estão próximas dos valores reais da população estudada, seguindo com as análises a partir dos dados amostrais coletados semanalmente, exceto para o consumo de ração (CR). Normalmente, o CR não apresenta comportamento assintótico (HENN et al. 2014), no entanto foi obtido ótimo ajuste aos dados às curvas de crescimento $\left(R^{2}{ }_{\text {aj }}>99 \%\right)$ e mantido esta característica nas análises.

De acordo Fitzhugh 1976 existem três características especiais para determinar o método de escolha da curva de crescimento ajustada: 1) ter uma correta interpretação biológica dos dados podendo aplicar a mesma interpretação em outros dados; 2) possuir um bom ajuste dos dados, minimizando os resíduos de erros; 3) Dificuldade computacional da função deve ser levada em consideração na escolha.

Foi observado que dos seis modelos utilizados no atual estudo, Brody e Richards não convergiram para nenhuma das características avaliadas dos frangos. O modelo de Brody foi excluído da seleção pela dificuldade na convergência e o modelo de Richards foi re-parametrizado $(m=1 / n)$, convergindo para algumas das características analisadas. Uma vez que convergência é a capacidade dos algoritmos matemáticos em resolver o problema de estimativa de parâmetros nãolinear (ZUIDHOF, 2005).

$\mathrm{Na}$ Tabela 4 estão mostrados os critérios utilizados para avaliação dos modelos que convergiram mostrando os melhores ajustes sobre as características de consumo de ração (CR), peso corporal (PC), peso corporal em jejum e depenado (PCJD), penas (PN), carcaça (CÇ), cortes da carcaça (peito (PT), coxa (CX), sobrecoxa (SCX), asa) e órgãos (coração (COR), fígado (FG) e moela (ML)) (Figuras 
4, 5, 6, 7, 8 e 9). A avaliação dos modelos foi feita em relação ao coeficiente de determinação $\left(R^{2}\right)$, coeficiente de determinação ajustado $\left(R^{2} a j\right)$, Critério de informação de Akaike (AIC) e Critério de informação Bayesiano de Schwarz (BIC) que foram calculados apenas quando houve convergência completa dos modelos (Tabela 4).

$\mathrm{O} \mathrm{R}^{2}$ e $\circ \mathrm{R}^{2}$ aj utilizados para descrever o consumo de ração, crescimento corporal e cortes e dos animais apresentaram valores acima de 99\%, para penas e órgãos os valores foram acima de $98 \%$. Deste modo, todos os modelos que convergiram podem ser utilizados, indicando boa qualidade dos ajustes, considerando-se o aspecto estatístico, mas não são suficientes para a escolha da melhor equação.

O uso do coeficiente de determinação na avaliação da qualidade do ajuste dos modelos não lineares deve ser feita com cautela, pois a soma dos resíduos não é necessariamente igual a zero e a soma dos quadrados dos resíduos mais a soma dos quadrados da regressão não é necessariamente igual à soma total dos quadrados (SILVA et al., 2011), necessitando de verificação através dos critérios de informação (AIC e BIC).

O modelo de Richards apresentou falhas de convergência causadas pela não melhoria das estimativas chegando ao limite máximo de iterações do programa (100 iterações), para o peso de penas de ambos os sexos e para fêmeas no peso de carcaça, peito, sobrecoxa e asa a diferença no ajuste das curvas de acordo com os pesos médios, podendo observar na tabela 4 e demostradas nas Figuras 4, 5, 6 e 7. Segundo Sarmento et al. (2006), este modelo não deve ser escolhido para representar curva média, já que dificuldade em atingir convergência é maior que a qualidade de ajuste, provavelmente por esse modelo estimar um parâmetro a mais.

Outros autores (FARIDI et al., 2014; FITZHUGH Jr.,1976; PORTER et al., 2010) também encontraram dificuldades de convergência com o modelo Richards evidenciando que, apesar da maior flexibilidade, por não fixar o ponto de inflexão, esse modelo apresenta maiores dificuldades no processo iterativo em seu ajustamento. Deste modo, corroborando com Braccini Neto et al. (1996), é mais apropriado o ajuste de modelos com três parâmetros.

Os modelos com três parâmetros que mais se destacaram pelo desempenho foram nesta ordem Von Bertalanffy, Gompertz e Logístico 2. O modelo Von Bertalanffy se destacou por apresentar valor inicial (1 dia) estimado mais próximo do 
Tabela 4 - Avaliação do ajuste médio de modelos matemáticos (com 3 e 4 parâmetros) das características avaliadas de frangos machos $(M)$ e fêmeas $(F)$, através do coeficiente de determinação (R2) ajustado $\left(R^{2}{ }_{a j}\right)$ e pelos critérios de informação de Akaike (AIC) e Bayesiano de Schwarz (BIC)

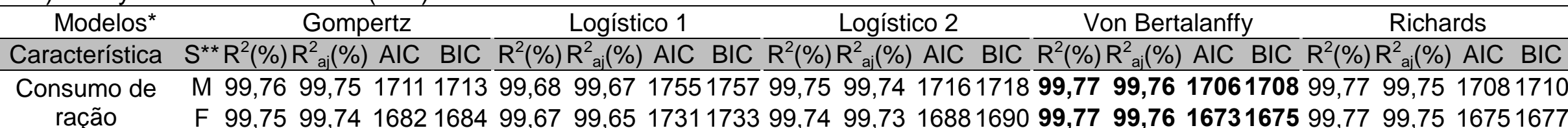

F $99,7599,741682168499,6799,651731173399,7499,731688169099,7799,761673167599,7799,7516751677$

Peso corporal M 99,90 99,9014021404 99,82 99,81 15001502 99,90 99,891412141499,9099,9014071409 99,90 99,90 14011403 (PC) $\quad F \quad 99,8199,801453145699,6499,631555155799,7899,771473147599,8499,841420142299,8599,8514121414$

PC em jejum e M 99,90 99,89 13801382 99,8499,83 $1454145699,9099,891383138599,8899,881399140199,9099,8913821384$ depenado

F 99,83 99,82 $1404140699,6799,651509151199,8099,801423142599,8699,851373137599,8699,8613701372$

Penas

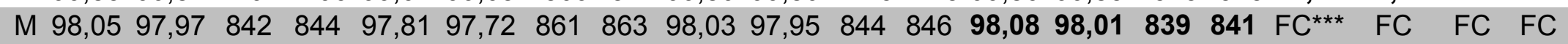

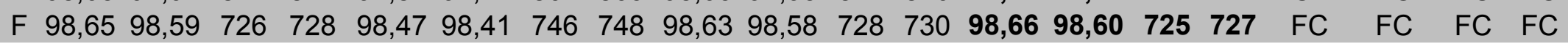
Carcaça M 99,79 99,78 14051407 99,72 99,71 14451448 99,78 99,77 14071409 99,78 99,77 $1412141499,7999,7714071409$

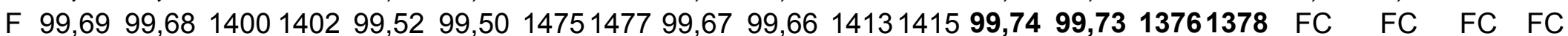
Peito M M9,22 99,19 $1232123499,1499,101249125199,22$ 99,1912331235 99,22 99,19 $1232123499,2399,1812341236$

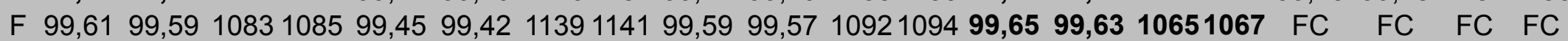

$\begin{array}{llllllllllllllllllllll} & M & 99,74 & 99,73 & 806 & 808 & 99,70 & 99,69 & 829 & 831 & 99,74 & 99,73 & 804 & 806 & 99,71 & 99,70 & 823 & 825 & 99,74 & 99,73 & 806 & 808\end{array}$ $\begin{array}{llllllllllllllllllllllllll}\text { Coxa } & F & 99,59 & 99,57 & 799 & 801 & 99,45 & 99,43 & 845 & 847 & 99,57 & 99,56 & 804 & 806 & \mathbf{9 9 , 6 0} & \mathbf{9 9 , 5 8} & \mathbf{7 9 5} & \mathbf{7 9 7} & 99,60 & 99,57 & 797 & 799 \\ & \mathrm{M} & 99,77 & 99,76 & 873 & 875 & 99,40 & 99,37 & 962 & 964 & \mathbf{9 9 , 7 8} & \mathbf{9 9 , 7 7} & \mathbf{8 7 1} & \mathbf{8 7 3} & \mathbf{9 9 , 7 5} & \mathbf{9 9 , 7 4} & 889 & 891 & 99,78 & 99,76 & 873 & 875\end{array}$ $\begin{array}{lllllllllllllllllllllllllll}\text { Sobrecoxa } & \text { F } & 99,56 & 99,54 & 912 & 914 & 99,75 & 99,74 & 890 & 892 & 99,54 & 99,52 & 919 & 921 & \mathbf{9 9 , 5 9} & \mathbf{9 9 , 5 8} & \mathbf{8 9 9} & \mathbf{9 0 1} & \text { FC } & \text { FC } & \text { FC } & \text { FC }\end{array}$ Asa

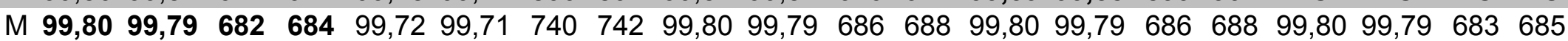

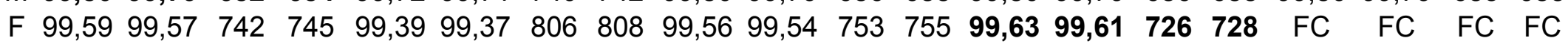

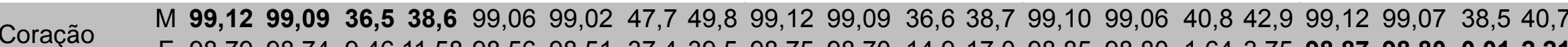

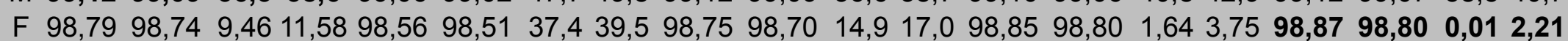

Fígado

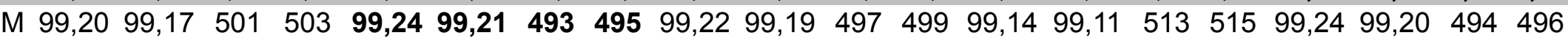
Moela

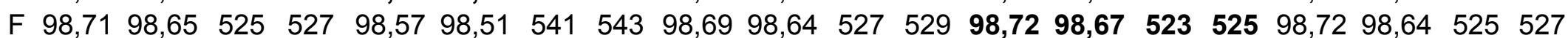

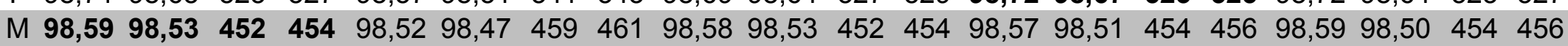

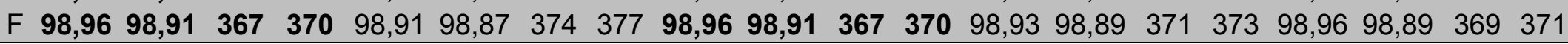
*Valores em negrito são os melhores ajustes para o respectivo modelo, segundo os critérios adotados; ${ }^{* *}$ Sexo (S); ${ }^{* * *}$ Falha na convergência (FC);

Fonte: Própria autoria. 
Figura 4- Ajustes dos modelos de crescimento sobre as características de consumo de ração (CR -1) e peso corporal (PC - 2) de frangos de corte machos (-) e fêmeas (- - -)

1)

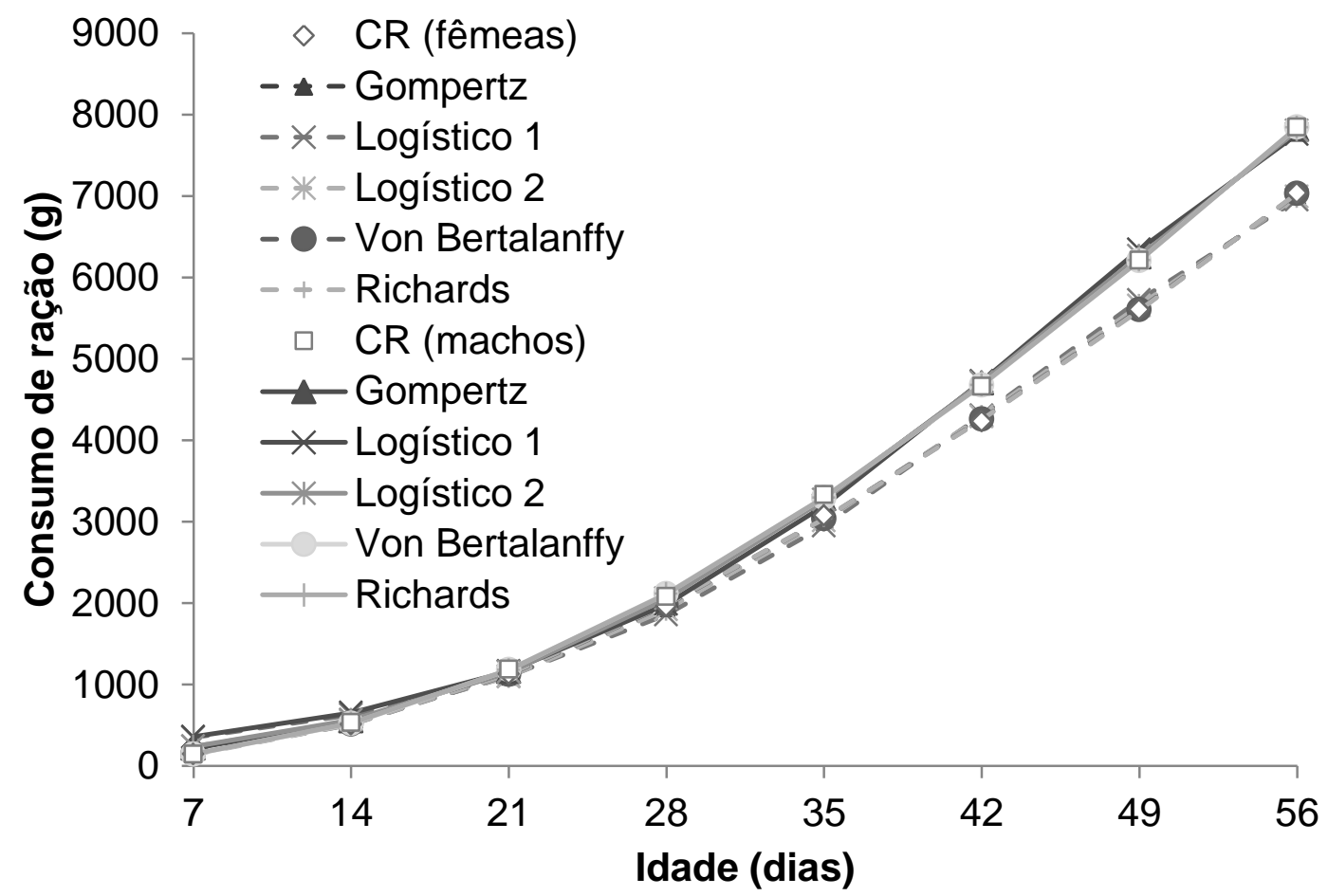

2)

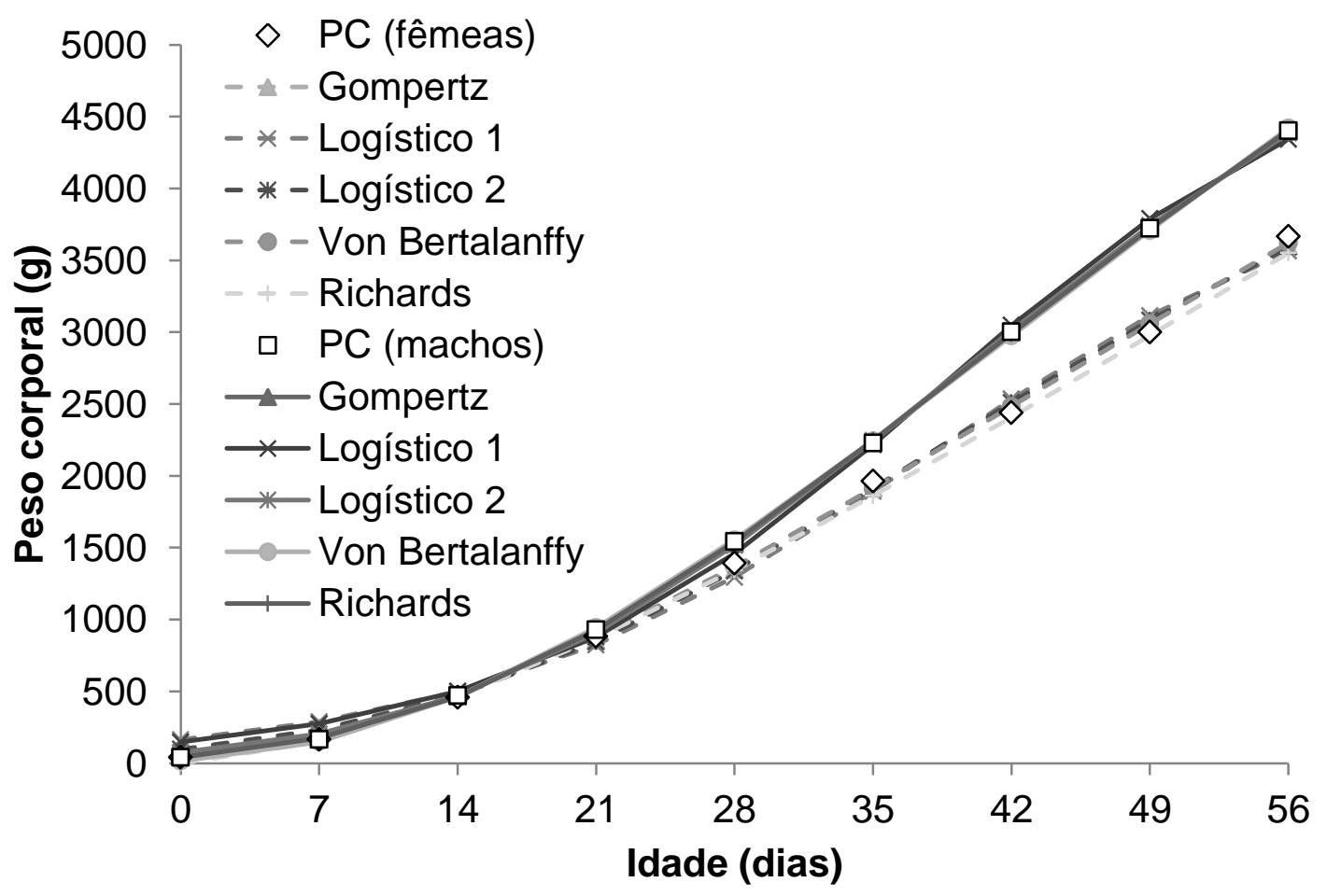

Fonte: Própria autoria. 
Figura 5- Ajustes dos modelos de crescimento sobre as características de PC de frangos de corte em jejum e depenado (PCJD- 1) e das penas (2) de machos (-) e fêmeas (- - )
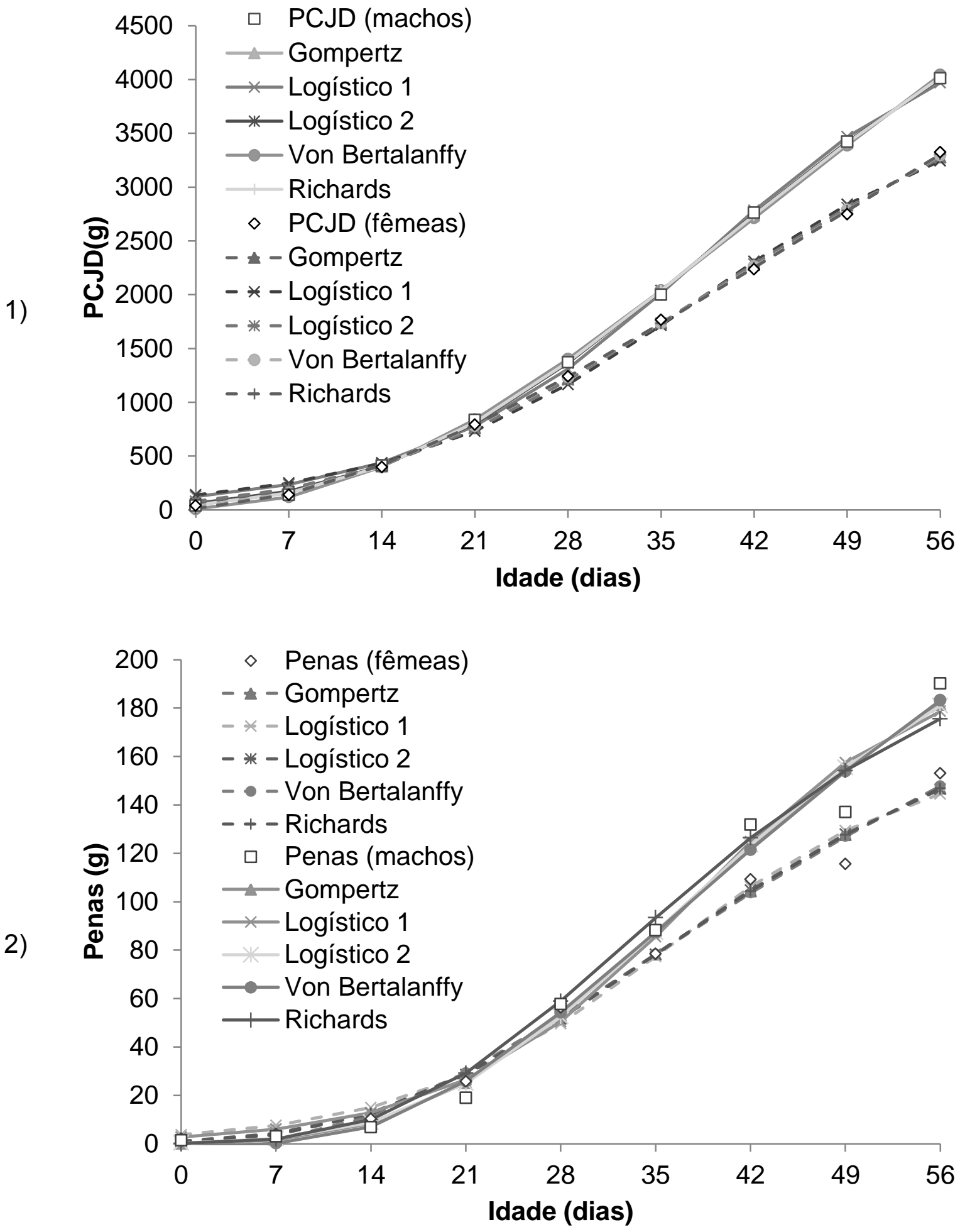

Fonte: Própria autoria. 
Figura 6- Ajustes dos modelos de crescimento sobre as características de carcaça (1) e peito (2) de frangos de corte machos (-) e fêmeas (- - -)

1)
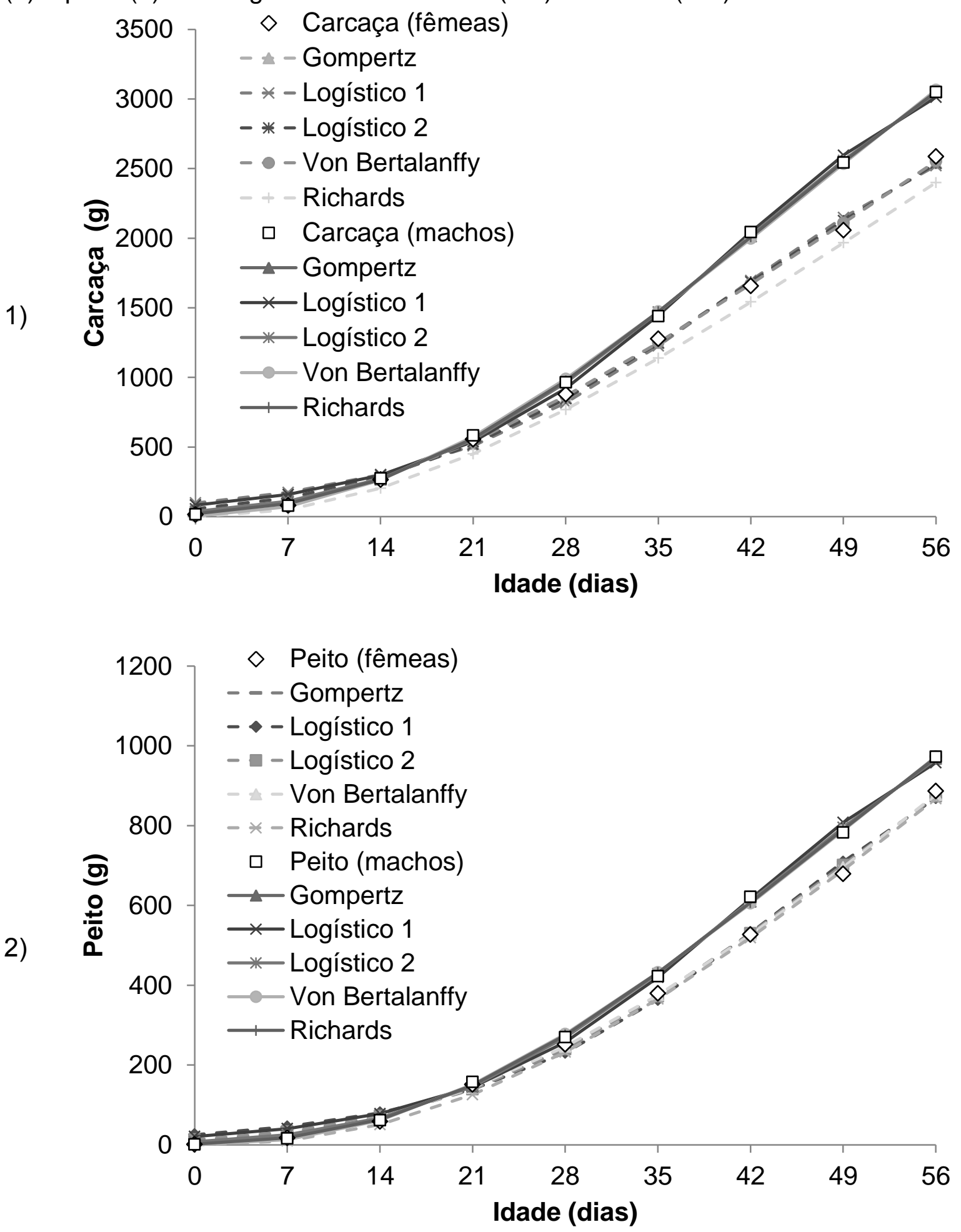

Fonte: Própria autoria. 
Figura 7 - Ajustes dos modelos de crescimento sobre as características de coxa (1) e sobrecoxa (2) para frangos de corte machos (-) e fêmeas (- - -)
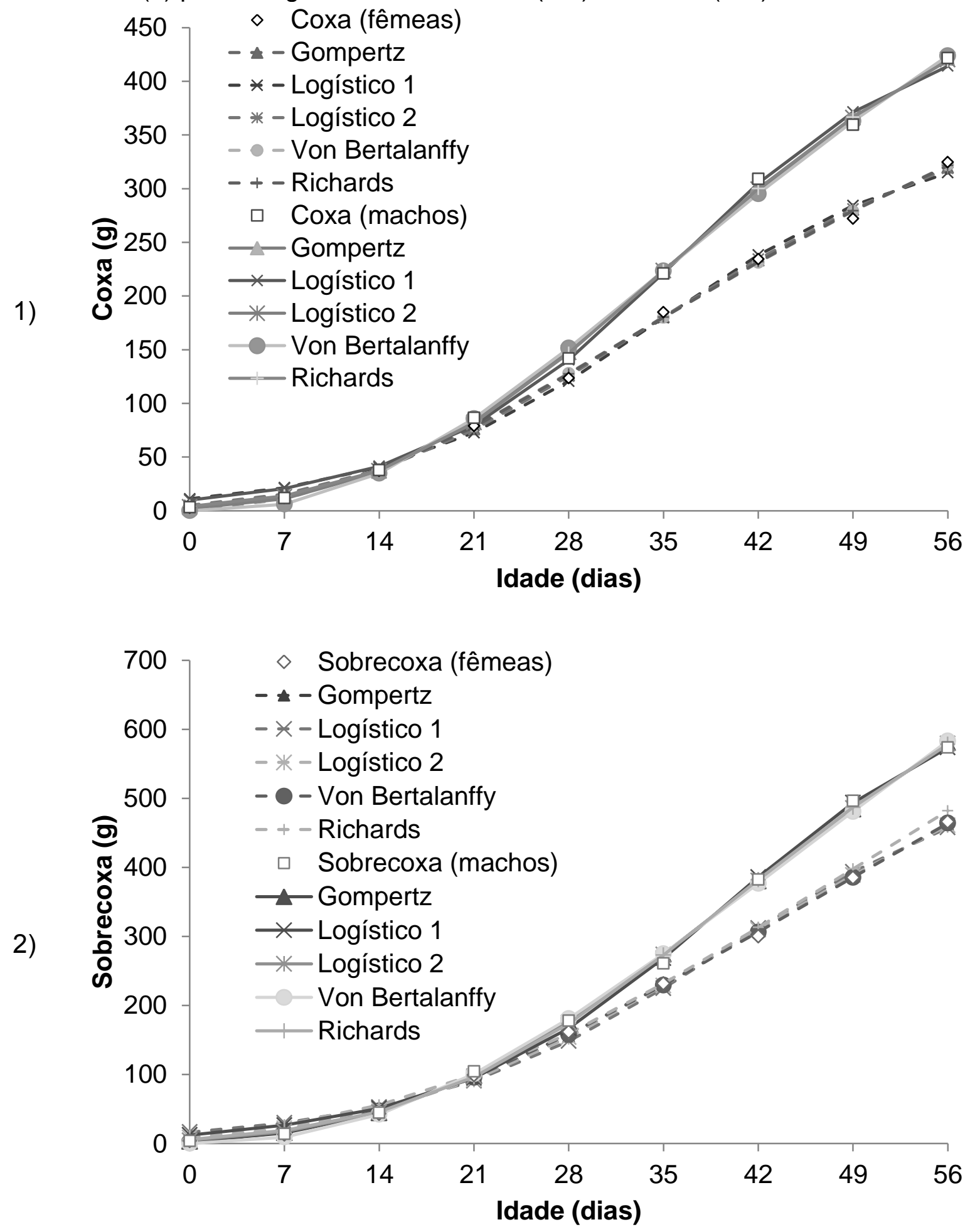

Fonte: Própria autoria. 
Figura 8 - Ajustes dos modelos de crescimento sobre as características de asa (1) e moela (2) para frangos de corte machos (-) e fêmeas (- - -)
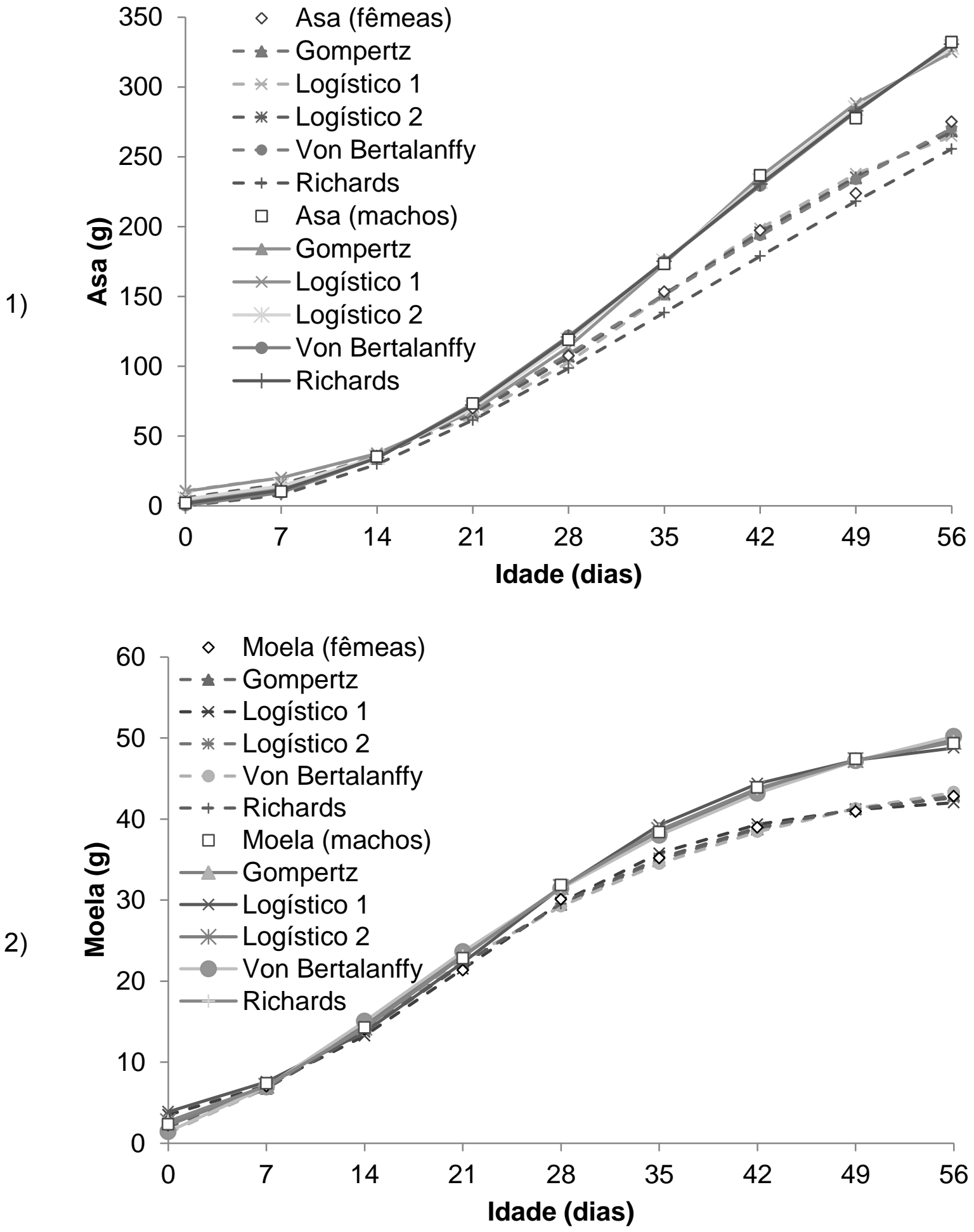

Fonte: Própria autoria. 
Figura 9 - Ajustes dos modelos de crescimento sobre as características de coração (1) e fígado (2) para frangos de corte machos (-) e fêmeas (- - -)

1)
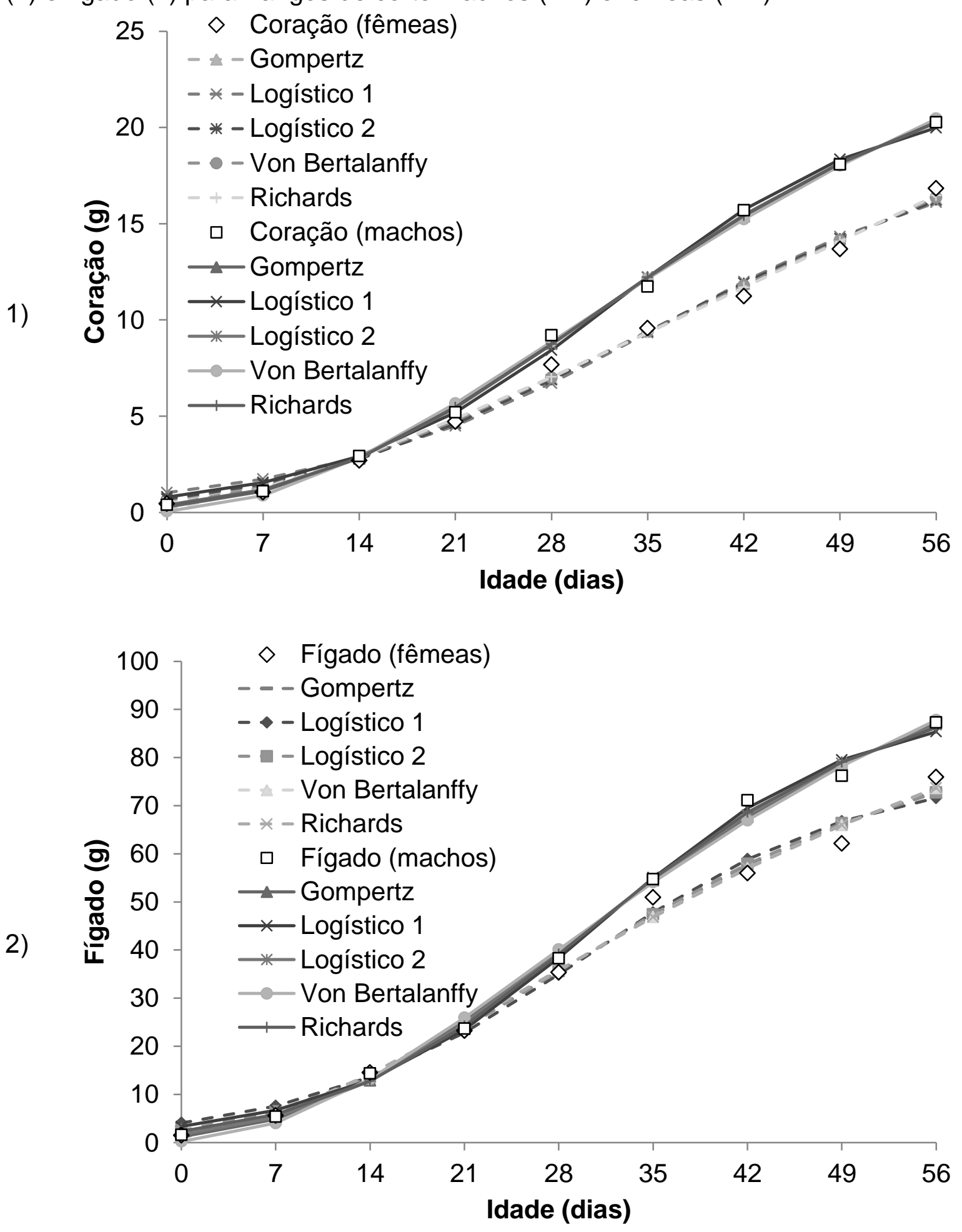

Fonte: Própria autoria. 
observado (dados não mostrados) quase sempre subestimando os valores, enquanto que os demais modelos superestimaram os valores iniciais estimados

Apesar de ter convergido para todas as características o modelo Logístico 1 apresentou valores iniciais bastante superestimados sendo bem visível quando plotado ao dados nas Figuras 4, 5, 6, 7, 8 e 9 apresentando para a maioria das características, qualidade de ajuste inferior quando comparado aos demais modelos (Tabela 4).

Para as características de $\mathrm{CR}$ e penas o modelo de Von Bertalanffy apresentou os melhores critérios de avaliação com melhor ajuste para machos e fêmeas. Notou-se ainda que o modelo Von Bertalanffy apresentou o melhor desempenho entre os modelos para fêmeas nas características avaliadas do PCJD, carcaça, peito, coxa, sobrecoxa, asa, coração e fígado com o segundo melhor ajuste para o modelo de Gompertz.

O modelo de Gompertz apresentou desempenho superior de avaliação para o peso de moela em machos e fêmeas, porém para as características do PCJD, carcaça, peito, coxa, asa e coração de machos, o modelo de Gompertz, foi o que melhor se ajustou. Os modelos Logístico 1 e Logístico 2 apresentaram os melhores ajustes para os dados de pesos de fígado e sobrecoxa de machos, respectivamente.

Como reportado por Gbangboche et al. (2008), a escolha do modelo afeta a estimativa dos parâmetros, influenciando no ponto de inflexão da curva, que para o modelo de Gompertz este ponto é $36,8 \%$ do peso à maturidade da ave $(0,368 \mathrm{a})$ (MARCATO et al., 2008; MIGNON-GRASTEAU et al., 2000 e WINSOR, 1932); o modelo Von Bertalanffy possui um ponto de inflexão próximo de $26,9 \%$ do valor de "a"; para o modelo Logístico 1 este ponto satisfaz cerca de $50 \%$ do valor de "a" $(0,5 a)$ e já os modelos Logístico 2 e Richards, variam de acordo com os parâmetros "a", "m" e "b".

É comum que exista uma correlação entre os parâmetros estimados dos modelos de crescimento, sugerindo que a posição do ponto de inflexão seja influenciada fortemente pelo valor constante da taxa de crescimento $(k)$ e do peso da ave à maturidade (a) (AGGREY 2002; BARBATO, 1991; MIGNON-GRASTEAU et al., 2000 e ZUIDHOF, 2005).

O ponto de inflexão $(\mathrm{PI})$ é um importante indicativo econômico, pois o crescimento animal segue um padrão sigmoidal, com aceleração da taxa de crescimento até certo ponto (Yi; Ti), no qual ocorre uma desaceleração mudando o 
formato da curva de côncava para convexa (THORNLEY; FRANCE, 2007). Portanto, o dia no qual a taxa de crescimento é máxima pode ser utilizado como uma previsão do dia de abate da ave, sendo que este ponto varia de acordo com o valores dos parâmetros em cada modelo de crescimento utilizado.

Através dos parâmetros estimados (Tabela 5) percebe-se que diferentes modelos podem ser adequados e que de modo geral os modelos seguem padrões semelhantes, mas variam nos valores entre si, tendo o modelo Richards e Von Bertalanffy apresentado valores superiores aos observados nos modelos de Gompertz, logístico 1 e 2. Kuhi et al. (2003), também observaram variação no valor do mesmo parâmetro entre os modelos de crescimento corporal de frangos de corte, corroborando com o presente estudo.

Em geral, visa-se encontrar o modelo mais preciso para estimar o crescimento animal, porém como existem vários modelos e diferenças experimentais, são encontrados na literatura diferentes resultados e conclusões por parte dos autores. Aggrey (2002) comparou os modelos de Richards, Gompertz e Logístico 1 e um modelo de regressão linear em frangos e verificaram que o modelo de Richards teve o melhor a ajuste aos dados, percebendo que o valor do parâmetro que dá forma a curva $(\mathrm{m})$ foi próximo de 1, correspondendo ao modelo de Gompertz; e este mesmo efeito foi observado por Goliomytis et al. (2003), sendo que no atual estudo não foi observado este efeito.

Em estudo com galinha caipira dentre os modelos não-lineares (Logístico 1, Gompertz e Von Bertalanffy), o modelo de Von Bertalanffy obteve o melhor ajuste, entretanto também foi verificado valores elevados (irreais) de parâmetros para este modelo não possuindo coerência biológica, concordando com o presente estudo (YANG et al., 2006).

Noutro estudo comparando modelos de Gompertz e Logístico 1 em variedades de machos e fêmeas Hubbard em sistema orgânico foi observado valores de "a" inferiores no modelo Logístico 1 quando comparados aos de Gompertz, assim como no atual estudo, tendo o melhor ajuste para Logístico 1 (ELEROGLU et al., 2015).

Diferentes genótipos de frangos tipo caipira foram analisados através das curvas de crescimento de Brody, Logístico 2, Gompertz e Von Bertalanffy e Richards re-parametrizado, não obtendo convergência quando utilizado o modelos de Richards e o modelo proposto por Von Bertalanffy foi o mais adequado para 
Tabela 5 - Estimativas dos parâmetros $(\mathrm{a}, \mathrm{b}, \mathrm{k} \text { e } \mathrm{m})^{1}$ dos modelos matemáticos não ponderados (NP) e ponderados (P) em características $(C)$ avaliadas de frangos machos $(M)$ e fêmeas $(F)$

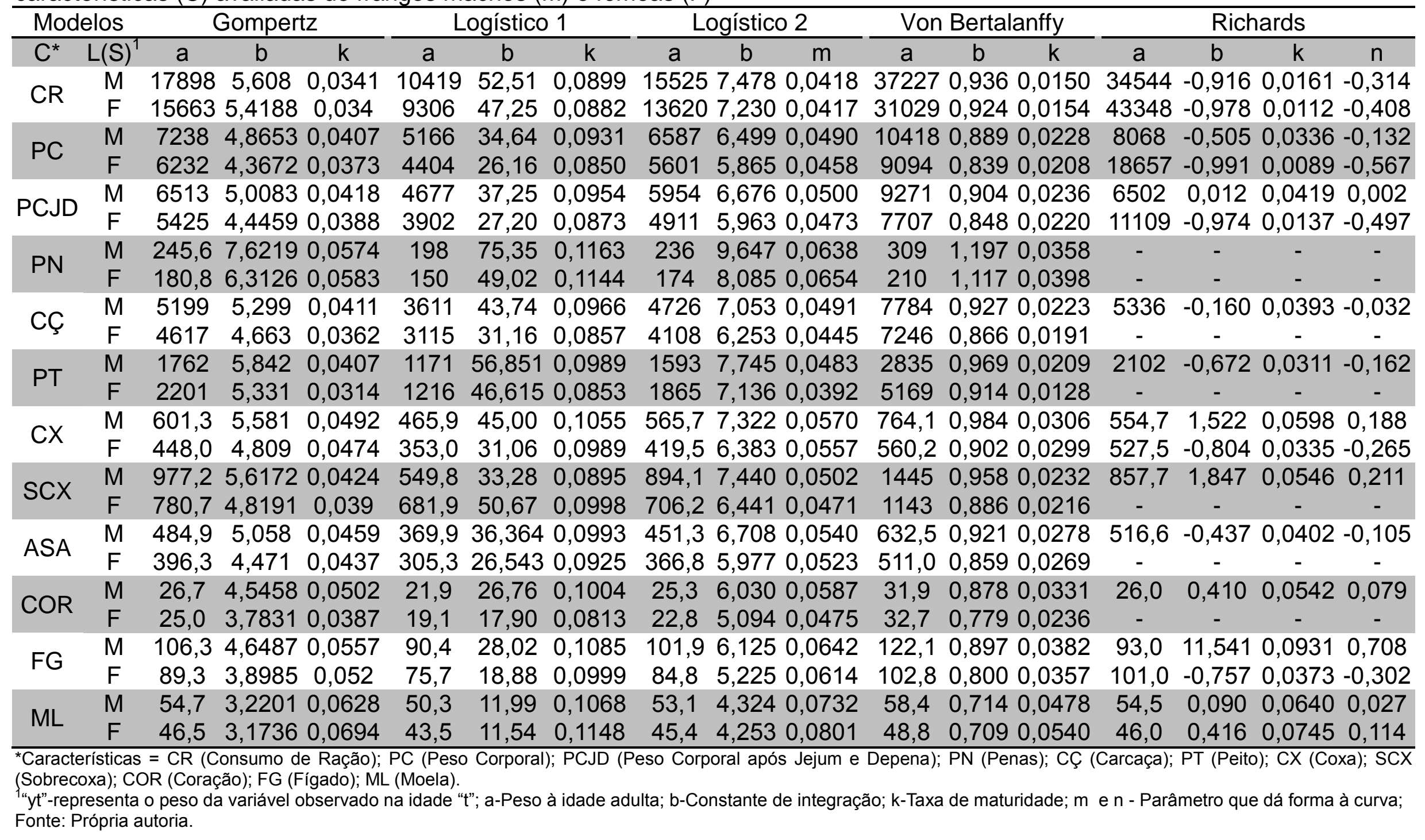


descrever o crescimento dos genótipos de frangos caipiras (VELOSO et al., 2015).

Em estudo semelhante ao atual, notaram que Gompertz encontrava-se entre os melhores modelos selecionados para estimar o crescimento de frangos de corte de alto desempenho (VELOSO et al., 2016a) e apesar da variedade de funções de crescimento existente o modelo de Gompertz é um dos mais recomendados pelos autores (BARBATO, 1991; FREITAS, 2005; GOUS et al., 1999; HANCOCK et al., 1995; KNIZETOVA et al., 1985; MOHAMMED, 2015; PRESCOTT et al., 1985; TZENG; BECKER, 1981; 1991; RICKLEFS, 1985; ROGERS et al., 1987; SANTOS et al., 2005; WINKELSTROTER 2013 ) no estudo de crescimento animal.

Com isso, no presente trabalho foi verificado que os modelos Richards e Von Bertalanffy tiveram os melhores ajustes, mas houve falhas na convergência dos parâmetros para o modelo de Richards e valores exagerados de peso à maturidade para algumas características nos modelos de Richards e Von Bertalanffy, não possuindo coerência biológica para as características quando a ave atinge o peso adulto. Assim, podemos concluir que Gompertz é o mais versátil modelo, possuindo a melhor interpretação dos parâmetros e qualidade de ajuste dentre os modelos usados para explicar o crescimento de frangos de corte.

\subsection{EQUAÇÕES ALOMETRICAS}

A alometria tradicional baseia-se na relação entre as diferenças quantitativas. $\mathrm{Na}$ natureza existem várias formas de se comparar a similaridade entre diferentes medidas, sendo o tamanho animal a característica de maior importância. Para isto, utiliza-se das leis de potência ou equações alométricas, sendo necessário definir uma variável independente comum às variáveis dependentes (BARBOSA, 2007). No caso de frangos de corte pode-se utilizar o componente físico ou químico do corpo, como variável dependente e o do peso corporal ou peso de proteína corporal da ave como variável independente.

A utilização do peso proteico como variável independente ocorre, pois a proteína tende a ter um crescimento constante com o PC, sendo que os demais nutrientes possuem maior variação na deposição corporal como o peso lipídico corporal que muda de acordo com a dieta e temperatura do ambiente ou ainda a água corporal que decresce com o desenvolvimento da ave, assim a uso do peso 
proteico em equações alométricas melhoram a precisão das equações (MARCATO et al., 2008).

Gous (2014) sugeriu que diferenças certamente existem entre genótipos de frangos de corte, quando os pesos das partes são plotados (regressão) em relação à idade ou peso corporal, mas diminuem quando plotados com a proteína do corpo. Danisman e Gous $(2011$; 2013) verificaram distintas relações alométricas entre o peso corporal proteico e partes do corpo de frangos sobre a interação linhagem e sexo, apresentando maiores distinções quando estes foram alimentados com diferentes níveis de proteína, sendo justificado pela diferença na deposição de lipídios em cada parte do corpo em resposta ao conteúdo proteico da dieta. Sabendo disso, alguns autores (GOUS et al., 1999; MARCATO et al., 2008; SAKOMURA et al., 2011) preferem utilizar o peso proteico corporal como variável independente nas equações alométricas entre os componentes corporais.

Foi feita comparação dos coeficientes de determinação de regressões lineares simples utilizando como variáveis independentes o peso corporal da ave em jejum (PCJ), peso corporal da ave em jejum depenada (PCJD) e o peso de proteína corporal em relação aos componentes físicos e químicos do corpo da ave (Tabelas 6 e Apêndice B). De acordo com os coeficientes de determinação ajustado a maioria das regressões alométricas apresentou valores próximos de $100 \%$ para os componentes do corpo em relação ao PCJ, PCJD ou peso de proteína corporal, com exceção de penas (Apêndice $C$ ), peito (Apêndice $D$ e $E$ ) e órgãos, principalmente o peso de moela (Apêndice F) utilizando dados contendo o primeiro dia de vida dos animais.

Gous (2014) observou que entre as medidas dos componentes do corpo de frangos deve haver uma taxa comum para obter maior eficiência alométrica e esta pode ser obtida através da curva de Gompertz. Este autor ainda observou que o peso de penas tem difícil ajuste, porque o seu crescimento não compartilha da mesma taxa de maturidade que o crescimento corporal. No atual estudo, a velocidade de crescimento $(k)$ das penas foi cerca de $30 \%$ superior em relação ao crescimento corporal (Tabela 5) e teve menor ajuste na alometria $\left(R^{2}\right.$ aj $=95$ a $\left.97 \%\right)$, em relação aos outros componentes do corpo avalizados (Tabela 6).

Outra característica avaliada que apresentou valores de ajustes inferiores $\left(R^{2}{ }_{a j}=96\right.$ a $\left.98 \%\right)$ foi a moela, visto que este órgão também teve taxa de maturidade 
Tabela 6 - Avaliação do ajuste médio da equação alométrica das características avaliadas de frangos machos $(M)$ e fêmeas $(F)$, através do coeficiente de determinação ajustado $\left(R^{2}{ }_{\text {aj }}\right)$ e pelos critérios de informação de Akaike (AIC) e Bayesiano de Schwarz (BIC)*

\begin{tabular}{|c|c|c|c|c|c|c|c|c|c|c|}
\hline \multirow{2}{*}{\multicolumn{2}{|c|}{ Variáveis }} & \multicolumn{9}{|c|}{ Independentes } \\
\hline & & \multicolumn{3}{|c|}{ PCJ } & \multicolumn{3}{|c|}{ PCJD } & \multicolumn{3}{|c|}{ PB } \\
\hline & & $\mathrm{R}^{2}{ }_{\mathrm{aj}}(\%)$ & AIC & $\mathrm{BIC}$ & $\mathrm{R}^{2}{ }_{\mathrm{aj}}(\%)$ & AIC & $\mathrm{BIC}$ & $\mathrm{R}^{2}{ }_{\mathrm{aj}}(\%)$ & AIC & $\mathrm{BIC}$ \\
\hline \multirow{2}{*}{ Água } & $\mathrm{M}$ & 99,94 & -1050 & -1048 & 99,93 & -1040 & -1038 & 99,59 & -750 & -72 \\
\hline & - & 99,95 & -1136 & -1134 & 99,95 & -1133 & -1131 & 99,57 & -778 & -77 \\
\hline \multirow{2}{*}{ Água** } & M & 99,87 & -920 & -918 & 99,88 & -930 & -928 & 99,14 & -650 & -6 \\
\hline & $\Gamma$ & 99,90 & -995 & -993 & 99,90 & -1000 & -998 & 99,11 & -682 & -68 \\
\hline \multirow{2}{*}{ Prote } & $\mathrm{M}$ & & -841 & -839 & 99,79 & -848 & -845 & & & \\
\hline & & 99,74 & -848 & -846 & 99,76 & -860 & -858 & - & - & \\
\hline \multirow{2}{*}{ Proteína } & M & 9,54 & -732 & -730 & 9,56 & -739 & -737 & & & \\
\hline & $\mathrm{F}$ & ,49 & -752 & -750 &, 50 & -756 & -754 & - & - & \\
\hline \multirow{2}{*}{ Gordura } & M & & -618 & -616 & ,37 & -621 & -619 & 99,23 & -591 & \\
\hline & $-5+2-$ & & -707 & -705 & ,62 & -709 & -707 & & -700 & 0. \\
\hline \multirow{2}{*}{ Gordura $^{* *}$} & iv & 98,71 & -545 & -543 & 3,72 & -546 & -544 & 98,51 & -525 & \\
\hline & $\mathrm{F}$ & 27 & -630 & -628 & 9,29 & -632 & -630 & 99,34 & -644 & -6 \\
\hline \multirow{2}{*}{ Cinzas } & $\mathrm{M}$ & & -609 & -607 & 99,28 & -622 & -620 & 99,29 & -626 & -62 \\
\hline & $ᄃ$ & & -692 & -690 & 52 & -710 & -708 & ,66 & -767 & -76 \\
\hline \multirow{2}{*}{ Cinzas $^{* *}$} & IVI & 13 & -636 & -634 & 9,13 & -637 & -635 & 9,35 & -676 & -67 \\
\hline & $\tau$ & 13 & -715 & -713 &, 44 & -719 & -717 & 9,59 & -764 & -76 \\
\hline \multirow{2}{*}{ Penas } & M & & -326 & -324 & 52 & -316 & -314 & 5,14 & -303 & -30 \\
\hline & $\mathrm{F}$ & & -405 & -403 & 26 & -393 & -391 & 95,72 & -372 & -37 \\
\hline \multirow{2}{*}{ Penas } & M & & -358 & -356 & 08 & -349 & -347 & 95,23 & -321 & -31 \\
\hline & $\mathrm{F}$ & 8 & -445 & -443 & 7 & -434 & -432 & 6,35 & -408 & $-4 C$ \\
\hline \multirow{2}{*}{ Carcaç } & M & $y$ & -778 & -776 & 77 & -810 & -808 & 9,56 & -703 & -70 \\
\hline & 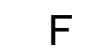 & & -753 & -751 & & -784 & -782 & & -731 & -72 \\
\hline \multirow{2}{*}{ Carcaça** $^{*}$} & M & 9 & -929 & -927 & 91 & -952 & -950 & 99,55 & -722 & -72 \\
\hline & $\mathrm{F}$ & & -969 & -967 & & -980 & -978 & 99,53 & -733 & -73 \\
\hline \multirow{2}{*}{ Peitc } & $\mathrm{M}$ & & -281 & -279 & & -274 & -272 & 53 & -274 & -27 \\
\hline & $F$ & ,72 & -292 & -290 & 16 & -313 & -311 & 97,01 & -307 & -30 \\
\hline \multirow{2}{*}{ Peito** } & M & 64 & -717 & -715 & 35 & -722 & -720 & 9,24 & -611 & $-6 c$ \\
\hline & $\mathrm{F}$ & & -766 & -764 & & -759 & -757 & 20 & -617 & -61 \\
\hline Coxa & $\begin{array}{l}M \\
\end{array}$ & & $\begin{array}{l}-908 \\
-845\end{array}$ & $\begin{array}{l}-906 \\
-843\end{array}$ & & $\begin{array}{l}-909 \\
-872\end{array}$ & $\begin{array}{l}-907 \\
-870\end{array}$ & $\begin{array}{l}99,70 \\
99,71\end{array}$ & $\begin{array}{l}-783 \\
-788\end{array}$ & -78 \\
\hline \multirow{2}{*}{ Coxa' } & $M$ & & -7 & $-7 c$ & & -798 & -796 & 99,38 & -678 & -67 \\
\hline & $-5+2>$ & & -802 & -80 & 73 & -807 & -805 & 99,41 & -697 & -65 \\
\hline \multirow{2}{*}{ Sobrecoxa } & $\bar{M}$ & $9 !$ & -940 & -938 & ,90 & -949 & -946 & 99,68 & -758 & -75 \\
\hline & $-\pi$ & & -896 & -894 & & -890 & -888 & 99,58 & -730 & -72 \\
\hline & M & 6 & -876 & -874 & 36 & -878 & -876 & 99,44 & -682 & -68 \\
\hline sobrecoxa & - & & & -85 & & -859 & -857 & 99,37 & -682 & $-6 \varepsilon$ \\
\hline & M & & -6 & -6 & & -671 & -669 & 99,25 & -624 & -62 \\
\hline & $\mathrm{F}$ & & -5 & -57 & & -598 & -596 & 99,10 & -602 & -60 \\
\hline & M & 9 & -794 & -792 & 99,72 & -803 & -801 & 99,43 & -703 & -70 \\
\hline & 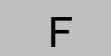 & & -793 & -791 & & -798 & -796 & 99,39 & -713 & -71 \\
\hline & $\bar{M}$ & & -721 & -7 & & -715 & -713 & 99,15 & -67 & \\
\hline & & & -732 & & & 723 & 721 & 8,99 & & \\
\hline
\end{tabular}


Tabela 6 - Avaliação do ajuste médio da equação alométrica das características avaliadas de frangos machos $(M)$ e fêmeas $(F)$, através do coeficiente de determinação ajustado $\left(R^{2}{ }_{a j}\right)$ e pelos critérios de informação de Akaike (AIC) e Bayesiano de Schwarz $(\mathrm{BIC})^{*}$

\begin{tabular}{|c|c|c|c|c|c|c|c|c|c|c|}
\hline Variáveis & & & & & & & & \multicolumn{3}{|c|}{ Independentes } \\
\hline \multirow{2}{*}{ Dependentes } & \multirow{2}{*}{ Sexo } & \multicolumn{3}{|c|}{ PCJ } & \multicolumn{3}{|c|}{ PCJD } & \multicolumn{3}{|c|}{ PB } \\
\hline & & $\mathrm{R}_{\mathrm{ai}}^{2}(\%)$ & AIC & $\mathrm{BIC}$ & $\mathrm{R}_{\mathrm{aj}}^{2}(\%)$ & AIC & $\mathrm{BIC}$ & $\mathrm{R}_{\mathrm{ai}}^{2}(\%)$ & $\mathrm{AIC}$ & $\mathrm{BIC}$ \\
\hline \multirow{2}{*}{ Coração** } & $\bar{M}$ & 98,92 & -651 & -649 & 98,89 & -647 & -645 & 98,52 & $\begin{array}{l}-606 \\
\end{array}$ & -604 \\
\hline & $\mathrm{F}$ & 98,88 & -664 & -662 & 98,87 & -663 & -661 & 98,42 & -615 & -613 \\
\hline \multirow{2}{*}{ Fígado } & $M$ & 99,17 & -683 & -681 & 99,20 & -689 & -687 & 98,95 & -646 & -644 \\
\hline & $\mathrm{F}$ & 98,96 & -648 & -646 & 99,04 & -659 & -657 & 99,05 & -661 & -659 \\
\hline \multirow{2}{*}{ Fígado** } & $M$ & 98,93 & -672 & -670 & 98,93 & -671 & -668 & 98,56 & -629 & -626 \\
\hline & $\mathrm{F}$ & 98,51 & -639 & -637 & 98,52 & -639 & -637 & 98,33 & -623 & -621 \\
\hline \multirow{2}{*}{ Moela } & $\bar{M}$ & 97,56 & -596 & -594 & 97,67 & -604 & -601 & 97,59 & -598 & -596 \\
\hline & $F$ & 97,82 & -614 & -612 & 97,93 & -623 & -621 & 98,03 & -630 & -628 \\
\hline \multirow{2}{*}{ Moela** } & M & 96,61 & -609 & -607 & 96,62 & -609 & -607 & 96,55 & -606 & -604 \\
\hline & $F$ & 97,22 & -640 & -638 & 97,21 & -640 & -638 & 97,05 & -632 & -630 \\
\hline
\end{tabular}

superior que as variáveis independentes (Apêndice $F$ ), tendo assim crescimento diferenciado do PC e peso de proteína corporal da ave.

A alometria entre as variáveis independentes e alguns componentes (peso de cinzas, peito e moela) apresentaram valores iniciais abaixo da reta plotada utilizando regressão linear simples, devido à logaritmização dos pesos, sendo o peso de peito uma característica de grande importância econômica e que teve $\mathrm{R}^{2}{ }_{\text {aj }}=96$ a $97 \%$ da regressão alométrica. Apesar de valores altos de coeficientes, esses ajustes foram insatisfatórios para esta característica, sendo melhores depois de retirados valores do primeiro dia de vida (GOUS et al., 1999; SAKOMURA et al., 2011 e DANISMAN; GOUS, 2011 e 2013).

O peso médio de peito de machos e fêmeas correspondeu a 1,37\% e 1,47\% do peso corporal, respectivamente, $($ machos $=0,39 \mathrm{~g}$ ou $\ln (0,39)=-0,51$ e fêmeas $=$ $0,45 \mathrm{~g}$ ou In $(0,45)=-0,48)$ no primeiro dia de vida dos pintinhos e na segunda semana estes foram bem mais elevados ( machos $=10,91 \%$ e fêmeas $=11,86 \%$ ).

Segundo Ricklefs (1985), durante o desenvolvimento do embrião, geralmente as aves precociais (como o frango de corte), tem maior peso de tegumento (pele e penas) e músculos das pernas, sendo mais homeotérmicos e mais ágeis do que as aves altriciais, garantindo maior independência ao nascimento, porém com menor 
quantidade de músculos do peito. Neste sentido, Lilja e Olsson ${ }^{4}$ (1987, p. 301-308 apud SILVA et al., 2008, p. 27) sugeriram que durante o crescimento do embrião de aves precociais, os órgãos de abastecimento do corpo como o coração, fígado e intestino tem preferência no crescimento do que os órgãos de demanda como músculo e sangue, obtendo assim peso relativo de peito menor no primeiro dia de vida em relação ao PC ou proteína bruta corporal.

A partir do explanado foram retirados os valores do primeiro dia de vida das aves para nova regressão linear simples obtendo melhor qualidade de ajustes observados através do aumento do coeficiente de determinação ajustado $\left(R^{2}{ }_{a j}\right)$, diminuição dos valores dos critérios de informação de Akaike (AIC) e Critério de Informação Bayesiano de Schwarz (BIC) (Tabela 6) para as características de peso de cinzas, penas, carcaça, peito e asa em relação às variáveis independentes (PCJ, PCJD e PB), sendo que para o peso de água, proteína e gordura corporal, peso das pernas (coxa e sobrecoxa), peso dos órgãos (coração, fígado e moela) não houve melhora sobre o $\mathrm{R}^{2}$ aj e AIC quando retirados os dados iniciais.

De acordo com os dados do presente estudo, o modelo de crescimento que teve maior coerência biológica foi Gompertz (Tabela 4), apresentando os melhores ajustes para o peso corporal em jejum e depenado. Os ajustes estimados para os componentes corporais através da regressão linear simples (alometria) utilizando o peso corporal em jejum (PCJ) ou em jejum depenado (PCJD) na maior parte das vezes foram melhores do que os ajustados pela proteína corporal, exceto para penas, peito com dados de 1 dia de vida e moela.

\subsection{AVALIAÇÃO DOS PARÂMETROS ESTIMADOS DO CONSUMO DE RAÇÃO, CRESCIMENTO CORPORAL, COMPONENTES FÍSICOS E DEPOSIÇÃO DE NUTRIENTES CORPORAIS}

A partir dos dados coletados semanalmente e da decisão de que o modelo de crescimento de Gompertz é o mais adequado biologicamente para utilização no estudo do crescimento de frangos de corte, foram realizadas estimativas dos

\footnotetext{
${ }^{4}$ Lilja C; Olsson U. Changes in embryonic development associated with long-term selection for high growth rate in Japanese quail. Growth, v.51, p.301-308, 1987.
} 
parâmetros do modelo para avaliar o consumo de ração, o crescimento do corpo e seus componentes e ainda relacionar estes componentes ao peso proteico de diferentes linhagens de frangos de corte, machos e fêmeas, usando a alometria. A comparação das características estimadas fornece o potencial de crescimento dos frangos de corte, podendo ser combinadas com outras informações para cálculo das necessidades nutricionais (SAKOMURA, 2004).

\subsubsection{Consumo de ração e crescimento corporal}

Na Tabela 7 estão mostrados as médias estimadas dos parâmetros do modelo de Gompertz, as propriedades estimadas a partir dos dados observados para consumo de ração $(\mathrm{CR})$, o peso corporal $(\mathrm{PC})$ por sexo e linhagem dentro de cada sexo. Na Tabela 8, contém as médias semanais para o consumo diário de ração e o

Tabela 7 - Estimativas médias e erros-padrões dos parâmetros ( $a, b$ e k), taxa máxima de crescimento ou consumo (TMC) e idade de inflexão (Ti) do modelo de Gompertz sobre o consumo de ração (CR) e peso corporal (PC) de frangos machos (M) e fêmeas (F) das linhagens Cobb $500(C)$, Ross $308(R)$ e Hubbard Flex (H)

\begin{tabular}{|c|c|c|c|c|c|}
\hline * & \multicolumn{5}{|c|}{ Parâmetros e propriedades } \\
\hline L S & $a^{1}(g)$ & $b^{2}$ & $k^{3}\left(t^{-1}\right)$ & $\mathrm{Ti}$ (dias) & TMC (g/d) \\
\hline \multicolumn{6}{|c|}{ CR } \\
\hline $\mathrm{CM}$ & $16131 \pm 250^{b}$ & $5,447 \pm 0,033^{b}$ & $0,0351 \pm 0,0002^{a}$ & $48,3 \pm 0,2^{b}$ & $208,3 \pm 2,7^{b}$ \\
\hline R M & $18108 \pm 884^{a}$ & $5,682 \pm 0,034^{a}$ & $0,0355 \pm 0,0010^{a}$ & $49,1 \pm 1,3^{b}$ & $235,2 \pm 5,4^{a}$ \\
\hline $\mathrm{HM}$ & $18643 \pm 282^{a}$ & $5,740 \pm 0,021^{a}$ & $0,0333 \pm 0,0002^{b}$ & $52,5 \pm 0,3^{a}$ & $228,3 \pm 2,2^{a}$ \\
\hline M & $17599 \pm 387^{A}$ & $5,620 \pm 0,036^{A}$ & $0,0346 \pm 0,0004^{A}$ & $50,0 \pm 0,6$ & $223,3 \pm 3,4^{A}$ \\
\hline $\mathrm{CF}$ & $14078 \pm 395^{b}$ & $5,377 \pm 0,050$ & $0,0346 \pm 0,0006$ & $47,8 \pm 1,0^{b}$ & $182,2 \pm 2,7^{b}$ \\
\hline$R F$ & $16837 \pm 472^{a}$ & $5,403 \pm 0,050$ & $0,0336 \pm 0,0006$ & $50,2 \pm 0,9^{a b}$ & $208,0 \pm 3,4^{a}$ \\
\hline $\mathrm{H} \mathrm{F}$ & $16333 \pm 345^{a}$ & $5,497 \pm 0,025$ & $0,0333 \pm 0,0004$ & $51,2 \pm 0,5^{a}$ & $200,0 \pm 3,1^{a}$ \\
\hline $\mathrm{F}$ & $15749 \pm 365^{B}$ & $5,426 \pm 0,027^{\mathrm{B}}$ & $0,0338 \pm 0,0003^{B}$ & $49,7 \pm 0,6$ & $196,7 \pm 3,1^{\mathrm{A}}$ \\
\hline \multicolumn{6}{|c|}{ PC } \\
\hline$\overline{C M}$ & $7307 \pm 263$ & $4,728 \pm 0,045^{b}$ & $0,0397 \pm 0,0011$ & $39,2 \pm 1,0$ & $106,3 \pm 1,0^{b}$ \\
\hline $\mathrm{R} \mathrm{M}$ & $6876 \pm 232$ & $4,918 \pm 0,057^{\mathrm{a}}$ & $0,0435 \pm 0,0014$ & $36,8 \pm 1,0$ & $109,4 \pm 0,6^{a b}$ \\
\hline $\mathrm{H} \mathrm{M}$ & $7280 \pm 202$ & $5,060 \pm 0,051^{a}$ & $0,0412 \pm 0,0001$ & $39,5 \pm 0,8$ & $109,9 \pm 0,7^{a}$ \\
\hline M & $7145 \pm 134^{A}$ & $4,912 \pm 0,043^{A}$ & $0,0416 \pm 0,0007^{A}$ & $38,4 \pm 0,6$ & $108,7 \pm 0,6^{\mathrm{A}}$ \\
\hline $\mathrm{CF}$ & $6824 \pm 438^{a}$ & $4,317 \pm 0,031$ & $0,0343 \pm 0,0019^{b}$ & $43,1 \pm 2,1^{a}$ & $84,7 \pm 1,0$ \\
\hline $\mathrm{RF}$ & $5440 \pm 195^{b}$ & $4,324 \pm 0,047$ & $0,0425 \pm 0,0016^{a}$ & $35,0 \pm 1,0^{b}$ & $84,5 \pm 0,8$ \\
\hline $\mathrm{HF}$ & $6626 \pm 464^{\text {ab }}$ & $4,442 \pm 0,050$ & $0,0368 \pm 0,0021^{a}$ & $41,2 \pm 2,1^{a}$ & $87,9 \pm 1,8$ \\
\hline $\mathrm{F}$ & $6297 \pm 256^{\text {B }}$ & $4,363 \pm 0,028^{B}$ & $0,0379 \pm 0,0013^{\text {В }}$ & $39,7 \pm 1,3$ & $85,7 \pm 0,8^{B}$ \\
\hline
\end{tabular}

${ }^{*}$ Médias em função do sexo (S) e linhagem (L) dentro de cada sexo $L(S)$, seguidas de letras distintas maiúsculas (macho e fêmea) e minúsculas (linhagem dentro de cada sexo) diferem significativamente pelo teste de TukeyKramer $(\mathrm{p}<0,05)$;

${ }^{1} \mathrm{a}$ - Peso da ave (ou consumo de ração) à idade adulta; ${ }^{2} \mathrm{~b}$ - Constante de integração; ${ }^{3} \mathrm{k}$ - Taxa de maturidade; Fonte: Própria autoria. 
Tabela 8 - Média semanal do ganho de peso corporal $(P C)$ e consumo de ração (CR) diário de frangos machos $(\mathrm{M})$ e fêmeas $(\mathrm{F})$ das linhagens Cobb $500(\mathrm{C})$, Ross $308(R)$ e Hubbard Flex $(H)$, segundo modelo de Gompertz

\begin{tabular}{|c|c|c|c|c|c|c|c|c|c|}
\hline \multirow{2}{*}{${ }^{*}{ }^{*}$} & \multicolumn{9}{|c|}{ Idade (dias) } \\
\hline & 0 & 7 & 14 & 21 & 28 & 35 & 42 & 49 & 56 \\
\hline \multicolumn{10}{|c|}{ CR (g/dia) } \\
\hline$C M$ & - & 34,07 & 67,43 & 109,01 & 150,43 & 183,42 & 203,02 & 208,32 & 201,48 \\
\hline $\mathrm{R} M$ & - & 33,88 & 70,07 & 116,93 & 165,06 & 204,49 & 228,81 & 236,48 & 229,74 \\
\hline $\mathrm{H} M$ & - & 29,90 & 60,95 & 102,07 & 146,30 & 185,39 & 213,08 & 226,67 & 226,79 \\
\hline M & - & 32,62 & 66,15 & 109,34 & 153,93 & 191,10 & 214,97 & 223,82 & 219,34 \\
\hline C F & - & 30,14 & 58,62 & 93,83 & 128,86 & 156,93 & 173,91 & 178,98 & 173,78 \\
\hline $\mathrm{R} \mathrm{F}$ & - & 33,85 & 65,51 & 105,06 & 145,24 & 178,54 & 200,03 & 208,27 & 204,65 \\
\hline $\mathrm{H} \mathrm{F}$ & - & 30,46 & 59,67 & 96,83 & 135,35 & 168,10 & 190,12 & 199,66 & 197,73 \\
\hline $\mathrm{F}$ & - & 31,48 & 61,27 & 98,57 & 136,48 & 167,86 & 188,02 & 195,64 & 192,06 \\
\hline \multicolumn{10}{|c|}{ PC (g/dia) } \\
\hline$C M$ & 12,23 & 29,19 & 52,69 & 76,97 & 95,81 & 105,65 & 106,31 & 99,80 & 88,91 \\
\hline $\mathrm{R} M$ & 11,34 & 30,41 & 57,78 & 85,24 & 104,43 & 111,65 & 108,00 & 97,07 & 82,67 \\
\hline $\mathrm{H} M$ & 9,25 & 24,58 & 47,80 & 73,45 & 94,56 & 106,55 & 108,62 & 102,70 & 91,75 \\
\hline M & 10,94 & 28,06 & 52,76 & 78,55 & 98,26 & 107,95 & 107,64 & 99,86 & 87,78 \\
\hline$C F$ & 13,42 & 26,55 & 43,15 & 60,06 & 74,01 & 82,87 & 86,06 & 84,23 & 78,68 \\
\hline $\mathrm{R} \mathrm{F}$ & 13,70 & 30,84 & 52,07 & 71,01 & 82,69 & 85,64 & 81,32 & 72,42 & 61,48 \\
\hline $\mathrm{H} \mathrm{F}$ & 12,16 & 25,75 & 43,55 & 61,87 & 76,76 & 85,74 & 88,27 & 85,31 & 78,50 \\
\hline$F$ & 13,09 & 27,72 & 46,26 & 64,31 & 77,82 & 84,75 & 85,22 & 80,65 & 72,89 \\
\hline
\end{tabular}

crescimento diário peso corporal da ave viva em gramas.

Analisando o parâmetro "a" da curva de consumo de ração, que representa a ingestão da ave à maturidade, verificou-se que houve diferença para este no qual frangos das linhagens Ross 308 e Hubbard Flex obtiveram superior $(P<0,05)$ consumo à maturidade em relação à linhagem Cobb 500, para macho e fêmea, e como esperado os machos à maturidade ingerem mais ração do que fêmeas. Para o peso corporal não houve diferença $(P>0,05)$ no parâmetro "a" entre as linhagens de macho, porém em aves fêmeas a linhagem Cobb 500 apresentou peso superior à maturidade que Ross 308, sendo fêmea Hubbard Flex semelhante às demais linhagens de fêmeas.

O parâmetro " $k$ " representa a taxa de maturidade e quanto maior o valor de "k" maior é a velocidade de crescimento da ave e menor é o tempo gasto para atingir o peso à maturidade (SANTOS et al., 2007). O modelo estudado apresentou valor de " $k$ " estatisticamente superior $(P<0,05)$ para machos em relação às fêmeas para as 
características avaliadas, podendo afirmar que machos possuem maior velocidade de consumo chegando ao peso à maturidade precocemente, com maior CR e PC.

Apesar de numericamente menor a velocidade de consumo $(k)$ foi comum $(P>0,05)$ dentre as aves fêmeas, no entanto fêmea Hubbard Flex apresentou idade de inflexão (Ti) tardia em relação à fêmea Cobb 500. Entre machos houve diferença significativa $(P<0,05)$ entre as médias de "k" para o consumo de ração, em que Hubbard Flex apresentou menor valor que as demais linhagens, levando mais tempo para alcançar o ponto de inflexão (PI) da curva de consumo de ração.

O CR normalmente não apresenta comportamento assintótico (HENN et al. 2014), sendo preferível o ajuste de curva sem um ponto de inflexão, como o caso da curva de Brody, porém esta não se ajustou bem aos dados. Apesar disso, esta característica teve ótimo ajuste aos dados obtidos $\left(R^{2}>0,9975\right)$ da curva de Gompertz na fase de crescimento dos frangos de corte e deste modo discutida no presente estudo.

Quando observados os valores de peso corporal de macho e fêmea Ross 308 nota-se que estas aves aparentemente apresentaram menor idade de inflexão da curva, contudo pode-se inferir que apenas em fêmea Ross 308 houve maior precocidade em relação às demais linhagens de fêmeas, pois não foi verificado diferença estatística entre as linhagens de machos para a idade de inflexão (Ti).

Foi observado em estudos (MARCATO et al., 2008; MIGNON-GRASTEAU et al., 2000; WINKELSTROTER, 2013) utilizando curvas de crescimento em linhagens de frangos de corte, padrão de comportamento semelhante ao presente estudo para o parâmetro "a", ou seja, valores de peso à maturidade de frangos machos maiores que de fêmeas. Entretanto, os autores destes estudos verificaram padrão de comportamento contrário ao presente estudo para o parâmetro "k", em que fêmeas apresentaram valores superiores $(P<0,05)$ em relação aos machos, portanto as aves fêmeas nesses estudos chegariam mais cedo á maturidade com o peso menor que os machos. Em contrapartida, outros autores (AGGREY, 2002; GOUS et al., 1999; HENN et al., 2014; SAKOMURA et al., 2005) perceberam desempenho semelhante ao presente trabalho sobre os parâmetros "a" e "k", ou seja, os machos de modo geral apresentaram peso maior à vida adulta e maior taxa de maturidade comparados às fêmeas.

Uma propriedade de grande importância obtida através da curva de crescimento é a taxa máxima de crescimento (TMC) corporal ou de consumo de 
ração (TMCR) que é estimada a partir dos parâmetros "b" e "k" que representa o incremento no peso no ponto de inflexão (PI) da curva, tendo neste ponto a mudança da taxa de crescimento de crescente para decrescente (FREITAS, 2005).

Para o consumo de ração os frangos machos tiveram maior TMCR $(223,3$ g/dia) que fêmeas (196,7 g/dia) com idade de inflexão da curva de 50 e 49,7 dias de idade, respectivamente. Dentre as linhagens, Cobb 500 tiveram TMCR inferior às demais linhagens, para machos (208,3 g/dia) e fêmeas (182,2 g/dia), sendo que os frangos machos Ross 308 tiveram maior TMCR (228,3 g/dia) em idade tardia (52,5 dias) quando comparado com machos Cobb 500 (48,3 dias). No caso do peso corporal, as linhagens dentro de fêmeas não apresentaram $(P>0,05)$ diferenças entre a taxa máxima de crescimento (TMC) corporal e idade de inflexão da curva, já os frangos machos Hubbard Flex apresentaram maiores $(P<0,05)$ ganhos de peso que machos Cobb 500 em idade semelhante, sendo que machos Ross 308 apresentaram ganho semelhante às demais linhagens de macho.

Observa-se na Figura 10.1 que a curva de consumo de ração estende sua forma côncava comparada a curva de peso corporal (Figura 10.2), tendo maior peso assintótico e idade de inflexão da curva mais tardia como mostrado nos dados da Tabela 8. Pode-se verificar ainda que a diferença do peso corporal entre frangos sobre as curvas de CR e PC para as linhagens de machos e de fêmeas confirmam diferentes necessidades nutricionais entre estas.

Veloso et al. (2016b) em estudo sobre a divergência genética utilizado as mesmas linhagens e sexo do atual estudo, demonstraram que macho Cobb 500 foi mais precoce, apresentando maior taxa de crescimento quando comparado com o macho Ross 308. No entanto, aos 42 dias de idade, macho Ross 308 foi superior aos outros grupos (machos e fêmeas de Cobb 500 e Hubbard Flex), fato este justificado pelos autores como um ganho compensatório desta linhagem no período analisado, sendo mais eficientes na conversão de ração em músculo (proteína). No presente estudo frangos Ross 308 teve maior peso e ganho de peso até o ponto de inflexão da curva, porém houve ganho compensatório tardio para aves Cobb 500 e Hubbard Flex, chegando ao final do experimento com pesos próximos.

Henn et al. (2014) utilizaram dietas conforme linhagem e sexo para estimar o peso de ração consumido através dos parâmetros da curva de Gompertz em macho $(a=5178,7$ e $k=0,0536)$ e fêmea $(a=4256,1$ e $k=0,0527)$ da linhagem Cobb 500 até os 49 dias de idade e observaram TMCR de 188 e 163 g/dia, respectivamente, aos 
Figura 10 - Curvas e taxas de consumo de ração (1) e crescimento corporal (2) em linhagens Cobb $500(C)$, Ross $308(R)$, Hubbard Flex $(H)$, machos (a) e fêmeas (b), segundo modelo de Gompertz
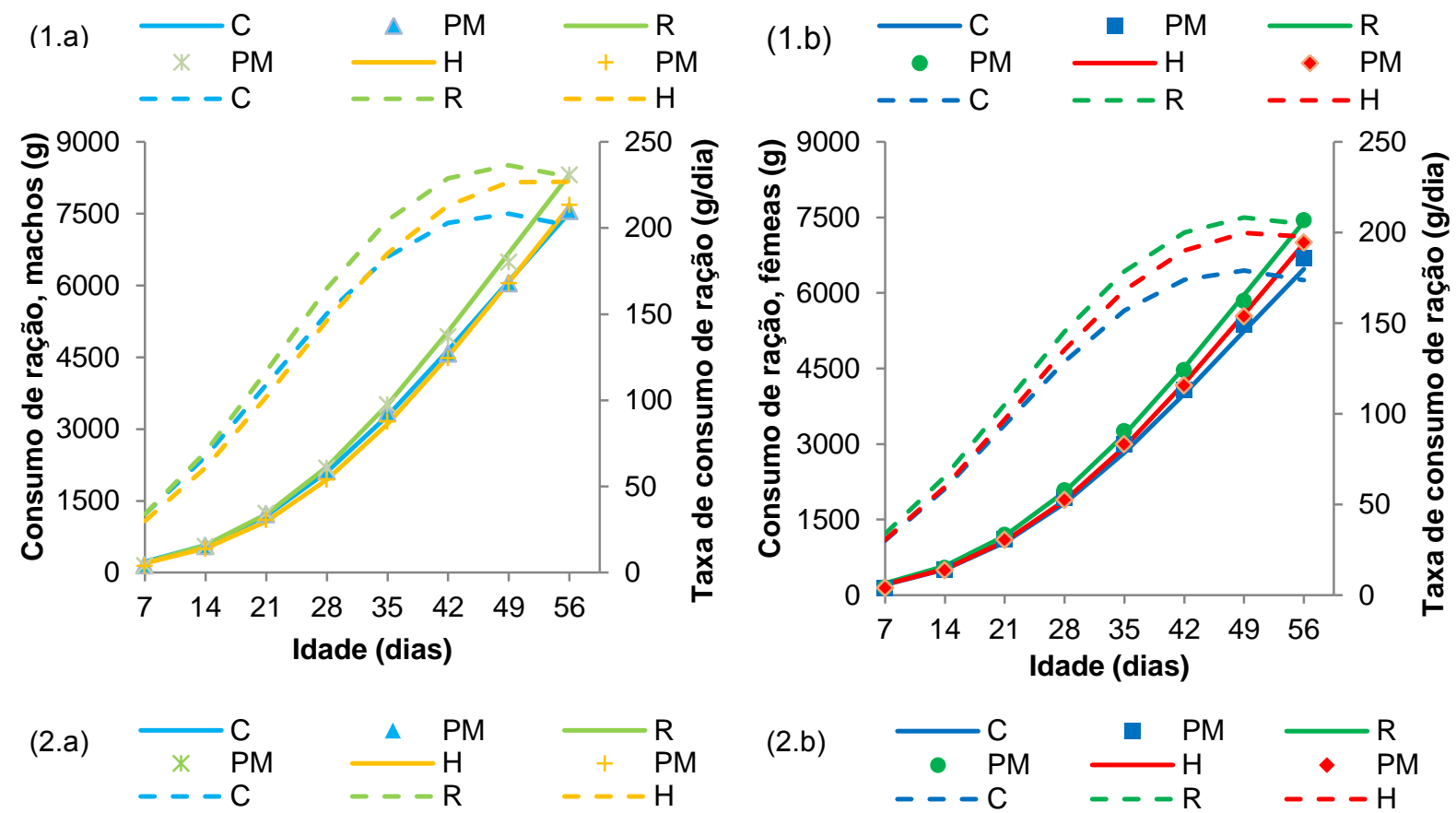

(2.b)
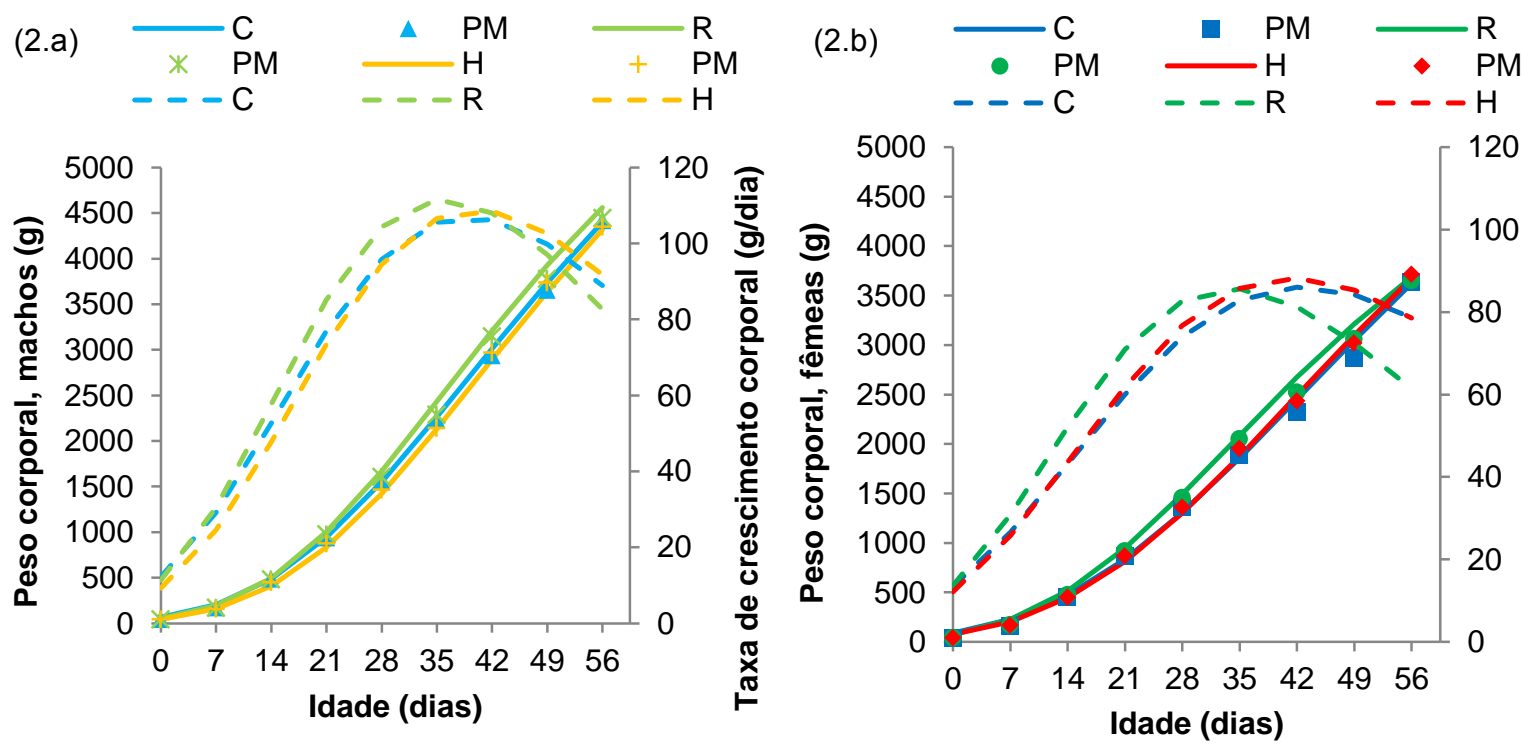

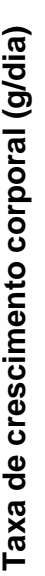

${ }^{*}$ Curvas de peso - linha contínua; Taxa de deposição - linha tracejada; PM- peso médio observado para respectiva cor de linhagem e sexo.

Fonte: Própria autoria.

38 dias de idade. Entretanto, no presente trabalho o TMCR para machos Cobb 500 foi de 208,3 g/dia aos 48,3 dias e nas fêmeas Cobb 500 de 182,2 g/dia aos 47,8 dias de idade, aproximadamente 10 dias após o encontrado por Henn et al. (2014). Estes mesmos autores estimaram valores de TMC corporal de 100,65 e 82,36 g/dia aos 29,6 e 28,66 dias de idade para Cobb 500, macho e fêmea, respectivamente, porém no atual estudo o ponto de inflexão foi mais tardio com superior TMC de 106,3 e 84,9 g/dia aos 39,1 e 43,2 dias de idade para machos e fêmeas, respectivamente. Podese observar que apesar de ambos os estudos utilizarem o mesmo modelo, linhagem e sexo os pontos de inflexões foram diferentes, possivelmente causados por 
diferenças entre os experimentos (dietas, manejo, instalações, clima, período experimental, peso inicial dos pintinhos) que afetaram o peso à maturidade verificando ponto de inflexão diferente entre os estudos.

Observa-se valores superiores de peso corporal à maturidade de machos no estudo de Marcato et al. (2008) quando comparados ao presente estudo sobre macho Cobb 500 (7591,79 g vs 7307 g) e macho Ross 308 (7831,77 g vs 6876 g) e valores inferiores para o peso à maturidade de fêmea Cobb 500 (4627,41 g vs 6824 g) e fêmea Ross 308 (5107,94 g vs 5440 g), sendo bem próxima a idade de inflexão da curva e TMC (40,59 dias com 106,13 g/dia vs 39,2 dias com 106,3 g/dia) para macho Cobb 500 e fêmea Ross 308 (35,48 dias com 82,68 g/dia vs 35,0 dias com 84,5 g/dia), tardia para macho Ross 308 (42,01 dias com 118,13 g/dia vs 36,8 dias com 109,4 g/dia) e precoce para as fêmea de Cobb 500 (32,55 dias com 83,41 g/dia vs 43,1 dias com 84,7 g/dia). Estes resultados mostram grande variedade sobre estimativas dos parâmetros da curva de Gompertz, influenciados por diferentes fatores em diferentes estudos.

$\mathrm{Na}$ literatura notam-se outros valores sobre o ponto de inflexão e TMC do modelo de Gompertz para o peso corporal de frangos de corte: Sakomura et al. (2005), observaram Ti de 39 e 38 dias de idade para aves Ross 308 com TMC próximos de 85,95 e 63,1 g/dia de macho e fêmea, respectivamente; Scheuermann et al. (2003), utilizando várias linhagens de frangos de corte machos e fêmeas e alcançaram Ti aos 34,4 e 31,2 dias de idade com ganho máximo de peso de 108,58 e 85,46 g/dia, respectivamente; Gous et al. (1999), obtiveram valores de Ti para cruzamentos entre linhagens comerciais aos 42,7 e 43,5 dias de idade com ganho máximo de peso de 85,54 e 81,23 g/dia para machos e Ti de 43,4 e 44,9 dias de idade com ganho máximo de peso de 68,13 e 64,87 g/dia para fêmeas; e Hancook et al. (1995), constatou diferentes Ti em seis diferentes linhagens comerciais para machos de 41,9 a 44,2 dias de idade com taxa máxima de crescimento corporal entre 74,96 a 80,25g/dia e para fêmeas Ti de 39,2 a 41,8 dias com TMC corporal entre 60,93 a $57,14 \mathrm{~d} / \mathrm{dia}$.

De modo geral, observa-se que estudos mais recentes utilizando frangos de alto desempenho apresentam ponto de inflexão da curva mais precoce com superior ganho máximo de peso, corroborando com Havenstein, Ferket e Qureshi (2003) que utilizaram linhagens de 1957 e 2001 alimentados com dietas de 1957 e de 2001 e reportaram que a seleção genética das empresas comerciais sobre os genótipos 
trouxe em torno de 85 a $90 \%$ de mudança na taxa de crescimento do animal e a nutrição contribuiu com cerca de 10 a $15 \%$ dessa mudança.

5.3.2 Crescimento e deposição de nutrientes sobre o peso corporal das aves em jejum (PCJ) e depenadas (PCJD) e das penas

\subsubsection{Crescimento, deposição dos nutrientes no PCJD e alometria}

$\mathrm{Na}$ Tabela 9 apresentam-se as estimativas dos parâmetros do modelo de Gompertz e na Tabela 10 encontram-se o ganho médio de peso corporal diário das aves após jejum de 24 horas (PCJ) e depenadas (PCJD), no qual foram obtidos através do modelo estudado.

Tabela 9 - Médias e erros-padrões das estimativas dos parâmetros ( $a$, b e k), taxa máxima de crescimento (TMC) e idade de inflexão (Ti) da curva de Gompertz sobre o peso corporal de frangos em jejum de 24 horas (PCJ) e depenados (PCJD), em machos (M) e fêmeas (F), das linhagens Cobb 500 (C), Ross 308 (R) e Hubbard Flex (H)

\begin{tabular}{|c|c|c|c|c|c|}
\hline * & \multicolumn{5}{|c|}{ Parâmetros e propriedades } \\
\hline L S & $a^{1}(g)$ & $b^{2}$ & $k^{3}\left(t^{-1}\right)$ & Ti (dias) & TMC $(g / d)$ \\
\hline \multicolumn{6}{|c|}{ PCJ } \\
\hline $\mathrm{CM}$ & $7016 \pm 303$ & $4,924 \pm 0,051^{b}$ & $0,0406 \pm 0,0012$ & $39,4 \pm 1,1$ & $104,2 \pm 1,3$ \\
\hline $\mathrm{R} M$ & $6482 \pm 241$ & $5,150 \pm 0,080^{a}$ & $0,0449 \pm 0,0016$ & $36,6 \pm 1,0$ & $106,4 \pm 0,6$ \\
\hline $\mathrm{HM}$ & $6830 \pm 221$ & $5,259 \pm 0,063^{a}$ & $0,0425 \pm 0,0011$ & $39,2 \pm 0,9$ & $106,3 \pm 0,7$ \\
\hline$M$ & $6762 \pm 147^{\mathrm{A}}$ & $5,122 \pm 0,050^{A}$ & $0,0428 \pm 0,0009^{A}$ & $38,3 \pm 0,6$ & $105,7 \pm 0,5^{\mathrm{A}}$ \\
\hline C F & $6346 \pm 408^{a}$ & $4,443 \pm 0,041$ & $0,0356 \pm 0,0020^{b}$ & $42,5 \pm 2,1^{a}$ & $81,6 \pm 0,8$ \\
\hline $\mathrm{R} F$ & $5091 \pm 149^{b}$ & $4,550 \pm 0,073$ & $0,0438 \pm 0,0013^{a}$ & $34,7 \pm 0,8^{b}$ & $81,7 \pm 0,8$ \\
\hline H F & $6162 \pm 436^{a b}$ & $4,576 \pm 0,046$ & $0,0380 \pm 0,0021^{b}$ & $40,5 \pm 2,1^{a}$ & $84,6 \pm 1,5$ \\
\hline $\mathrm{F}$ & $5867 \pm 235^{\mathrm{B}}$ & $4,523 \pm 0,033^{B}$ & $0,0391 \pm 0,0013^{B}$ & $39,2 \pm 1,3$ & $82,7 \pm 0,7^{\mathrm{B}}$ \\
\hline \multicolumn{6}{|c|}{ PCJD } \\
\hline $\mathrm{CM}$ & $6764 \pm 285$ & $4,871 \pm 0,053^{b}$ & $0,0401 \pm 0,0012$ & $39,6 \pm 1,1$ & $99,4 \pm 1,2$ \\
\hline $\mathrm{R} M$ & $6219 \pm 229$ & $5,056 \pm 0,086^{a b}$ & $0,0443 \pm 0,0016$ & $36,7 \pm 1,0$ & $100,7 \pm 0,7$ \\
\hline $\mathrm{H} \mathrm{M}$ & $6515 \pm 196$ & $5,222 \pm 0,063^{a}$ & $0,0425 \pm 0,0011$ & $39,0 \pm 0,8$ & $101,4 \pm 0,7$ \\
\hline M & $6484 \pm 138^{A}$ & $5,060 \pm 0,052^{A}$ & $0,042 \pm 0,0008^{A}$ & $38,4 \pm 0,6$ & $100,6 \pm 0,5^{A}$ \\
\hline $\mathrm{CF}$ & $6160 \pm 416$ & $4,424 \pm 0,037$ & $0,0352 \pm 0,0020^{b}$ & $42,9 \pm 2,2^{a}$ & $78,3 \pm 1,0$ \\
\hline $\mathrm{R} F$ & $4872 \pm 168$ & $4,512 \pm 0,081$ & $0,0436 \pm 0,0016^{a}$ & $34,7 \pm 1,0^{b}$ & $77,7 \pm 0,7$ \\
\hline $\mathrm{HF}$ & $5958 \pm 510$ & $4,555 \pm 0,050$ & $0,0379 \pm 0,0023^{a b}$ & $40,7 \pm 2,5^{a}$ & $81,1 \pm 1,9$ \\
\hline $\mathrm{F}$ & $5663 \pm 253^{B}$ & $4,497 \pm 0,034^{B}$ & $0,0389 \pm 0,0014^{\mathrm{B}}$ & $39,4 \pm 1,4$ & $79,0 \pm 0,8^{B}$ \\
\hline \multicolumn{6}{|c|}{$\begin{array}{l}\text { *Médias em função do sexo }(S) \text { e linhagem }(L) \text { dentro de cada sexo } L(S) \text {, seguidas de letras distintas maísculas (macho e } \\
\text { fêmea) e minúsculas (linhagem dentro de cada sexo) diferem significativamente pelo teste de Tukey-Kramer }(\mathrm{p}<0,05) ; \\
\text { a a - Peso do componente à idade adulta; } \\
\text { 2 b - Constante de integração; } \\
{ }^{3} \mathrm{k} \text { - Taxa de maturidade; } \\
\text { Fonte: Própria autoria. }\end{array}$} \\
\hline
\end{tabular}


Tabela 10 - Média semanal de ganho diário de peso corporal após jejum de 24 horas (PCJ) e peso corporal depenado em jejum de 24 horas (PCJD) de frangos machos (M) e fêmeas (F) das linhagens Cobb 500 (C), Ross 308 (R) e Hubbard Flex $(\mathrm{H})$, segundo modelo de Gompertz

\begin{tabular}{|c|c|c|c|c|c|c|c|c|c|}
\hline * & \multicolumn{9}{|c|}{ Idade (dias) } \\
\hline L S & 0 & 7 & 14 & 21 & 28 & 35 & 42 & 49 & 56 \\
\hline \multicolumn{10}{|c|}{ PCJ (g/dia) } \\
\hline C M & 10,14 & 25,24 & 46,92 & 69,94 & 88,26 & 98,21 & 99,38 & 93,60 & 83,51 \\
\hline $\mathrm{R} \quad \mathrm{M}$ & 8,89 & 25,11 & 49,51 & 74,96 & 93,52 & 101,24 & 98,77 & 89,28 & 76,32 \\
\hline $\mathrm{H} \quad \mathrm{M}$ & 7,80 & 22,19 & 44,69 & 69,65 & 89,71 & 100,30 & 100,95 & 93,98 & 82,55 \\
\hline$M$ & 8,94 & 24,18 & 47,04 & 71,52 & 90,50 & 99,92 & 99,70 & 92,29 & 80,79 \\
\hline C F & 11,49 & 23,60 & 39,25 & 55,36 & 68,64 & 76,96 & 79,75 & 77,71 & 72,16 \\
\hline $\mathrm{R} F$ & 10,53 & 25,43 & 44,94 & 63,08 & 74,75 & 78,16 & 74,55 & 66,43 & 56,31 \\
\hline $\mathrm{H} \quad \mathrm{F}$ & 10,83 & 24,02 & 41,60 & 59,57 & 73,73 & 81,62 & 82,93 & 78,90 & 71,38 \\
\hline $\mathrm{F}$ & 10,95 & 24,35 & 41,93 & 59,34 & 72,37 & 78,91 & 79,07 & 74,34 & 66,62 \\
\hline \multicolumn{10}{|c|}{ PCJD (g/dia) } \\
\hline C M & 9,06 & 24,36 & 47,07 & 71,17 & 89,65 & 98,62 & 98,10 & 90,54 & 79,04 \\
\hline $\mathrm{R} \quad \mathrm{M}$ & 8,94 & 25,16 & 49,41 & 74,57 & 92,79 & 100,24 & 97,62 & 88,12 & 75,23 \\
\hline $\mathrm{H} \quad \mathrm{M}$ & 8,38 & 22,68 & 44,51 & 68,62 & 88,31 & 99,25 & 100,78 & 94,83 & 84,29 \\
\hline $\mathrm{M}$ & 8,80 & 24,07 & 47,00 & 71,45 & 90,25 & 99,37 & 98,83 & 91,16 & 79,52 \\
\hline C $F$ & 8,88 & 22,43 & 41,07 & 59,27 & 71,74 & 76,29 & 73,72 & 66,38 & 56,73 \\
\hline$R \quad F$ & 9,18 & 24,81 & 46,08 & 65,38 & 76,49 & 77,91 & 71,86 & 61,73 & 50,38 \\
\hline $\mathrm{H} \quad \mathrm{F}$ & 8,99 & 22,90 & 42,24 & 61,37 & 74,75 & 79,92 & 77,60 & 70,16 & 60,19 \\
\hline $\mathrm{F}$ & 9,01 & 23,38 & 43,13 & 62,01 & 74,33 & 78,04 & 74,39 & 66,09 & 55,77 \\
\hline
\end{tabular}

*Linhagem (L) e Sexo (S)

Fonte: Própria autoria.

Foi observado semelhante efeito entre o PC e PCJ. Quando retirado as penas das aves após o jejum de 24 horas, não houve efeito $(P=0,055)$ para o peso à maturidade entre as linhagens dentro de fêmeas e apenas fêmea Cobb 500 se diferenciaram $(P<0,05)$ de fêmea Ross 308 para a taxa de maturidade $(k)$. Houve diferença estatística $(P<0,05)$ em Ti em linhagens de aves fêmeas, tendo fêmeas Ross 308 atingindo idade de inflexão aos 34,7 dias de idade para o PCD e PCJD.

$\mathrm{Na}$ Tabela 10 pode-se verificar que os machos chegam à vida adulta com maior ganho de peso $(P<0,05)$ que as aves fêmeas devido ao maior potencial genético de machos, desde a fase embrionária (UDEH; EZEBOR; AKPORAHUARHO, 2015).

A Figura 11.1.b mostra que as aves da linhagem Ross 308 fêmea, alcançaram idade de inflexão (Ti) da curva mais cedo que as demais linhagens de fêmeas, como observado anteriormente para o peso corporal (Figura 10.2). Portanto, a partir do ponto de inflexão da curva de machos e fêmeas pode-se indicar que o abate de 
Figura 11 - Curvas e taxa de crescimento do peso corporal em jejum de 24 horas (PCJ - 1) e depenado (PCJD - 2) em linhagens Cobb 500 (C), Ross 308 (R), Hubbard Flex $(\mathrm{H})$, machos (a) e fêmeas (b), segundo modelo de Gompertz*
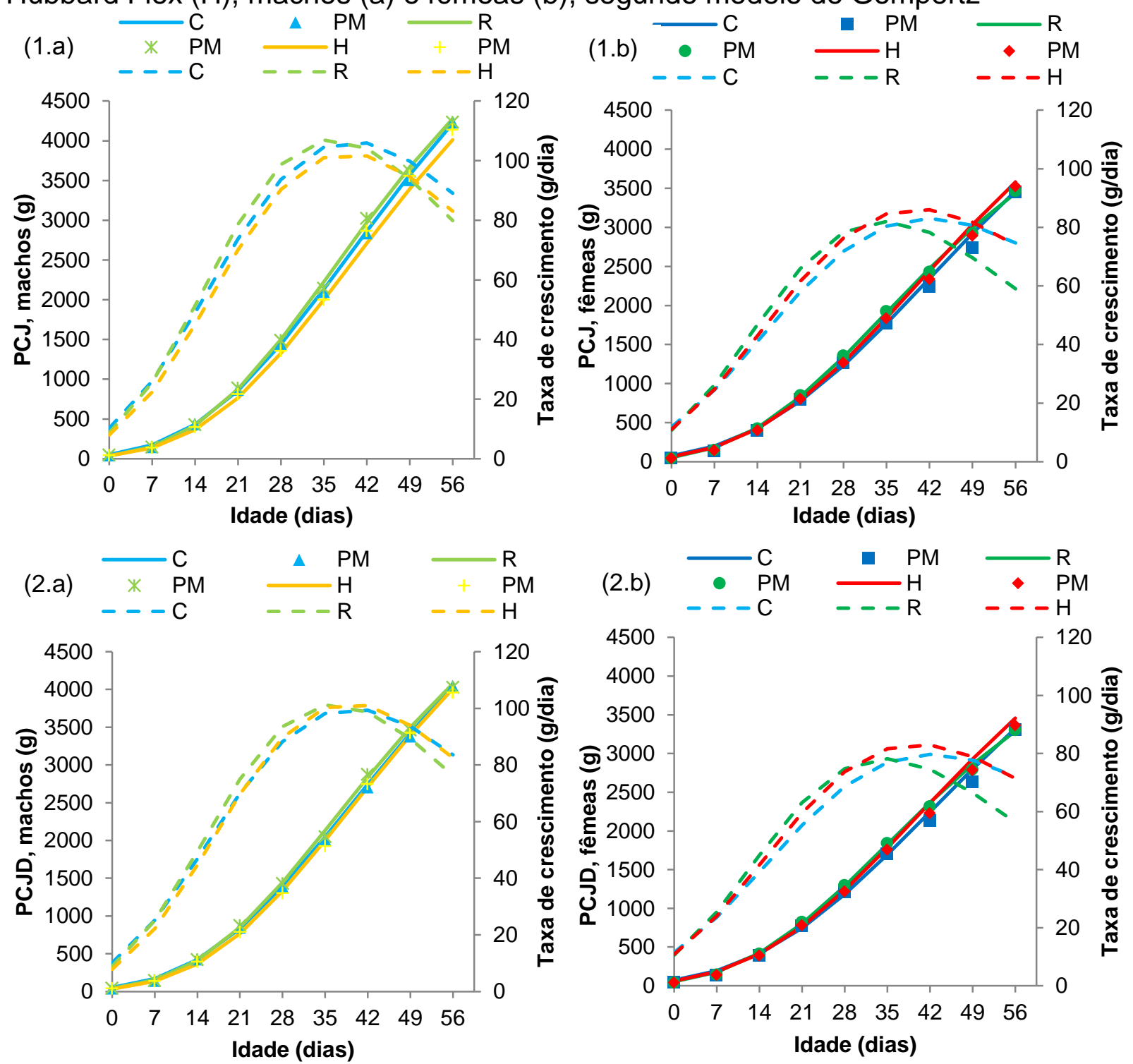

*Curvas de peso - linha contínua; Taxa de deposição - linha tracejada; PM- peso médio observado para respectiva cor de linhagem e sexo.

Fonte: Própria autoria.

frangos de corte seja entre 35 e 42 dias de idade, onde ocorreu o maior crescimento e após esta idade as taxas de crescimento diário tendem a diminuir acentuadamente.

$\mathrm{Na}$ Tabela 11 são mostrados os valores estimados dos parâmetros e propriedades do modelo de Gompertz para a deposição dos nutrientes em linhagens de frangos de corte dentro de cada sexo as médias dos nutrientes (peso de água, proteína bruta, gordura e cinzas) depositados sobre o peso corporal de aves em jejum de 24 horas e depenadas (PCJD). Na Tabela 12 observa-se o ganho de peso 
Tabela 11 - Médias e erros-padrões das estimativas dos parâmetros (a, b e k), taxa máxima de deposição (TMD) e idade de inflexão (Ti) da curva de Gompertz sobre nutrientes depositados (água, proteína bruta, gordura e cinzas) no corpo em jejum de 24 horas e depenado (PCJD) de frangos machos (M) e fêmeas (F) das linhagens Cobb 500 (C), Ross 308 (R) e Hubbard Flex (H)

\begin{tabular}{|c|c|c|c|c|c|}
\hline * & & Parâ & metros e Propriec & des & \\
\hline L S & $a^{1}(g)$ & $b^{2}$ & $k^{3}\left(t^{-1}\right)$ & $\mathrm{Ti}$ (dias) & TMD $(g / d)$ \\
\hline & & & Água & & \\
\hline$\overline{C M}$ & $4735 \pm 211$ & $4,919 \pm 0,063^{b}$ & $0,0391 \pm 0,0013$ & $40,9 \pm 1,2$ & $67,7 \pm 0,8$ \\
\hline $\mathrm{RM}$ & $4384 \pm 152$ & $4,932 \pm 0,078^{b}$ & $0,0420 \pm 0,0015$ & $38,1 \pm 1,0$ & $67,4 \pm 0,7$ \\
\hline $\mathrm{HM}$ & $4548 \pm 138$ & $5,198 \pm 0,061^{a}$ & $0,0413 \pm 0,0010$ & $40,0 \pm 0,8$ & $68,9 \pm 0,5$ \\
\hline$M$ & $4545 \pm 95^{\mathrm{A}}$ & $5,022 \pm 0,049^{A}$ & $0,0409 \pm 0,0008$ & $39,6 \pm 0,6$ & $68,0 \pm 0,4^{A}$ \\
\hline $\mathrm{CF}$ & $4010 \pm 371$ & $4,329 \pm 0,034$ & $0,0351 \pm 0,0025^{b}$ & $42,7 \pm 3,0^{a}$ & $50,2 \pm 1,1$ \\
\hline $\mathrm{R} F$ & $2998 \pm 153$ & $4,378 \pm 0,10$ & $0,0449 \pm 0,0024^{a}$ & $33,2 \pm 1,4^{b}$ & $48,9 \pm 0,6$ \\
\hline $\mathrm{HF}$ & $3687 \pm 345$ & $4,453 \pm 0,065$ & $0,0391 \pm 0,0027^{a b}$ & $39,1 \pm 2,7^{a b}$ & $51,4 \pm 1,3$ \\
\hline $\mathrm{F}$ & $3565 \pm 195^{\mathrm{B}}$ & $4,387 \pm 0,040^{B}$ & $0,0397 \pm 0,0017$ & $38,3 \pm 1,6$ & $50,2 \pm 0,6^{B}$ \\
\hline & & & Proteína Bruta & & \\
\hline$\overline{C M}$ & $1061 \pm 35,0^{a}$ & $4,805 \pm 0,105^{b}$ & $0,0405 \pm 0,0014^{b}$ & $38,9 \pm 0,9^{a}$ & $15,9 \pm 0,1^{b}$ \\
\hline $\mathrm{R} M$ & $811,6 \pm 26,4^{b}$ & $5,349 \pm 0,123^{a}$ & $0,0534 \pm 0,0021^{a}$ & $32,0 \pm 0,7^{b}$ & $15,8 \pm 0,2^{b}$ \\
\hline $\mathrm{HM}$ & $995,3 \pm 35,1^{a}$ & $5,400 \pm 0,100^{a}$ & $0,0458 \pm 0,0017^{b}$ & $36,8 \pm 0,8^{a}$ & $16,7 \pm 0,1^{a}$ \\
\hline$M$ & $955,9 \pm 31,0^{A}$ & $5,161 \pm 0,093^{A}$ & $0,0466 \pm 0,0017^{A}$ & $35,9 \pm 0,8$ & $16,2 \pm 0,1^{\mathrm{A}}$ \\
\hline $\mathrm{CF}$ & $830,1 \pm 41,6$ & $4,335 \pm 0,045$ & $0,0379 \pm 0,0016^{b}$ & $39,0 \pm 1,5^{a}$ & $11,4 \pm 0,2$ \\
\hline $\mathrm{R} \mathrm{F}$ & $717,7 \pm 14,3$ & $4,517 \pm 0,075$ & $0,0454 \pm 0,0010^{a}$ & $33,3 \pm 0,6^{b}$ & $12,0 \pm 0,1$ \\
\hline $\mathrm{HF}$ & $823,7 \pm 41,3$ & $4,413 \pm 0,081$ & $0,0398 \pm 0,0017^{a b}$ & $37,6 \pm 1,5^{a}$ & $11,9 \pm 0,2$ \\
\hline $\mathrm{F}$ & $790,5 \pm 22,7^{\mathrm{B}}$ & $4,422 \pm 0,041^{B}$ & $0,0410 \pm 0,0011^{B}$ & $36,6 \pm 0,9$ & $11,8 \pm 0,1^{\text {В }}$ \\
\hline & & & Gordura & & \\
\hline $\mathrm{CM}$ & $907,9 \pm 54,0$ & $5,332 \pm 0,111$ & $0,0401 \pm 0,0021$ & $42,2 \pm 1,8$ & $13,2 \pm 0,2$ \\
\hline $\mathrm{RM}$ & $986,2 \pm 93,7$ & $5,265 \pm 0,123$ & $0,0394 \pm 0,0027$ & $43,0 \pm 2,7$ & $13,8 \pm 0,3$ \\
\hline $\mathrm{HM}$ & $960,8 \pm 128,9$ & $5,303 \pm 0,127$ & $0,0376 \pm 0,0024$ & $45,2 \pm 3,5$ & $12,8 \pm 0,6$ \\
\hline $\mathrm{M}$ & $951,1 \pm 50,8$ & $5,300 \pm 0,065^{B}$ & $0,0391 \pm 0,0013$ & $43,4 \pm 1,5$ & $13,3 \pm 0,2^{B}$ \\
\hline$\overline{C F}$ & $1348,9 \pm 169,8$ & $5,412 \pm 0,111$ & $0,0331 \pm 0,0024$ & $52,2 \pm 3,9$ & $15,8 \pm 0,8$ \\
\hline $\mathrm{R} F$ & $1028,5 \pm 62,5$ & $5,703 \pm 0,175$ & $0,0401 \pm 0,0023$ & $43,9 \pm 1,9$ & $14,9 \pm 0,3$ \\
\hline $\mathrm{HF}$ & $1028,6 \pm 138,7$ & $5,456 \pm 0,073$ & $0,0356 \pm 0,0029$ & $45,6 \pm 3,9$ & $14,1 \pm 0,6$ \\
\hline $\mathrm{F}$ & $1128,7 \pm 77,2$ & $5,540 \pm 0,084^{A}$ & $0,0366 \pm 0,0016$ & $47,0 \pm 2,0$ & $14,9 \pm 0,3^{A}$ \\
\hline & & & Cinzas & & \\
\hline $\mathrm{CM}$ & $200,1 \pm 8,7$ & $4,985 \pm 0,139$ & $0,0494 \pm 0,0020$ & $32,6 \pm 1,0$ & $3,61 \pm 0,06$ \\
\hline $\mathrm{R} M$ & $197,3 \pm 8,7$ & $5,403 \pm 0,210$ & $0,0532 \pm 0,0029$ & $31,9 \pm 1,0$ & $3,82 \pm 0,05$ \\
\hline $\mathrm{HM}$ & $204,5 \pm 10$ & $5,487 \pm 0,247$ & $0,0512 \pm 0,0027$ & $33,4 \pm 1,1$ & $3,81 \pm 0,10$ \\
\hline M & $200,7 \pm 5,0$ & $5,292 \pm 0,122^{A}$ & $0,0513 \pm 0,0014^{A}$ & $32,6 \pm 0,6^{B}$ & $3,75 \pm 0,04^{A}$ \\
\hline $\mathrm{CF}$ & $244,6 \pm 8,5^{a}$ & $4,503 \pm 0,044$ & $0,0352 \pm 0,0010^{b}$ & $42,9 \pm 1,2^{a}$ & $3,15 \pm 0,04$ \\
\hline $\mathrm{R} F$ & $180,8 \pm 5,8^{b}$ & $4,967 \pm 0,127$ & $0,0492 \pm 0,0011^{a}$ & $32,6 \pm 0,8^{c}$ & $3,26 \pm 0,07$ \\
\hline $\mathrm{HF}$ & $220,6 \pm 11^{a}$ & $4,826 \pm 0,136$ & $0,0418 \pm 0,0021^{b}$ & $37,9 \pm 1,3^{b}$ & $3,35 \pm 0,08$ \\
\hline $\mathrm{F}$ & $215,3 \pm 8,0$ & $4,765 \pm 0,076^{B}$ & $0,0420 \pm 0,0016^{B}$ & $37,8 \pm 1,2^{A}$ & $3,25 \pm 0,04^{B}$ \\
\hline $\begin{array}{l}1 \mathrm{r} \\
1 \mathrm{a} \\
2 \mathrm{~b} \\
3\end{array}$ & $\begin{array}{l}0<0,05) \text {; } \\
\text { do componen } \\
\text { stante de integ } \\
\text { de maturidade } \\
\text { ópria autoria. }\end{array}$ & $\begin{array}{l}\text { xo (S) e linhagem } \\
\text { sculas (linhagem d } \\
\\
\text { à idade adulta; }\end{array}$ & 1 & & stintas maiús \\
\hline
\end{tabular}


Tabela 12 - Média semanal de ganho de peso médio dos nutrientes (água, proteína bruta, gordura e cinzas) depositados no peso corporal em jejum de 24 horas e depenado ( $\mathrm{g}$ ) de frangos machos $(\mathrm{M})$ e fêmeas $(\mathrm{F})$ das linhagens Cobb 500 (C), Ross $308(\mathrm{R})$ e Hubbard Flex $(\mathrm{H})$, segundo modelo de Gompertz

\begin{tabular}{|c|c|c|c|c|c|c|c|c|c|}
\hline * & \multicolumn{9}{|c|}{ Idade (dias) } \\
\hline L S & 0 & 7 & 14 & 21 & 28 & 35 & 42 & 49 & 56 \\
\hline \multicolumn{10}{|c|}{ Água } \\
\hline$C M$ & 6,65 & 16,42 & 30,58 & 45,97 & 58,71 & 66,23 & 68,00 & 64,97 & 58,79 \\
\hline $\mathrm{R} M$ & 6,56 & 17,18 & 32,67 & 48,91 & 61,29 & 67,27 & 66,88 & 61,78 & 54,03 \\
\hline $\mathrm{H} M$ & 5,40 & 14,92 & 29,71 & 46,27 & 59,94 & 67,66 & 68,89 & 64,93 & 57,76 \\
\hline M & 6,18 & 16,17 & 31,00 & 47,10 & 60,08 & 67,19 & 68,07 & 64,02 & 56,95 \\
\hline $\mathrm{C} \mathrm{F}$ & 8,04 & 16,15 & 26,42 & 36,80 & 45,19 & 50,30 & 51,83 & 50,29 & 46,56 \\
\hline $\mathrm{R} \mathrm{F}$ & 7,41 & 17,63 & 30,49 & 41,79 & 48,33 & 49,35 & 46,04 & 40,19 & 33,44 \\
\hline $\mathrm{H} \mathrm{F}$ & 7,48 & 16,52 & 28,28 & 39,85 & 48,44 & 52,63 & 52,50 & 49,07 & 43,66 \\
\hline $\mathrm{F}$ & 7,73 & 16,98 & 28,81 & 40,17 & 48,30 & 51,91 & 51,24 & 47,42 & 41,80 \\
\hline \multicolumn{10}{|c|}{ Proteína Bruta } \\
\hline C M & 1,69 & 4,17 & 7,68 & 11,33 & 14,16 & 15,62 & 15,68 & 14,66 & 12,99 \\
\hline $\mathrm{R} M$ & 1,10 & 4,02 & 8,71 & 13,21 & 15,66 & 15,67 & 13,95 & 11,46 & 8,91 \\
\hline$H M$ & 1,11 & 3,55 & 7,54 & 11,93 & 15,26 & 16,70 & 16,33 & 14,72 & 12,50 \\
\hline M & 1,30 & 3,91 & 7,98 & 12,16 & 15,03 & 16,00 & 15,32 & 13,61 & 11,47 \\
\hline $\mathrm{C} \mathrm{F}$ & 1,79 & 3,76 & 6,26 & 8,70 & 10,52 & 11,45 & 11,48 & 10,82 & 9,72 \\
\hline $\mathrm{R} F$ & 1,61 & 4,00 & 7,12 & 9,94 & 11,62 & 11,94 & 11,17 & 9,76 & 8,12 \\
\hline $\mathrm{H} \mathrm{F}$ & 1,75 & 3,88 & 6,62 & 9,26 & 11,16 & 12,01 & 11,86 & 10,99 & 9,69 \\
\hline $\mathrm{F}$ & 1,72 & 3,88 & 6,67 & 9,30 & 11,10 & 11,80 & 11,51 & 10,52 & 9,17 \\
\hline \multicolumn{10}{|c|}{ Gordura } \\
\hline C M & 0,94 & 2,62 & 5,30 & 8,42 & 11,16 & 12,88 & 13,40 & 12,89 & 11,69 \\
\hline $\mathrm{R} M$ & 1,06 & 2,86 & 5,68 & 8,96 & 11,84 & 13,69 & 14,30 & 13,83 & 12,62 \\
\hline $\mathrm{H} M$ & 0,95 & 2,50 & 4,94 & 7,84 & 10,52 & 12,40 & 13,24 & 13,11 & 12,23 \\
\hline M & 0,98 & 2,66 & 5,31 & 8,41 & 11,18 & 13,00 & 13,67 & 13,30 & 12,20 \\
\hline $\mathrm{C} \mathrm{F}$ & 1,08 & 2,61 & 5,03 & 8,08 & 11,20 & 13,84 & 15,61 & 16,37 & 16,20 \\
\hline $\mathrm{R} F$ & 0,79 & 2,40 & 5,20 & 8,70 & 11,99 & 14,25 & 15,16 & 14,83 & 13,62 \\
\hline $\mathrm{H} \mathrm{F}$ & 0,85 & 2,21 & 4,41 & 7,13 & 9,83 & 11,95 & 13,17 & 13,45 & 12,94 \\
\hline $\mathrm{F}$ & 0,91 & 2,43 & 4,92 & 8,05 & 11,13 & 13,53 & 14,87 & 15,11 & 14,45 \\
\hline \multicolumn{10}{|c|}{ Cinzas } \\
\hline C M & 0,34 & 1,03 & 2,04 & 2,99 & 3,55 & 3,61 & 3,31 & 2,81 & 2,26 \\
\hline R M & 0,26 & 0,95 & 2,07 & 3,17 & 3,79 & 3,81 & 3,41 & 2,81 & 2,19 \\
\hline $\mathrm{H} M$ & 0,24 & 0,87 & 1,93 & 3,02 & 3,71 & 3,84 & 3,53 & 2,99 & 2,39 \\
\hline M & 0,27 & 0,95 & 2,01 & 3,06 & 3,68 & 3,76 & 3,42 & 2,87 & 2,28 \\
\hline $\mathrm{C} \mathrm{F}$ & 0,43 & 0,90 & 1,51 & 2,15 & 2,69 & 3,04 & 3,16 & 3,10 & 2,88 \\
\hline$R \quad F$ & 0,31 & 0,93 & 1,83 & 2,68 & 3,18 & 3,25 & 2,98 & 2,54 & 2,05 \\
\hline $\mathrm{H} \mathrm{F}$ & 0,36 & 0,90 & 1,68 & 2,48 & 3,09 & 3,37 & 3,34 & 3,08 & 2,69 \\
\hline $\mathrm{F}$ & 0,37 & 0,92 & 1,70 & 2,49 & 3,06 & 3,32 & 3,27 & 3,00 & 2,61 \\
\hline
\end{tabular}


diário depositado de cada nutriente no corpo do frango livre de penas.

Não houve diferença $(P>0,05)$ entre as médias de sexo para a taxa de maturidade $(k)$ sobre o peso de água no PCJD, bem como nas linhagens dentro de machos para o peso à maturidade (a) e " $k$ ". No entanto, foram observadas diferenças $(P<0,05)$ entre sexo para "a" e TMD do peso de água com médias superiores para os frangos machos e dentre fêmeas foi observado que fêmea Cobb 500 teve menor taxa de maturidade com PI da curva de deposição de água mais tardio $(P<0,05)$ do que fêmea Ross 308 . Na Figura 12.1 pode-se verificar que os machos Cobb 500 e Ross 308 tiveram deposição de água semelhante, diferenciando $(P<0,05)$ de machos Hubbard Flex somente pela constante da curva (b) e que fêmea Ross 308 possui Ti precoce em relação à deposição de água de fêmea Cobb 500 .

Houve diferenças entre os parâmetros das linhagens de machos para o peso de PB corporal, em que macho Ross 308 apresentou inferior $(P<0,05)$ deposição à maturidade com maior taxa de maturidade e menor idade de inflexão (Ti) que as demais linhagens e machos Hubbard Flex apresentaram valor superior para o TMD de PB corporal. Nas fêmeas, as aves da linhagem Cobb 500 apresentaram inferior "k" e consequentemente superior Ti em relação à linhagem Ross 308 , com aves da linhagem Hubbard Flex semelhante às demais linhagens.

Segundo alguns autores (BARBATO, 1991; MIGNON-GRASTEAU et al., 2000; AGGREY, 2002) é comum que exista uma correlação entre os parâmetros estimados dos modelos de crescimento, sugerindo que a posição do ponto de inflexão seja influenciada fortemente pelo valor constante da taxa de crescimento e do peso da ave à maturidade.

Na Figura 12 observa-se certa semelhança no padrão da curva de água e proteína para cada sexo, no qual a menor deposição de proteína caracteriza menor ganho de peso, principalmente por efeito da água (VARGAS, 2006), pois cada grama de proteína está associada a quatro gramas de água segundo Lesson (1995) e no presente trabalho esta relação foi de $4,65 \mathrm{~g}$ de água por cada grama de PB depositada no PCJD da ave adulta, a partir do modelo.

Pode-se verificar ainda (Tabela 11) que houve diferença $(P<0,05)$ entre sexo e dentre as linhagens de machos para a TMD de $\mathrm{PB}$, no qual frangos machos possuem o maior ganho máximo de peso de PB e dentre estes, macho Hubbard Flex apresentou maior ganho de PB tendo maior platô. De acordo com Kessler 
Figura 12 - Curvas e taxas de deposição de agua (1) e proteína (2) no peso corporal em jejum de 24 horas e depenado (PCJD) em linhagens Cobb 500 (C), Ross 308 $(R)$, Hubbard Flex $(H)$, machos (a) e fêmeas $(b)$, segundo modelo de Gompertz ${ }^{*}$
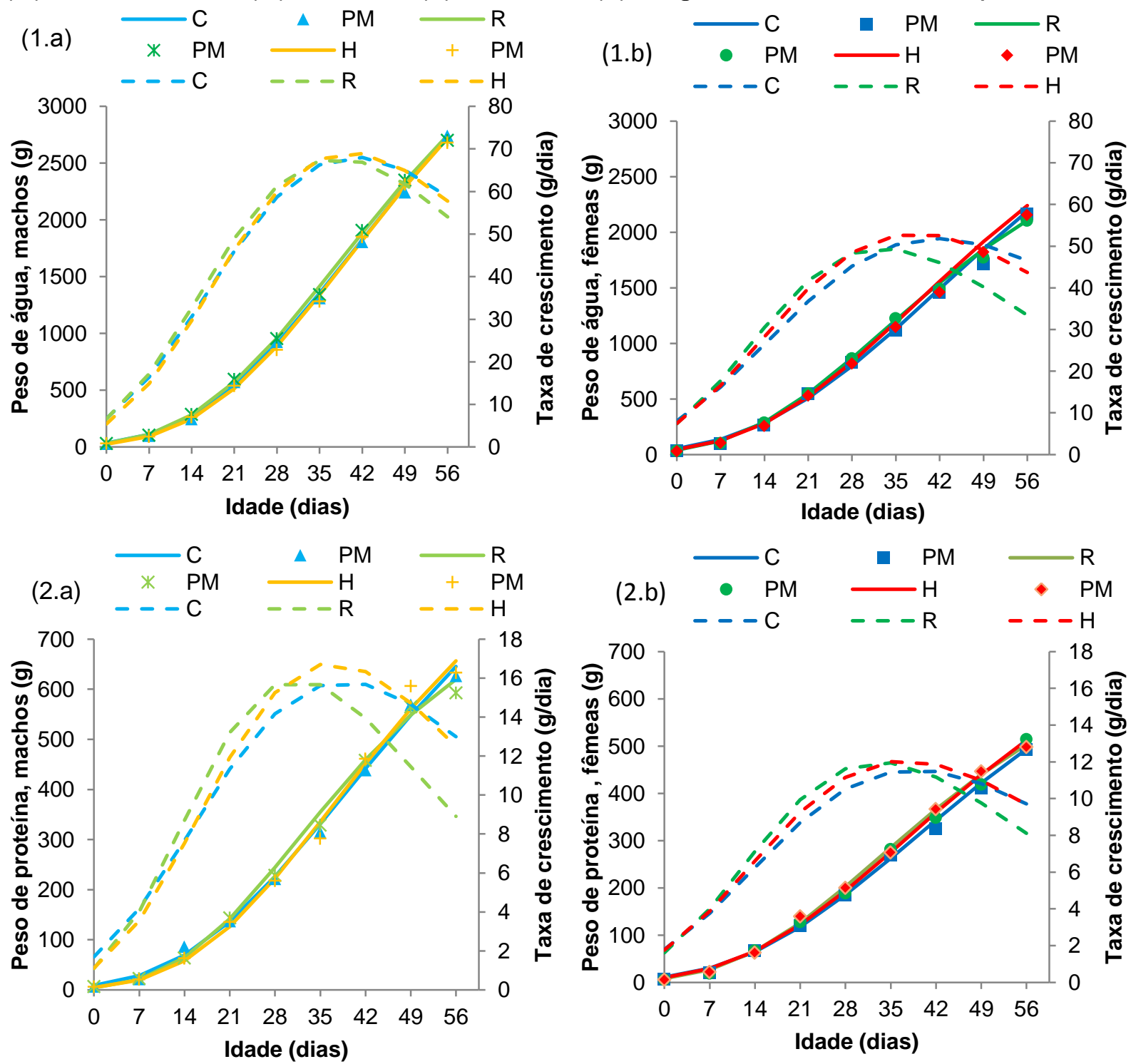

${ }^{*}$ Curvas de peso - linha contínua; Taxa de deposição - linha tracejada; PM - peso médio observado para respectiva cor de linhagem e sexo.

Fonte: Própria autoria.

(2000), quanto maior e mais prolongado for o platô da curva de deposição de proteína, mais eficiente será o animal para produzir carne e melhor a composição da carcaça.

Segundo Marcato et al. (2008), os frangos machos possuem as maiores taxas de deposição proteica, como no presente trabalho, e macho ( $\mathrm{Ti}=44,02$ dias) e fêmea $(\mathrm{Ti}=37,88$ dias) Ross 308 são mais tardias que macho $(\mathrm{Ti}=37,19$ dias $)$ e fêmea $(\mathrm{Ti}=31,02$ dias) Cobb 500 com maior TMC (18,07 g/dia) e queda acentuada 
da curva após o PI, assim frangos Cobb 500 tiveram maior platô, mas não o mais prolongado, segundo os autores do estudo. Entretanto, no atual estudo a idade de inflexão da curva para macho ( $\mathrm{Ti}=38,9$ dias) e fêmea $(\mathrm{Ti}=39,0$ dias) Cobb 500 foram tardias $(\mathrm{P}<0,05)$ em relação ao macho $(\mathrm{Ti}=32,0$ dias $)$ e fêmea $(\mathrm{Ti}=33,3$ dias) Ross 308, porém com platô mais prolongado que Ross 308 e este com súbita queda da curva após PI, indicando diferença no padrão das aves de Ross 308 quanto a deposição de proteína no atual estudo.

A Figura 12.2.a resume a deposição de proteína no PCJD mostrando que dentre as linhagens os frangos da linhagem Ross 308 são mais precoce. Apesar de machos Hubbard Flex chegarem ao ponto de inflexão com maior deposição diária de proteína que as demais linhagens de frangos machos, porém observa-se que macho Ross 308 teve maior deposição de PB antes do PI da curva, chegando mais cedo ao peso à maturidade. Observa-se ainda que na Figura 12.2, fêmeas tiveram taxa de deposição de PB inferior aos machos.

Não houve diferença significativa $(P>0,05)$ para os parâmetros "a", "k" e Ti da curva de deposição de gordura, porém houve valores superiores de "b" e "TCM" para as fêmeas $(\mathrm{TCM}=14,9 \mathrm{~g} / \mathrm{dia}$ ) sobre o máximo peso de gordura depositado em machos $(\mathrm{TCM}=13,3 \mathrm{~g} / \mathrm{dia})$, podendo notar que os valores de teor de gordura depositado em fêmeas em relação a machos aos 56 dias de idade $(16,16 \%$ vs $13,01 \%$ de gordura na matéria natural) foram numericamente elevados, como demostrados na Figura 13.1.

O efeito significativo de "a" sobre o sexo da ave foi verificado por Gous et al. (1999) em que o peso de gordura corporal aumentou substancialmente a partir dos 56 dias de idade, sendo que neste estudo os animais foram criados até 112 dias de idade. A gordura corporal adicional observado em fêmeas deve-se a preparação da ave para a postura de ovos induzindo a produção de hormônios sexuais que influenciam na formação de gordura (reserva energética), explicando o alto conteúdo de gordura corporal de fêmeas (GOUS et al., 1999; KESSLER, 2000) nas últimas idades observadas neste estudo.

De modo geral, o peso de cinzas depositadas no corpo dos frangos machos teve superior $(\mathrm{P}<0,05)$ taxa de maturidade, Ti e ganho de cinzas diário do que fêmeas, sem diferenças entre as linhagens para os machos (Figura 13.2). Porém dentre as fêmeas, Ross 308 tiveram inferior $(P<0,05)$ peso à maturidade de cinzas, com maior $(P<0,05)$ taxa de maturidade, e menor $(P<0,05)$ ponto de inflexão da 
Figura 13 - Curvas e taxas de deposição de gordura (1) e cinzas (2) no peso corporal em jejum de 24 horas depenado (PCJD) em linhagens Cobb 500 (C), Ross $308(\mathrm{R})$, Hubbard Flex $(\mathrm{H})$, machos (a) e fêmeas (b), segundo modelo de Gompertz*
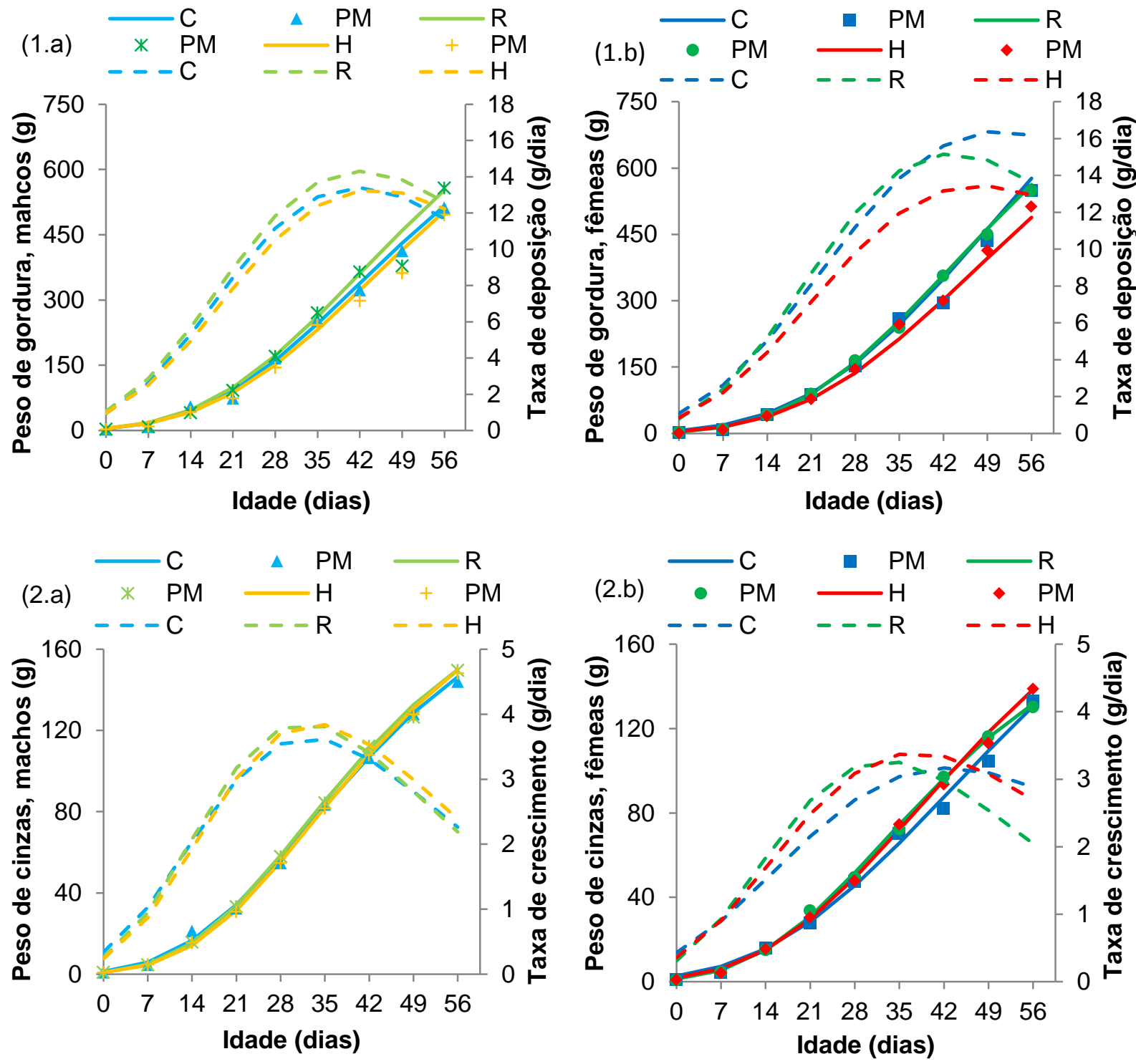

*Curvas de peso - linha contínua; Taxa de deposição - linha tracejada; PM - peso médio observado para respectiva cor de linhagem e sexo.

Fonte: Própria autoria.

curva $(\mathrm{Ti}=32,6$ dias $)$, sendo mais precoce que fêmea Hubbard Flex $(\mathrm{Ti}=37,9$ dias $)$ estas mais precoces que fêmea Cobb 500 ( $\mathrm{Ti}=42,9$ dias $)$.

Gous et al. (1999), Sakomura et al. (2005) e Henn et al. (2014) corroborando com o atual estudo observaram maior potencial de deposição corporal de nutrientes em frangos de corte machos do que em fêmeas, com exceção da gordura corporal, utilizando o modelo de Gompertz. 
No estudo realizado por Marcato et al. (2008) verificou-se diferenças nos efeitos de deposição de nutrientes na carcaça de frangos, no qual as fêmeas foram precoces em relação aos machos em todos os nutrientes e aves Cobb 500 tiveram menor taxa de deposição de cinzas que Ross 308, sendo estes mais precoces. No atual estudo observa-se que fêmeas tem PI tardio em relação aos machos para PB e cinzas, com PI da curva de peso de cinzas para fêmea Cobb 500 superior as demais linhagens de fêmeas (Figura 13.2).

Foram realizadas as estimativas alométricas de deposição de nutrientes no corpo das aves (Apêndice B) e observados os valores de intercepto estimado (não discutidos) e as diferenças entre os coeficientes alométricos de frangos machos e fêmeas. Estes coeficientes apresentaram valores menores que 1 (heterogônico negativo), para a deposição de água corporal; semelhantes a 1 (isogônico) para PB corporal; e superiores a 1 (heterogônico positivo) para cinzas e gordura corporal, o que significa que a quantidade relativa de água depositada no corpo da ave diminuiu de acordo com a idade sendo precoce em relação aos demais nutrientes, enquanto que a deposição relativa de PB permaneceu praticamente constante durante todo o crescimento da ave e a proporção de cinzas e gordura aumentou de acordo com o crescimento corporal.

De acordo com os coeficientes alométricos da Tabela 13, houve diminuição proporcional da água corporal com o aumento do peso proteico corporal com maior coeficiente $(P<0,05)$ para machos, sendo estes mais precoces do que fêmeas na deposição de água. A linhagem Cobb 500 apresentou maior coeficiente dentre fêmeas e entre machos, tendo Cobb 500 e Ross 308 semelhantes coeficientes alométricos de água.

Para a gordura corporal, machos e fêmeas Cobb 500, tiveram o maior $(P<0,05)$ coeficiente alométrico dentre os sexos. Não houve diferenças $(P>0,05)$ dos coeficientes alométricos para a deposição de cinzas corporal em relação à proteína corporal dentre os machos, somente dentre fêmeas em que Ross 308 apresentou maior $(P<0,05)$ coeficiente alométrico de cinzas do que fêmea Hubbard Flex, de acordo com a deposição de proteína corporal.

Marcato et al. (2008), verificaram em seu estudo diferenças apenas entre os valores de coeficiente alométrico para gordura corporal em relação a proteína corporal, em que machos Cobb $500(\beta=1,164)$ e machos Ross $308(\beta=1,210)$ foram semelhantes entre si, e machos Cobb 500 apresentaram menor coeficiente 
Tabela 13 - Médias e erros-padrões do intercepto $(\alpha)$, coeficiente de regressão $(\beta)$ e coeficiente de determinação $\left(R^{2}\right)$ das equações alométricas de água, gordura e cinzas em função da proteína corporal de frangos machos $(M)$ e fêmeas (F) das linhagens Cobb $500(\mathrm{C})$, Ross $308(\mathrm{R})$ e Hubbard Flex $(\mathrm{H})$

\begin{tabular}{|c|c|c|c|}
\hline \multicolumn{4}{|c|}{$\ln ($ água $)=\alpha+\beta \ln \left(\right.$ proteína corporal) ${ }^{* *}$} \\
\hline L S & $\alpha$ & $\beta$ & $\mathrm{R}^{2}$ \\
\hline $\mathrm{C} \mathrm{M}$ & $1,499 \pm 0,048^{b}$ & $0,984 \pm 0,006^{a}$ & $99,44 \pm 0,14$ \\
\hline $\mathrm{R} M$ & $1,608 \pm 0,038^{a}$ & $0,972 \pm 0,007^{a b}$ & $99,77 \pm 0,03$ \\
\hline $\mathrm{H} \quad \mathrm{M}$ & $1,610 \pm 0,034^{a}$ & $0,963 \pm 0,005^{b}$ & $99,78 \pm 0,05$ \\
\hline M & $1,573 \pm 0,025^{B}$ & $0,973 \pm 0,004^{A}$ & $99,67 \pm 0,06$ \\
\hline $\mathrm{C} \quad \mathrm{F}$ & $1,583 \pm 0,015^{b}$ & $0,973 \pm 0,003^{a}$ & $99,56 \pm 0,11$ \\
\hline $\mathrm{R} F$ & $1,737 \pm 0,019^{a}$ & $0,945 \pm 0,002^{b}$ & $99,78 \pm 0,03$ \\
\hline $\mathrm{H} \quad \mathrm{F}$ & $1,730 \pm 0,008^{a}$ & $0,946 \pm 0,004$ & $99,66 \pm 0,07$ \\
\hline $\mathrm{F}$ & $1,683 \pm 0,019^{A}$ & $0,955 \pm 0,004^{\mathrm{B}}$ & $99,67 \pm 0,05$ \\
\hline \multicolumn{4}{|c|}{$\ln ($ gordura $)=\alpha+\beta \ln ($ proteína corporal) } \\
\hline L S & A & $\beta$ & $\mathrm{R}^{2}$ \\
\hline C $\mathrm{M}$ & $-1,552 \pm 0,029^{b}$ & $1,213 \pm 0,005^{a}$ & $99,64 \pm 0,08$ \\
\hline $\mathrm{R} \quad \mathrm{M}$ & $-1,300 \pm 0,044^{a}$ & $1,176 \pm 0,006^{b}$ & $99,38 \pm 0,10$ \\
\hline $\mathrm{H} \quad \mathrm{M}$ & $-1,280 \pm 0,031^{a}$ & $1,153 \pm 0,004^{b}$ & $99,23 \pm 0,12$ \\
\hline M & $-1,327 \pm 0,036^{A}$ & $1,180 \pm 0,007^{\mathrm{B}}$ & $99,42 \pm 0,07$ \\
\hline $\mathrm{C} \quad \mathrm{F}$ & $-1,800 \pm 0,024^{b}$ & $1,307 \pm 0,005^{a}$ & $99,88 \pm 0,02$ \\
\hline $\mathrm{R} F$ & $-1,448 \pm 0,045^{a}$ & $1,235 \pm 0,008^{b}$ & $99,66 \pm 0,07$ \\
\hline $\mathrm{H} \quad \mathrm{F}$ & $-1,513 \pm 0,044^{a}$ & $1,236 \pm 0,009^{b}$ & $99,75 \pm 0,04$ \\
\hline $\mathrm{F}$ & $-1,581 \pm 0,043^{B}$ & $1,260 \pm 0,009^{A}$ & $99,76 \pm 0,03$ \\
\hline \multicolumn{4}{|c|}{$\ln ($ cinzas $)=\alpha+\beta \ln ($ proteína corporal) } \\
\hline L S & A & $\beta$ & $\mathrm{R}^{2}$ \\
\hline C M & $-1,995 \pm 0,016$ & $1,100 \pm 0,004$ & $99,36 \pm 0,06$ \\
\hline $\mathrm{R} M$ & $-1,974 \pm 0,024$ & $1,098 \pm 0,006$ & $99,52 \pm 0,04$ \\
\hline $\mathrm{H} \quad \mathrm{M}$ & $-1,931 \pm 0,033$ & $1,086 \pm 0,006$ & $99,11 \pm 0,12$ \\
\hline$M$ & $-1,967 \pm 0,015^{A}$ & $1,095 \pm 0,005^{B}$ & $99,33 \pm 0,06$ \\
\hline $\mathrm{C} \quad \mathrm{F}$ & $-2,049 \pm 0,017^{a b}$ & $1,124 \pm 0,003^{a b}$ & $99,71 \pm 0,03$ \\
\hline $\mathrm{R} F$ & $-2,093 \pm 0,024^{b}$ & $1,131 \pm 0,005^{a}$ & $99,69 \pm 0,07$ \\
\hline $\mathrm{H} \quad \mathrm{F}$ & $-1,969 \pm 0,038^{a}$ & $1,112 \pm 0,007^{b}$ & $99,71 \pm 0,07$ \\
\hline $\mathrm{F}$ & $-2,037 \pm 0,020^{B}$ & $1,122 \pm 0,004^{\mathrm{A}}$ & $99,70 \pm 0,03$ \\
\hline
\end{tabular}

alométrico que fêmeas sendo estas semelhantes entre si para a relação de gordura e proteína corporal.

\subsubsection{Crescimento e deposição dos nutrientes sobre as penas}

Foram estimados os parâmetros e propriedades da curva de Gompertz que se encontram na Tabela 15 e o ganho de peso médio de penas e nutrientes 
depositados nestas estão apresentados na Tabela 16. Não houve diferença $(P>0,05)$ sobre os parâmetros ( $a, b$ e k) e Ti da curva de crescimento e deposição de proteína bruta nas penas sobre sexo e linhagens dentro de sexo, porém foram verificadas diferenças de TMC de penas e TMD de nutrientes, no qual a linhagem Ross 308 apresentou superior $(P<0,05)$ ganho máximo de penas, dentro de cada sexo, com maior $(P<0,05)$ deposição de água e proteína bruta $(P B)$ diária dentre as linhagens de machos, enquanto que entre fêmea Ross 308 teve superior $(P<0,05)$ deposição de água e PB em relação às fêmeas Hubbard Flex e Cobb 500, respectivamente.

$\mathrm{O}$ peso à maturidade de água e gordura depositada nas penas foi superior $(P<0,05)$ em machos, assim como o ganho máximo de peso para todos os nutrientes (Tabela 14 e 15; Figuras 14, 15 e 16). Tendo macho Ross 308, superior peso de gordura à maturidade e ganho máximo de água e proteína nas penas superior $(P<0,05)$ para macho e fêmea desta linhagem.

As médias observadas de taxa de maturidade das penas ( macho $=0,0557 \mathrm{e}$ fêmea $=0,0559 \mathrm{t}^{-1}$ ) foram superiores quando comparados às taxas de maturidade do peso corporal em jejum e depenados (macho $=0,0420$ e fêmea $=0,0389$ ) e de proteína corporal (macho $=0,0466$ e fêmea $=0,0410$ ). Hancock et al. $(1995)$ e Gous et al. (1999) observaram que estes não possuem a mesma velocidade de crescimento, corroborando com o atual estudo.

O ponto de inflexão de deposição dos nutrientes nas penas foi entre 31,2 e 42,2 dias de idade, com exceção da gordura nas penas que alcançou valores mais precoces de inflexão da curva (entre 19,3 a 28,3 dias de vida das aves) que os demais nutrientes depositados nas penas.

De acordo com Hardiman e Katanbaf (2012), existe mais de 8000 penas espalhadas sobre o corpo de frangos aos 42 dias de idade e durante o crescimento a ave passa por duas mudas. A primeira muda ocorre nas primeiras duas semanas de vida com perdas das penugens e substituídas por penas jovens e a segunda muda ocorre entre a quarta e quinta semanas de idade, chegando ao completo empenamento aos 50 dias de idade. Algumas linhagens e aves dentro das linhagens podem exceder ou não chegar ao total crescimento das penas (Edens, 2000).

Durante a primeira e segunda semana de vida dos animais foi observado mudança das penugens para penas jovens nas aves, tendo fêmeas maiores valores peso de penas que machos (Figura 14.2). Este fato pode ser explicado através da 
Tabela 14 - Médias e erros-padrões das estimativas dos parâmetros (a, b e k), taxa máxima de crescimento ou deposição (TMC/D) e idade de inflexão (Ti) da curva de Gompertz sobre o peso e nutrientes depositados (água, proteína bruta (PB), gordura e cinzas) das penas de frangos machos $(M)$ e fêmeas $(F)$ das linhagens Cobb 500 (C), Ross 308 (R) e Hubbard Flex $(\mathrm{H})$

\begin{tabular}{|c|c|c|c|c|c|}
\hline * & \multicolumn{5}{|c|}{ Parâmetros e Propriedades da curva } \\
\hline $\mathrm{LS}$ & $a^{1}(g)$ & $b^{2}$ & $k^{3}\left(t^{-1}\right)$ & Ti (dias) & TMC/D (g/d) \\
\hline \multicolumn{6}{|c|}{ Penas } \\
\hline $\mathrm{CM}$ & $258,3 \pm 16,0$ & $6,954 \pm 0,256$ & $0,0536 \pm 0,0028$ & $36,4 \pm 1,3$ & $5,02 \pm 0,12^{b}$ \\
\hline $\mathrm{R} M$ & $279,4 \pm 22,0$ & $8,650 \pm 0,819$ & $0,0605 \pm 0,0049$ & $35,8 \pm 1,5$ & $6,06 \pm 0,09^{a}$ \\
\hline $\mathrm{H} M$ & $242,6 \pm 9,9$ & $6,918 \pm 0,119$ & $0,0527 \pm 0,0010$ & $36,7 \pm 0,4$ & $4,70 \pm 0,11^{b}$ \\
\hline M & $261,1 \pm 10,2$ & $7,510 \pm 0,347$ & $0,0557 \pm 0,0021$ & $36,3 \pm 0,7$ & $5,28 \pm 0,16^{A}$ \\
\hline $\mathrm{CF}$ & $214,9 \pm 22,4$ & $5,847 \pm 0,623$ & $0,0505 \pm 0,0062$ & $36,1 \pm 2,9$ & $3,76 \pm 0,13^{b}$ \\
\hline $\mathrm{R} \mathrm{F}$ & $212,9 \pm 27,6$ & $7,306 \pm 0,945$ & $0,0611 \pm 0,0088$ & $33,6 \pm 3,0$ & $4,45 \pm 0,18^{a}$ \\
\hline $\mathrm{HF}$ & $193,3 \pm 19,2$ & $6,498 \pm 0,502$ & $0,0569 \pm 0,0055$ & $33,6 \pm 2,1$ & $3,86 \pm 0,07^{b}$ \\
\hline $\mathrm{F}$ & $206,7 \pm 12,6$ & $6,506 \pm 0,397$ & $0,0559 \pm 0,0038$ & $34,5 \pm 1,5$ & $4,00 \pm 0,10^{B}$ \\
\hline \multicolumn{6}{|c|}{ Água } \\
\hline $\mathrm{CM}$ & $19,24 \pm 1,91$ & $7,188 \pm 0,153$ & $0,0619 \pm 0,0033$ & $32,0 \pm 1,5$ & $0,434 \pm 0,020^{b}$ \\
\hline R M & $28,17 \pm 4,44$ & $7,392 \pm 1,353$ & $0,0527 \pm 0,0082$ & $38,4 \pm 3,7$ & $0,521 \pm 0,023^{a}$ \\
\hline $\mathrm{HM}$ & $27,53 \pm 3,45$ & $5,580 \pm 0,128$ & $0,0409 \pm 0,0030$ & $42,2 \pm 2,6$ & $0,411 \pm 0,021^{b}$ \\
\hline $\mathrm{M}$ & $24,66 \pm 2,34^{A}$ & $6,862 \pm 0,528$ & $0,0532 \pm 0,0043$ & $36,9 \pm 2,1$ & $0,461 \pm 0,021^{A}$ \\
\hline $\mathrm{CF}$ & $18,75 \pm 0,86$ & $5,033 \pm 0,433$ & $0,0470 \pm 0,0030$ & $34,4 \pm 1,5$ & $0,323 \pm 0,014^{a b}$ \\
\hline $\mathrm{R} \mathrm{F}$ & $18,54 \pm 4,59$ & $6,720 \pm 1,616$ & $0,0614 \pm 0,0189$ & $32,3 \pm 6,0$ & $0,387 \pm 0,025^{a}$ \\
\hline $\mathrm{H} \mathrm{F}$ & $15,69 \pm 0,46$ & $5,345 \pm 0,035$ & $0,0538 \pm 0,0011$ & $31,2 \pm 0,6$ & $0,310 \pm 0,004^{b}$ \\
\hline $\mathrm{F}$ & $17,55 \pm 1,07^{\mathrm{B}}$ & $5,572 \pm 0,423$ & $0,0531 \pm 0,0043$ & $32,7 \pm 1,3$ & $0,334 \pm 0,014^{B}$ \\
\hline \multicolumn{6}{|c|}{ Proteína Bruta } \\
\hline $\mathrm{CM}$ & $216,6 \pm 20,9$ & $7,026 \pm 0,324^{a b}$ & $0,0533 \pm 0,0043$ & $36,9 \pm 2,1$ & $4,17 \pm 0,09^{b}$ \\
\hline $\mathrm{R} M$ & $223,1 \pm 11,8$ & $10,162 \pm 1,853^{a}$ & $0,0651 \pm 0,0061$ & $35,2 \pm 0,8$ & $5,29 \pm 0,24^{a}$ \\
\hline $\mathrm{HM}$ & $245,7 \pm 27,0$ & $6,453 \pm 0,296^{b}$ & $0,0450 \pm 0,0041$ & $41,9 \pm 3,0$ & $3,99 \pm 0,15^{b}$ \\
\hline M & $228,5 \pm 11,3$ & $7,880 \pm 0,796$ & $0,0545 \pm 0,0038$ & $38,0 \pm 1,5$ & $4,49 \pm 0,22^{A}$ \\
\hline $\mathrm{C} \mathrm{F}$ & $171,5 \pm 25,9$ & $5,708 \pm 0,523$ & $0,0509 \pm 0,0070$ & $35,2 \pm 4,4$ & $3,08 \pm 0,08^{b}$ \\
\hline $\mathrm{R} \mathrm{F}$ & $203,9 \pm 31,7$ & $6,302 \pm 0,860$ & $0,0511 \pm 0,0102$ & $37,3 \pm 4,1$ & $3,59 \pm 0,09^{a}$ \\
\hline $\mathrm{H} \mathrm{F}$ & $166,4 \pm 30,8$ & $6,679 \pm 0,686$ & $0,0571 \pm 0,0094$ & $34,4 \pm 4,2$ & $3,29 \pm 0,08^{a b}$ \\
\hline $\mathrm{F}$ & $180,6 \pm 15,9$ & $6,230 \pm 0,379$ & $0,0531 \pm 0,0046$ & $35,6 \pm 2,1$ & $3,32 \pm 0,08^{B}$ \\
\hline \multicolumn{6}{|c|}{ Gordura } \\
\hline$\overline{C M}$ & $2,101 \pm 0,124^{b}$ & $75,28 \pm 29,22^{a}$ & $0,1777 \pm 0,0252^{a}$ & $24,0 \pm 1,1$ & $0,139 \pm 0,027$ \\
\hline $\mathrm{R} M$ & $3,137 \pm 0,106^{a}$ & $8,420 \pm 0,866^{b}$ & $0,0765 \pm 0,0084^{b}$ & $28,2 \pm 2,3$ & $0,088 \pm 0,007$ \\
\hline $\mathrm{HM}$ & $2,051 \pm 0,023^{b}$ & $13,13 \pm 1,811^{b}$ & $0,1197 \pm 0,0082^{a b}$ & $21,5 \pm 0,9$ & $0,090 \pm 0,005$ \\
\hline$M$ & $2,471 \pm 0,200^{A}$ & $26,90 \pm 11,96$ & $0,1180 \pm 0,0160$ & $24,6 \pm 1,4$ & $0,101 \pm 0,010^{A}$ \\
\hline$\overline{\mathrm{CF}}$ & $1,919 \pm 0,137$ & $5,163 \pm 0,336$ & $0,0807 \pm 0,0154$ & $20,9 \pm 3,2$ & $0,056 \pm 0,007$ \\
\hline $\mathrm{R} \mathrm{F}$ & $2,327 \pm 0,314$ & $11,846 \pm 6,522$ & $0,1104 \pm 0,0395$ & $21,5 \pm 2,1$ & $0,090 \pm 0,021$ \\
\hline $\mathrm{H} \mathrm{F}$ & $1,881 \pm 0,156$ & $8,940 \pm 3,588$ & $0,1049 \pm 0,0138$ & $19,3 \pm 2,1$ & $0,072 \pm 0,011$ \\
\hline $\mathrm{F}$ & $2,020 \pm 0,124^{B}$ & $8,691 \pm 2,223$ & $0,0996 \pm 0,0117$ & $20,4 \pm 1,2$ & $0,073 \pm 0,008^{B}$ \\
\hline
\end{tabular}

*Médias em função do sexo (S) e linhagem (L) dentro de cada sexo L(S), seguidas de letras distintas maiúsculas (macho e fêmea) e minúsculas (linhagem dentro de cada sexo) diferem significativamente pelo teste de TukeyKramer $(\mathrm{p}<0,05)$;

$1 \mathrm{a}$ - Peso da ave à idade adulta;

${ }^{2} \mathrm{~b}$ - Constante de integração;

${ }^{3} \mathrm{k}$ - Taxa de maturidade;

Fonte: Própria autoria. 
Tabela 15 - Média da deposição diária de nutrientes (água, proteína bruta e gordura) de penas de frangos machos $(M)$ e fêmeas $(F)$ das linhagens Cobb $500(C)$, Ross $308(\mathrm{R})$ e Hubbard Flex $(\mathrm{H})$, em intervalos de 7 dias, segundo o modelo de Gompertz

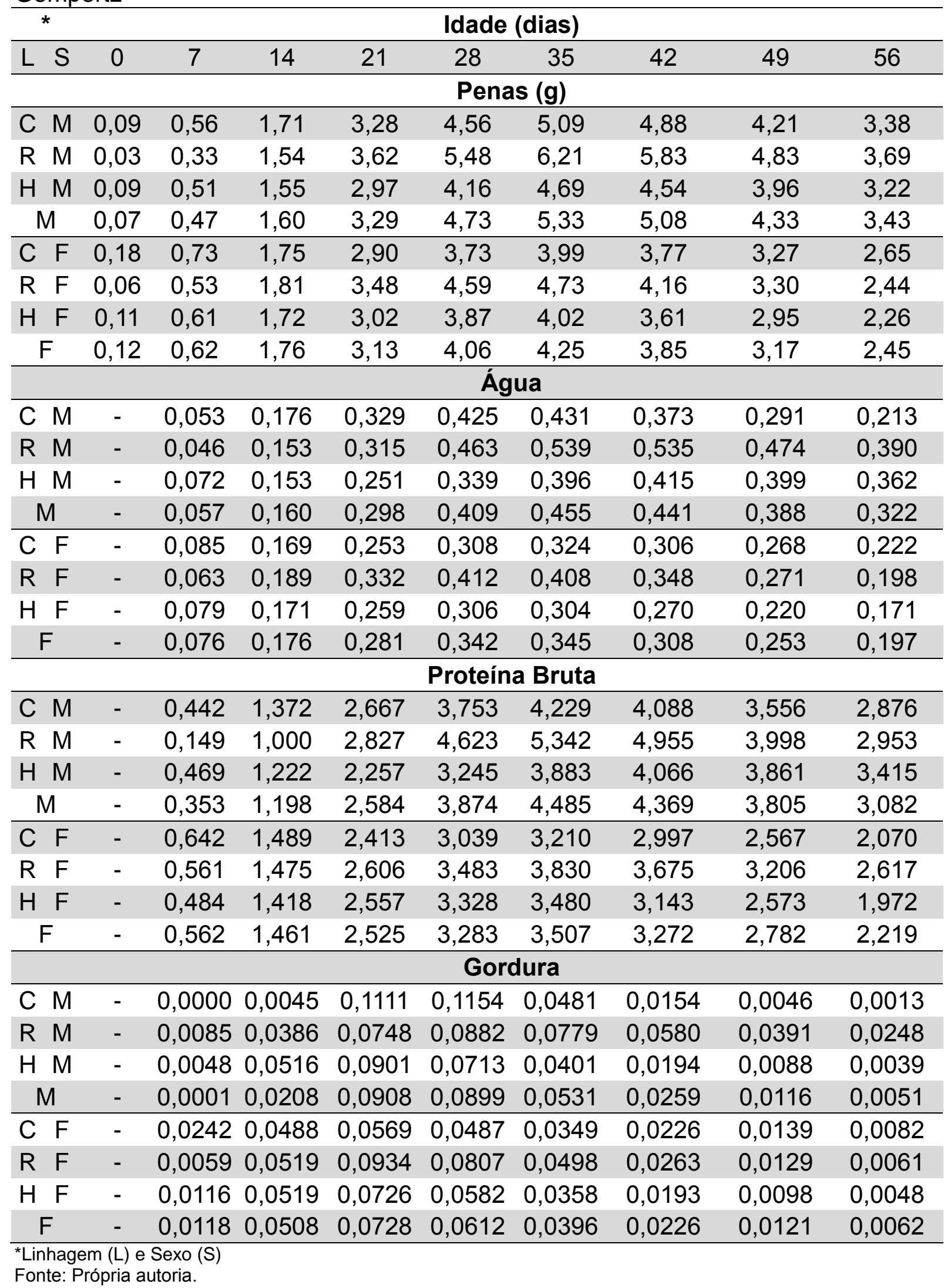


Figura 14 - Curvas e taxas de crescimento de penas em linhagens Cobb 500 (C), Ross $308(\mathrm{R})$, Hubbard Flex $(\mathrm{H})$, machos e fêmeas, segundo modelo de Gompertz*
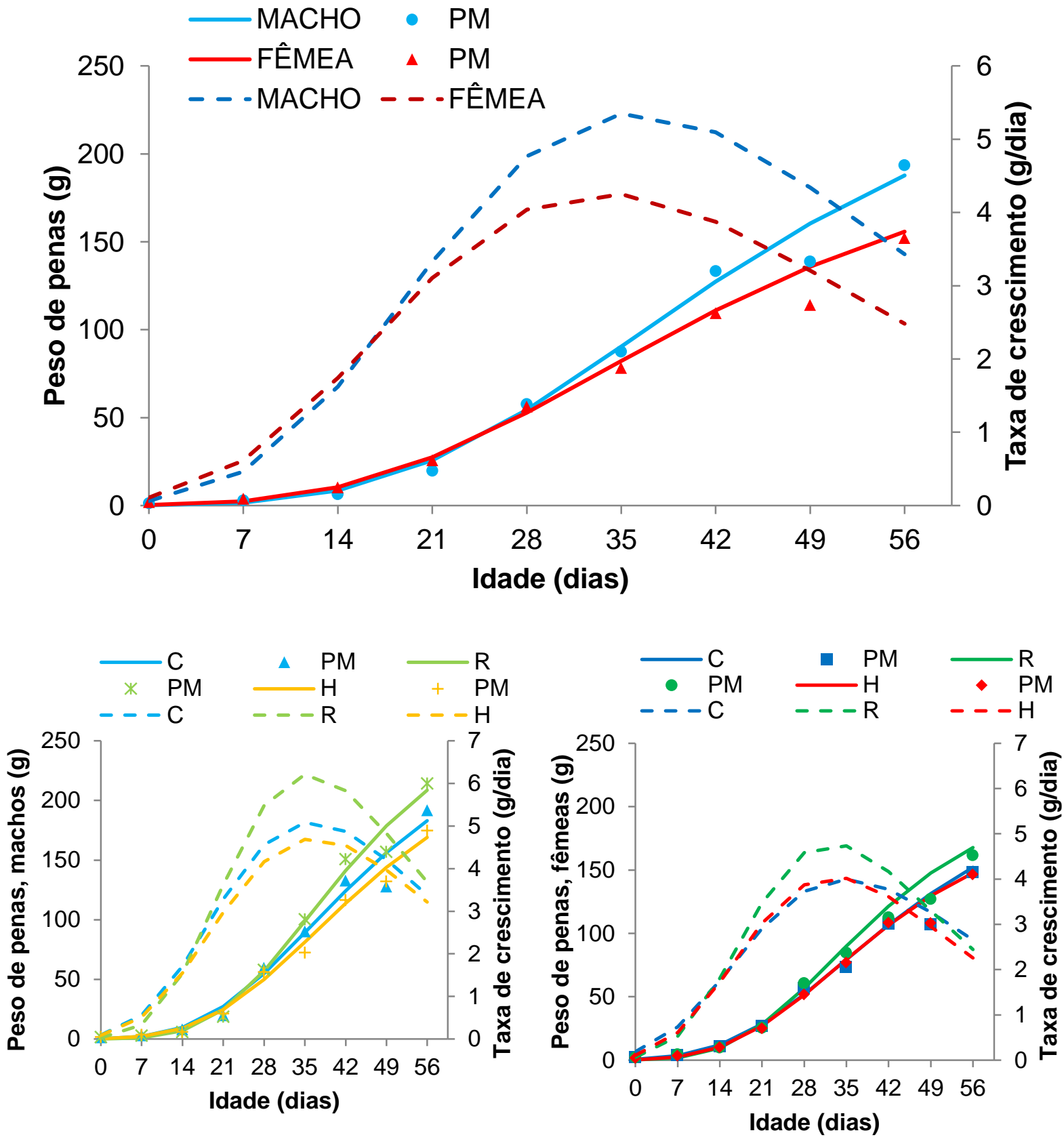

*Curvas de peso - linha contínua; Taxa de crescimento - linha tracejada; PM- peso médio observado para respectiva cor de linhagem e sexo.

Fonte: Própria autoria.

seleção de reprodutores, pois o gene $(K)$ situado no cromossomo sexual $Z$ destas aves está relacionado com a taxa de crescimento das penas, podendo ter aves de empenamento lento machos $\left(Z^{K} Z^{K}\right.$ ou $\left.Z^{K} Z^{k}\right)$ e fêmeas $\left(Z^{K} W\right)$ ou machos $\left(Z^{k} Z^{k}\right)$ e fêmeas $\left(Z^{k} W\right)$ de empenamento rápido, que quando cruzados machos reprodutoras de empenamento rápido $\left(Z^{k} Z^{k}\right)$ com matrizes de empenamento lento $\left(Z^{K} W\right)$, obtêm- 
Figura 15 - Curvas e taxas de deposição de água (1) e proteína bruta (2) nas penas em linhagens Cobb $500(\mathrm{C})$, Ross $308(\mathrm{R})$, Hubbard Flex $(\mathrm{H})$, machos (a) e fêmeas (b), segundo modelo de Gompertz*
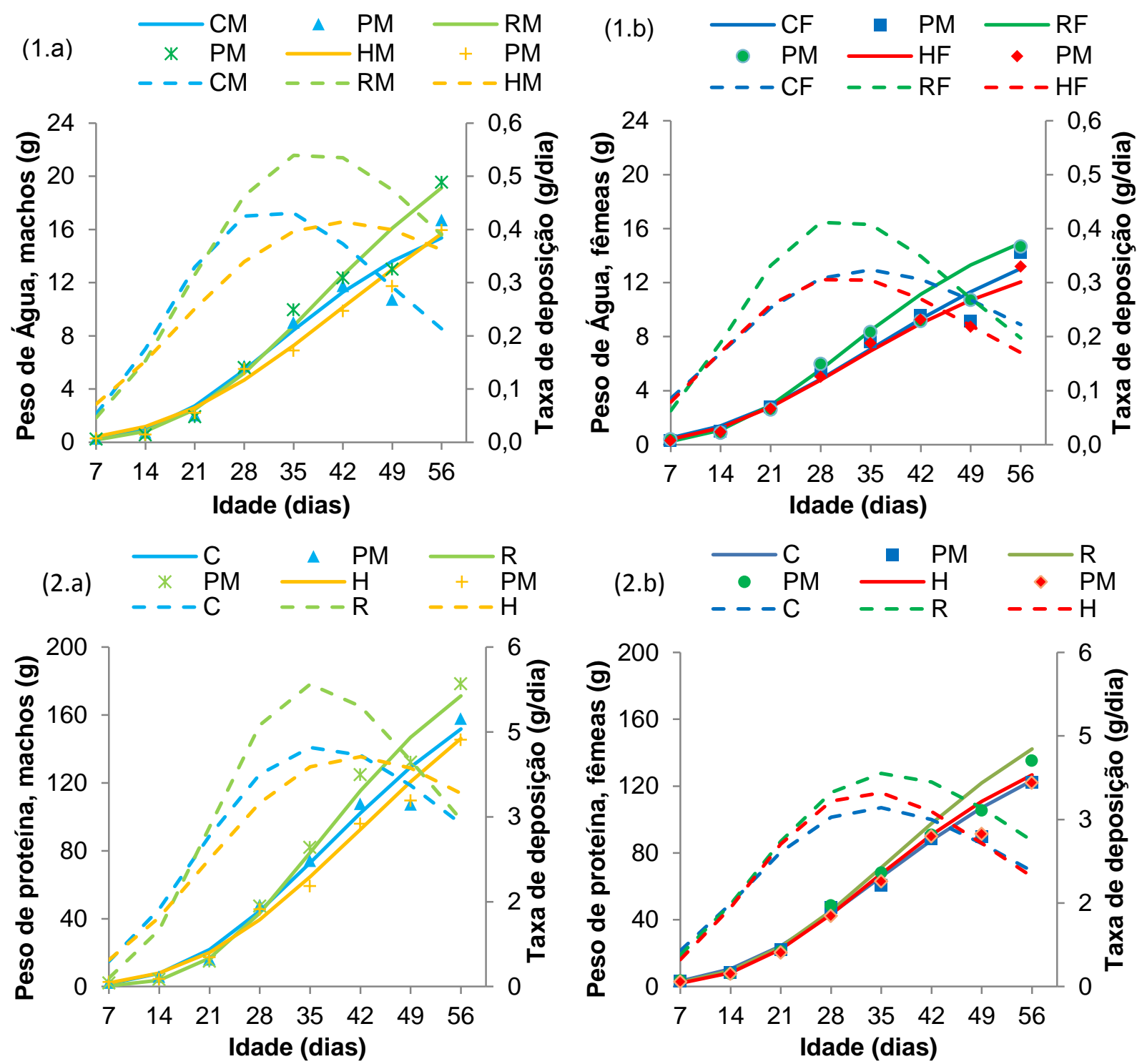

${ }^{*}$ Curvas de peso - linha contínua; Taxa de crescimento - linha tracejada; PM- peso médio observado para respectiva cor de linhagem e sexo.

Fonte: Própria autoria.

se fêmeas de empenamento rápido $\left(Z^{k} W\right)$ ou machos de empenamento lento $\left(Z^{k} Z^{k}\right.$ ou $\left.Z^{Z} Z^{k}\right)$. Assim, este processo ajuda a sexagem dos pintinhos no primeiro dia de vida em que machos terão as penas primarias da asa (camada inferior) menor ou do mesmo tamanho das coberturas e fêmeas com penas primárias da asa maior do que as da cobertura e empenamento mais rápido que machos até os 21 dias de idade (MENDES; NAAS; MACARI, 2004). 
Figura 16 - Curvas e taxas de deposição de gordura nas penas em linhagens Cobb $500(\mathrm{C})$, Ross $308(\mathrm{R})$, Hubbard Flex $(\mathrm{H})$, machos e fêmeas, segundo modelo de Gompertz*
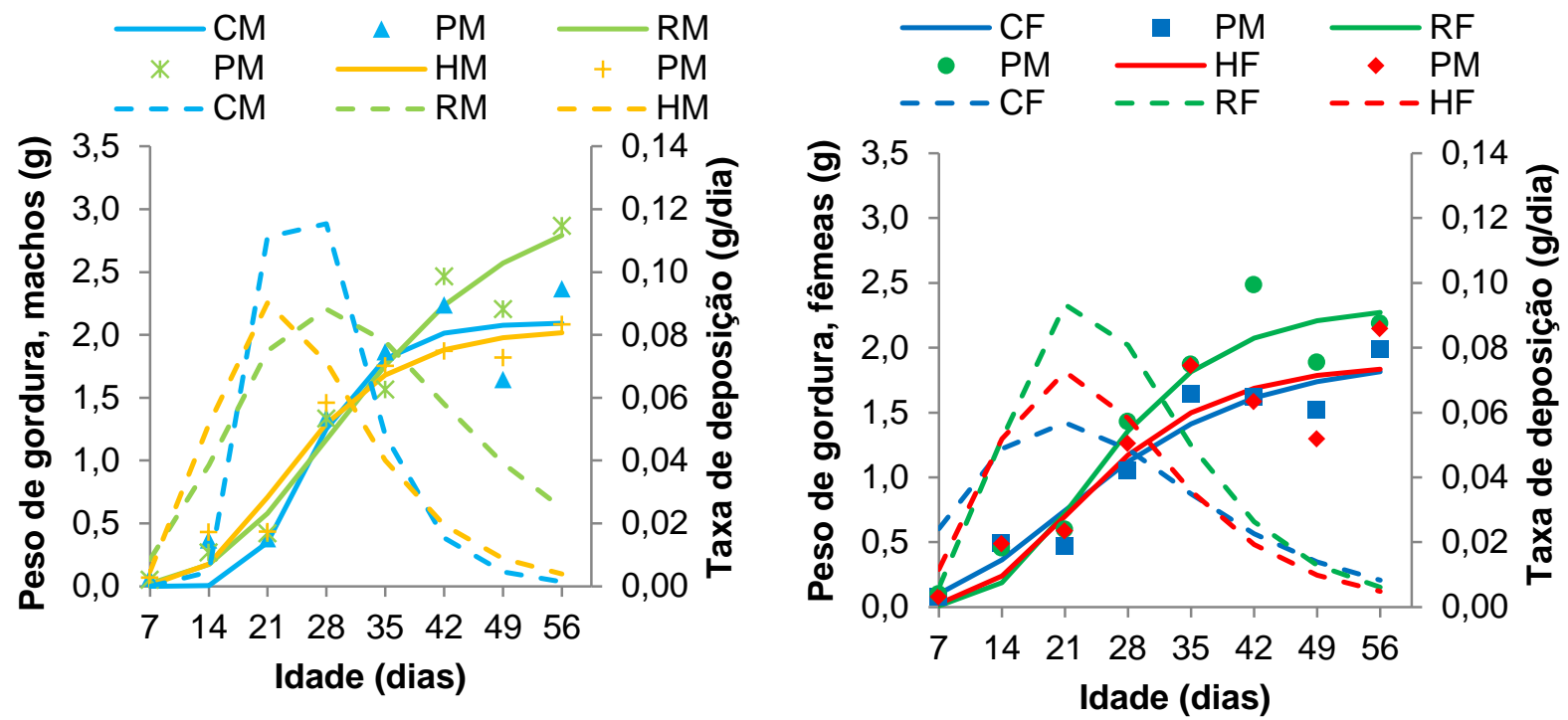

${ }^{*}$ Curvas de peso - linha contínua (Fêmea) e tracejada com ponto (M); Taxa de crescimento - linha tracejada; PM - peso médio observado para respectiva linhagem e sexo.

Fonte: Própria autoria.

O ponto de inflexão da curva foi próximo dos 35 dias de idade das aves, no qual foi o momento de maior crescimento de penas podendo ter ocorrido na segunda muda, em que novas penas empurram o primeiro conjunto de penas para fora com menor crescimento de penas aos 42 e 49 dias de idade (Tabela 16), pois o peso médio (PM) de penas neste período permaneceu quase que constante. No entanto houve aumento do peso de penas aos 56 dias de idade, superestimando os valores da curva de crescimento e deposição de nutrientes nas penas aos 49 dias de idade (Figuras 14, 15 e 16).

$\mathrm{Na}$ literatura encontram-se grande variedade sobre o dia de inflexão na curva de Gompertz para o peso de penas de frangos de corte, como visto nos seguintes estudos: Marcato et al. (2008), estimaram dia de inflexão (Ti) da curva aos 48,95 a 57,56 dias de idade para machos e 37,05 a 45,22 dias de idade para fêmeas Cobb 500 e Ross 308, respectivamente; Sakomura et al. (2005) estimaram Ti de 31 e 32 dias de idade para machos e fêmeas, respectivamente, da linhagem Ross 308; Gous et al. (1999) estudaram o crescimento de cruzamentos de frangos e obtiveram Ti para peso de penas de 42,4 a 44,0 e 39,5 a 40,7 dias de idade para machos e fêmeas, respectivamente; Hancook et al. (1995) utilizaram seis linhagens e verificaram Ti de 29,7 a 35,8 e 28,8 a 36,3 dias de idade para machos e fêmeas, respectivamente. 


\subsubsection{Crescimento da carcaça}

Na Tabela 16 estão as estimativas dos parâmetros e propriedades da curva de Gompertz para o peso de carcaça (soma dos pesos de asa, peito sem osso e pele, coxa, sobrecoxa, osso e pele do peito+dorso). O ganho de peso médio de carcaça, em intervalos de sete dias, para cada linhagem e sexo estão apresentadas na Tabela 17.

Tabela 16 - Médias e erros-padrões das estimativas dos parâmetros (a, b e k), taxa máxima de crescimento (TMC) e da idade de inflexão (Ti) do modelo de Gompertz sobre a carcaça e componentes físicos da carcaça de frangos machos (M) e fêmeas (F) das linhagens Cobb 500 (C), Ross 308 (R) e Hubbard Flex (H)

\begin{tabular}{cccccc}
\hline${ }^{*}$ & \multicolumn{5}{c}{ Parâmetros e Propriedades da curva } \\
\hline L S & $\mathrm{a}^{1}(\mathrm{~g})$ & $\mathrm{b}^{2}$ & $\mathrm{k}^{3}\left(\mathrm{t}^{-1}\right)$ & $\mathrm{Ti}($ dias $)$ & $\mathrm{TMC}(\mathrm{g} / \mathrm{d})$ \\
\hline C M & $5696 \pm 234^{\mathrm{a}}$ & $5,172 \pm 0,090$ & $0,0384 \pm 0,0014^{\mathrm{b}}$ & $43,0 \pm 1,2^{\mathrm{a}}$ & $79,9 \pm 1,0^{\mathrm{a}}$ \\
R M & $4739 \pm 224^{\mathrm{a}}$ & $5,338 \pm 0,093$ & $0,0446 \pm 0,0018^{\mathrm{a}}$ & $37,8 \pm 1,3^{\mathrm{a}}$ & $76,9 \pm 0,6^{\mathrm{a}}$ \\
H M & $5787 \pm 419^{\mathrm{a}}$ & $5,412 \pm 0,098$ & $0,0388 \pm 0,0019^{\mathrm{ab}}$ & $43,9 \pm 1,9^{\mathrm{a}}$ & $81,2 \pm 1,8^{\mathrm{a}}$ \\
M & $5408 \pm 202$ & $5,308 \pm 0,056$ & $0,0406 \pm 0,0012^{\mathrm{A}}$ & $41,6 \pm 1,1^{\mathrm{B}}$ & $79,4 \pm 0,8^{\mathrm{A}}$ \\
\hline C F & $5967 \pm 348^{\mathrm{a}}$ & $4,710 \pm 0,044$ & $0,0309 \pm 0,0011^{\mathrm{b}}$ & $50,4 \pm 1,9^{\mathrm{a}}$ & $67,3 \pm 1,8^{\mathrm{a}}$ \\
R F & $4079 \pm 285^{\mathrm{b}}$ & $4,762 \pm 0,099$ & $0,0416 \pm 0,0024^{\mathrm{a}}$ & $38,1 \pm 2,0^{\mathrm{b}}$ & $61,2 \pm 0,7^{\mathrm{b}}$ \\
H F & $5569 \pm 433^{\mathrm{a}}$ & $4,747 \pm 0,043$ & $0,0330 \pm 0,0013^{\mathrm{b}}$ & $47,5 \pm 2,1^{\mathrm{a}}$ & $66,8 \pm 2,3^{\mathrm{a}}$ \\
F & $5205 \pm 278$ & $4,740 \pm 0,037$ & $0,0352 \pm 0,0014^{\mathrm{B}}$ & $45,3 \pm 1,7^{\mathrm{A}}$ & $65,1 \pm 1,2^{\mathrm{B}}$
\end{tabular}

${ }^{{ }^{*} M e ́ d i a s ~ e m ~ f u n c ̧ a ̃ o ~ d o ~ s e x o ~(S) ~ e ~ l i n h a g e m ~(L) ~ d e n t r o ~ d e ~ c a d a ~ s e x o ~} \mathrm{~L}(\mathrm{~S})$, seguidas de letras distintas maiúsculas (macho e fêmea) e minúsculas (linhagem dentro de cada sexo) diferem significativamente pelo teste de TukeyKramer $(p<0,05)$;

1 a - Peso da carcaça à idade adulta;

${ }^{2} \mathrm{~b}$ - Constante de integração;

${ }^{3} \mathrm{k}$ - Taxa de maturidade.

Fonte: Própria autoria.

Tabela 17 - Média de ganho diário de peso de carcaça (g) de frangos machos (M) e fêmeas $(F)$ das linhagens Cobb $500(C)$, Ross $308(R)$ e Hubbard Flex $(H)$, em intervalos de 7 dias, segundo modelo de Gompertz

\begin{tabular}{ccccccccccc}
\hline \multicolumn{1}{c}{$*$} & \multicolumn{8}{c}{ Idade (dias) } \\
\hline L & S & 0 & 7 & 14 & 21 & 28 & 35 & 42 & 49 & 56 \\
\hline C & M & 6,41 & 16,57 & 32,15 & 50,09 & 65,99 & 76,48 & 80,36 & 78,34 & 72,13 \\
R & M & 5,42 & 16,58 & 34,58 & 54,49 & 69,91 & 77,16 & 76,30 & 69,60 & 59,86 \\
H & M & 5,42 & 14,97 & 30,43 & 49,00 & 66,03 & 77,70 & 82,46 & 80,89 & 74,72 \\
M & 5,75 & 16,04 & 32,39 & 51,19 & 67,31 & 77,11 & 79,71 & 76,28 & 68,90 \\
\hline C & F & 7,82 & 15,76 & 26,55 & 38,76 & 50,39 & 59,68 & 65,57 & 67,83 & 66,82 \\
R & F & 6,90 & 17,17 & 31,52 & 46,14 & 56,99 & 62,01 & 61,37 & 56,59 & 49,49 \\
H & F & 7,58 & 16,04 & 27,70 & 40,75 & 52,76 & 61,75 & 66,69 & 67,59 & 65,12 \\
F & 7,44 & 16,32 & 28,59 & 41,88 & 53,38 & 61,15 & 64,55 & 64,00 & 60,47 \\
\hline
\end{tabular}

*Linhagem (L) e Sexo (S)

Fonte: Própria autoria. 
Observa-se que não houve diferença estatística para o peso da carcaça à maturidade entre sexo, com semelhante "a" entre as linhagens de machos. No entanto, verificou-se que frangos machos possuem taxa de maturidade $(k)$ de carcaça superior $(P<0,05)$ as fêmeas, com menor $(P<0,05)$ ponto de inflexão e maior $(\mathrm{P}<0,05)$ taxa máxima de crescimento, assim frangos machos são mais precoces, alcançando maior peso de carcaça em menor tempo e segundo Madeira et al. (2006) os machos sempre são superiores as fêmeas em relação ao peso da carcaça, independente da linhagem sendo isto observado na indústria quanto em estudos.

Dentre as linhagens de machos verifica-se que Ross 308 tem maior $(P<0,05)$ taxa de maturidade de carcaça que Cobb 500 e estes resultados não diferiram dos encontrados para aves Hubbard Flex. Para as fêmeas houve maior diferença de carcaça entre as linhagens, no qual Ross 308 distinguiu-se $(P<0,05)$ das demais em todos os parâmetros e propriedades da curva. Com isso, pode-se inferir que aves Ross 308 fêmea chegam mais cedo à idade adulta, pois possuem taxa de maturidade maior, tendo maior precocidade dentre as linhagens de fêmeas.

Na figura 17 visualizam-se resultados da Tabela 16 e 17, em que as curvas de frangos machos diferem das fêmeas e inflexionam mais cedo que estas, sendo observado que a linhagem Ross 308 possui menor ponto de inflexão (PI) da curva

Figura 17 - Curvas e taxas de crescimento do peso da carcaça em linhagens Cobb $500(\mathrm{C})$, Ross $308(\mathrm{R})$, Hubbard Flex $(\mathrm{H})$, machos e fêmeas, segundo modelo de Gompertz*
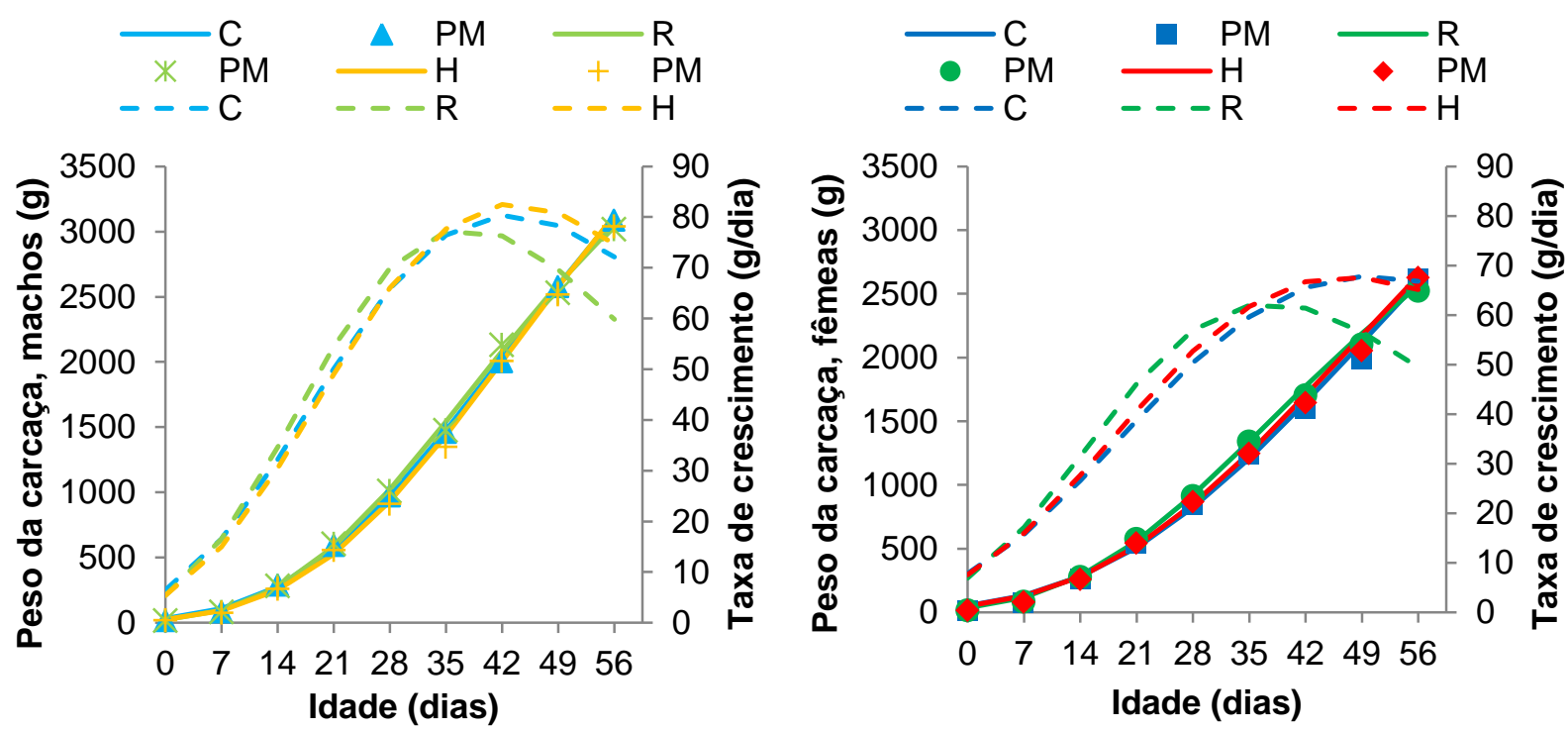

*Curvas de peso - linha contínua (F) e tracejada com ponto (M); Taxa de crescimento - linha tracejada; PM peso médio observado para respectiva linhagem e sexo.

Fonte: Própria autoria. 
entre as linhagens dentro de cada sexo, sendo mais perceptível $(P<0,05)$ para Ross fêmea. Portanto, a linhagem Ross 308 tem maior ganho de peso diário de carcaça até 35 dias de idade, com acentuada queda após o $\mathrm{PI}$, enquanto que as linhagens Cobb 500 e Hubbard Flex tem maior ganho de peso diário a partir dos 42 dias de idade.

\subsubsection{Crescimento do peito}

As estimativas dos parâmetros da curva de crescimento de peso de peito dos frangos na Tabela 18. As médias semanais do ganho diário de peso de peito sem osso e sem pele das linhagens e sexo estão apresentadas na Tabela 19. Foram observadas diferenças $(P<0,05)$ entre sexo em todos os parâmetros, exceto o "b", e propriedades da curva de peso de peito. Fêmeas tiveram valores superiores $(P<0,05)$ para "a" e "Ti", sendo então conferida maior precocidade para deposição de peito em machos, chegando estes à ave adulta com menor peso de peito.

Foi constatado dentre as linhagens em machos, que o peso à maturidade e o ganho de peito máximo foram superiores $(P<0,05)$ para as aves da linhagem Cobb 500 macho, com ponto de inflexão tardio em relação ao macho Ross 308 e Ti semelhante estatisticamente $(P>0,05)$ ao macho Hubbard Flex. Para as fêmeas Cobb 500 e Hubbard Flex, foram verificados os maiores $(P<0,05)$ pesos à maturidade assim como maiores TMC de peito, contudo fêmea Ross 308 apresentou maior precocidade sobre o ponto de inflexão da curva.

$\mathrm{Na}$ Tabela 18, observa-se que aves da linhagem Ross 308 dentro de cada sexo apresentaram ganho de peso diário máximo de peito superior às demais linhagens antes do PI e a partir da idade de inflexão houve acentuada queda do ganho de peso de peito, observando que Ross 308 fêmea apresentou padrão de ganho de peso diário próximo aos machos, sendo significantemente $(P<0,05)$ diferente das demais linhagens de fêmeas sobre os parâmetros "a" e "k" em relação ao crescimento de peito.

Os frangos são criados numa fase em que a taxa de crescimento corporal é crescente tendo o ponto de inflexão da curva, onde ocorre uma desaceleração do ganho de peso diário. Com isso, a idade no qual ocorre esse ponto é de grande interesse econômico para realização do abate e comercialização do produto, ainda 
Tabela 18 - Médias e erros-padrões das estimativas dos parâmetros (a, b e k), taxa máxima de crescimento (TMC) e da idade de inflexão (Ti) do modelo de Gompertz sobre o peso do peito de frangos machos (M) e fêmeas (F) das linhagens Cobb 500 (C), Ross $308(\mathrm{R})$ e Hubbard Flex $(\mathrm{H})$

\begin{tabular}{|c|c|c|c|c|c|}
\hline * & \multicolumn{5}{|c|}{ Parâmetros e Propriedades da curva } \\
\hline $\mathrm{LS}$ & $a^{1}(g)$ & $b^{2}$ & $\mathrm{k}^{3}\left(\mathrm{t}^{-1}\right)$ & Ti (dias) & TMC (g/d) \\
\hline$\overline{\mathrm{CM}}$ & $2481 \pm 171^{a}$ & $5,642 \pm 0,049$ & $0,0340 \pm 0,0013^{b}$ & $51,1 \pm 2,0^{a}$ & $30,8 \pm 0,9^{a}$ \\
\hline $\mathrm{R} M$ & $1456 \pm 45^{b}$ & $6,104 \pm 0,211$ & $0,0479 \pm 0,0020^{a}$ & $37,8 \pm 0,8^{b}$ & $25,6 \pm 0,3^{b}$ \\
\hline $\mathrm{HM}$ & $1613 \pm 142^{b}$ & $6,266 \pm 0,297$ & $0,0429 \pm 0,0036^{a b}$ & $43,5 \pm 2,4^{a b}$ & $24,7 \pm 0,3^{b}$ \\
\hline M & $1832 \pm 145^{B}$ & $6,024 \pm 0,144$ & $0,0417 \pm 0,0022^{A}$ & $44,1 \pm 1,8^{\mathrm{B}}$ & $26,8 \pm 0,8$ \\
\hline $\mathrm{CF}$ & $2895 \pm 196^{a}$ & $5,410 \pm 0,043$ & $0,0279 \pm 0,0014^{b}$ & $60,7 \pm 2,7^{\mathrm{a}}$ & $29,5 \pm 0,8^{a}$ \\
\hline$R F$ & $1598 \pm 154^{b}$ & $5,584 \pm 0,279$ & $0,0410 \pm 0,0041^{\mathrm{a}}$ & $42,9 \pm 2,8^{b}$ & $23,2 \pm 0,3^{b}$ \\
\hline $\mathrm{HF}$ & $2729 \pm 216^{a}$ & $5,488 \pm 0,044$ & $0,0282 \pm 0,0011^{b}$ & $60,9 \pm 2,6^{a}$ & $27,8 \pm 1,0^{a}$ \\
\hline $\mathrm{F}$ & $2396 \pm 185^{A}$ & $5,499 \pm 0,090$ & $0,0324 \pm 0,0021^{\mathrm{B}}$ & $54,9 \pm 2,7^{\mathrm{A}}$ & $26,7 \pm 0,8$ \\
\hline
\end{tabular}

*Médias em função do sexo (S) e linhagem (L) dentro de cada sexo $L(S)$, seguidas de letras distintas maiúsculas (macho e fêmea) e minúsculas (linhagem dentro de cada sexo) diferem significativamente pelo teste de TukeyKramer $(p<0,05)$;

${ }^{1}$ a - Peso do componente à idade adulta;

${ }^{2} \mathrm{~b}$ - Constante de integração;

${ }^{3} \mathrm{k}$ - Taxa de maturidade.

Fonte: Própria autoria.

Tabela 19 - Média semanal de ganho diário de peso de peito $(\mathrm{g})$ de frangos machos (M) e fêmeas (F) das linhagens Cobb 500 (C), Ross $308(R)$ e Hubbard Flex $(H)$, segundo modelo de Gompertz

\begin{tabular}{cccccccccc}
\multicolumn{2}{l}{${ }^{*}$} & \multicolumn{10}{c}{ Idade (dias) } \\
\hline L S & 0 & 7 & 14 & 21 & 28 & 35 & 42 & 49 & 56 \\
\hline C M & 1,69 & 4,40 & 8,90 & 14,74 & 20,85 & 26,06 & 29,54 & 31,00 & 30,61 \\
R M & 0,95 & 3,88 & 9,61 & 16,72 & 22,58 & 25,44 & 25,18 & 22,71 & 19,18 \\
H M & 0,82 & 3,10 & 7,65 & 13,82 & 19,80 & 23,91 & 25,44 & 24,63 & 22,25 \\
M & 1,15 & 3,79 & 8,72 & 15,09 & 21,08 & 25,14 & 26,72 & 26,12 & 24,01 \\
\hline C F & 1,96 & 4,21 & 7,63 & 12,02 & 16,87 & 21,53 & 25,41 & 28,13 & 29,54 \\
R F & 1,37 & 4,15 & 8,86 & 14,58 & 19,72 & 23,03 & 24,09 & 23,19 & 20,99 \\
H F & 1,74 & 3,82 & 7,03 & 11,19 & 15,83 & 20,31 & 24,05 & 26,68 & 28,04 \\
F & 1,69 & 4,06 & 7,84 & 12,60 & 17,47 & 21,62 & 24,52 & 26,00 & 26,19 \\
\hline
\end{tabular}

*Linhagem (L) e Sexo (S)

Fonte: Própria autoria.

mais quando se trata de uma parte tão nobre como o peito do frango. De acordo com a Figura 18, a linhagem Ross 308 foi precoce no PI da curva com superior no ganho de peso de peito quando comparadas as outras linhagens neste ponto, alcançando valor inferior de peso de peito à maturidade. A linhagem Cobb 500 teve maior taxa de crescimento de peito, porém tardiamente e junto às aves Hubbard Flex, sendo que macho desta ultima linhagem não apresentou ganho de peso de peito tão expressivo quanto macho Cobb 500. Assim, o produto final e idade de abate podem influenciar economicamente na escolha da linhagem. 
Figura 18 - Curvas e taxa de crescimento do peso do peito em linhagens Cobb 500 $(\mathrm{C})$, Ross $308(\mathrm{R})$, Hubbard Flex $(\mathrm{H})$, machos e fêmeas, segundo modelo de Gompertz $^{*}$

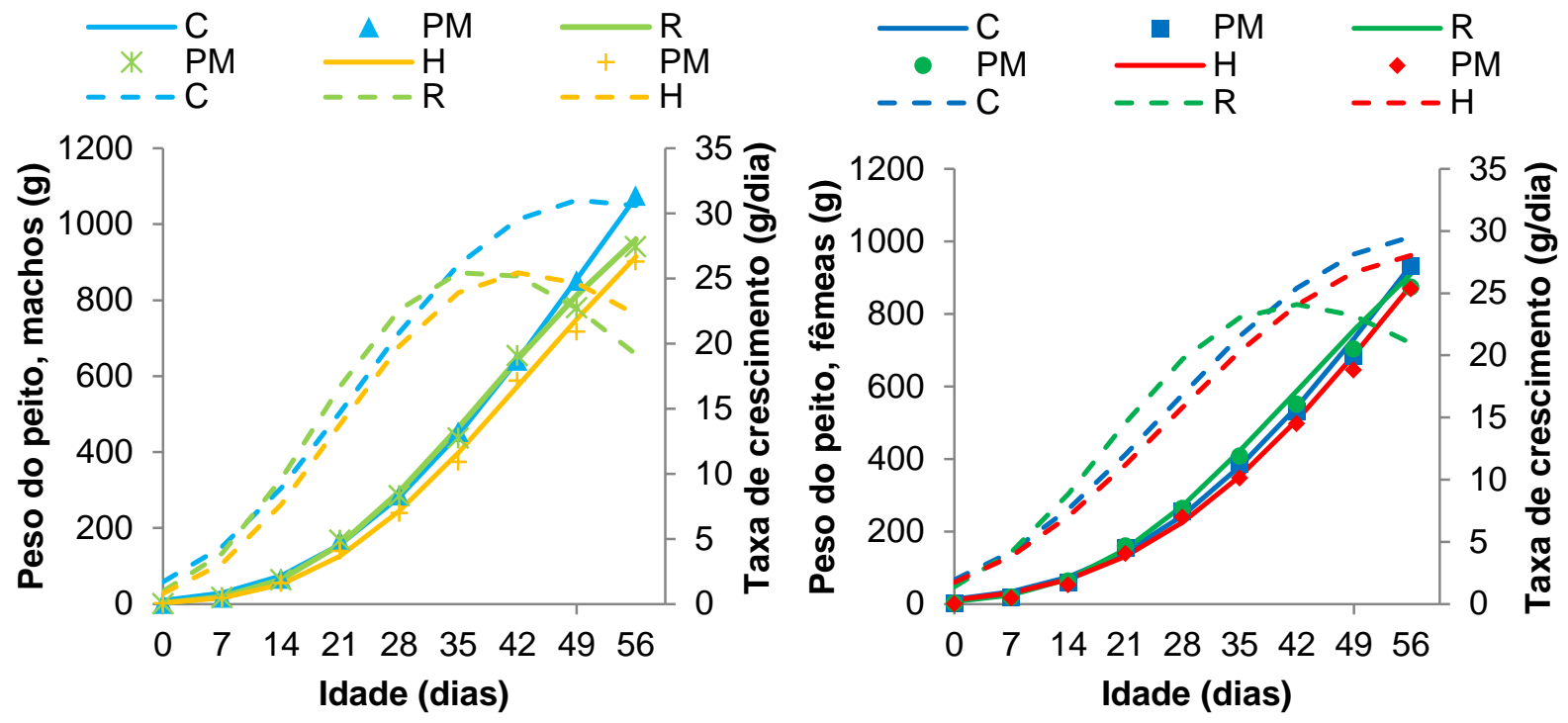

*Curvas de peso - linha contínua (F) e tracejada com ponto (M); Taxa de crescimento - linha tracejada; PM peso médio observado para respectiva linhagem e sexo.

Fonte: Própria autoria.

Scheuermann et al. (2003) ajustaram a curva de Gompertz para oito diferentes linhagens comerciais de frangos de corte até os 57 dias de idade e observaram pontos de inflexão da curva para peso do peito de machos aos 38,4 dias de idade com TMC calculado de 23,0 g/dia e fêmeas aos 35,2 dias de idade com TMC calculado de $17,8 \mathrm{~g} / \mathrm{dia}$, respectivamente.

No presente estudo foi observado valor superior de TCM para os machos (26,8 g/dia aos 44,1 dias) das linhagens estudadas, enquanto que no estudo de ajuste de curva de Richards para o peso corporal e partes do frango utilizando duas linhagens de frangos comerciais machos até 154 dias de idade realizado por Goliomytis Panopoulou e Rogdakis (2003), não houve diferença entre as curvas estimando um ponto de inflexão da curva de peito com 47 dias com TCM de 24,4 $\mathrm{g} / \mathrm{dia}$ para as linhagens estudadas.

Marcato (2007) concluíram que machos das linhagens Cobb 500 chegam a idade de abate aos 42 dias com taxa de crescimento do peito de $31,88 \mathrm{~g} /$ dia e Ross 308 aos 35 dias de idade com taxa de crescimento do peito de 30,25 g/dia e que Cobb 500 fêmea tiveram menor taxa máxima de crescimento de peito com diferentes idade que Ross 308 fêmea, 24,74 g/dia aos 35 dias de idade e 25,06 g/dia aos 42 dias de idade, respectivamente. Estes resultados concordam em parte com 0 
presente estudo, em que macho Cobb 500 (30,8 g/dia) e machos em geral apresentaram maiores TMC de peito, e que o ponto de inflexão de frangos Cobb 500 macho (51,1 dias de idade) é mais tardio em relação ao de Ross 308 macho $(37,8$ dias de idade), mas discordam dos resultados encontrados no presente estudo para fêmea Cobb 500 que apresentaram maior ganho diário de peito (29,5 g/dia aos 60,7 dias de idade) em relação à fêmea Ross 308 (23,2 g/dias aos 42,9 dias de idade) com PI superior. Estas diferenças encontradas podem estar relacionadas às diferentes dietas utilizada em cada sexo, assim como fases de vida, instalações, clima.

De acordo com Fernandes et al. (2013) e Nikolova e Pavlovski (2009) a escolha para linhagem de melhor rendimento de peito depende do sexo, tendo observado superiores rendimento de peito aos 43 dias de idade pela linhagem Cobb. Entretanto, Marcato (2007) observou que se a criação de frangos de corte for para a venda de partes da carcaça, como o peito, os machos teriam maiores vantagens que fêmeas para este fim, mesmo considerando maior rendimento do peito para fêmea do que para os machos.

Numa comparação do ponto de inflexão (dias) do peso corporal (Tabela 7) com peso de peito (Tabela 18) verifica-se que o ponto de taxa de crescimento máxima foi alcançado mais cedo para o peso corporal do que o peito, assim as aves continuam depositando músculo no peito numa fase mais tardia do que para o peso corporal, indicando a existência de diferenças entre machos e fêmeas e ainda diferentes linhagens para peso corporal e para o peso de peito, sendo o principal fator para as diferenças sexuais no peso corporal e musculosidade pode ser determinada durante o desenvolvimento embrionário, quando é estabelecido o número de fibras musculares (SCHEUERMANN et al., 2003).

Segundo Reddish e Lilburn $(2004)^{5}$ citando Siegel e Dunnington (1997), qualquer método de seleção usado para alterar o padrão de crescimento animal, de curto ou longo prazo, resulta em efeitos em outras características e que diferenças nas características estruturais do músculo do peito entre linhagens encontradas por estes autores podem refletir em diferenças no comprimento do músculo, largura e

\footnotetext{
${ }^{5}$ SIEGEL, P. B.; DUNNINGTON E. A. Genetic selection strategies-population genetics. Poultry Science, v.76, p.1062-1065, 1997.
} 
profundidade resultando em diferente número de fibras musculares ou tamanho da fibra muscular.

\subsubsection{Crescimento de coxa}

Os parâmetros para crescimento da coxa em frangos de corte utilizando o modelo de Gompertz estão apresentados na Tabela 20 e o ganho de peso médio diário de coxa para coxa de linhagens e sexo de frangos de corte, em intervalos de sete dias encontra-se na Tabela 21, neste peso inclui osso e pele de duas coxas.

Observou-se que não houve diferença estatística $(P>0,05)$ para a taxa de maturidade $(k)$ apresentando $\mathrm{Ti}$ comum $(P>0,05)$ entre sexo, tendo os frangos machos taxa máxima de crescimento superior $(P<0,05)$ no $P I$ em relação às fêmeas, chegando à idade adulta com peso superior $(\mathrm{P}<0,05)$ de coxa.

Comparando o peso de coxa entre as linhagens de machos, verificou-se que as aves da linhagem Hubbard Flex alcançaram os maiores pesos de coxa à maturidade (a) com menor velocidade de maturidade (k) e maior TMC, já a linhagem Ross 308 apresentou inferior $(P<0,05)$ "a", superior $(P<0,05)$ "k" e deste modo $\mathrm{Ti}$

Tabela 20 - Médias e erros-padrões das estimativas dos parâmetros (a, b e k), taxa máxima de crescimento (TMC) e da idade de inflexão (Ti) do modelo de Gompertz sobre o peso de coxa de frangos machos (M) e fêmeas (F) das linhagens Cobb 500 (C), Ross $308(\mathrm{R})$ e Hubbard Flex $(\mathrm{H})$

\begin{tabular}{|c|c|c|c|c|c|}
\hline * & \multicolumn{5}{|c|}{ Parâmetros e Propriedades da curva } \\
\hline L S & $a^{1}(g)$ & $b^{2}$ & $k^{3}\left(t^{-1}\right)$ & Ti (dias) & TMC $(g / d)$ \\
\hline $\mathrm{CM}$ & $612 \pm 31^{\text {ab }}$ & $5,373 \pm 0,105$ & $0,0470 \pm 0,0022^{b}$ & $36,1 \pm 1,3^{a b}$ & $10,45 \pm 0,07^{c}$ \\
\hline $\mathrm{R} M$ & $546 \pm 18^{b}$ & $5,903 \pm 0,221$ & $0,0552 \pm 0,0021^{a}$ & $32,2 \pm 0,6^{b}$ & $11,02 \pm 0,09^{b}$ \\
\hline $\mathrm{HM}$ & $679 \pm 25^{a}$ & $5,693 \pm 0,102$ & $0,0466 \pm 0,0015^{b}$ & $37,5 \pm 1,0^{\text {a }}$ & $11,56 \pm 0,08^{a}$ \\
\hline M & $612 \pm 19^{A}$ & $5,656 \pm 0,098$ & $0,0496 \pm 0,0014$ & $35,3 \pm 0,8$ & $11,0 \pm 0,12^{\mathrm{A}}$ \\
\hline $\mathrm{CF}$ & $533 \pm 35^{a}$ & $4,616 \pm 0,118$ & $0,0395 \pm 0,0021^{b}$ & $39,1 \pm 1,9^{a}$ & $7,75 \pm 0,15^{b}$ \\
\hline $\mathrm{RF}$ & $414 \pm 12^{b}$ & $5,147 \pm 0,207$ & $0,0538 \pm 0,0023^{a}$ & $30,5 \pm 0,7^{b}$ & $8,20 \pm 0,19^{a}$ \\
\hline $\mathrm{HF}$ & $456 \pm 23^{a b}$ & $4,937 \pm 0,106$ & $0,0490 \pm 0,0026^{a}$ & $32,9 \pm 1,4^{b}$ & $8,23 \pm 0,11^{a}$ \\
\hline $\mathrm{F}$ & $468 \pm 18^{B}$ & $4,900 \pm 0,097$ & $0,0475 \pm 0,0019$ & $34,2 \pm 1,2$ & $7,97 \pm 0,10^{B}$ \\
\hline th & $05)$ & $\begin{array}{l}\text { (S) e linhager } \\
\text { ulas (linhagem } \\
\text { idade adulta; } \\
\text { o; }\end{array}$ & & guidas de I & stintas maiús \\
\hline
\end{tabular}


Tabela 21 - Média de ganho diário de peso de coxa $(\mathrm{g})$ de frangos machos $(\mathrm{M})$ e fêmeas $(F)$ das linhagens Cobb $500(\mathrm{C})$, Ross $308(\mathrm{R})$ e Hubbard Flex $(\mathrm{H})$, em intervalos de 7 dias, segundo modelo de Gompertz

\begin{tabular}{cccccccccc}
\multicolumn{1}{c}{$*$} & \multicolumn{7}{c}{ Idade (dias) } \\
\hline L S & 0 & 7 & 14 & 21 & 28 & 35 & 42 & 49 & 56 \\
\hline C M & 0,73 & 2,33 & 4,91 & 7,67 & 9,64 & 10,37 & 9,97 & 8,84 & 7,39 \\
R M & 0,51 & 2,23 & 5,40 & 8,72 & 10,69 & 10,85 & 9,70 & 7,94 & 6,13 \\
H M & 0,62 & 2,15 & 4,82 & 7,90 & 10,32 & 11,44 & 11,27 & 10,18 & 8,65 \\
M & 0,62 & 2,23 & 5,04 & 8,10 & 10,22 & 10,89 & 10,31 & 8,99 & 7,39 \\
\hline C F & 0,96 & 2,23 & 3,93 & 5,67 & 6,99 & 7,66 & 7,69 & 7,20 & 6,42 \\
R F & 0,67 & 2,30 & 4,79 & 7,03 & 8,12 & 7,97 & 6,99 & 5,67 & 4,37 \\
H F & 0,79 & 2,36 & 4,64 & 6,77 & 8,02 & 8,18 & 7,51 & 6,39 & 5,16 \\
F & 0,81 & 2,30 & 4,45 & 6,49 & 7,71 & 7,94 & 7,39 & 6,42 & 5,32 \\
\hline
\end{tabular}

*Linhagem (L) e Sexo (S)

Fonte: Própria autoria.

inferior $(P>0,05)$ aos frangos da linhagem Hubbard Flex, tendo a linhagem Cobb 500 "a" e Ti semelhante $(P>0,05)$ às demais linhagens com o menor ganho diário de coxa dentre os machos, portanto frangos machos alcançaram diferentes pesos de coxa com diferente PI para Ross 308. Para o peso de coxa de fêmeas, observa-se que as aves de Cobb 500 alcançam superior $(\mathrm{P}<0,05)$ peso à maturidade em relação às aves de Ross 308 fêmea, sendo Hubbard Flex semelhante $(P>0,05)$ entre as linhagens de fêmeas. Contudo, aves Ross 308 e Hubbard Flex distinguem-se $(P<0,05)$ de Cobb 500 para " $k$ ", Ti e TCM, portanto foram mais precoces alcançando maior peso de coxa no PI da curva.

$\mathrm{Na}$ curva da Figura 19 observa-se que frangos machos possuem peso de coxa superior que fêmeas a partir dos 21 dias de idade, com maior $(P<0,05)$ ganho de coxa diário. Dentre os frangos machos a linhagem Hubbard Flex possui taxa de crescimento de coxa superior às demais linhagens, próximo aos 35 dias de idade, com maior ganho de peso de coxa aos 42 dias e Ross 308 observa-se que houve acentuada queda da taxa de crescimento próximo ao Ti (32,2 dias) desta linhagem de macho, explicando a diferença no peso à maturidade entre Ross 308 e Hubbard Flex. Para as aves fêmeas observa-se que Cobb 500 possuem menor taxa de crescimento com PI tardio (39,1 dias) em relação às outras linhagens, apresentando peso à maturidade maior que Ross 308 . De modo geral, observa-se que Ross 308 , machos e fêmeas, atingiu o PI mais cedo com maior taxa de crescimento. 
Goliomytis, Panopoulou e Rogdakis (2003), estimaram os parâmetros ("a" = 492,2g, "k" = 0,035 t - $^{-1} \mathrm{Ti}=50$ dias) para equação de Richards sobre os dados de coxa de frangos de corte machos e comparando os valores destes parâmetros com o presente estudo $\left(a=575 \mathrm{~g} ; \mathrm{k}=0,0516 \mathrm{t}^{-1}\right.$ e $\mathrm{Ti}=35,3$ dias) para o modelo de Gompertz verifica-se que houve uma diminuição no número de dias (-14,7 dias) e aumento do peso final estimado $(+82,8 \mathrm{~g})$, dando maior precocidade para os frangos do atual estudo.

Quando comparados os parâmetros estimados por Marcato (2007) para o modelo de Gompertz verifica-se que machos Ross 308 tiveram maior precocidade no atual estudo $\left(\mathrm{a}=613,69 \mathrm{~g}\right.$ vs $546 \mathrm{~g}, \mathrm{k}=0,047 \mathrm{t}^{-1}$ vs 0,0552 $\mathrm{t}^{-1} \mathrm{e} \mathrm{Ti}=36,85$ dias vs 32,2 dias) e para machos Cobb 500 os parâmetros foram mais próximos ( $a=564,84$ $\mathrm{g}$ vs $612 \mathrm{~g}, \mathrm{k}=0,048 \mathrm{t}^{-1}$ vs 0,0470 $\mathrm{t}^{-1} \mathrm{e} \mathrm{Ti}=34,86$ dias vs 36,1 dias). Comparando às aves fêmeas ao atual estudo, a mesma autora observou valores inferiores de "a" (Cobb fêmea $=379,8$ g vs 533 g e Ross fêmea = 376,5 g vs 414 g), superior para "k" (Cobb fêmea $=0,056 \mathrm{t}^{-1}$ vs $0,0395 \mathrm{t}^{-1}$ e Ross fêmea $=0,055 \mathrm{t}^{-1}$ vs $0,0538 \mathrm{t}^{-1}$ ) com Ti precoce para Cobb 500 fêmea ( $\mathrm{Ti}=30,47$ vs 39,1 dias) e semelhante para Ross 308 ( $\mathrm{Ti}=31,20$ dias vs 30,5 dias). Todavia estas diferenças no presente estudo sobre linhagens, em ambos os sexos, foram decorrentes dos diferentes fatores existentes entre os estudos.

Figura 19 - Curva e taxa de crescimento do peso de coxa em linhagens Cobb 500 $(\mathrm{C})$, Ross $308(\mathrm{R})$, Hubbard Flex $(\mathrm{H})$, machos e fêmeas, segundo modelo de Gompertz*
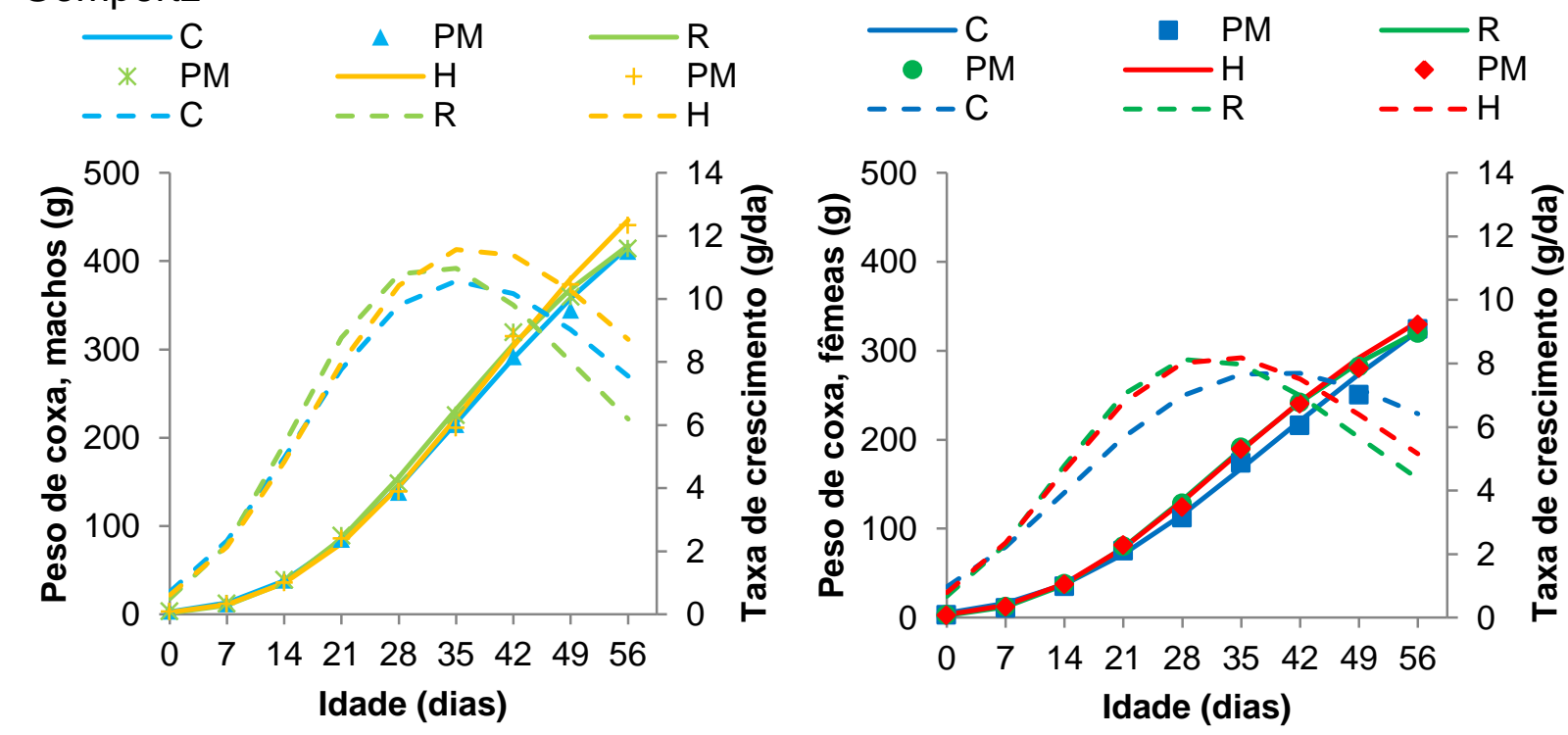

${ }^{*}$ Curvas de peso - linha contínua (F) e tracejada com ponto (M); Taxa de crescimento - linha tracejada; PM peso médio observado para respectiva linhagem e sexo. Fonte: Própria autoria. 
No estudo de Nikolova e Pavlovski (2009) não foram encontradas diferenças estatísticas para o peso e rendimento de coxa entre frangos Cobb 500 e Hubbard Classic, sendo que no presente estudo a linhagem Hubbard Flex teve superior ganho máximo de peso que Cobb 500.

\subsubsection{Crescimento de sobrecoxa}

Os parâmetros e propriedades da curva de Gompertz sobre o crescimento do peso de sobrecoxa dos frangos de corte estão na Tabela 22. O ganho de peso médio diário de sobrecoxa, em intervalos de sete dias, das linhagens de Cobb 500, Ross 308 e Hubbard Flex, machos e fêmeas, estão apresentados na Tabela 23, neste peso inclui osso e pele de duas sobrecoxas. Verifica-se que frangos machos tiveram maior $(P<0,05)$ peso à maturidade com maior $(P<0,05)$ velocidade de maturação com superior taxa máxima de crescimento de sobrecoxa que fêmeas, porém não foi obtido valor significativo entre sexo para o ponto de inflexão podendo observar, numericamente, que os frangos machos chegaram mais cedo ao PI da curva de sobrecoxa do que fêmeas.

Tabela 22 - Médias e erros-padrões das estimativas dos parâmetros (a, b e k), taxa máxima de crescimento (TMC) e da idade de inflexão (Ti) do modelo de Gompertz sobre o peso de sobrecoxa de frangos machos $(M)$ e fêmeas $(F)$ das linhagens Cobb 500 (C), Ross 308 (R) e Hubbard Flex (H)

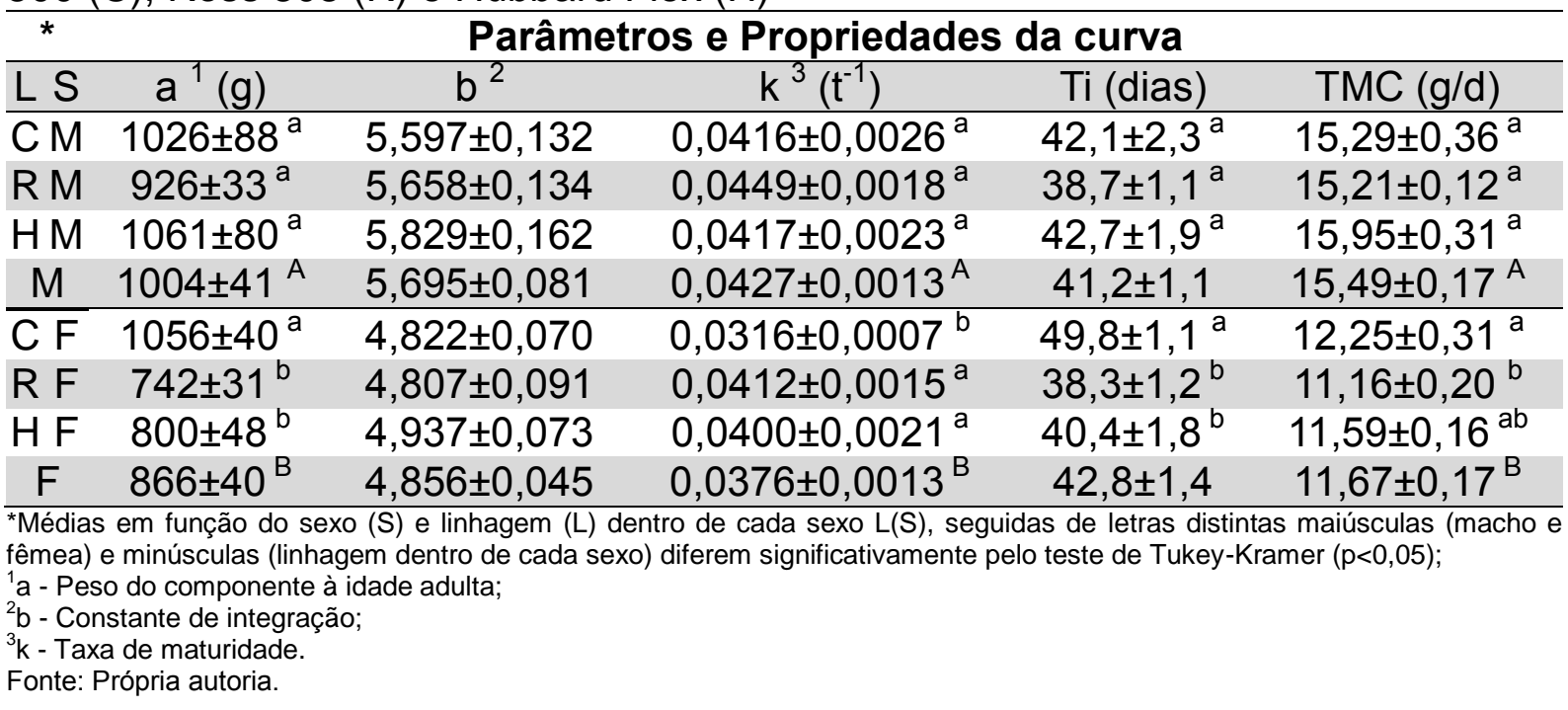


Tabela 23 - Média de ganho diário de peso de sobrecoxa (g) de frangos machos (M) e fêmeas $(F)$ das linhagens Cobb $500(C)$, Ross $308(R)$ e Hubbard Flex $(H)$, em intervalos de 7 dias, segundo modelo de Gompertz

\begin{tabular}{cccccccccc}
\hline \multicolumn{1}{c}{$*$} & \multicolumn{7}{c}{ Idade (dias) } \\
\hline L S & 0 & 7 & 14 & 21 & 28 & 35 & 42 & 49 & 56 \\
\hline C M & 0,89 & 2,72 & 5,85 & 9,63 & 12,99 & 15,09 & 15,69 & 15,00 & 13,48 \\
R M & 0,82 & 2,77 & 6,16 & 10,14 & 13,42 & 15,11 & 15,15 & 13,93 & 12,04 \\
H M & 0,76 & 2,48 & 5,57 & 9,48 & 13,09 & 15,48 & 16,28 & 15,71 & 14,20 \\
M & 0,82 & 2,65 & 5,86 & 9,75 & 13,17 & 15,23 & 15,71 & 14,88 & 13,24 \\
\hline C F & 1,30 & 2,71 & 4,67 & 6,93 & 9,09 & 10,81 & 11,89 & 12,28 & 12,06 \\
R F & 1,20 & 3,00 & 5,54 & 8,17 & 10,17 & 11,15 & 11,11 & 10,30 & 9,06 \\
H F & 1,13 & 2,86 & 5,37 & 8,08 & 10,28 & 11,52 & 11,72 & 11,10 & 9,94 \\
F & 1,21 & 2,85 & 5,20 & 7,73 & 9,85 & 11,16 & 11,57 & 11,23 & 10,36 \\
\hline
\end{tabular}

*Linhagem (L) e Sexo (S)

Fonte: Própria autoria.

Dentro de sexo, notou-se que não houve diferença entre as linhagens de machos para os parâmetros da curva de sobrecoxa, entretanto entre as linhagens de fêmeas observou-se que a linhagem Cobb 500 apresentou o maior peso de sobrecoxa à maturidade com a menor velocidade de maturação e assim idade de inflexão da curva tardia em relação às linhagens Ross 308 e Hubbard Flex, fêmeas. Além do maior $\mathrm{Ti}$ as aves Cobb 500 fêmeas obtiveram a maior taxa máxima de crescimento de sobrecoxa, apresentando deste modo aumento do ganho de peso diário nas últimas idades do estudo, enquanto que as demais linhagens de fêmeas e machos diminuíam o ganho de peso de sobrecoxa (Figura 20).

Goliomytis, Panopoulou e Rogdakis (2003), estimaram "a" (359 g) e "k" (0,034 t1) para a curva de sobrecoxa de frangos machos com dia de inflexão de 47 dias, sendo que os valores dos parâmetros encontrados no presente trabalho são superiores, exceto para o $\mathrm{Ti}$, aos achados por estes autores, assim como observado por Marcato (2007) que encontrou diferenças para o peso de sobrecoxa entre as linhagens e sexo para "a" (macho Cobb $500=1095,56$ g; macho Ross $308=799,70$ g; fêmea Cobb 500 = 690,55 g; fêmea Ross $308=615,69 \mathrm{~g}$ ), "k" (macho Cobb $500=$ $0,037 \mathrm{t}^{-1}$; macho Ross $308=0,048 \mathrm{t}^{-1}$; fêmea Cobb $500=0,043 \mathrm{t}^{-1}$; fêmea Ross 308 $=0,048 \mathrm{t}^{-1}$ ) e Ti (macho Cobb $500=46,03$ dias; macho Ross $308=37,97$ dias; fêmea Cobb 500 = 39,53 dias; fêmea Ross $308=36,82$ dias), concluindo que macho Cobb 500 foi mais tardio para alcançar o ponto de inflexão do que macho Ross, colaborando em partes com o presente estudo, em que macho Cobb $500(\mathrm{Ti}=42,1$ 
Figura 20 - Curvas e taxa de crescimento do peso de sobrecoxa em linhagens Cobb $500(\mathrm{C})$, Ross $308(\mathrm{R})$, Hubbard Flex $(\mathrm{H})$, machos e fêmeas, segundo modelo de Gompertz*
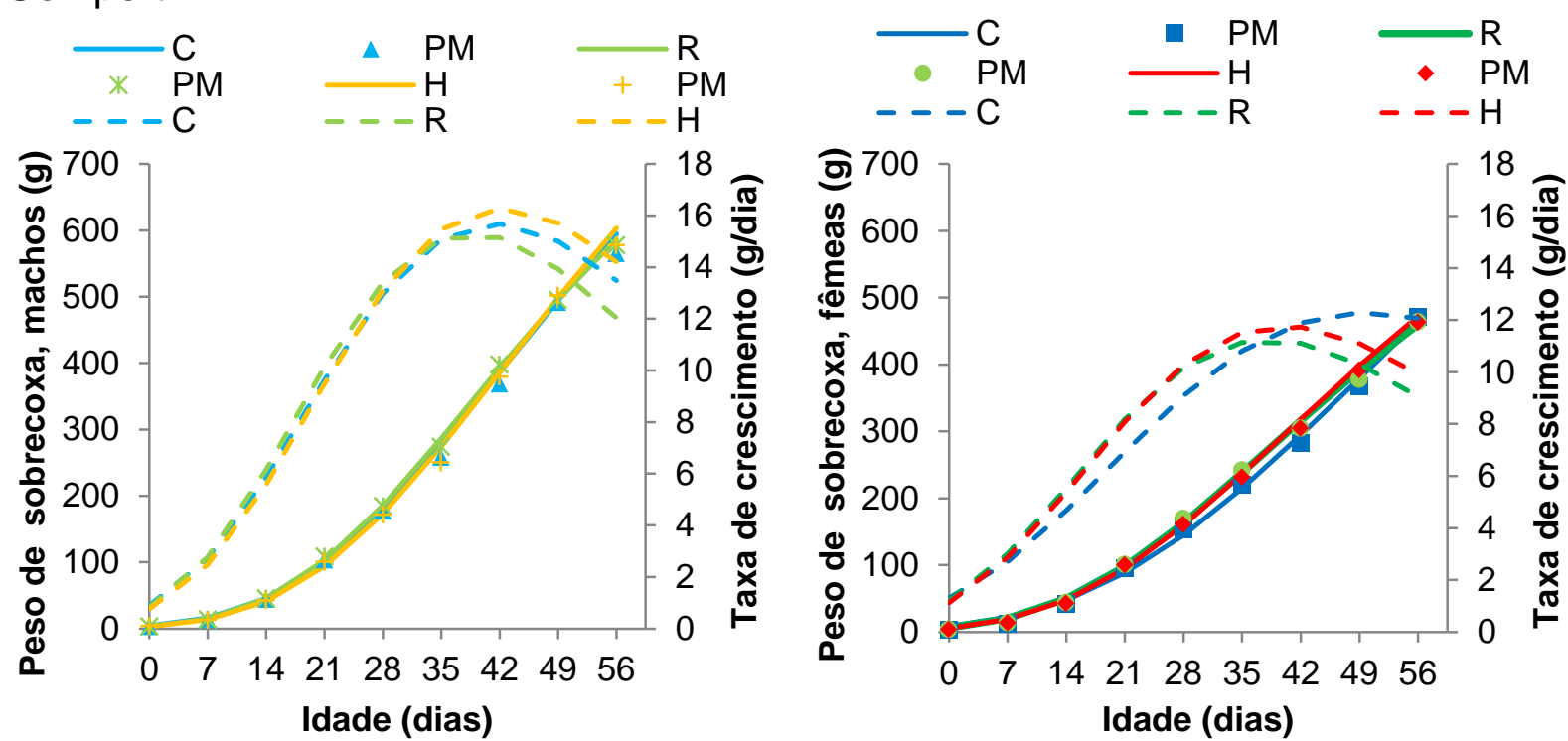

*Curvas de peso - linha contínua (F) e tracejada com ponto (M); Taxa de crescimento - linha tracejada; PM peso médio observado para respectiva linhagem e sexo.

Fonte: Própria autoria.

dias) obteve $\mathrm{Ti}$ semelhante $(P>0,05)$ a macho Ross $308(\mathrm{Ti}=38,7$ dias $)$, apesar da idade de inflexão na curva apresentar valor numericamente maior para macho Cobb 500, e entre fêmeas a linhagem Cobb $500(\mathrm{Ti}=49,8$ dias $)$ apresentou-se mais tardia $(\mathrm{P}<0,05)$ do que Ross 308 ( $\mathrm{Ti}=38,3$ dias $)$.

Assim, admite-se maior precocidade e ganho sobre as partes da carcaça do frango de corte atual devido à maior pressão de seleção genética nas aves nas ultimas décadas.

\subsubsection{Crescimento de asa}

Os parâmetros da curva de Gompertz sobre o peso da asa estão apresentados na Tabela 24 e os ganhos de peso médio diário de asa das linhagens dentro de cada sexo de frangos de corte, em intervalos de sete dias, estão exibidos na Tabela 25, este peso inclui osso e pele de duas asas. O parâmetro de peso à maturidade (a) de asa foi maior $(P<0,05)$ para os machos, no qual macho Hubbard Flex apresentou média superior $(P<0,05)$ seguida do macho Ross 308 , sendo que macho Cobb 500 apresentou valor semelhante estatisticamente $(P>0,05)$ em relação as demais linhagens de macho. As aves fêmeas apresentaram menores $(P<0,05)$ 
Tabela 24 - Médias e erros-padrões das estimativas dos parâmetros (a, b e k), (Ti) taxa máxima de crescimento (TMC) e da idade de inflexão (Ti) do modelo de Gompertz sobre os peso da asa de frangos machos $(M)$ e fêmeas $(F)$ das linhagens Cobb $500(\mathrm{C})$, Ross $308(\mathrm{R})$ e Hubbard Flex (H)

\begin{tabular}{|c|c|c|c|c|c|}
\hline * & \multicolumn{5}{|c|}{ Parâmetros e Propriedades da curva } \\
\hline L S & $a^{1}(g)$ & $b^{2}$ & $\mathrm{k}^{3}\left(\mathrm{t}^{-1}\right)$ & Ti (dias) & TMC $(g / d)$ \\
\hline$\overline{C M}$ & $528 \pm 23^{a b}$ & $4,877 \pm 0,063$ & $0,0421 \pm 0,0015^{b}$ & $37,8 \pm 1,2^{a}$ & $8,12 \pm 0,10^{b}$ \\
\hline $\mathrm{RM}$ & $432 \pm 15^{b}$ & $5,302 \pm 0,160$ & $0,0520 \pm 0,0022^{a}$ & $32,2 \pm 0,8^{b}$ & $8,21 \pm 0,08{ }^{a b}$ \\
\hline $\mathrm{HM}$ & $531 \pm 32^{a}$ & $5,175 \pm 0,073$ & $0,0442 \pm 0,0021^{b}$ & $37,5 \pm 1,5^{\mathrm{a}}$ & $8,53 \pm 0,14^{a}$ \\
\hline$M$ & $497 \pm 17^{\mathrm{A}}$ & $5,118 \pm 0,073$ & $0,0461 \pm 0,0015$ & $35,8 \pm 0,9$ & $8,29 \pm 0,07^{A}$ \\
\hline$\overline{\mathrm{CF}}$ & $437 \pm 29^{a}$ & $4,432 \pm 0,073$ & $0,0401 \pm 0,0024^{b}$ & $37,7 \pm 1,9^{a}$ & $6,32 \pm 0,12^{b}$ \\
\hline $\mathrm{R} F$ & $348 \pm 14^{b}$ & $4,687 \pm 0,145$ & $0,0510 \pm 0,0026^{a}$ & $30,5 \pm 1,0^{b}$ & $6,45 \pm 0,09^{a b}$ \\
\hline $\mathrm{HF}$ & $458 \pm 32^{a}$ & $4,496 \pm 0,046$ & $0,0407 \pm 0,0022^{b}$ & $37,4 \pm 1,9^{a}$ & $6,74 \pm 0,14^{a}$ \\
\hline $\mathrm{F}$ & $414 \pm 18^{B}$ & $4,538 \pm 0,059$ & $0,0439 \pm 0,0018$ & $35,2 \pm 1,2$ & $6,50 \pm 0,08^{B}$ \\
\hline
\end{tabular}

${ }^{*}$ Médias em função do sexo (S) e linhagem (L) dentro de cada sexo $L(S)$, seguidas de letras distintas maiúsculas (macho e fêmea) e minúsculas (linhagem dentro de cada sexo) diferem significativamente pelo teste de TukeyKramer $(p<0,05)$;

$1 \mathrm{a}$ - Peso do componente à idade adulta;

'b - Constante de integração;

${ }^{3} \mathrm{k}$ - Taxa de maturidade.

Fonte: Própria autoria.

Tabela 25 - Média de ganho diário de peso de asa (g) de frangos machos (M) e fêmeas (F) das linhagens Cobb 500 (C), Ross 308 (R) e Hubbard Flex (H), em intervalos de 7 dias, segundo modelo de Gompertz

\section{Idade (dias)}

\begin{tabular}{cccccccccc}
\hline L S & 0 & 7 & 14 & 21 & 28 & 35 & 42 & 49 & 56 \\
\hline C M & 0,83 & 2,14 & 4,03 & 5,98 & 7,45 & 8,13 & 8,05 & 7,42 & 6,47 \\
R M & 0,59 & 2,08 & 4,45 & 6,75 & 8,07 & 8,18 & 7,39 & 6,16 & 4,85 \\
H M & 0,69 & 2,00 & 4,04 & 6,23 & 7,87 & 8,61 & 8,47 & 7,70 & 6,62 \\
M & 0,70 & 2,07 & 4,17 & 6,32 & 7,80 & 8,31 & 7,97 & 7,09 & 5,98 \\
\hline C F & 0,92 & 2,06 & 3,53 & 4,95 & 5,97 & 6,42 & 6,33 & 5,85 & 5,14 \\
R F & 0,76 & 2,19 & 4,09 & 5,71 & 6,47 & 6,35 & 5,63 & 4,65 & 3,65 \\
H F & 0,94 & 2,15 & 3,73 & 5,27 & 6,37 & 6,84 & 6,73 & 6,19 & 5,42 \\
F & 0,87 & 2,13 & 3,79 & 5,31 & 6,27 & 6,54 & 6,23 & 5,56 & 4,74 \\
\hline
\end{tabular}

*Linhagem (L) e Sexo (S)

Fonte: Própria autoria.

valores de "a" havendo distinção da linhagem Ross 308 em relação às linhagens Cobb 500 e Hubbard Flex, apresentando o menor peso $(P<0,05)$ à maturidade e maior precocidade para atingir o $\mathrm{PI}$.

Não foi verificada diferença $(P>0,05)$ entre sexo para "k", 'Ti” de peso de asa, porém frangos machos tiveram maior $(\mathrm{P}<0,05)$ ganho de peso diário no $\mathrm{Pl}$ do que fêmeas. Dentre as linhagens, Cobb 500 e Hubbard Flex, apresentaram padrão comum de efeito dentro de cada sexo para "k", "Ti" e TMC, sendo que Hubbard Flex 
obteve superior $(P<0,05)$ TMC que Cobb 500 e para Ross 308 o TMC foi semelhante $(P>0,05)$ à Hubbard Flex, porém com PI mais precoce $(P<0,05)$. Na Figura 21 podese observar que machos ganham mais peso de asa que fêmeas e que a linhagem Ross 308, machos e fêmeas, possuem PI menor que as demais linhagens chegando a vida adulta com menor peso de asa sendo o PI na curva mais tardio para as linhagens Cobb 500 e Hubbard Flex.

Marcato (2007) em estudo de crescimento de asa de frangos observou que macho Cobb 500 apresentou inferior valor de "k" $\left(0,045 \mathrm{t}^{-1}\right)$ e superior de "a" $(462,17$ g) e Ti (35,97 dias) do que o macho Ross 308 (a=430,51 g; $k=0,051 \mathrm{t}^{-1}$ e Ti=33,59 dias), tendo semelhança dos parâmetros para as fêmeas Cobb 500 (a=313,09 g; k= $0,052 \mathrm{t}^{-1}$ e $\mathrm{Ti}=30,98$ dias) e Ross 308 ( $\mathrm{a}=330,09 \mathrm{~g} ; \mathrm{k}=0,052 \mathrm{t}^{-1}$ e Ti=31,71 dias), no entanto no presente estudo fêmeas da linhagem Cobb 500 obtiveram maior peso à maturidade com menor Ti do que fêmea Ross 308 e apesar de numericamente superior, macho Cobb 500 apresentou semelhante "a" em relação a macho Ross 308 (Tabela 24).

A seleção genética pode resultar em diferentes padrões de crescimento do frango de corte, bem como das partes da carcaça. No atual estudo para as linhagens e sexo, Ross 308 (macho e fêmea) apresentou maior precocidade de

Figura 21 - Curvas e taxa de crescimento do peso de asa em linhagens Cobb 500 $(\mathrm{C})$, Ross $308(\mathrm{R})$, Hubbard Flex $(\mathrm{H})$, machos e fêmeas, segundo modelo de Gompertz*

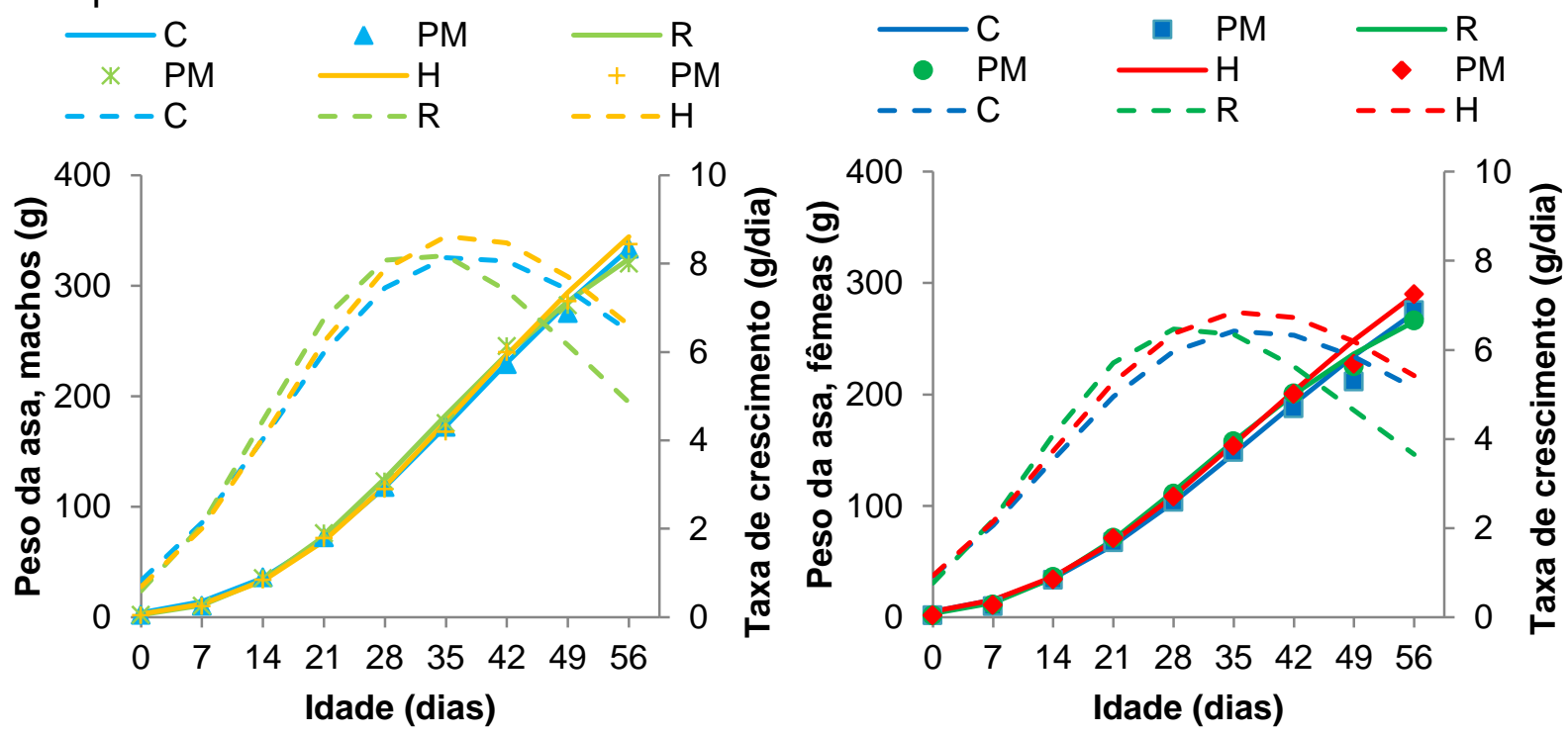

${ }^{*}$ Curvas de peso - linha contínua (F) e tracejada com ponto (M); Taxa de crescimento - linha tracejada; PM peso médio observado para respectiva linhagem e sexo.

Fonte: Própria autoria. 
inflexão sobre as curvas dos componentes de carcaça dos frangos, chamando a atenção para as linhagens Cobb 500 (macho e fêmea) e Hubbard Flex (macho e fêmea) que apresentaram PI da curva mais tardia em todas as características e para a característica de peso de peito da linhagem Cobb 500 que apresentou maior TMC ( $\mathrm{g} / \mathrm{dia}$ ) dentro de cada sexo alcançando ao final do período experimental o maior peso de peito (macho Cobb 500 $=1074 \mathrm{~g}$ e fêmea Cobb $500=930 \mathrm{~g}$ ). Para o peso de coxa observa-se que Hubbard Flex apresentou maior e mais tarde ponto de inflexão da curva de coxa, chegando ao final do período experimental com maior peso de coxa (macho Hubbard $=440,9 \mathrm{~g}$ e fêmea Hubbard $=329,6 \mathrm{~g}$ ), sendo o mesmo observado para asa (Hubbard macho $=337,3 \mathrm{~g}$ e Hubbard fêmea $=290,1 \mathrm{~g}$ ).

Outro ponto observado foi diferentes PI dos componentes da carcaça, que para o peso de peito o crescimento foi mais tardia $($ machos $=44,1$ dias e fêmeas $=$ 54,9 dias) seguido do peso da sobrecoxa (machos $=41,2$ dias e fêmeas $=42,8$ dias), peso de asa (machos $=35,8$ dias e fêmeas $=35,2$ dias) e peso de coxa ( machos $=35,3$ dias e fêmeas $=34,2$ dias $)$.

Marcato (2007) constataram que o peito, a coxa, e sobrecoxa de frangos Cobb 500 mostrou-se mais precoce com melhores taxas de crescimento do que frangos de Ross 308 , sendo que no presente estudo as aves Ross 308 foram mais precoces com maior taxa de crescimento para as características de carcaça e suas partes do que Cobb 500, exceto para peito, o que indica uma mudança sobre a atual linhagem Ross 308 para as demais partes da carcaça. Danisman e Gous (2011; 2013), estudaram o comportamento do crescimento de linhagens e sexos de frangos de corte utilizando diferentes níveis de proteína na dieta e perceberam que frangos Cobb 500 tiveram maior peso corporal e de peito do que as aves de Ross 788 e Ross 308, porém foi observado peso inicial de Cobb 500 maior em relação às demais linhagens. Nikolova e Pavlovski (2009) relataram semelhante peso de peito, coxa e sobrecoxa na linhagem Cobb em comparação com a linhagem Hubbard Classic no qual os machos tiveram maiores pesos que as fêmeas, porém houve maior rendimento de peito para Cobb 500. 
5.3.8 Alometria da carcaça e componentes da carcaça em função da proteína bruta corporal

Na Tabela 26 estão os interceptos (não discutido) e coeficientes das equações alométricas do peso da carcaça, peito, coxa, sobrecoxa e asa em relação à proteína corporal em frangos de corte. Em busca de melhores ajustes foram retirados os valores iniciais de carcaça, peito, asa e proteína bruta $(\mathrm{PB})$ corporal. Percebe-se que o coeficiente alométrico de todas as características foi superior a um (heterogônico positivo), tendo então aumento proporcional destes em relação ao peso proteico do corpo, exceto alguns coeficientes de asa que tiveram coeficientes próximos de um, tendo crescimento constante conforme a deposição de PB no corpo.

Tabela 26 - Médias e erros-padrões das estimativas do intercepto ( $\alpha$ ) e coeficiente de regressão $(\beta)$ alométrico de peso de carcaça, peito, coxa, sobrecoxa e asa em função do peso proteína bruta (PB) corporal de frangos machos (M) e fêmeas $(F)$ das linhagens Cobb $500(\mathrm{C})$, Ross $308(\mathrm{R})$ e Hubbard Flex $(\mathrm{H})^{*}$

\begin{tabular}{|c|c|c|c|c|}
\hline \multicolumn{3}{|c|}{ ** $\ln ($ Carcaça $)=\alpha+\beta \ln ($ PB corporal $)$ * } & \multicolumn{2}{|c|}{$\ln ($ peito $)=\alpha+\beta \ln ($ PB corporal) $* \star$} \\
\hline L S & $\alpha$ & $\beta$ & $\alpha$ & $\beta$ \\
\hline $\mathrm{CM}$ & $1,028 \pm 0,087$ & $1,082 \pm 0,014$ & $-1,096 \pm 0,105$ & $1,245 \pm 0,018^{a}$ \\
\hline $\mathrm{R} M$ & $1,101 \pm 0,073$ & $1,071 \pm 0,013$ & $-0,934 \pm 0,093$ & $1,211 \pm 0,016$ \\
\hline H M & $1,130 \pm 0,059$ & $1,058 \pm 0,010$ & $-0,899 \pm 0,076$ & $1,184 \pm 0,014^{b}$ \\
\hline M & $1,086 \pm 0,041$ & $1,070 \pm 0,007$ & $-0,976 \pm 0,054$ & $1,213 \pm 0,010^{\mathrm{B}}$ \\
\hline $\mathrm{CF}$ & $0,886 \pm 0,058^{b}$ & $1,120 \pm 0,010^{a}$ & $-1,159 \pm 0,057$ & $1,280 \pm 0,011^{a}$ \\
\hline $\mathrm{R} F$ & $1,109 \pm 0,044^{a b}$ & $1,078 \pm 0,008^{b}$ & $-0,977 \pm 0,054$ & $1,238 \pm 0,010^{a b}$ \\
\hline $\mathrm{H} F$ & $1,179 \pm 0,071^{a}$ & $1,063 \pm 0,014^{b}$ & $-0,974 \pm 0,086$ & $1,225 \pm 0,016^{b}$ \\
\hline $\mathrm{F}$ & $1,058 \pm 0,044$ & $1,087 \pm 0,008$ & $-1,037 \pm 0,042$ & $1,248 \pm 0,009^{A}$ \\
\hline \multicolumn{3}{|c|}{$\ln (\operatorname{coxa})=\alpha+\beta \ln (\mathrm{PB}$ corporal $)$} & \multicolumn{2}{|c|}{$\ln ($ sobrecoxa $)=\alpha+\beta \ln ($ PB corporal) } \\
\hline $\mathrm{CM}$ & $-0,817 \pm 0,035$ & $1,060 \pm 0,004$ & $-0,998 \pm 0,043^{b}$ & $1,136 \pm 0,006^{a}$ \\
\hline $\mathrm{R} \mathrm{M}$ & $-0,813 \pm 0,034$ & $1,069 \pm 0,006$ & $-0,910 \pm 0,039^{b}$ & $1,129 \pm 0,007^{a}$ \\
\hline $\mathrm{H} \mathrm{M}$ & $-0,798 \pm 0,032$ & $1,064 \pm 0,004$ & $-0,739 \pm 0,030^{a}$ & $1,091 \pm 0,004^{b}$ \\
\hline M & $-0,809 \pm 0,018$ & $1,064 \pm 0,003$ & $-0,883 \pm 0,033^{B}$ & $1,119 \pm 0,006^{\mathrm{A}}$ \\
\hline $\mathrm{CF}$ & $-0,908 \pm 0,027^{b}$ & $1,080 \pm 0,004^{a}$ & $-1,017 \pm 0,031^{c}$ & $1,151 \pm 0,005^{a}$ \\
\hline $\mathrm{R} F$ & $-0,755 \pm 0,020^{a}$ & $1,056 \pm 0,005^{b}$ & $-0,689 \pm 0,026^{b}$ & $1,090 \pm 0,006^{b}$ \\
\hline H F & $-0,810 \pm 0,034^{a b}$ & $1,071 \pm 0,007^{a b}$ & $-0,555 \pm 0,027^{a}$ & $1,069 \pm 0,005^{c}$ \\
\hline $\mathrm{F}$ & $-0,824 \pm 0,021$ & $1,069 \pm 0,004$ & $-0,754 \pm 0,049^{A}$ & $1,104 \pm 0,009^{B}$ \\
\hline \multicolumn{5}{|c|}{$\ln ($ asa $)=\alpha+\beta \ln (\mathrm{PB}$ corporal) ** } \\
\hline & \multicolumn{2}{|r|}{ r } & \multicolumn{2}{|c|}{$\beta$} \\
\hline$\star * *$ & \multicolumn{2}{|c|}{$-0,730$} & \multicolumn{2}{|c|}{1,018} \\
\hline \multicolumn{5}{|c|}{$\begin{array}{l}{ }^{*} \text { Médias em função do sexo }(S) \text { e linhagem }(L) \text { dentro de cada sexo } L(S) \text {, seguidas de letras distintas maiúsculas } \\
\text { (macho e fêmea) e minúsculas (linhagem dentro de cada sexo) diferem significativamente pelo teste de Tukey- } \\
\text { Kramer ( } p<0,05) ; \\
{ }^{* *} \text { Retirados os valores referentes ao primeiro dia de vida das aves } \\
{ }^{* * *} \text { Intercepto e coeficiente comum para linhagens e sexos. } \\
\text { Fonte: Própria autoria. }\end{array}$} \\
\hline
\end{tabular}


Não houve diferença dos coeficientes alométricos entre machos $(\beta=1,070)$ e fêmeas $(\beta=1,087)$ para o peso de carcaça apenas entre fêmeas, com maior proporção de carcaça com o avanço da idade para fêmeas Cobb 500 ( $\beta=1,120)$, ou seja, mais tardia. Já para o coeficiente da equação alométrica realizada entre o peso de peito e peso proteico corporal, foi observado que fêmeas $(\beta=1,248$ ) tiveram maior valor que machos $(\beta=1,213)$, então de acordo com o aumento de deposição de proteína corporal as fêmeas tiveram maior proporção de peso de peito que machos. Dentre as linhagens machos e fêmeas, Cobb $500\left(\beta_{m}=1,245\right.$ e $\left.\beta_{f}=1,280\right)$ e Ross $308\left(\beta_{\mathrm{m}}=1,211\right.$ e $\left.\beta_{\mathrm{f}}=1,238\right)$, tiveram os maiores coeficientes alométricos de peito em relação a PB corporal, sendo Cobb 500 diferentes estatisticamente de Hubbard Flex $\left(\beta_{\mathrm{m}}=1,184 \mathrm{e} \beta_{\mathrm{f}}=1,225\right)$. Entretanto, Sakomura et al. (2011), observou que machos Cobb $500(\beta=1,158)$ apresentaram superior coeficiente alométrico que machos Ross 308 ( $\beta=1,139)$ e inferior a fêmeas $(\beta=1,217)$.

Os coeficientes alométricos para o peso de coxa em relação ao peso proteico corporal foram semelhantes entre sexo e dentre as linhagens de machos, porém foi observada diferença significativa dentre as linhagens de fêmeas, em que fêmea Cobb 500 ( $\beta=1,080)$ apresentou superior coeficiente que fêmea Ross 308 ( $\beta=$ 1,056). Para sobrecoxa de frangos em função do peso proteico corporal observou-se que machos Cobb 500 e Ross 308 ( $\beta=1,136$ e 1,129, respectivamente) tiveram superiores coeficientes para este gênero. Já entre fêmeas, o maior coeficiente foi de fêmea Cobb 500 ( $\beta=1,151)$ quando comparada à fêmea Ross 308 ( $\beta=1,090)$ e estas tiveram superior coeficiente em relação à fêmea Hubbard Flex $(\beta=1,069)$.

Para o peso de asa em função do peso proteico corporal, não foi verificado diferença entre os coeficientes alométrico para sexo ou entre as linhagens dentro de cada sexo, assim como observado por Sakomura et al. (2011) no qual estudaram equações alométricas de frangos de corte, porém estes autores encontraram coeficientes comuns para o peso de coxa para fêmeas e machos de Cobb 500 e Ross 308, diferente do atual estudo.

\subsubsection{Crescimento do coração}

Os valores dos parâmetros da equação de Gompertz sobre o crescimento do coração estão apresentados na Tabela 27 e na Tabela 28 observa-se o ganho peso médio diário de coração, em intervalos de 7 dias, das linhagens dentro de cada sexo 
Tabela 27 - Médias e erros-padrões das estimativas dos parâmetros (a, b e k), taxa máxima de crescimento (TMC) e da idade de inflexão (Ti) do modelo de Gompertz sobre o coração de frangos machos (M) e fêmeas (F) das linhagens Cobb 500 (C), Ross $308(\mathrm{R})$ e Hubbard Flex $(\mathrm{H})$

\begin{tabular}{cccccc}
\hline \multicolumn{7}{c}{ Parâmetros e Propriedades da curva } \\
\hline L S & $\mathrm{a}^{1}(\mathrm{~g})$ & $\mathrm{b}^{2}$ & $\mathrm{k}^{3}\left(\mathrm{t}^{-1}\right)$ & Ti (dias) & TMC $(\mathrm{g} / \mathrm{d})$ \\
\hline C M & $28,84 \pm 1,83$ & $4,253 \pm 0,131$ & $0,0441 \pm 0,0034^{\mathrm{b}}$ & $33,4 \pm 1,8^{\mathrm{a}}$ & $0,458 \pm 0,013^{\mathrm{b}}$ \\
R M & $25,81 \pm 1,63$ & $5,152 \pm 0,231$ & $0,0595 \pm 0,0034^{\mathrm{a}}$ & $27,8 \pm 1,2^{\mathrm{a}}$ & $0,555 \pm 0,013^{\mathrm{a}}$ \\
H M & $28,34 \pm 1,21$ & $4,590 \pm 0,126$ & $0,0478 \pm 0,0020^{\mathrm{b}}$ & $32,0 \pm 0,9^{\mathrm{a}}$ & $0,494 \pm 0,010^{\mathrm{b}}$ \\
M & $27,29 \pm 0,99$ & $4,767 \pm 0,159$ & $0,0520 \pm 0,0028^{\mathrm{A}}$ & $30,7 \pm 1,0^{\mathrm{B}}$ & $0,507 \pm 0,013^{\mathrm{A}}$ \\
\hline C F & $23,95 \pm 1,90$ & $3,713 \pm 0,100$ & $0,0392 \pm 0,0027$ & $34,3 \pm 2,6^{\text {ab }}$ & $0,337 \pm 0,015^{\mathrm{b}}$ \\
R F & $23,60 \pm 1,20$ & $3,921 \pm 0,190$ & $0,0435 \pm 0,0025$ & $31,6 \pm 1,3^{\mathrm{b}}$ & $0,374 \pm 0,018^{\text {ab }}$ \\
H F & $31,55 \pm 4,27$ & $3,982 \pm 0,111$ & $0,0359 \pm 0,0044$ & $40,5 \pm 4,3^{\mathrm{a}}$ & $0,390 \pm 0,017^{\mathrm{a}}$ \\
F & $26,06 \pm 1,6$ & $3,865 \pm 0,082$ & $0,0397 \pm 0,0019^{\mathrm{B}}$ & $35,2 \pm 1,8^{\mathrm{A}}$ & $0,366 \pm 0,011^{\mathrm{B}}$ \\
\hline
\end{tabular}

${ }^{*}$ Médias em função do sexo (S) e linhagem (L) dentro de cada sexo $L(S)$, seguidas de letras distintas maiúsculas (macho e fêmea) e minúsculas (linhagem dentro de cada sexo) diferem significativamente pelo teste de TukeyKramer $(p<0,05)$;

'a - Peso do componente à idade adulta;

${ }^{2} \mathrm{~b}$ - Constante de integração;

${ }^{3} \mathrm{k}$ - Taxa de maturidade.

Fonte: Própria autoria.

Tabela 28 - Média de ganho diário de peso de coração (g) de frangos machos (M) e fêmeas $(F)$ das linhagens Cobb $500(\mathrm{C})$, Ross $308(\mathrm{R})$ e Hubbard Flex $(\mathrm{H})$, em intervalos de 7 dias, segundo modelo de Gompertz

\begin{tabular}{ccccccccccc}
\multicolumn{2}{c}{$*$} & \multicolumn{10}{c}{ Idade (dias) } \\
\hline L & S & 0 & 7 & 14 & 21 & 28 & 35 & 42 & 49 & 56 \\
\hline C & M & 0,079 & 0,174 & 0,287 & 0,384 & 0,438 & 0,446 & 0,417 & 0,366 & 0,307 \\
R & M & 0,038 & 0,170 & 0,374 & 0,529 & 0,561 & 0,496 & 0,390 & 0,284 & 0,198 \\
H & M & 0,065 & 0,167 & 0,301 & 0,418 & 0,482 & 0,486 & 0,445 & 0,381 & 0,310 \\
M M & 0,061 & 0,170 & 0,321 & 0,443 & 0,494 & 0,476 & 0,417 & 0,344 & 0,272 \\
\hline C & F & 0,084 & 0,152 & 0,226 & 0,286 & 0,321 & 0,329 & 0,315 & 0,286 & 0,248 \\
R & F & 0,081 & 0,167 & 0,260 & 0,332 & 0,366 & 0,361 & 0,329 & 0,284 & 0,234 \\
H & F & 0,084 & 0,147 & 0,220 & 0,288 & 0,342 & 0,374 & 0,383 & 0,373 & 0,348 \\
F F & 0,083 & 0,155 & 0,235 & 0,302 & 0,343 & 0,355 & 0,342 & 0,314 & 0,277 \\
\hline
\end{tabular}

*Linhagem (L) e Sexo (S)

Fonte: Própria autoria.

de frangos de corte machos e fêmeas. Não foi verificada diferença significativa $(P>0,05)$ entre as linhagens dentro e entre sexo para o parâmetro de peso à maturidade (a) de coração e dentre as linhagens de fêmeas a velocidade de maturação $(k)$ também foi semelhante $(P>0,05)$.

Houve diferença $(P<0,05)$ na velocidade de maturação $(k)$ entre as linhagens de machos, no qual macho Ross 308 apresentou superior " $k$ ", com maior $(P<0,05)$ ganho de peso de coração, porem não houve diferença na idade de inflexão da curva (Ti) $(P>0,05)$ entre as linhagens de machos. Foi observado que fêmea 
Hubbard Flex foi mais tardia $(P<0,05)$ que fêmea Ross 308 chegando a diferentes idades de inflexão da curva, porém com ganho máximo de peso de coração semelhante $(P>0,05)$ às fêmeas Ross 308 e superior $(P<0,05)$ à fêmea Cobb 500 .

Observa-se na Figura 22 que a taxa de crescimento do coração nas linhagens de machos foram superiores $(P<0,05)$ as de fêmeas, assim como a apresentada na Tabela 28. As aves da linhagem Ross 308, principalmente fêmeas, apresentaram os maiores ganhos de peso de coração, maior precocidade em relação às demais linhagens, com ligeira queda sobre a taxa de crescimento após o pico de ganho de peso que foi próximo dos 28 dias de idade (Tabela 27).

Marcato et al. (2010) observaram que não houve diferenças entre os parâmetros estimados da curva do peso de coração entre frangos de corte machos e fêmeas, diferente do atual estudo que apresentou diferenças para os " $\mathrm{k}$ " e Ti, no entanto em ambos estudos foi verificado maior taxa de crescimento em machos do que fêmeas a partir dos 14 dias de idade proporcionando maior peso de coração em machos do que em fêmeas a partir dos 21 dias de idade, como observado na Figura 22 para o atual estudo.

Rance, Mcentee e Mcdevitt (2002), observaram que o critério de seleção através do ganho de peso corporal tem aumentado à proporção de carcaça em frangos de corte tendendo assim a maior proporção de carne magra e menor de

Figura 22 - Curvas e taxas de crescimento de coração em linhagens Cobb 500 (C), Ross $308(\mathrm{R})$, Hubbard Flex $(\mathrm{H})$, machos e fêmeas, segundo modelo de Gompertz*

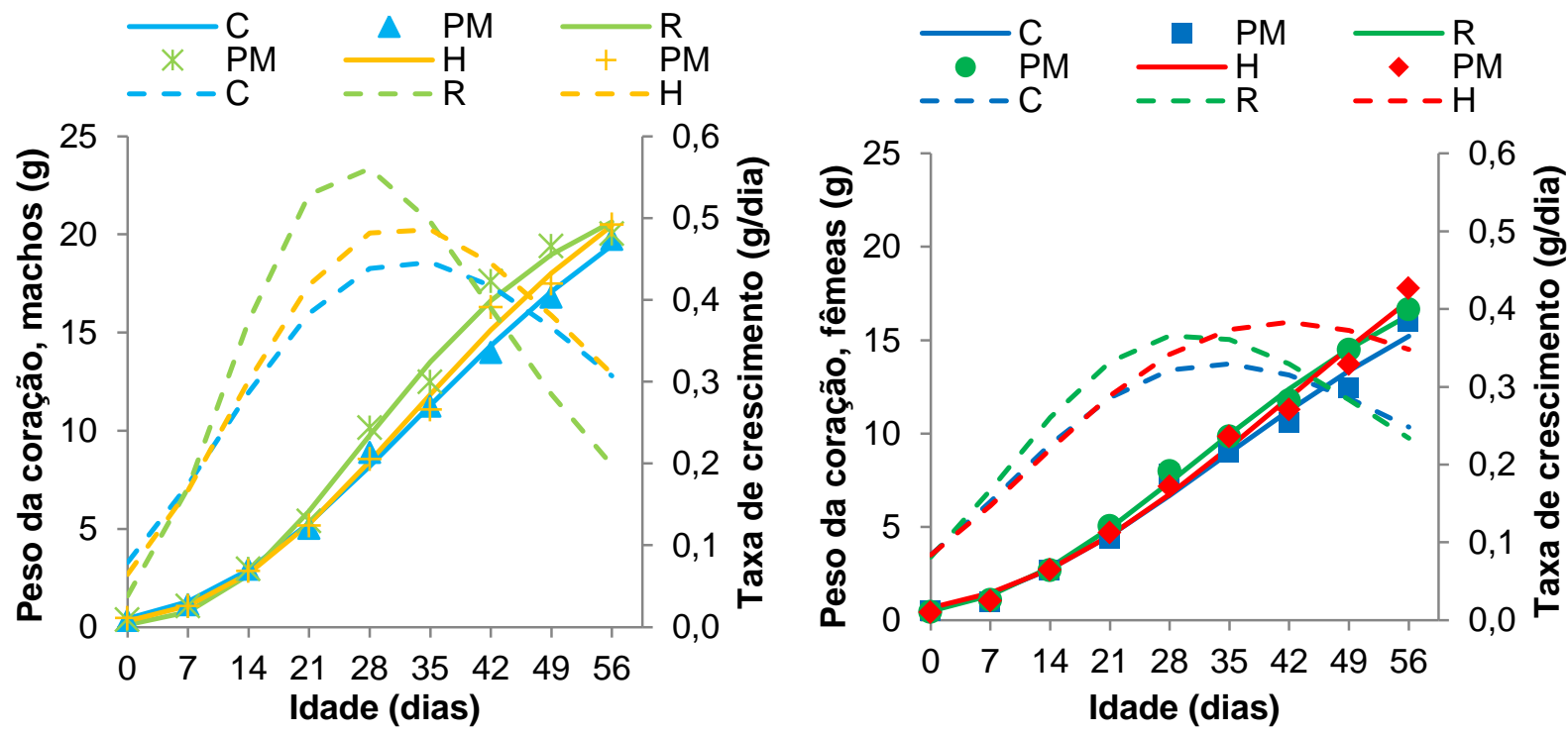

${ }^{*}$ Curvas de peso - linha contínua (F) e tracejada com ponto (M); Taxa de crescimento - linha tracejada; PM peso médio observado para respectiva linhagem e sexo.

Fonte: Própria autoria. 
órgãos e estes autores observaram ainda que a continuidade desse critério de seleção de frangos pode aumentar a incidência de doenças metabólicas, principalmente a ascite, prejudicando a saúde da ave e podendo levar a morte.

No atual estudo foi registrada mortalidade total (aves de descarte + morte desconhecida) de 82 aves, com 61\% de morte para machos e 39\% de fêmeas, sendo a linhagem Cobb 500 com maior mortalidade $(46,4 \%)$ dentre as linhagens estudadas. Como o objetivo deste estudo não incluía a avaliação da causa do óbito destas aves não foi possível inferir sobre a causa da morte destas.

Observando a taxa de maturidade $(k)$ dos frangos machos pode-se verificar que estes possuem superior "k" para o peso de coração $\left(0,0520 t^{-1}\right)$ quando comparado ao peso corporal apresentado na Tabela $7\left(0,0416 \mathrm{t}^{-1}\right)$, tendo crescimento crescente do peso do coração até os 30,7 dias e de 38,4 dias de idade para o coração e peso corporal de frangos machos, respectivamente. Para as fêmeas, houve menor diferença sobre o valor de "k" entre o peso do coração $(0,0397$ $\left.\mathrm{t}^{-1}\right)$ e peso corporal $\left(0,0379 \mathrm{t}^{-1}\right)$, indicando velocidade de crescimento próxima entre estas características, mas ainda assim houve diferença de 4,5 dias na idade de inflexão da curva destas.

Segundo De Greef et al. (2001), o tamanho relativo do coração é o mais importante indicador de qual ave é mais susceptível a ascite, sendo que o coração é o órgão responsável em suprir sangue para todos os componentes do corpo. Desta maneira, Rance, Mcentee e Mcdevitt (2002) observaram que o peso de coração deve ser incluído na taxa de seleção dos cientistas para prevenir a incidência das doenças metabólicas em linhagens de frangos de corte.

Garcia-Neto e Campos (2004) em estudo sobre a suscetibilidade de síndrome ascítica utilizaram as mesmas linhagens de alto desempenho de frangos de corte do presente trabalho e observaram que machos ganharam mais peso que fêmeas e todas as linhagens apresentaram casos de ascite na quarta semana em diante, com maior tendência de mortes para machos, causada pela maior demanda de oxigênio sobrecarregando os pulmões coração e fígado, e assim extrapolando os limites fisiológicos do sistema cardiopulmonar. Verifica-se que este assunto deve ser motivo de outras pesquisas nas relações comentadas para obter informações mais aprofundadas. 
5.3.10 Crescimento do fígado

Os valores dos parâmetros da equação de Gompertz para o peso de fígado estão na Tabela 29. O ganho de peso médio de fígado estão apresentados na Tabela 30 , em intervalos de 7 dias, para as linhagens de frangos de corte dentro de cada sexo. Não foi verificada diferença significativa $(P>0,05)$ para o parâmetro de peso à maturidade (a) entre as linhagens de fêmeas e parâmetros "k" e Ti entre machos.

Tabela 29 - Médias e erros-padrões das estimativas dos parâmetros (a, b e k), taxa máxima de crescimento (TMC) e da idade de inflexão (Ti) do modelo de Gompertz sobre o fígado de frangos machos (M) e fêmeas (F) das linhagens Cobb $500(C)$, Ross $308(\mathrm{R})$ e Hubbard Flex $(\mathrm{H})$

\begin{tabular}{cccccc}
\hline${ }^{*}$ & \multicolumn{5}{c}{ Parâmetros e Propriedades da curva } \\
\hline L S & $\mathrm{a}^{1}(\mathrm{~g})$ & $\mathrm{b}^{2}$ & $\mathrm{k}^{3}\left(\mathrm{t}^{-1}\right)$ & Ti (dias) & TMC $(\mathrm{g} / \mathrm{d})$ \\
\hline C M & $94,02 \pm 4,28^{\mathrm{b}}$ & $4,852 \pm 0,193$ & $0,0610 \pm 0,0031^{\mathrm{a}}$ & $26,0 \pm 0,9^{\mathrm{a}}$ & $2,10 \pm 0,05^{\mathrm{b}}$ \\
RM & $108,06 \pm 6,90^{\mathrm{ab}}$ & $4,882 \pm 0,182$ & $0,0602 \pm 0,0035^{\mathrm{a}}$ & $26,6 \pm 1,2^{\mathrm{a}}$ & $2,35 \pm 0,05^{\mathrm{a}}$ \\
H M & $124,02 \pm 6,24^{\mathrm{a}}$ & $4,530 \pm 0,150$ & $0,0488 \pm 0,0022^{\mathrm{a}}$ & $31,1 \pm 1,1^{\mathrm{a}}$ & $2,21 \pm 0,04^{\mathrm{ab}}$ \\
M & $107,80 \pm 4,37^{\mathrm{A}}$ & $4,768 \pm 0,104$ & $0,0571 \pm 0,0021$ & $27,7 \pm 0,8$ & $2,22 \pm 0,04^{\mathrm{A}}$ \\
\hline C F & $94,22 \pm 6,37^{\mathrm{a}}$ & $3,775 \pm 0,063$ & $0,0465 \pm 0,0037^{\mathrm{b}}$ & $29,3 \pm 2,0^{\mathrm{a}}$ & $1,57 \pm 0,04^{\mathrm{b}}$ \\
R F & $85,74 \pm 6,54^{\mathrm{a}}$ & $4,386 \pm 0,223$ & $0,0635 \pm 0,0061^{\mathrm{a}}$ & $23,9 \pm 1,5^{\mathrm{b}}$ & $1,94 \pm 0,07^{\mathrm{a}}$ \\
H F & $100,40 \pm 11,25^{\mathrm{a}}$ & $3,971 \pm 0,109$ & $0,0500 \pm 0,0047^{\text {ab }}$ & $28,5 \pm 2,7^{\text {ab }}$ & $1,77 \pm 0,03^{\mathrm{a}}$ \\
F & $90,04 \pm 3,64^{\mathrm{B}}$ & $4,057 \pm 0,112$ & $0,0546 \pm 0,0032$ & $26,5 \pm 1,1$ & $1,75 \pm 0,05^{\mathrm{B}}$ \\
\hline
\end{tabular}

${ }^{{ }^{*} M e ́ d i a s ~ e m ~ f u n c ̧ a ̃ o ~ d o ~ s e x o ~(S) ~ e ~ l i n h a g e m ~(L) ~ d e n t r o ~ d e ~ c a d a ~ s e x o ~} \mathrm{~L}(\mathrm{~S})$, seguidas de letras distintas maiúsculas (macho e fêmea) e minúsculas (linhagem dentro de cada sexo) diferem significativamente pelo teste de TukeyKramer $(p<0,05)$;

1 a - Peso do componente à idade adulta;

${ }^{2} \mathrm{~b}$ - Constante de integração;

${ }^{3} \mathrm{k}$ - Taxa de maturidade.

Fonte: Própria autoria.

Tabela 30 - Média de ganho diário de peso de fígado (g) de frangos machos (M) e fêmeas $(F)$ das linhagens Cobb 500 (C), Ross $308(R)$ e Hubbard Flex $(H)$, em intervalos de 7 dias, segundo modelo de Gompertz

\begin{tabular}{ccccccccccc}
\multicolumn{2}{c}{$*$} & \multicolumn{7}{c}{ Idade (dias) } \\
\hline L & S & 0 & 7 & 14 & 21 & 28 & 35 & 42 & 49 & 56 \\
\hline C & M & 0,22 & 0,77 & 1,50 & 2,01 & 2,09 & 1,85 & 1,48 & 1,10 & 0,78 \\
R & M & 0,24 & 0,85 & 1,67 & 2,26 & 2,38 & 2,13 & 1,72 & 1,29 & 0,92 \\
H & M & 0,30 & 0,78 & 1,41 & 1,94 & 2,20 & 2,19 & 1,97 & 1,66 & 1,33 \\
M M & 0,25 & 0,80 & 1,53 & 2,07 & 2,23 & 2,06 & 1,72 & 1,35 & 1,01 \\
\hline C & F & 0,38 & 0,78 & 1,20 & 1,50 & 1,61 & 1,55 & 1,37 & 1,15 & 0,93 \\
R & F & 0,30 & 0,92 & 1,62 & 1,98 & 1,92 & 1,61 & 1,22 & 0,87 & 0,60 \\
H & F & 0,36 & 0,85 & 1,38 & 1,71 & 1,76 & 1,60 & 1,33 & 1,05 & 0,79 \\
F & 0,34 & 0,85 & 1,40 & 1,73 & 1,77 & 1,59 & 1,31 & 1,02 & 0,77 \\
\hline
\end{tabular}

*Linhagem (L) e Sexo (S)

Fonte: Própria autoria. 
Os machos apresentaram superiores $(P<0,05)$ peso de fígado adulto (a) e taxa máxima de crescimento com taxa de maturidade e idade de inflexão da curva semelhante $(P>0,05)$ às fêmeas. $O$ peso de fígado na fase adulta de macho Cobb 500 foi inferior $(P<0,05)$ ao macho Hubbard Flex e taxa de máximo ganho inferior $(P<0,05)$ quando comparados ao macho Ross 308. Para as aves fêmeas, foi observado peso de fígado adulto semelhante $(P>0,05)$ entre estas, com superior " $k$ " $(P<0,05)$ e assim menor idade de inflexão da curva $(P<0,05)$ para a linhagem Ross 308 em relação à fêmea Cobb 500 sendo que a taxa de máximo crescimento para esta ultima foi inferior $(P<0,05)$ às demais linhagens de fêmeas.

Quando comparadas taxas de maturidade da curva de crescimento estimadas para o $\mathrm{PC}$ (machos $=0,0416 \mathrm{t}^{-1}$ e fêmeas $=0,0379 \mathrm{t}^{-1}$ ) com o mesmo parâmetro do peso de fígado (machos $=0,0571 \mathrm{t}^{-1}$ e fêmeas $=0,0546 \mathrm{t}^{-1}$ ) pode-se observar que estas foram superiores para o PC apresentando assim inferior idade de inflexão da curva (Tabela 29). Com isso, pode-se dizer que o peso de fígado das linhagens de alto ganho de peso tem ponto de inflexão da curva mais precoce que o PC da ave, possuindo menor rendimento de fígado a partir deste ponto.

Em estudo com crescimento de frangos de corte Marcato et al. (2010) observaram que macho Cobb 500 obtiveram os maiores pesos de fígado na idade adulta $(\mathrm{a}=183,57 \mathrm{~g}$ ) e taxa máxima de crescimento superior $(\mathrm{TMC}=2,28 \mathrm{~g} / \mathrm{dia}) \mathrm{em}$ idade mais tardia ( $\mathrm{Ti}=49$ dias) quando comparado a macho Ross 308 ( $\mathrm{a}=94,68 \mathrm{~g}$, $\mathrm{TMC}=1,64 \mathrm{~g} / \mathrm{dia}$ e $\mathrm{Ti}=28 \mathrm{dias})$, diferente do atual estudo, no qual machos Cobb $500(\mathrm{a}=94,02 \mathrm{~g}, \mathrm{TMC}=2,10 \mathrm{~g} / \mathrm{dia}$ e $\mathrm{Ti}=26 \mathrm{dias})$ e Ross 308 tiveram os maiores ganho de peso com maior taxa de máximo crescimento ( $\mathrm{TMC}=2,35 \mathrm{~g} / \mathrm{dia}$ ) de fígado até a idade de inflexão da curva (26,6 dias) e macho Hubbard Flex ( $\mathrm{a}=124,02 \mathrm{~g}$, $\mathrm{TMC}=1,64 \mathrm{~g} / \mathrm{dia}$ e $\mathrm{Ti}=31,1$ ) diferiram entre as linhagens de macho.

$\mathrm{Na}$ figura 23, pode-se verificar que nas últimas idades o peso de fígado foi superior em frangos machos do que fêmeas, para as linhagens foi observado superior peso de fígado para Ross 308 e Hubbard Flex em relação à linhagem Cobb 500 , sendo que fêmeas Ross 308 tiveram maior precocidade sobre fígado.

O peso de fígado, assim como do coração, tem sido motivo de vários estudos (OLIVEIRA et al. 2006; DE GREEF et al. 2001; MARCATO et al. 2010) pois são órgãos metabolicamente ativos e normalmente comercializados para alimentação humana, tendo este último importante participação na digestão das aves, principalmente na metabolização dos lipídios, que para sintetizarem a gordura 
Figura 23 - Curvas e taxas de crescimento do fígado em linhagens Cobb 500 (C), Ross $308(R)$, Hubbard Flex $(H)$, machos e fêmeas, segundo modelo de Gompertz*
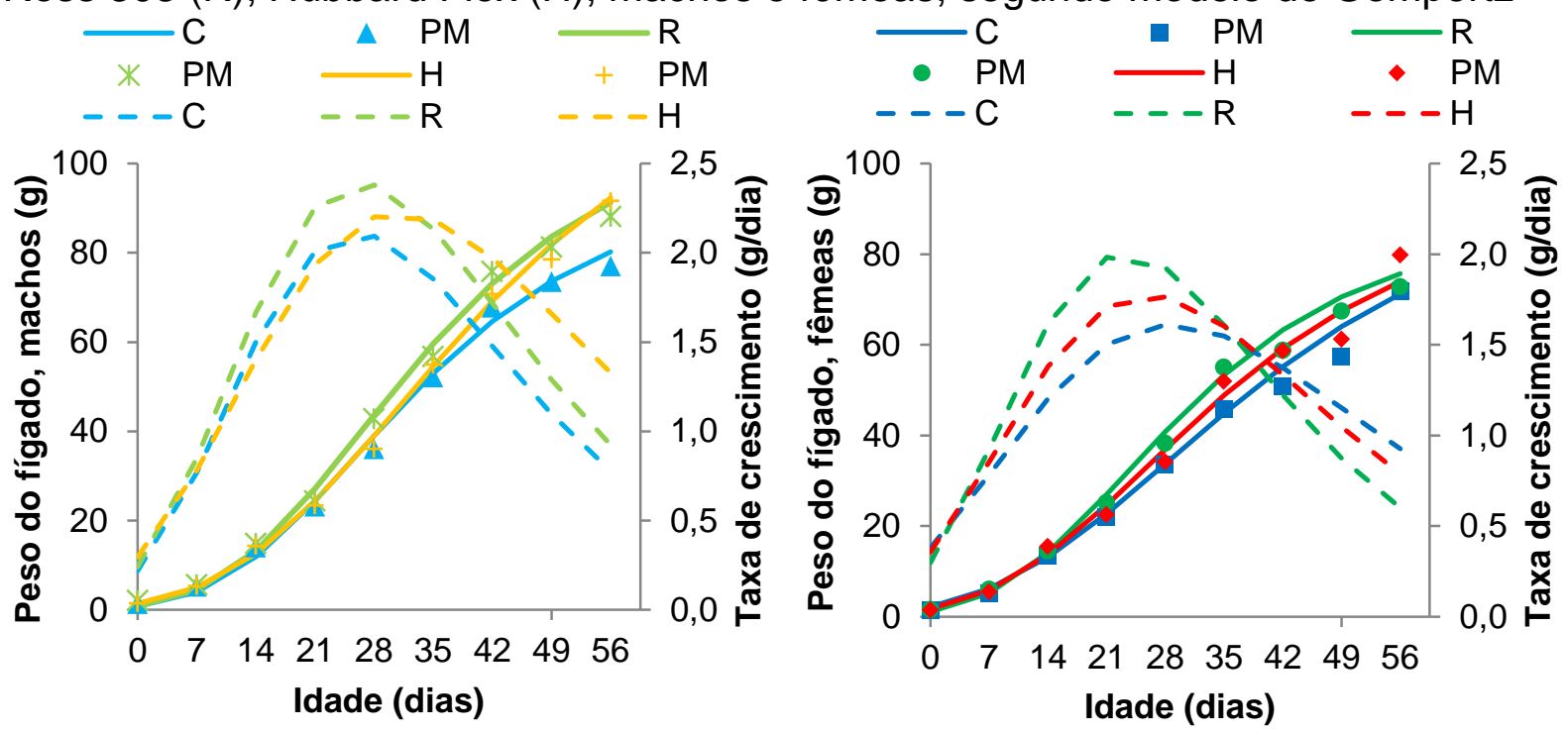

${ }^{*}$ Curvas de peso - linha contínua (F) e tracejada com ponto (M); Taxa de crescimento - linha tracejada; PM peso médio observado para respectiva linhagem e sexo.

Fonte: Própria autoria.

corporal utiliza exclusivamente o fígado, sendo que em mamíferos pode ocorrer no tecido adiposo e fígado (RANCE, MCENTEE E MCDEVITT, 2002).

De Greef et al. (2001) em estudo considerou que o peso de fígado pode ser o segundo melhor preditor de ascite em linhagens de frangos de corte devido a pressão de seleção por maiores rendimentos de carcaça, sendo em primeiro lugar o coração, entretanto Gaya (2003) observaram que pode haver discrepância entre achados na literatura quanto à relação do peso do coração e fígado com o peso de carcaça, já que em seu estudo foi verificado a seleção de maiores carcaças provocava diminuição do peso de fígado, tendo esta característica maior influência que o peso de coração. Em contrapartida, Santos et al. (2005) observaram que a linhagem Cobb 500 apresentaram maiores proporções de fígado que aves caipiras que possui baixo ganho de peso, relacionando este fato a maior capacidade digestiva das linhagens de alto desempenho em relação às de baixo desempenho.

De modo geral, pode-se observar que alterações nestes órgãos (coração e fígado) através da seleção artificial podem acarretar problemas metabólicos em aves podendo ser estudadas com auxilio de curva de crescimento. 


\subsubsection{Crescimento da moela}

Foram estimados a curvas de crescimento para o peso de moela analisados e apresentados na Tabela 31. Na tabela 32 encontra-se o ganho de peso médio de moela observado em intervalos semanais para linhagens de frangos de corte machos e fêmeas até os 56 dias de idade. Não foi observado diferença $(P>0,05)$ entre taxas de maturidade dos frangos machos e fêmeas, no entanto o peso adulto, idade de inflexão e taxa máxima de crescimento foram superiores $(P<0,05)$ em machos.

Tabela 31 - Médias e erros-padrões das estimativas dos parâmetros (a, b e k), taxa máxima de crescimento (TMC) e da idade de inflexão (Ti) do modelo de Gompertz sobre a moela de frangos machos (M) e fêmeas (F) das linhagens Cobb 500 (C), Ross $308(\mathrm{R})$ e Hubbard Flex $(\mathrm{H})$

\begin{tabular}{|c|c|c|c|c|c|}
\hline * & & Parâmetro & Propriedades d & urva & \\
\hline $\mathrm{LS}$ & $a^{1}(g)$ & $b^{2}$ & $k^{3}\left(t^{-1}\right)$ & $\mathrm{Ti}$ (dias) & TMC (g/d) \\
\hline$\overline{C M}$ & $68,13 \pm 2,81^{a}$ & $3,074 \pm 0,074$ & $0,0486 \pm 0,0024^{b}$ & $23,2 \pm 0,9^{a}$ & $1,21 \pm 0,02^{a}$ \\
\hline $\mathrm{R} M$ & $48,67 \pm 1,16^{b}$ & $3,511 \pm 0,092$ & $0,0791 \pm 0,0042^{a}$ & $16,0 \pm 0,5^{b}$ & $1,41 \pm 0,05^{a}$ \\
\hline $\mathrm{H} \mathrm{M}$ & $52,47 \pm 3,25^{b}$ & $3,421 \pm 0,090$ & $0,0688 \pm 0,0052^{a}$ & $18,3 \pm 1,4^{b}$ & $1,30 \pm 0,04^{a}$ \\
\hline $\mathrm{M}$ & $55,73 \pm 2,46^{A}$ & $3,351 \pm 0,066$ & $0,0665 \pm 0,0039$ & $18,9 \pm 0,9^{A}$ & $1,31 \pm 0,03^{A}$ \\
\hline $\mathrm{CF}$ & $48,25 \pm 2,47^{a}$ & $3,310 \pm 0,150$ & $0,0696 \pm 0,0053^{a}$ & $17,5 \pm 1,2^{a}$ & $1,21 \pm 0,05^{a}$ \\
\hline$R F$ & $45,11 \pm 2,32^{a}$ & $3,210 \pm 0,120$ & $0,0725 \pm 0,0045^{a}$ & $16,3 \pm 0,9^{a}$ & $1,18 \pm 0,02^{b}$ \\
\hline $\mathrm{HF}$ & $49,20 \pm 2,92^{a}$ & $3,195 \pm 0,102$ & $0,0681 \pm 0,0059^{a}$ & $17,6 \pm 1,3^{a}$ & $1,20 \pm 0,05^{a b}$ \\
\hline$F$ & $47,52 \pm 1,46^{\mathrm{B}}$ & $3,238 \pm 0,069$ & $0,0700 \pm 0,0029$ & $17,1 \pm 0,6^{B}$ & $1,20 \pm 0,02^{B}$ \\
\hline $\begin{array}{l}\text { Kram } \\
1 \mathrm{a}-\mathrm{P} \\
{ }^{2} \mathrm{~b}-\mathrm{c} \\
{ }^{3} \mathrm{k}-\mathrm{T} \\
\text { Fonte }\end{array}$ & $\begin{array}{l}\text { fêmea) e minú } \\
0<0,05) ; \\
\text { do component } \\
\text { tante de integra } \\
\text { de maturidade. } \\
\text { ópria autoria. }\end{array}$ & $\begin{array}{l}\text { e linhagem (L } \\
\text { (linhagem de } \\
\text { de adulta; }\end{array}$ & $\begin{array}{l}\text { e cada sexo } L(S \\
\text { da sexo) diferen }\end{array}$ & & stintas $m$ \\
\hline
\end{tabular}

Tabela 32 - Média de ganho diário de peso de moela $(\mathrm{g})$ de frangos machos $(\mathrm{M})$ e fêmeas (F) das linhagens Cobb 500 (C), Ross $308(R)$ e Hubbard Flex $(H)$, em intervalos de 7 dias, segundo modelo de Gompertz

\begin{tabular}{|c|c|c|c|c|c|c|c|c|c|}
\hline * & & & & & lade ( & & & & \\
\hline L S & 0 & 7 & 14 & 21 & 28 & 35 & 42 & 49 & 56 \\
\hline $\mathrm{CM}$ & 0,47 & 0,81 & 1,09 & 1,21 & 1,19 & 1,06 & 0,89 & 0,71 & 0,55 \\
\hline $\mathrm{R} M$ & 0,40 & 1,03 & 1,40 & 1,32 & 1,01 & 0,68 & 0,43 & 0,26 & 0,15 \\
\hline $\mathrm{H} \mathrm{M}$ & 0,40 & 0,92 & 1,28 & 1,30 & 1,09 & 0,82 & 0,57 & 0,38 & 0,24 \\
\hline $\mathrm{M}$ & 0,43 & 0,92 & 1,26 & 1,28 & 1,10 & 0,85 & 0,63 & 0,45 & 0,31 \\
\hline$C F$ & 0,41 & 0,89 & 1,20 & 1,20 & 0,99 & 0,73 & 0,50 & 0,33 & 0,21 \\
\hline $\mathrm{R} F$ & 0,42 & 0,91 & 1,19 & 1,14 & 0,90 & 0,64 & 0,43 & 0,27 & 0,17 \\
\hline $\mathrm{H} \mathrm{F}$ & 0,44 & 0,91 & 1,20 & 1,19 & 0,99 & 0,74 & 0,51 & 0,34 & 0,22 \\
\hline $\mathrm{F}$ & 0,42 & 0,91 & 1,20 & 1,18 & 0,96 & 0,70 & 0,48 & 0,31 & 0,20 \\
\hline
\end{tabular}


As estimativas de peso adulto (a) de moela para frangos machos Cobb 500 foram superiores $(P<0,05)$ tendo a menor taxa de maturidade $(k)$ e assim idade de inflexão da curva maior $(P<0,05)$ que as demais linhagens de machos com semelhante $(P>0,05)$ taxa máxima de crescimento. Para fêmeas houve diferença apenas entre a taxa máxima de crescimento, no qual fêmea Cobb 500 teve maior ganho de peso de moela que fêmea Ross 308 no PI da curva.

$\mathrm{Na}$ Figura 24, nota-se que o peso da moela possui inflexão da curva precoce (entre 14 e 21 dias de idade) em relação às outras características analisadas anteriormente e diferenças entre o peso de moela de machos e fêmeas apresentamse a partir dos 28 dias de idade. Macho Cobb 500 apresentou ponto de inflexão da curva de peso de moela mais tarde, tendo este e fêmea Ross 308 apresentados o maior e menor peso de moela ao fim do experimento, respectivamente.

A moela é um órgão muscular que reduz o tamanho da partícula do alimento ingerido e mistura com as enzimas digestivas. Se houver maior atividade mecânica da musculatura lisa longitudinal (músculos intermediários e laterais) da moela, esta pode sofrer hipertrofia ou do contrário pode ocorrer atrofia destes músculos. Quando utilizado alimento (milho ou sorgo) moído finamente $(<600 \mu \mathrm{m})$ existe efeito negativo no tamanho da moela resultando em subdesenvolvimento relativo deste órgão

Figura 24 - Curvas e taxas de crescimento da moela em linhagens Cobb 500 (C), Ross $308(R)$, Hubbard Flex $(H)$, machos e fêmeas, segundo modelo de Gompertz

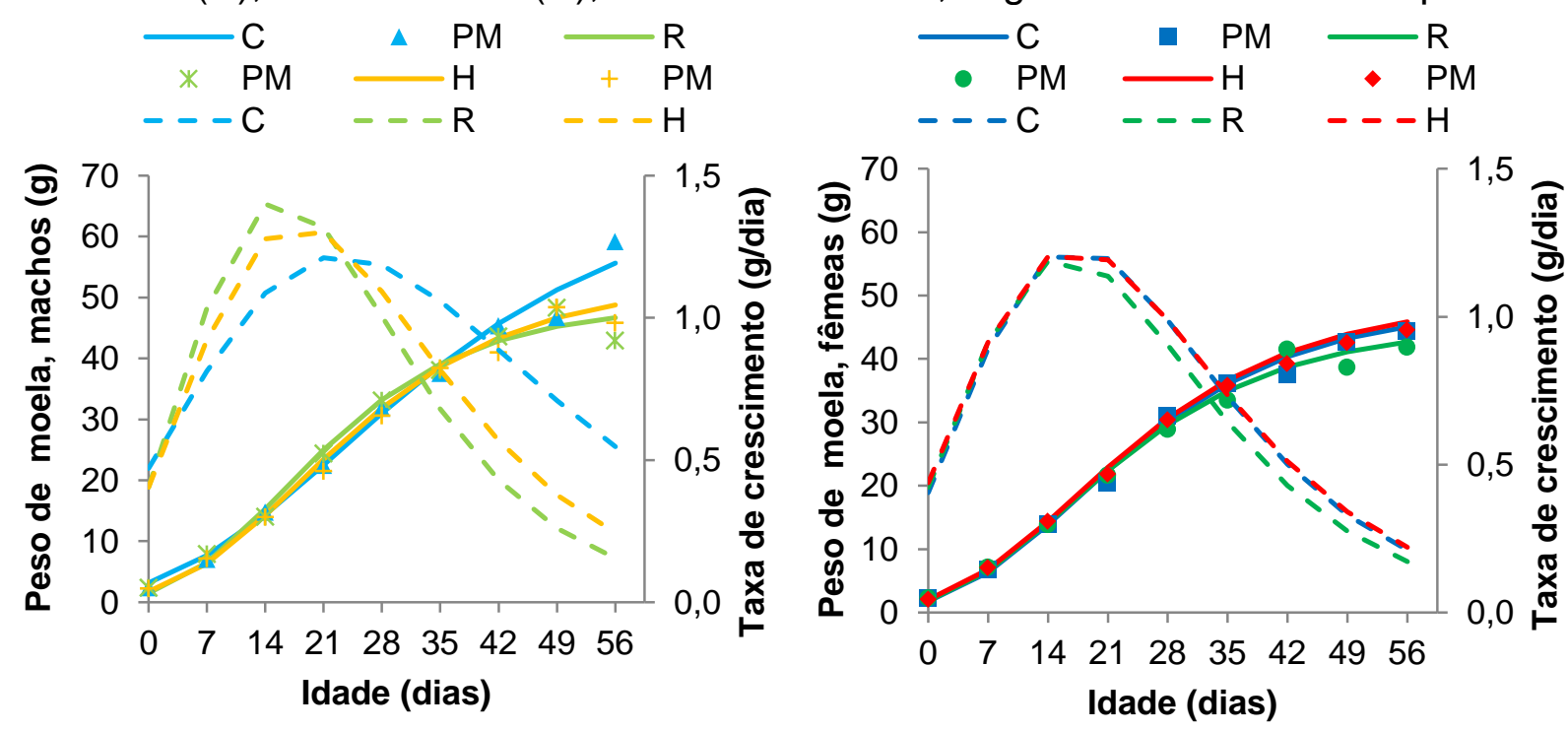

${ }^{*}$ Curvas de peso - linha contínua (F) e tracejada com ponto (M); Taxa de crescimento - linha tracejada; PM peso médio observado para respectiva linhagem e sexo.

Fonte: Própria autoria. 
(atrofia), sendo que o alimento moído mais grosseiramente (600 a $900 \mu \mathrm{m}$ ) obtêm efeito positivo no tamanho da moela (hipertrofia) melhorando o desempenho das aves (AMERAH et al., 2007; RIBEIRO; MAGRO; PENZ Jr, 2002).

No atual estudo foi utilizado milho moído finamente na ração notando baixo gando de peso de moela ao decorrer das idades observadas (Tabela 32), porém não foi possível realizar comparações sobre diferentes granulometria de milho na ração podendo ser objetivo de estudos futuros utilizando diferentes granulometria e curvas de crescimento corporal e de componentes corporais (incluindo a moela) analisando a deposição de nutrientes corporais.

Marcato et al. (2010) verificaram que o peso de moela com gordura à maturidade foi bem superior com menor taxa de maturidade e assim superior ponto de inflexão da curva quando comparados ao presente trabalho que analisou o peso da moela sem gordura (Tabela 31), em que Fêmea Cobb 500 teve peso de moela superior $\left(\mathrm{a}=198,84 \mathrm{~g} ; \mathrm{k}=0,027 \mathrm{t}^{-1} ; \mathrm{Ti}=52,47\right.$ dias) à fêmea Ross 308 ( $\mathrm{a}=148,40 \mathrm{~g}$; $\mathrm{k}=0,031 \mathrm{t}^{-1} ; \mathrm{Ti}=45,40$ dias $)$, não tendo diferenças entre machos Cobb $(\mathrm{a}=125,29$ $\mathrm{g} ; \mathrm{k}=0,036 \mathrm{t}^{-1} ; \mathrm{Ti}=38,47$ dias$)$ e Ross $\left(\mathrm{a}=119,20 \mathrm{~g} ; \mathrm{k}=0,031 \mathrm{t}^{-1} ; \mathrm{Ti}=40,27\right.$ dias $)$, sendo observado o contrário no atual estudo, machos apresentaram diferenças entre si com os maiores pesos à maturidade enquanto que fêmeas não apresentaram maiores diferenças entre as linhagens. Estas diferenças estão relacionadas com os diferentes fatores utilizados entre os estudos, no qual Marcato et al. (2010) utilizaram a gordura da moela para pesagem e uma ração para todos as aves e no atual estudo foi retirada a gordura da moela e utilizado um tipo de dieta para cada sexo, possuindo então diferentes quantidades de milho em cada dieta, podendo resultar em diferenças maiores no peso e idade de inflexão da moela entre machos e fêmeas.

Longo et al. (2005) avaliaram o desenvolvimento inicial de órgãos do trato gastrointestinal (TGI) em frangos agRoss alimentados com diferentes tipos de carboidratos e observaram maior crescimento da moela em relação ao peso vivo nas primeiras 24 horas, seguindo com menor desenvolvimento, sendo que no presente estudo não foram analisados o peso da moela diariamente e sim semanalmente, não sendo possível observar este crescimento nos primeiros dias de vida do animal, mas observou-se que o crescimento máximo da moela foi bem precoce chegando próximo do peso adulto ao final do experimento. 
5.3.12 Alometria dos órgãos em função da proteína bruta corporal

De modo geral, observam-se na Tabela 33 que os pesos de órgãos (coração, fígado e moela) possuem coeficientes alométricos inferiores a um (heterogônico negativo), indicando crescimento proporcionalmente inferior ao peso proteico corporal. No qual o peso dos órgãos aumentam com a idade do animal, mas tem proporções de crescimento menores que a deposição de proteína corporal, tendo as maiores proporções de peso de órgão na fase inicial de vida do animal do que na fase final.

Tabela 33 - Médias e erros-padrões das estimativas do intercepto ( $\alpha$ ) e coeficiente de regressão $(\beta)$ das equações alométricas de peso de coração em função do peso proteico corporal de frangos machos $(M)$ e fêmeas $(F)$ das linhagens Cobb $500(C)$, Ross $308(\mathrm{R})$ e Hubbard Flex $(\mathrm{H})^{\star}$

\begin{tabular}{|c|c|c|}
\hline \multicolumn{3}{|c|}{$\ln ($ coração) $=\alpha+\beta \ln ($ Proteína corporal) } \\
\hline L S & $\alpha$ & $\beta$ \\
\hline $\mathrm{C} \mathrm{M}$ & $-2,712 \pm 0,030^{b}$ & $0,883 \pm 0,007^{a}$ \\
\hline $\mathrm{R} M$ & $-2,695 \pm 0,026^{b}$ & $0,899 \pm 0,006^{a}$ \\
\hline $\mathrm{H} \quad \mathrm{M}$ & $-2,383 \pm 0,037^{a}$ & $0,833 \pm 0,006^{b}$ \\
\hline M & $-2,597 \pm 0,040^{B}$ & $0,872 \pm 0,008^{A}$ \\
\hline $\mathrm{C} F$ & $-2,330 \pm 0,028$ & $0,809 \pm 0,010$ \\
\hline $\mathrm{R} F$ & $-2,381 \pm 0,027$ & $0,826 \pm 0,006$ \\
\hline $\mathrm{H} \quad \mathrm{F}$ & $-2,382 \pm 0,032$ & $0,827 \pm 0,007$ \\
\hline $\mathrm{F}$ & $-2,364 \pm 0,017^{A}$ & $0,821 \pm 0,005^{B}$ \\
\hline \multicolumn{3}{|c|}{$\ln ($ fígado $)=\alpha+\beta \ln ($ Proteína corporal) } \\
\hline C M & $-1,233 \pm 0,036^{c}$ & $0,885 \pm 0,007^{a}$ \\
\hline $\mathrm{R} M$ & $-0,860 \pm 0,027^{a}$ & $0,838 \pm 0,005^{b}$ \\
\hline $\mathrm{H} \quad \mathrm{M}$ & $-1,116 \pm 0,037^{b}$ & $0,876 \pm 0,006^{a}$ \\
\hline M & $-1,070 \pm 0,042$ & $0,866 \pm 0,006$ \\
\hline $\mathrm{C} \mathrm{F}$ & $-1,141 \pm 0,027^{b}$ & $0,878 \pm 0,009$ \\
\hline $\mathrm{R} F$ & $-0,997 \pm 0,018^{a}$ & $0,867 \pm 0,007$ \\
\hline $\mathrm{H} \quad \mathrm{F}$ & $-1,005 \pm 0,040^{a}$ & $0,866 \pm 0,008$ \\
\hline $\mathrm{F}$ & $-1,048 \pm 0,023$ & $0,870 \pm 0,004$ \\
\hline \multicolumn{3}{|c|}{$\ln ($ moela $)=\alpha+\beta \ln ($ Proteína corporal) } \\
\hline $\mathrm{C} \mathrm{M}$ & $-0,258 \pm 0,020^{b}$ & $0,672 \pm 0,003^{a}$ \\
\hline $\mathrm{R} \quad \mathrm{M}$ & $-0,100 \pm 0,019^{a}$ & $0,638 \pm 0,003^{b}$ \\
\hline $\mathrm{H} \quad \mathrm{M}$ & $-0,129 \pm 0,054^{a}$ & $0,638 \pm 0,011^{b}$ \\
\hline M & $-0,162 \pm 0,025$ & $0,649 \pm 0,005$ \\
\hline $\mathrm{C} \quad \mathrm{F}$ & $-0,246 \pm 0,037$ & $0,673 \pm 0,009$ \\
\hline $\mathrm{R} F$ & $-0,175 \pm 0,035$ & $0,652 \pm 0,008$ \\
\hline $\mathrm{H} \quad \mathrm{F}$ & $-0,219 \pm 0,012$ & $0,671 \pm 0,004$ \\
\hline $\mathrm{F}$ & $-0,214 \pm 0,018$ & $0,665 \pm 0,005$ \\
\hline
\end{tabular}

*Médias em função do sexo (S) e linhagem (L) dentro de cada sexo L(S), seguidas de letras distintas maiúsculas (macho e fêmea) e minúsculas (linhagem dentro de cada sexo) diferem significativamente pelo teste de Tukey-Kramer $(p<0,05)$; Fonte: Própria autoria. 
Para os coeficientes alométricos de coração houve diferença entre machos e fêmeas, em que o crescimento do coração apresentou ser superior em machos houve com maiores proporções quando comparados com fêmeas na fase inicial de vida. Dentre os machos, Hubbard Flex obteve inferior valor de coeficiente, ou seja, este teve menor proporção de coração em relação ao depósito de proteína corporal.

Os coeficientes para fígado e moela não tiveram diferenças entre sexo e dentre as fêmeas, porém macho Cobb 500 e macho Hubbard Flex tiveram maiores coeficientes para fígado e macho Cobb 500 tiveram maiores coeficientes para moela. As diferenças encontradas nestes resultados indicam a maior pressão de seleção sobre frangos machos, contribuindo com as diferenças entre as linhagens de machos.

\subsection{ANÁLISE ECONÔMICA}

Para a avaliação econômica foi estimado a partir do consumo de ração (CR) e peso corporal em frangos com jejum de 24 horas (PCJ) através do modelo de Gompertz, sendo o PCJ para o abate predeterminado de $1350 \mathrm{~g}$ e $2350 \mathrm{~g}$ e ainda para a idade de abate predeterminada de 45 dias. A partir dos dados dos modelos foram calculados e analisados a conversão alimentar (CA) e margem bruta (MB) de comercialização para cada linhagem e sexo (Tabela 34).

De acordo com o elucidado, verificou-se que os frangos machos alcançaram $(P<0,05)$ os $P C J$ de $1350 \mathrm{~g}$ e $2350 \mathrm{~g}$ em idade média inferior $(27,1$ e 37,1 dias, respectivamente) ao estimado em fêmeas (29,2 e 41,7 dias, respectivamente), tendo esta diferença aumentada de acordo com o peso predeterminado, em que essa diferença foi de 2,1 dias e 4,6 dias para o frango com pesos de $1350 \mathrm{~g}$ e $2350 \mathrm{~g}$, respectivamente. Machos apresentaram o PCJ médio superior (3169 g) em relação às fêmeas $(2642 \mathrm{~g})$ aos 45 dias de idade.

Em todas as comparações houve melhor $(P<0,05)$ conversão alimentar $(C A)$ e margem bruta (MB) de comercialização para machos. O frango macho Ross 308 teve a menor $(p<0,05)$ idade para alcançar os pesos predeterminados de $1350 \mathrm{~g}$, semelhante a macho Cobb 500, porém sem diferenças entre machos para CA e MB. Entre fêmeas, para o peso de $1350 \mathrm{~g}$, Ross 308 também foi mais precoce e apresentou maior MB de comercialização, junto à fêmea Hubbard Flex que teve menor CA. 
Tabela 34 - Médias de idade ou peso de abate, conversão alimentar (CA) e margem bruta (MB) de comercialização em linhagens e sexo de frangos de corte de acordo com as predeterminações de abate (1350 g, $2350 \mathrm{~g}$ e com 45 dias de idade), utilizando o modelo de Gompertz para estimar o peso corporal em jejum (PCJ) e o consumo de ração

\begin{tabular}{|c|c|c|c|c|c|c|}
\hline \multirow{2}{*}{$\begin{array}{c}\text { Parâmetro } \\
\text { Sexo }\end{array}$} & \multicolumn{2}{|c|}{ Idade(dias) /Peso(g) } & \multicolumn{2}{|c|}{ CA } & \multicolumn{2}{|c|}{ MB } \\
\hline & Macho & Fêmea & Macho & Fêmea & Macho & Fêmea \\
\hline Linhagem & \multicolumn{6}{|c|}{$1350 \mathrm{~g}$} \\
\hline Cobb & $27,1^{b}$ & $30,0^{a}$ & 1,500 & $1,658^{b}$ & 1,01 & $0,83^{b}$ \\
\hline Ross & $26,5^{b}$ & $28,2^{b}$ & 1,503 & $1,586^{b}$ & 1,00 & $0,91^{\mathrm{a}}$ \\
\hline Hubbard & $27,8^{a}$ & $29,4^{a}$ & 1,459 & $1,581^{a}$ & 1,06 & $0,91^{\mathrm{a}}$ \\
\hline \multirow[t]{2}{*}{ Média } & $27,1^{\mathrm{B}}$ & $29,2^{\mathrm{A}}$ & $1,487^{B}$ & $1,608^{\mathrm{A}}$ & $1,02^{\mathrm{A}}$ & $0,88^{B}$ \\
\hline & \multicolumn{6}{|c|}{$2350 \mathrm{~g}$} \\
\hline Cobb & $37,2^{a}$ & $42,8^{a}$ & $1,600^{a b}$ & $1,847^{a}$ & $0,87^{\mathrm{ab}}$ & 0,67 \\
\hline Ross & $36,3^{b}$ & $40,6^{c}$ & $1,629^{a}$ & $1,841^{a b}$ & $0,85^{b}$ & 0,68 \\
\hline Hubbard & $37,7^{\mathrm{a}}$ & $41,7^{b}$ & $1,567^{b}$ & $1,791^{b}$ & $0,91^{\mathrm{a}}$ & 0,71 \\
\hline \multirow[t]{2}{*}{ Média } & $37,1^{\mathrm{B}}$ & $41,7^{\mathrm{A}}$ & $1,600^{B}$ & $1,826^{A}$ & $0,88^{A}$ & $0,69^{B}$ \\
\hline & \multicolumn{6}{|c|}{45 dias } \\
\hline Cobb & $3153^{b}$ & $2529^{c}$ & $1,688^{b}$ & $1,877^{b}$ & $0,79^{a}$ & $0,66^{a}$ \\
\hline Ross & $3252^{a}$ & $2686^{a}$ & $1,775^{a}$ & $1,941^{a}$ & $0,72^{b}$ & $0,61^{b}$ \\
\hline Hubbard & $3120^{b}$ & $2624^{b}$ & $1,676^{b}$ & $1,850^{b}$ & $0,80^{a}$ & $0,68^{a}$ \\
\hline Média & $3175^{A}$ & $2613^{B}$ & $1,713^{B}$ & $1,889^{A}$ & $0,77^{\mathrm{A}}$ & $0,69^{B}$ \\
\hline
\end{tabular}

*Médias em função do sexo (S) e linhagem (L) dentro de cada sexo $L(S)$, seguidas de letras distintas maiúsculas (macho e fêmea) e minúsculas (linhagem dentro de cada sexo) diferem significativamente pelo teste de Tukey-Kramer $(p<0,05)$; Fonte: Própria autoria.

Para alcançar $2350 \mathrm{~g}$, Ross 308 de ambos sexos, foram mais precoce do que as demais linhagens e sexo, porém com a pior CA, junto ao Cobb 500 em idade mais tardia, tendo Hubbard Flex melhor $\mathrm{CA}$ e superior MB para machos e macho Cobb 500 semelhante às demais linhagens de macho. Aos 45 dias de idade, Ross 308, apresentou-se mais pesado que as demais linhagens dentro de cada sexo, porém com pior $\mathrm{CA}$ e $\mathrm{MB}$ e dentre às fêmeas, Cobb 500 teve o menor PCJ.

Foi verificado que o peso ao abate com peso de $1350 \mathrm{~g}$ a linhagem Ross 308 apresentaram semelhante CA em relação à Cobb 500 e Hubbard Flex, para machos, e Cobb 500 tiveram menor MB devido ao seu crescimento tardio. Machos Hubbard Flex e Cobb 500 tiveram maior eficiência econômica (MB) em relação às demais linhagens de macho de acordo com o aumento do peso e idade. Observa-se que o avanço do peso/idade do frango houve maior diferenciação entre machos e fêmeas, com piora da eficiência técnica e econômica dos frangos em geral, sendo que os machos apresentaram melhor CA (Figura 25) e assim maior MB (Figura 26) do que fêmeas. 
Figura 25 - Conversão alimentar estimada a partir do modelo de Gompertz de acordo com as predeterminações de peso e idade para linhagens e sexo de frangos de corte

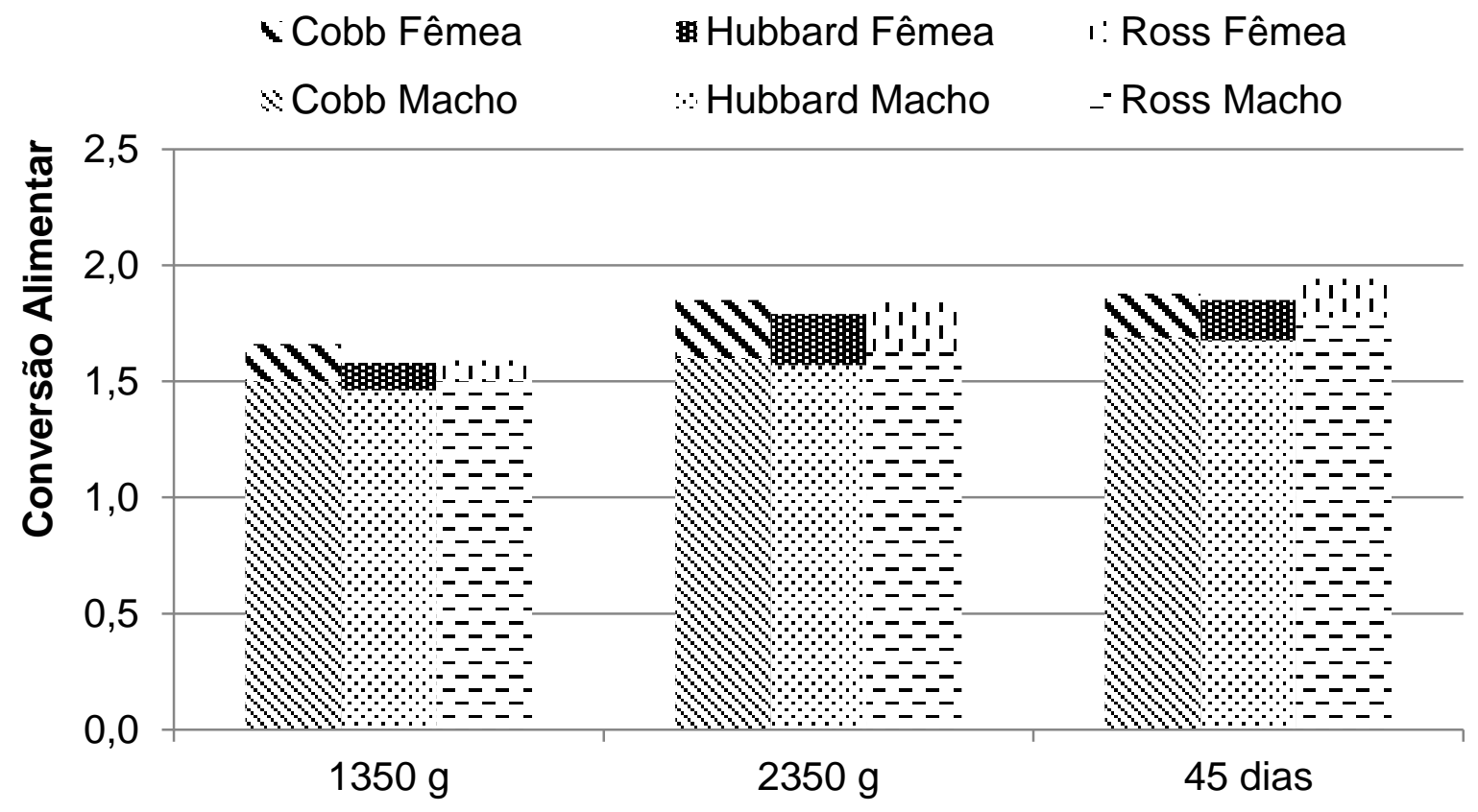

Prédeterminações de peso e idade

Fonte: Própria autoria.

Figura 26 - Margem bruta estimada a partir do modelo de Gompertz de acordo com as predeterminações de peso e idade para linhagens e sexo de frangos de corte
$\approx$ Cobb Macho
$\therefore$ Hubbard Macho $\cdot$ Ross Macho
:Cobb Fêmea
睡 Hubbard Fêmea ،' Ross Fêmea

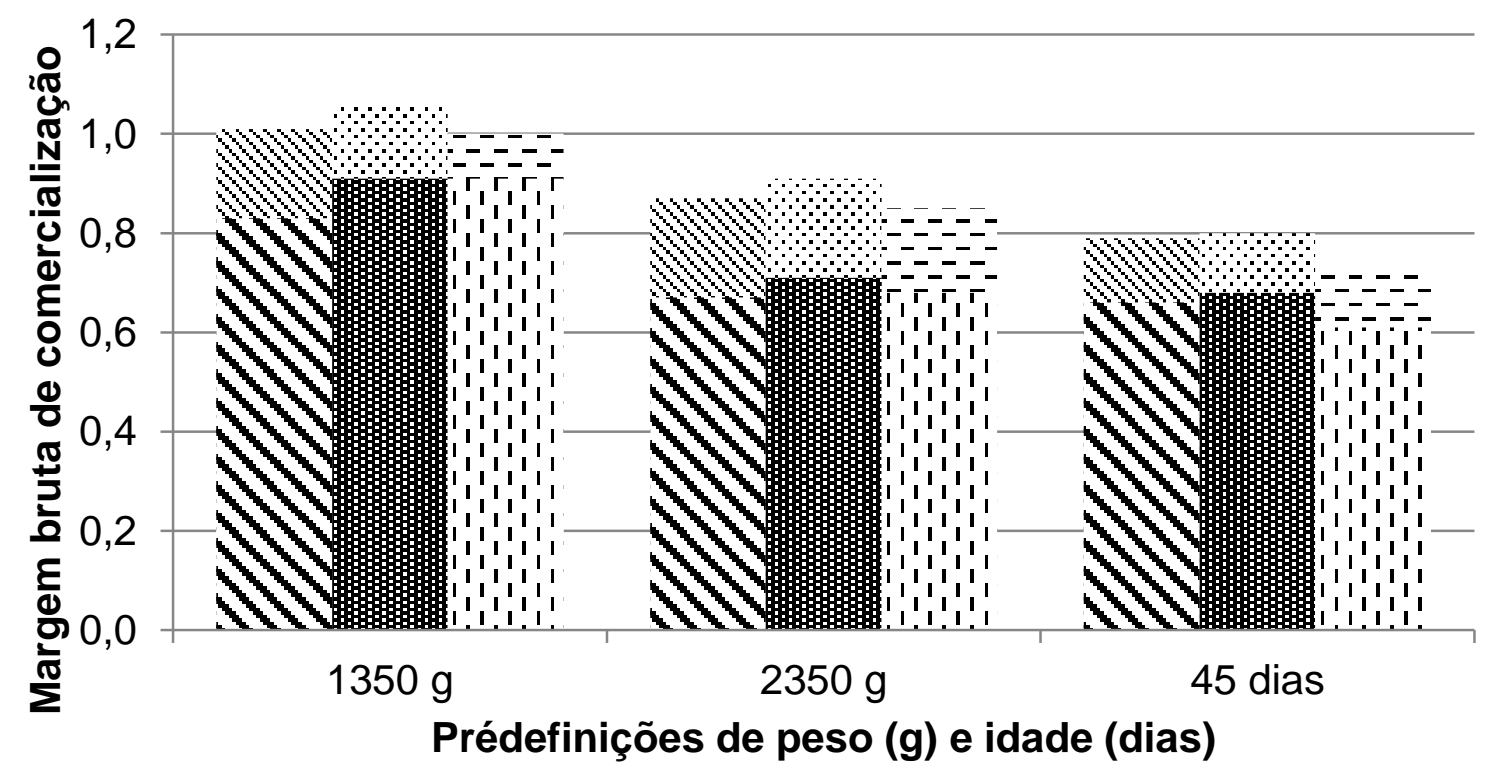

Fonte: Própria autoria. 


\section{CONCLUSÕES}

No ajuste dos modelos, Gompertz foi o mais adequado, explicando o crescimento corporal e dos componentes nos gêneros estudados. A alometria teve bom ajuste, porém os modelos de crescimento explicam melhor o desenvolvimento do animal através dos seus parâmetros.

Foi observada maior pressão de seleção sobre frangos machos, contribuindo com as diferenças entre as linhagens de macho, apresentando maior desenvolvimento corporal e dos componentes do corpo, exceto para gordura corporal.

As linhagens dentro de cada sexo tiveram pequenas diferenças no crescimento corporal e dos seus componentes. Entre os machos, Cobb 500 teve peso de peito superior, Hubbard Flex apresentou maior deposição de proteína corporal e no geral, a linhagem Ross 308 apresentou maior precocidade sobre o ponto de inflexão das curvas. Sendo assim, é possível observar diferenças no crescimento entre sexo e linhagens dentro de cada sexo que refletem em distintas exigências nutricionais.

As diferenças existentes entre as linhagens e sexos, estudados no presente trabalho, dificultam na escolha do genótipo para a criação. No cruzamento diíbrido, as aves comerciais, herdam suas características das aves reprodutoras, sendo muito importante que os criadores façam suas escolhas de acordo com o custo de produção das matrizes e demanda dos clientes que podem variar, justificando a necessidade de diferentes linhagens para suprir distintos mercados.

$\mathrm{Na}$ análise econômica utilizando o peso corporal em jejum como produto de comercialização, estimado pelo modelo de Gompertz, os machos tiveram a melhor eficiência produtiva. A linhagem Ross 308 não foi tão eficiente quanto às linhagens Cobb 500 e Hubbard Flex, apesar de ter apresentado precocidade no crescimento. 


\section{IMPLICAÇÕES GERAIS}

Nos resultados preditos, o valor inicial para as características foram superestimados, sendo que para as demais idades foram muito próximos do observado. Isso deve-se, principalmente, há algumas das pressuposições estatísticas (normalidade e a independências dos erros em tempos diferentes) que não foram levadas em consideração para realizar as estimativas dos parâmetros das curvas, devido as limitações do pacote estatístico utilizado. Sendo assim, preferível que se utilize pacotes estatísticos mais atuais para contornar esses efeitos indesejáveis, obtendo valores dos parâmetros dos modelos mais justos e consequentemente, com maior confiança sobre as inferências.

A utilização de duas rações experimentais, para cada sexo, mostrou que as linhagens possuem necessidades diferentes, já que apresentaram respostas diferentes de crescimento dentre os machos e fêmeas. Não foi possível concluir qual linhagem dentro de cada sexo foi melhor, uma vez que houve diferentes respostas para as características avaliadas. Da mesma forma, não foi levado em consideração a performance da matrizes fêmeas, como a produção e a eclodibilidade dos ovos, que são características que influência o custo final de produção avícola, além do desempenho do frango de corte.

A abordagem de crescimento do frango e dos seus componentes, a partir de dados longitudinais, promove melhor estratégia de seleção da ave, proporcionando a estimativa do peso em idade que normalmente não é realizada a pesagem, além de obter o ganho de peso diário do componente em estudo, predizendo a idade mais adequada ao abate e, consequentemente, maximizando o lucro do criador. 


\section{REFERÊNCIAS BIBLIOGRÁFICAS}

AGGREY, S. E. Comparison of three nonlinear and spline regression models for describing chicken growth curves. Poultry Science, Cary, v. 81, n. 12, p. 17821788, 2002.

AGUILAR, C.; FRIEDLI, C.; CANAS, R. The growth curve of animals. Agricultural Systems, Amsterdam, v. 10, p. 133-147, 1983.

AKAIKE, $\mathrm{H}$. A new look at the statistical model identification. IEEE Transactions on Automatic Control, Boston, v. 19, n. 6, p. 716-723, 1974.

AMERAH, A. M. et al. Feed particle size: Implications on the digestion and performance of poultry. World's Poultry Science Journal, Cambridge, v. 63, p. 439455, 2007.

ASSOCIAÇÃO BRASILEIRA DE PROTEÍNA ANIMAL - ABPA. A saga da avicultura brasileira: como o Brasil se tornou o maior exportador mundial de carne de frango. São Paulo: UBABEF, 2011. Disponível em:<http://abpabr.com.br/setores/avicultura/publicacoes/informes-especiais/2011> Acesso em: 18 jan. 2016.

ASSOCIAÇÃO BRASILEIRA DE PROTEÍNA ANIMAL. Relatório anual de atividades 2014. São Paulo: ABPA, 2015. Disponível em: <http://abpa-

br.com.br/setores/avicultura/publicacoes/relatorios-anuais> Acesso em: 18 jan. 2016.

AVISITE. Notícias. Disponível em:

<http://www.avisite.com.br/noticias/?codnoticia=15940 >. Acesso em: 04 jul. 2016.

BALDWIN, R. L. Modeling ruminant digestion and metabolism. London (UK): Chapman \& Hall, 1995.

BARBATO, G. F. Genetic architecture of growth curve parameters in chickens. Theoretical and Applied Genetics, Heidelberg, v. 83, p. 24-32, 1991.

BARBOSA, L. A. Leis de escala alométricas para as taxas metabólicas interespecíficas e para cadeias alimentares. 2007. $112 \mathrm{f}$. Tese (Doutorado) Universidade Federal de Minas Gerais, Belo Horizonte, 2007.

BRACCINI NETO, J. et al. Análise de curvas de crescimento de aves de postura. Revista da Sociedade Brasileira de Zootecnia, Viçosa, v. 25, n. 6, p. 1062-1073, 1996.

BRODY, S. Bioenergetics and growth: with special reference to the efficiency complex of domestic animals. New York: Hafner, 1945. 1023 p.

BROWN, D.; ROTHERY, P. Models in biology: mathematics, statistics and computing. England: John Wiley and Sons; Chichester, New York, Brisbane, Toronto, Singapore, 1993. 668 p. 
BROWN, J. H.; WEST, G. B.; ENQUIST, B. J. Scaling in biology: patterns and processes, causes and consequences, In: BROWN, J. H.; WEST, B. (Eds.). Scaling in biology. Oxford University Press, Oxford, 2000, p. 1-24.

COELHO, A. A. D.; SAVINO, V. J. M.; ROSÁRIO, M. F. Frango feliz: caminhos para a avicultura alternativa. Piracicaba: FEALQ, 2008.

DAHLKE, F. et al. Empenamento de frangos de corte: efeito da restrição alimentar qualitativa e quantitativa e temperatura ambiente. Acta Scientiarum. Animal Sciences, Maringa, v. 27 n. 3, p. 341-347, 2005.

DANISMAN, R. Predicting the weights of the physical parts of broilers. 2009 . 129 f. Dissertação (Mestrado) - University of KwaZulu-Natal, Pietermaritzburg, 2009.

DANISMAN, R.; GOUS, R. M. Effect of dietary protein on performance of four broiler strains and on the allometric relationships between carcass portions and body protein. South African Journal of Animal Science, Hatfield, v. 43, p. 25-37, 2013.

DANISMAN, R.; GOUS, R. M. Effect of dietary protein on the allometric relationships between some carcass portions and body protein in three broiler strains. South African Journal of Animal Science, Hatfield, v. 41, p. 194-208, 2011.

DE GREEF, K. H. et al. Evaluation of between-line variation for within-line selection against ascites in broilers. Poultry Science, Cary, v. 80, p. 13-21, 2001.

DUMAS, A.; DIJKSTRA, J.; FRANCE, J. Mathematical modelling in animal nutrition: a centenary review. The Journal of Agricultural Science, Cambridge, v. 146, n. 2, p. 123-142, 2008.

EDENS, F. W. Empenamento em frangos: Influência de aminoácidos e minerais da dieta. In: CONFERÊNCIA APINCO DE CIÊNCIA E TECNOLOGIA AVÍCOLAS, 2000. Campinas. Anais.... Campinas, 2000. p. 81-100.

ELEROGLU, $\mathrm{H}$. et al. Comparison of growth curves by growth models in slow growing chicken genotypes raised the organic system. International Journal of Agriculture \& Biology, Faisalabad, v. 16, p. 529-535, 2014.

EMMANS, G. C. Growth body composition and feed intake. World's Poultry Science Journal, Cambridge, v. 43, p. 208-227, 1987.

EUCLIDES FILHO, K. Melhoramento genético animal no Brasil: fundamentos, história e importância. Campo Grande: EMBRAPA Gado de Corte, 1999.

FARIDI, A. et al. Alternative growth functions for predicting body, carcass, and breast weight in ducks: Lomolino equation and extreme value function. Poultry Science, Cary, v. 93 p. 1031-1042, 2014.

FERNANDES, J. I. M. et al. Effect of strain, sex and age on carcass parameters of broilers. Acta Scientiarum. Animal Sciences, Maringa, v. 35, p. 99-105, 2013. 
FIGUEIREDO, E. A. P. Sistemas de produção de frangos de corte. Embrapa Suínos e Aves. Sistema de Produção de Frangos de Corte. 2003. Disponível em:<http://www.cnpsa.embrapa.br/FontesHTML/Ave/ProduçaodeFrangodeCorte/Rac as.html> Acesso em: 14 ago. 2015.

FITZHUGH JUNIOR, H. A. Analysis of growth curves and strategies for altering their shape. Journal of Animal Science, Champaign, v. 42, n. 4, p.1036-1051, 1976.

FRANCE, J. et al. On the use of response functions in energy balance analysis. Journal of Theoretical Biology, London, v. 140, p. 83-99, 1989.

FRANCE, J.; DIJKSTRA, J.; DHANOA, M. Growth functions and their application in animal science. Annales de Zootechnie, Paris, v. 45, suppl. 1, p. 165-174, 1996.

FREITAS, A. R. Curvas de crescimento na produção animal. Revista Brasileira de Zootecnia, Viçosa, v. 34, p. 786-795, 2005.

FREITAS, A. R. et al. Modelos de curvas de crescimento em frangos de corte. Pesquisa Agropecuária Brasileira, Brasília, v. 19, n. 9, p. 1057-1064, 1984.

GAMEIRO, A. H. Análise econômica aplicada à zootecnia: avanços e desafios. In: SANTOS, M. V. et al. Novos desafios da pesquisa em nutrição e produção animal. Pirassununga: 5D, 2009. p. 9-32.

GARCIA-NETO, M. PPFR: Programa prático para formulação de ração - versão 2.1 Excel 2014. Disponível em:

<https://sites.google.com/site/ppfrparaexcel2007ousuperior/>. Acesso em: 04 jul. 2016.

GARCIA-NETO, M.; CAMPOS, E. J. Suscetibilidade de linhagens de frangos de corte à síndrome ascética. Pesquisa Agropecuária Brasileira, Brasília, v. 39, n. 8, p. 803-808, 2004.

GAYA, L. G. Estudo genético da deposição de gordura abdominal e de características de desempenho, carcaça e composição corporal em linhagem de macho de frangos de corte. 2003. 99 f. Dissertação (Mestrado) - Faculdade de Zootecnia e Engenharia de Alimentos, Universidade de São Paulo, Pirassununga, 2003.

GBANGBOCHE, A. B. et al. Comparison of non-linear growth models to describe the growth curve in West African Dwarf sheep. Animal, Cambridge, v. 2, n. 2008, p. 1003-1012, 2008.

GOLIOMYTIS, M.; PANOPOULOU, E.; ROGDAKIS, E. Growth curves for body weight and major component parts, feed consumption, and mortality of male broiler chickens raised to maturity. Poultry Science, Cary, v. 82, p. 1061-1068, 2003.

GOMPERTZ, B. On the nature of the function expressive of the law of human mortality and on a new method of determining the value of life contingencies. 
Philosophical Transactions of the Royal Society, London, v. 115, p. 513-585, 1825.

GONZALES, E.; SARTORI, J. S. Crescimento e metabolismo muscular. In: MACARI, M.; FURLAN, R. L.; GONZALES, E. (Eds.). Fisiologia aviária aplicada a frangos de corte. Jaboticabal: FUNEP/UNESP, 2002. p. 279-298.

GOUS, R. M. Modeling as a research tool in poultry science. Poultry Science, Cary, v. 93, p. 1-7, 2014.

GOUS, R. M. Methodologies for modelling energy and amino acid responses in poultry. Revista Brasileira de Zootecnia, Viçosa, v. 36, p. 263-274, 2007.

GOUS, R. M. Consequências econômicas decorrentes das mudanças nos programas de alimentação de frangos. In: SIMPÓSIO TÉCNICO DE INCUBAÇÃO, MATRIZES DE CORTE E NUTRIÇÃO, 5., 2004, Balneário Camboriú. Anais... Balneário Camboriú, 2004. p. 6-28.

GOUS, R. M. Measurement of response in nutritional experiments. In: FISHER, C.; BOORMAN K. N. (Eds.). Nutrient requirements of poultry and nutritional research. London: Butterworths. 1986, p. 41-58.

GOUS R. M. et al. Evaluation of the parameters needed to describe the overall growth, the chemical growth, and the growth of feathers and breast muscles of broilers. Poultry Science, Cary, v. 78, n. 6, p. 812-821, 1999.

GOUS, R. M. et al. Nutritional effects on the growth and fatness of broilers. British Poultry Science, Abingdon, v. 31, p. 495-505, 1990.

HARDIMAN, J.; KATANBAF, M. Good feather cover for optimising energy use. World Poultry, Doetinchem, July. 2012. Disponível em:

<http://www.worldpoultry.net/Broilers/Nutrition/2012/7/Good-feather-cover-foroptimising-energy-utilisation-WP010672W/>. Acesso em: 20 jan. 2016.

HANCOCK, C. E. et al. The evaluation of the growth parameters of six strains of comercial broiler chickens. British Poultry Science, Abingdon, v. 36, p. 247-264, 1995.

HARTLEY, H. O. The modified Gauss-Newton method for the fitting of non-linear regression functions by least squares. Technometrics, Milwaukee, v. 3, p. 269-280, 1961.

HAVENSTEIN, G. B.; FERKET, P. R.; QURESHI, M. A. Growth, livability, and feed conversion of 1957 versus 2001 broilers when fed representative 1957 and 2001 diets. Poultry Science, Cary, v. 82, p.1500-1508, 2003.

HENN, J. D. et al. Growth and deposition of body components of intermediate and high performance broilers. Brazilian Journal of Poultry Science, Campinas, v. 16, n. 3, p. 319-328, 2014. 
HOFFMAN, R. Estatística para economistas. 2. ed. São Paulo: Pioneira, 1991. 426 p.

HUXLEY, J. S. Constant differential growth-ratios and their significance. Nature, London, v.114, p. 895-896, 1924.

HUXLEY, J. S.; TEISSIER, G. Terminology of relative growth. Nature, London, v. 137 , p. $780-781,1936$.

INSTITUTO DE ECONOMIA AGRÍCOLA - IEA. Banco de dados. Disponível em: <http://www.iea.sp.gov.br/out/bancodedados.html>. Acesso em: 04 jul. 2016

ÍNDICE NACIONAL DE PREÇOS AO CONSUMIDOR - INPC. Banco de dados. Disponível em: <http://www.portalbrasil.net/inpc.htm>. Acesso em: 04 jul. 2016.

KESSLER, A. M.; SNIZEK, P. N.; BRUGALLI, I. Manipulação da quantidade de gordura na carcaça de frangos. In: CONFERÊNCIA APINCO DE CIÊNCIA E TECNOLOGIA AVÍCOLAS, 2000. Campinas. Anais... Campinas, 2000. p.107-133.

KNIZETOVA, H. J. et al. Growth curves of chickens with different type of performance. Journal of Animal Breeding and Genetics, Berlin, v. 102 p. 256-270, 1985.

KOYA, P. R.; GOSHU, A. T. Generalized mathematical model for biological growths. Open Journal of Modelling and Simulation, Irvine, v. 1, n. 4, p. 42-53, 2013.

$\mathrm{KUHI}, \mathrm{H}$. D. et al. A review of mathematical functions for the analysis of growth in poultry. World's Poultry Science Journal, Cambridge, v. 66, p. 227- 239, 2010.

$\mathrm{KUHI}, \mathrm{H}$. D. et al. A comparative evaluation of functions for the analysis of growth in male broilers. Journal of Agricultural Science, Cambridge, v. 140, p. 451-459, 2003.

LAWRENCE, T. L. J.; FOWLER, V. R. Growth of farma animals. New York: CAB, 1997. $330 \mathrm{p}$.

LONGO, F. A. et al. Carboidratos na dieta pré-inicial de frangos de corte. Revista Brasileira de Zootecnia, Viçosa, v. 34, n. 1, p. 123-133, 2005.

MADEIRA, L. A. et al. Morfologia das fibras musculares esqueléticas de frangos de corte de diferentes linhagens criados em sistemas de confinamento e semiconfinamento. Revista Brasileira de Zootecnia, Viçosa, v. 35, n. 6, 2006.

MARCATO, S. M. Características do crescimento corporal, dos órgãos e tecidos de duas linhagens comerciais de frangos de corte. 2007. $183 \mathrm{f}$. Tese (Doutorado) - Universidade Estadual Paulista "Júlio de Mesquita Filho", Jaboticabal, 2007. 
MARCATO, S. M. et al. Crescimento e deposição de nutrientes nos órgãos de frangos de corte de duas linhagens comerciais. Revista Brasileira de Zootecnia, Viçosa, v. 39, n. 5, p. 1082-1091, 2010.

MARCATO, S. M. et al. Crescimento e deposição de nutrientes nas penas, músculo, ossos e pele de frangos de corte de duas linhagens comerciais. Ciência e Agrotecnologia, Lavras, v. 33, n. 4, p. 1159-1168, 2009.

MARCATO, S. M. et al. Growth and body nutrient deposition of two broiler commercial genetic lines. Brazilian Journal of Poultry Science, Campinas, v. 10, n. 2, p. 117-123, 2008.

MARTIN, P. A.; BRADFORD, G. D.; GOUS, R. M. A formal method of determining the dietary amino acid requirements of laying-type pullets during their growing period. British Poultry Science, Abingdon, v. 35, p. 709-724, 1994.

MARTINELLI, O. Estudo setorial setor de carnes no Brasil. 2009. (Proyecto: Políticas regionales de Innovación em el MERCOSUL: obstáculos y oportunidades). Disponível em:<https://idl-bnc.idrc.ca/dspace/bitstream/10625/45328/1/131794.pdf>. Acesso em: 10 nov. 2015.

MARTÍNEZ, C. A. et al. Descripción matemática de la función gompertz aplicada al crecimiento de animales. Revista de la Facultad de Medicina Veterinária y de Zootecnia, Colombia, v. 57, p. 76-80, 2010.

MENDES, A. A.; NAAS, I.A.; MACARI, M. Produção de frangos de corte. Campinas: FACTA, 2004. 342 p.

MIGNON-GRASTEAU, S. et al. Genetic analysis of growth curve parameters for male and female chickens resulting from selection on shape of growth curve. Journal of Animal Science, Champaign, v. 78, n. 10, p. 2515-2524, 2000.

MOHAMMED, F. A. Comparison of three nonlinear functions for describing chicken growth curves. Scientia Agriculturae, Pakistan, v. 9, n. 3, p. 120-123, 2015.

MORAIS, J. et al. Curva de crescimento de diferentes linhagens de frango de corte caipira. Ciência Rural, Santa Maria, 2015. (In press).

NATIONAL RESEARCH COUNCIL- NRC. Nutrient requirements of poultry. 9nd ed. rev. Washington DC, USA: National Academy Press, 1994.

NIKOLOVA, N.; PAVLOVSKI, Z. Major carcass parts of broiler chicken from different genotype, sex, age, and nutrition system. Biotechnology in Animal Husbandry, Serbia, v. 25, n. 5-6, p.1045-1054, 2009.

OLIVEIRA, G. A. de et al. Efeito da temperatura ambiente sobre o desempenho e as características de carcaça de frangos de corte dos 22 aos 42 dias. Revista

Brasileira de Zootecnia, Viçosa, v. 35, n. 4, p. 1398-1405, 2006. 
ORGANISATION FOR ECONOMIC COOPERATION AND DEVELOPMENT - OECD; FOOD AND AGRICULTURE ORGANIZATION -FAO. Agricultural Outlook 20142023. 2014.

Agricultural Outlook 2012-2021. 2012.

OVIEDO-RONDÓN, E. O.; FRITTS C. A.; WALDROUP, P. W. Accuracy of Omnipro® II Estimations for Amino Acid Requirements of Broilers. International Journal of Poultry Science, Cary, v. 1, n. 5, p. 119-126. 2002.

OVIEDO-RONDÓN, E. O. Uso da modelagem para obter melhor custo/benefício na produção de frangos de corte. In: CONGRESSO LATINO AMERICANO DE NUTRIÇÃO ANIMAL. 4, 2010, São Pedro, SP. Anais... São Paulo, 2010. p. 89-100.

PAZ, C. C. P. et al. Ajuste de modelos não-lineares em estudos de associação entre polimorfismos genéticos e crescimento em bovino de corte. Revista Brasileira de Zootecnia, Viçosa, v. 33, n. 6, p. 1416-1425, 2004.

PEARL, R. The Biology of population growth. New York: Alfred A. Knopf, 1925.

PESTI, G. M.; MILLER, B. R. Modelling for precision nutrition. The Journal of Applied Poultry Research, Cary, v. 6, n. 4, p. 483-494, 1997.

PORTER, T. et al. Flexible alternatives to the Gompertz equation for describing growth with age in turkey hens. Poultry Science, Cary, v. 89, n. 2, p. 371-378, 2010.

PRESCOTT, N. J. et al. Growth, food intake and development in broiler cockerels raised to maturity. Animal Production, Cambridge, v. 41, n. 02, p. 239-245, 1985.

RANCE, K. A.; MCENTEE, G. M.; MCDEVITT, R. M. Genetic and phenotypic relationships between and within support and demand tissues in a single line of broiler chicken. British Poultry Science, Abingdon, v. 43, n. 4, p. 518-527, 2002.

REDDISH, J. M.; LILBURN, M. S. A comparison of growth and development patterns in diverse genotypes of broilers. 1. male broiler growth. Poultry Science, Cary, v. 83, n. 7, p. 1067-1071, 2004.

RIBEIRO, A.; MAGRO, N.; PENZ JR, A. Granulometria do milho em rações de crescimento de frangos de corte e seu efeito no desempenho e metabolismo.

Revista Brasileira de Ciência Avícola, Campinas, v. 4, n. 1, p. 1-7, 2002.

RICHARDS, F. J. A flexible growth function for empirical use. Journal of Experimental Botany, Oxford, v. 10, p. 290-300, 1959.

RICKLEFS, R. E. Modification of growth and development of muscles of poultry. Poultry Science, Cary, v. 64, n. 8, p. 1563-1576, 1985. 
RICKLEFS, R. E.; STARCK J. M. Embryonic growth and development. In: STARCK, J. M.; RICKLEFS, R. E. (Org.) Avian growth and development. New York: Oxford University Press. 1998. cap. 2, p. 31-58.

ROBERTSON, T. B. On the normal rate of growth of an individual and its biochemical significance. Archiv fur Entwicklungsmechanik der Organismen, Heidelberg, v. 25, p. 581-614, 1908.

ROGERS, St R.; PESTI, G. M.; MARKS, H. L. Comparison of three nonlinear regression models for describing broiler growth curves. Growth, Everett, v. 51, n. 2, p. 229-239, 1987.

RONDÓN, E.; MURAKAMI, A.; SAKAGUTI, E. Modelagem computacional para produção e pesquisa em avicultura computer modeling for poultry production and research. Revista Brasileira de Ciência Avícola, Campinas, v. 4, n. 1, p. 199-207, 2002.

ROSTAGNO, H. S. et al. Composição de alimentos e exigências nutricionais: (tabelas brasileiras). Viçosa, MG: Universidade Federal de Viçosa, 2011. 141 p.

SAKOMURA, N. K. et al. Description of the growth of the major body components of 2 broiler chicken strains. Poultry Science, Cary, v. 90, p. 2888-2896, 2011.

SAKOMURA, N. K.; ROSTAGNO, H. S. Métodos de pesquisa em nutrição de monogástricos. Jaboticabal: Funep, 2007. 283 p.

SAKOMURA, N. K. et al,. Modeling energy utilization and growth parameter description for broiler chickens. Poultry Science, Cary, v. 84, p. 1363-1369, 2005.

SAKOMURA, N. K. Modeling energy utilization in broiler breeders, laying hens and broilers. Brazilian Journal of Poultry Science, v. 6, n. 1, p. 1-11, 2004.

SARMENTO, J. L. R. et al. Estudo da curva de crescimento de ovinos Santa Inês. Revista Brasileira de Zootecnia, Viçosa, v. 35, n. 2, p. 435-442, 2006.

SANTOS, A. L. et al. Estudo do crescimento, desempenho, rendimento de carcaça e qualidade de carne de três linhagens de frango de corte. Revista Brasileira de Zootecnia, Viçosa, v. 34, p. 1589-1598, 2005.

SANTOS, V. B. et al. Avaliação de curvas de crescimento morfométrico de linhagens de tilápia do nilo (Oreochromis niloticus). Ciência e Agrotecnologia, Lavras, v. 31, n. 5, p. 1486-1492, 2007.

SCHEUERMANN, G. N. et al. Breast muscle development in commercial broiler chickens. Poultry Science, Cary, v. 82, p. 1648-1658, 2003.

SCHMIDT-NIELSEN, K. Scaling: Why is animal size so important? Cambridge University Press, 1984. p. 1-32. 
SAWA, T. Information criteria for discriminating among alternative regression models. Econometrica, v.46, p. 1273-1282,1978.

SILVA, D. J.; QUEIROZ, A. C. Análise de alimentos (métodos químicos e biológicos), 3. ed. Viçosa, MG: Editora UFV, 2002. 235 p.

SILVA, F. H. A. et al. Influence of egg pre-storage heating period and storage length on the digestive tract of newly-hatched broiler chicks. Revista Brasileira de Ciência Avícola, Campinas, v. 10, n. 1, p. 23-28, Mar. 2008.

SILVA, F. L. et al. Growth curves in beef cows of different biological types. Pesquisa Agropecuária Brasileira, Brasília, v. 46, n. 3, p. 262-271, 2011.

SILVA, M. A. Evolução do melhoramento genético de aves no Brasil. Revista Ceres, Viçosa, v. 56, n. 3, p. 437-445, 2009.

SILVA, R. D. M.; NAKANO, M. Sistema caipira de criação de galinhas. Piracicaba: O Editor, 1998. $110 \mathrm{p}$.

SOUZA ALVES, J. M. Análise de patentes na indústria avícola. 2003. $122 \mathrm{f}$. Dissertação (Mestrado) - Universidade Federal do Rio Grande do Sul, Porto Alegre, 2003.

STATISTICAL ANALYSES SYSTEM - SAS. Version Release 9.3. for Windows. Cary, 2010.

THORNLEY, J. H. M.; FRANCE, J. Mathematical models in agriculture: quantitative methods for the plant, animal and ecological sciences. 2th ed. Wallingford, UK: CABI Publishing, 2007.

TREVISAN, R. B. et al. Feeding programs and their effects on broiler performance and economic indexes. The Journal Applied Poultry Research, Cary, n. 23, p. 593604, 2014.

TZENG, R. Y.; BECKER, W. A. Growth patterns of body and abdominal fat weights in male broiler chickens. Poultry Science, Cary, n. 60, p.1101-1106, 1981.

UDEH, I.; EZEBOR, P. N.; AKPORAHUARHO, P. O. Growth performance and carcass yield of three commercial strains of broiler chickens raised in a tropical environment. Journal of Biology, Agriculture and Healthcare, New York, v. 5, n. 2, p. 62-67, 2015.

UNITED STATES DEPARTMENT OF AGRICULTURE. Livestock and poultry: world markets and trade. Washington, D.C.: USDA, 2015. Disponível em: <http://apps.fas.usda.gov/psdonline/circulars/livestock_poultry.PDF> Acesso em: 18 jan. 2016.

VARGAS, G. D. A. et al. Modelagem do crescimento e do desenvolvimento de frangos de corte: validação. Ciência Rural, Santa Maria, v. 36, n. 5, p. 1664-1669, 2006. 
VELOSO, R. C. et al. Seleção e classificação multivariada de modelos não lineares para frangos de corte Arquivo Brasileiro de Medicina Veterinária e Zootecnia, Belo Horizonte, v. 68, n. 1, p. 191-200, $2016 a$.

VELOSO, R. C. et al. Genetic divergence between genotypes for male and female broilers. Ciência Rural, Santa Maria, v. 46, n. 3, p. 554-559, 2016b.

VELOSO, R. C. et al. Crescimento de genótipos de frangos tipo caipira. Arquivo Brasileiro de Medicina Veterinária e Zootecnia, Belo Horizonte, v. 67, n. 5, p.1361-1371, 2015.

VERHULST, P. F. Notice sur la loi que la population suit dans sa croissance. Correspondance. Mathématiques et Physique, v.10, p.113-121, 1838.

VON BERTALANFFY, L. A quantitative theory of organic growth. Human Biology, Detroit, n. 10, v. 2, p. 181-213, 1938.

VON BERTALANFFY, L. Quantitative laws in metabolism and growth. Quarterly Review of Biology, Chicago, v. 32, p. 217-231, 1957.

YANG, Y. et al. Analysis of fitting growth models in Jinghai mixed-sex Yellow chicken. International Journal of Poultry Science, Faisalabad, v. 5, n. 6, p. 517521, 2006.

WEST, G. B.; BROWN, J. H. Life's universal scaling laws. Physics Today, Melville, v. 57, p. $36-42,2004$.

WINKELSTROTER, L. K. Crescimento de três genótipos comerciais de frangos de corte. 2013. 55 f. Dissertação (Mestrado) - Universidade Federal dos Vales do Jequitinhonha e Mucuri, Diamantina, 2013.

WINSOR, C. P. The Gompertz curve as a growth curve. Proceedings of the National Academy of Sciences, Washington, v. 18, p. 1-17, 1932.

ZUIDHOF, M. J. Mathematical characterization of broiler carcass yield dynamics. Poultry Science, Cary, v. 84, p. 1108-1122, 2005. 


\section{APÊNDICES}

Apêndice A - Regressão linear simples dos dados de peso corporal (PC) de cada boxe por semana contra o respectivo PC da amostra retirada do boxe

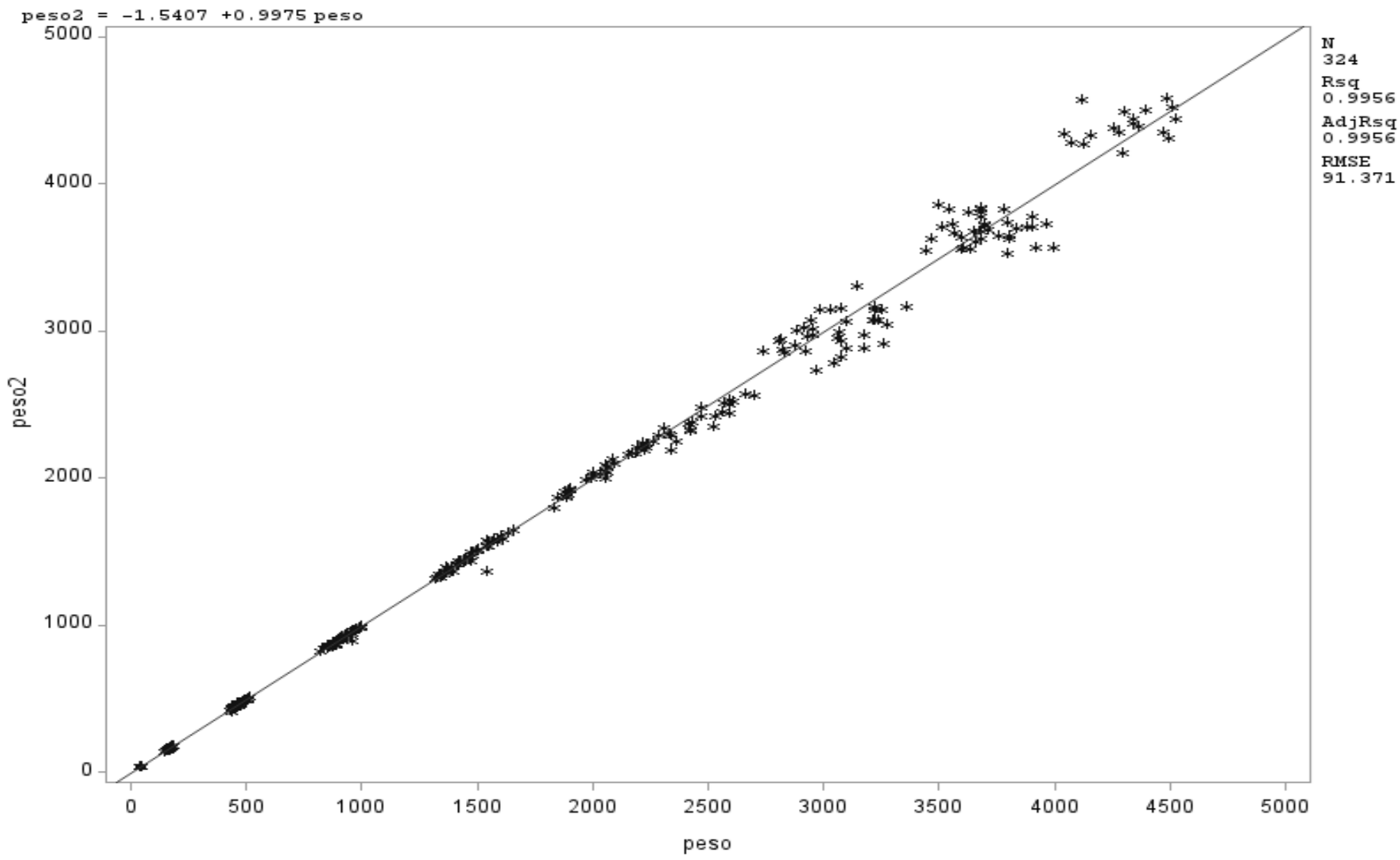


Apêndice B - Estimativas dos parâmentos alométricos $(\ln Y=\alpha+\beta(\ln X))$ das características avaliadas com e sem dados $\left({ }^{*}\right)$ do primeiro dia de vida levando em consideração diferente variáveis independentes (PCJD, PCJ e PB)

Continua

\begin{tabular}{|c|c|c|c|c|c|c|c|}
\hline \multirow{3}{*}{ Características } & & \multicolumn{6}{|c|}{ Parâmetros alométricos } \\
\hline & & \multicolumn{3}{|c|}{$\alpha$} & \multicolumn{3}{|c|}{$\beta$} \\
\hline & Sexo & PCJD & PCJ & PB & PCJD & PCJ & PB \\
\hline \multirow{2}{*}{ Água } & $\mathrm{M}$ & $-0,233$ & $-0,241$ & 1,580 & 0,989 & 0,980 & 0,972 \\
\hline & $\mathrm{F}$ & $-0,138$ & $-0,168$ & 1,698 & 0,967 & 0,960 & 0,952 \\
\hline \multirow{2}{*}{ Água* } & $\mathrm{M}$ & $-0,314$ & $-0,283$ & 1,566 & 0,980 & 0,989 & 0,974 \\
\hline & $\mathrm{F}$ & $-0,179$ & $-0,169$ & 1,631 & 0,960 & 0,967 & 0,965 \\
\hline \multirow{2}{*}{ Proteína } & $\mathrm{M}$ & $-1,847$ & $-1,854$ & - & 1,003 & 0,999 & - \\
\hline & $\mathrm{F}$ & $-1,908$ & $-1,939$ & - & 1,007 & 1,005 & - \\
\hline \multirow{2}{*}{ Proteína* } & $\mathrm{M}$ & $-1,887$ & $-1,854$ & - & 1,009 & 0,999 & - \\
\hline & $\mathrm{F}$ & $-1,831$ & $-1,821$ & - & 0,996 & 0,989 & - \\
\hline \multirow{2}{*}{ Gordura } & $M$ & $-3,506$ & $-3,514$ & $-1,325$ & 1,179 & 1,175 & 1,173 \\
\hline & $\mathrm{F}$ & $-3,989$ & $-4,028$ & $-1,575$ & 1,269 & 1,267 & 1,259 \\
\hline \multirow{2}{*}{ Gordura* } & $\mathrm{M}$ & $-3,391$ & $-3,355$ & $-1,194$ & 1,164 & 1,153 & 1,150 \\
\hline & $\mathrm{F}$ & $-4,052$ & $-4,040$ & $-1,689$ & 1,278 & 1,269 & 1,280 \\
\hline \multirow{2}{*}{ Cinzas } & $\mathrm{M}$ & $-3,999$ & $-4,005$ & $-1,970$ & 1,099 & 1,095 & 1,095 \\
\hline & $\mathrm{F}$ & $-4,182$ & $-4,216$ & $-2,037$ & 1,130 & 1,129 & 1,122 \\
\hline \multirow{2}{*}{ Cinzas* } & $\mathrm{M}$ & $-3,459$ & $-3,427$ & $-1,532$ & 1,027 & 1,018 & 1,017 \\
\hline & $\mathrm{F}$ & $-3,746$ & $-3,736$ & $-1,769$ & 1,071 & 1,063 & 1,073 \\
\hline \multirow{2}{*}{ Penas } & $\mathrm{M}$ & $-4,364$ & $-4,384$ & $-2,253$ & 1,142 & 1,139 & 1,136 \\
\hline & $\mathrm{F}$ & $-3,540$ & $-3,581$ & $-1,540$ & 1,044 & 1,044 & 1,033 \\
\hline \multirow{2}{*}{ Penas* } & $\mathrm{M}$ & $-5,665$ & $-5,638$ & $-3,180$ & 1,316 & 1,306 & 1,300 \\
\hline & $\mathrm{F}$ & $-4,679$ & $-4,676$ & $-2,437$ & 1,200 & 1,193 & 1,198 \\
\hline \multirow{2}{*}{ Carcaça } & $M$ & $-1,297$ & $-1,303$ & 0,787 & 1,129 & 1,124 & 1,123 \\
\hline & $\mathrm{F}$ & $-1,384$ & $-1,417$ & 0,795 & 1,145 & 1,143 & 1,135 \\
\hline \multirow{2}{*}{ Carcaça* $^{*}$} & $\mathrm{M}$ & $-0,935$ & $-0,901$ & 1,093 & 1,080 & 1,070 & 1,069 \\
\hline & $F$ & $-0,952$ & $-0,942$ & 1,068 & 1,086 & 1,078 & 1,085 \\
\hline
\end{tabular}


Apêndice B - Estimativas dos parâmentos alométricos (In $Y=\alpha+\beta(\ln X))$ das características avaliadas com e sem dados $\left.{ }^{*}\right)$ do primeiro dia de vida levando em consideração diferente variáveis independentes (PCJD, PCJ e PB)

Conclusão

\begin{tabular}{|c|c|c|c|c|c|c|c|}
\hline \multirow{2}{*}{ Características } & \multirow{2}{*}{ Sexo } & \multicolumn{3}{|c|}{$\alpha$} & \multicolumn{3}{|c|}{$\beta$} \\
\hline & & PCJD & PCJ & PB & PCJD & PCJ & PB \\
\hline \multirow{2}{*}{ Peito } & $\mathrm{M}$ & $-5,351$ & $-5,352$ & $-2,570$ & 1,504 & 1,496 & 1,496 \\
\hline & $\mathrm{F}$ & $-5,450$ & $-5,489$ & $-2,537$ & 1,534 & 1,531 & 1,523 \\
\hline \multirow{2}{*}{ Peito* } & $M$ & $-3,270$ & $-3,232$ & $-0,969$ & 1,225 & 1,214 & 1,212 \\
\hline & $\mathrm{F}$ & $-3,350$ & $-3,338$ & $-1,025$ & 1,247 & 1,238 & 1,245 \\
\hline \multirow{2}{*}{ Coxa } & $M$ & $-2,780$ & $-2,788$ & $-0,808$ & 1,069 & 1,065 & 1,064 \\
\hline & $\mathrm{F}$ & $-2,875$ & $-2,907$ & $-0,823$ & 1,078 & 1,076 & 1,069 \\
\hline \multirow{2}{*}{ Coxa* } & $M$ & $-2,818$ & $-2,785$ & $-0,802$ & 1,074 & 1,064 & 1,063 \\
\hline & $\mathrm{F}$ & $-2,702$ & $-2,692$ & $-0,743$ & 1,054 & 1,047 & 1,054 \\
\hline \multirow{2}{*}{ Sobrecoxa } & $M$ & $-2,952$ & $-2,960$ & $-0,878$ & 1,124 & 1,119 & 1,118 \\
\hline & $\mathrm{F}$ & $-2,870$ & $-2,905$ & $-0,748$ & 1,113 & 1,111 & 1,102 \\
\hline \multirow{2}{*}{ Sobrecoxa* } & $\mathrm{M}$ & $-2,919$ & $-2,885$ & $-0,817$ & 1,119 & 1,109 & 1,107 \\
\hline & $\mathrm{F}$ & $-2,962$ & $-2,951$ & $-0,867$ & 1,125 & 1,117 & 1,124 \\
\hline \multirow{2}{*}{ Asa } & $M$ & $-3,264$ & $-3,269$ & $-1,223$ & 1,106 & 1,101 & 1,100 \\
\hline & $\mathrm{F}$ & $-3,418$ & $-3,450$ & $-1,270$ & 1,130 & 1,128 & 1,122 \\
\hline \multirow{2}{*}{ Asa* } & $\mathrm{M}$ & $-2,689$ & $-2,657$ & $-0,760$ & 1,029 & 1,019 & 1,018 \\
\hline & $\mathrm{F}$ & $-2,617$ & $-2,607$ & $-0,721$ & 1,021 & 1,014 & 1,021 \\
\hline \multirow{2}{*}{ Coração } & $M$ & $-4,207$ & $-4,214$ & $-2,592$ & 0,875 & 0,872 & 0,871 \\
\hline & $\mathrm{F}$ & $-3,947$ & $-3,974$ & $-2,365$ & 0,829 & 0,828 & 0,821 \\
\hline \multirow{2}{*}{ Coração* } & $\mathrm{M}$ & $-4,235$ & $-4,210$ & $-2,586$ & 0,879 & 0,871 & 0,870 \\
\hline & $\mathrm{F}$ & $-4,200$ & $-4,193$ & $-2,591$ & 0,863 & 0,858 & 0,862 \\
\hline \multirow{2}{*}{ Fígado } & $M$ & $-2,674$ & $-2,680$ & $-1,067$ & 0,870 & 0,867 & 0,866 \\
\hline & $\mathrm{F}$ & $-2,714$ & $-2,740$ & $-1,047$ & 0,877 & 0,876 & 0,870 \\
\hline \multirow{2}{*}{ Fígado* } & $M$ & $-2,412$ & $-2,386$ & $-0,844$ & 0,835 & 0,828 & 0,827 \\
\hline & $\mathrm{F}$ & $-2,275$ & $-2,267$ & $-0,761$ & 0,817 & 0,811 & 0,818 \\
\hline \multirow{2}{*}{ Moela } & $M$ & $-1,372$ & $-1,374$ & $-0,169$ & 0,654 & 0,651 & 0,651 \\
\hline & $\mathrm{F}$ & $-1,485$ & $-1,504$ & $-0,212$ & 0,670 & 0,669 & 0,665 \\
\hline \multirow{2}{*}{ Moela* } & $\mathrm{M}$ & $-0,817$ & $-0,798$ & 0,263 & 0,579 & 0,574 & 0,575 \\
\hline & $\mathrm{F}$ & $-0,907$ & $-0,902$ & 0,189 & 0,590 & 0,586 & 0,590 \\
\hline
\end{tabular}


Apêndice C - Alometria de penas com (1) e sem (2) $01^{\circ}$ dia de vida das aves em relação ao peso corporal em jejum e depenado (PCJD) em machos (a) e fêmeas (b)

Fit Plot for Penas

1.a)

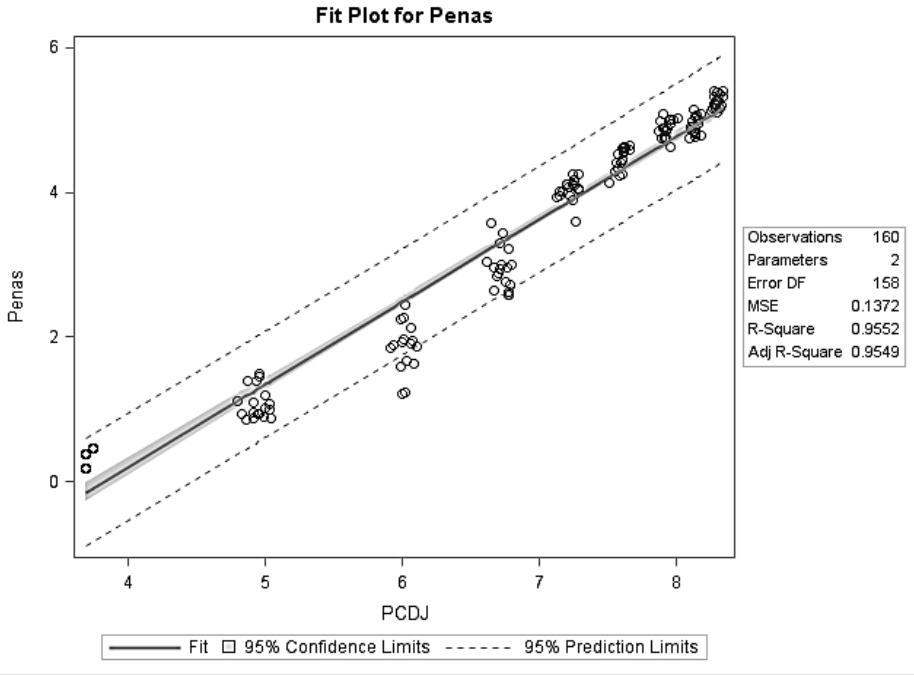

2.a)

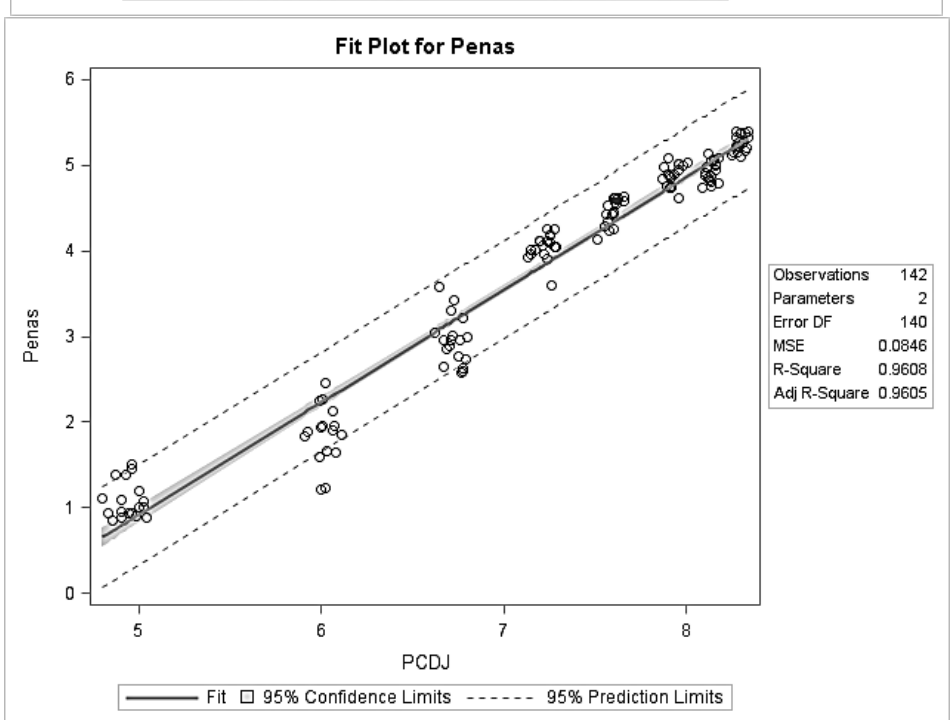

1.b)

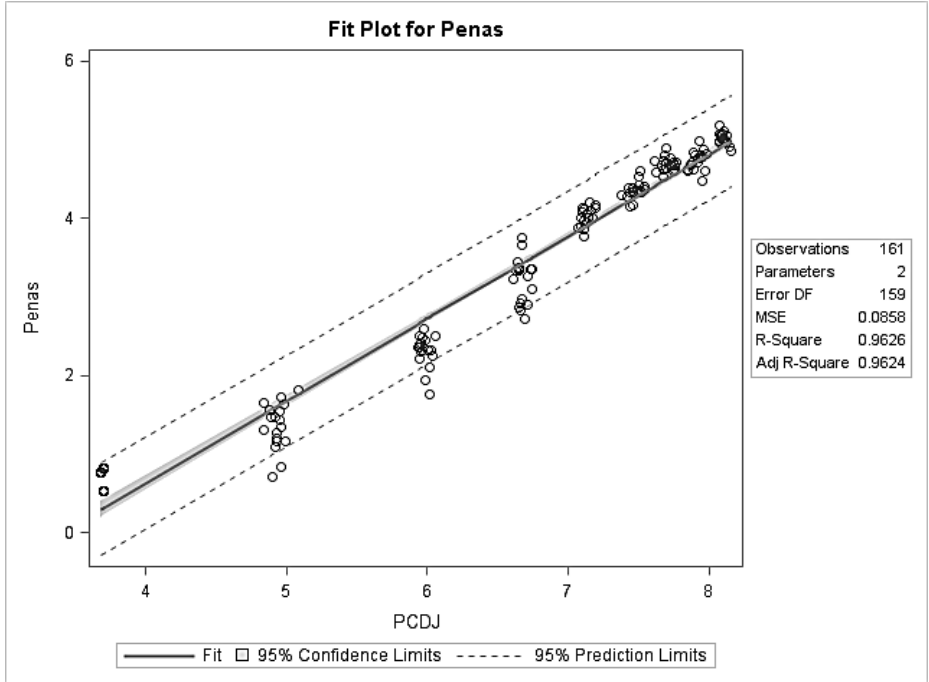

2.b)

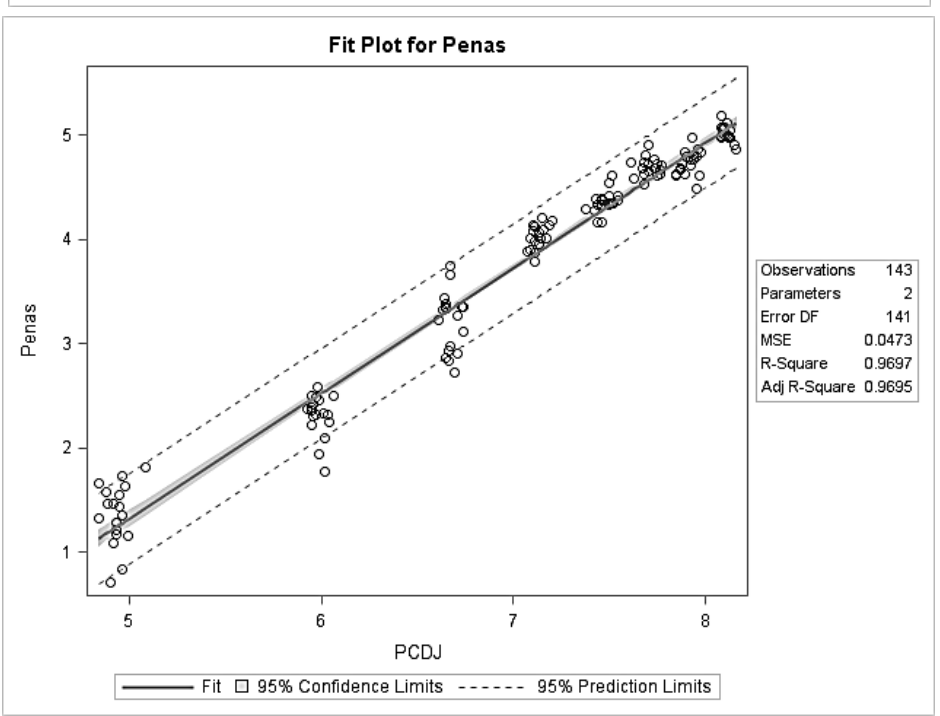


Apêndice D - Alometria de peito com (1) e sem (2) o $1^{\circ}$ dia de vida das aves em relação à proteína corporal em machos (a)

1a)

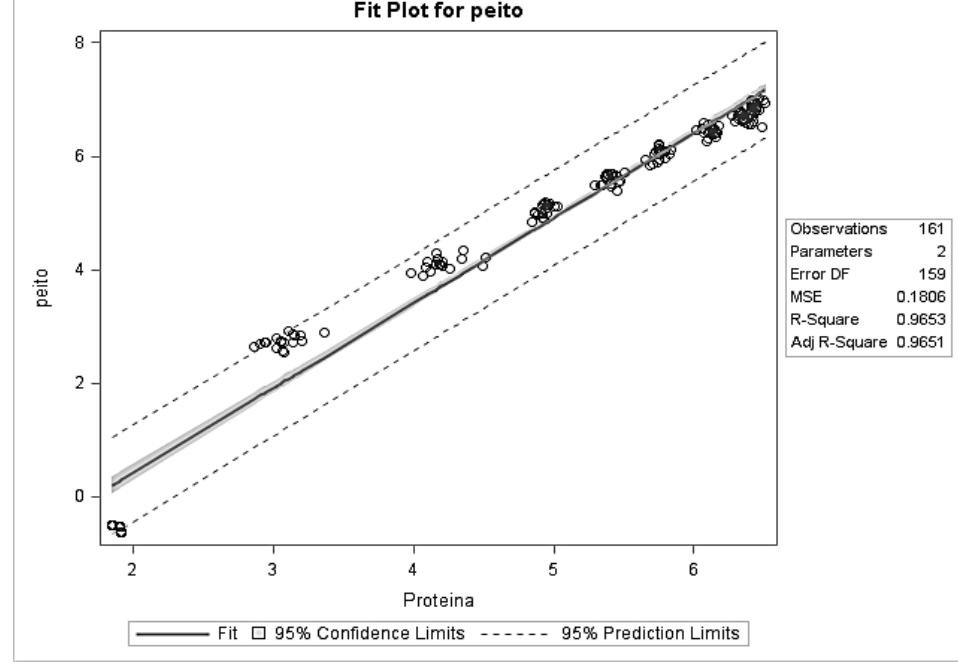

Fit Plot for peito

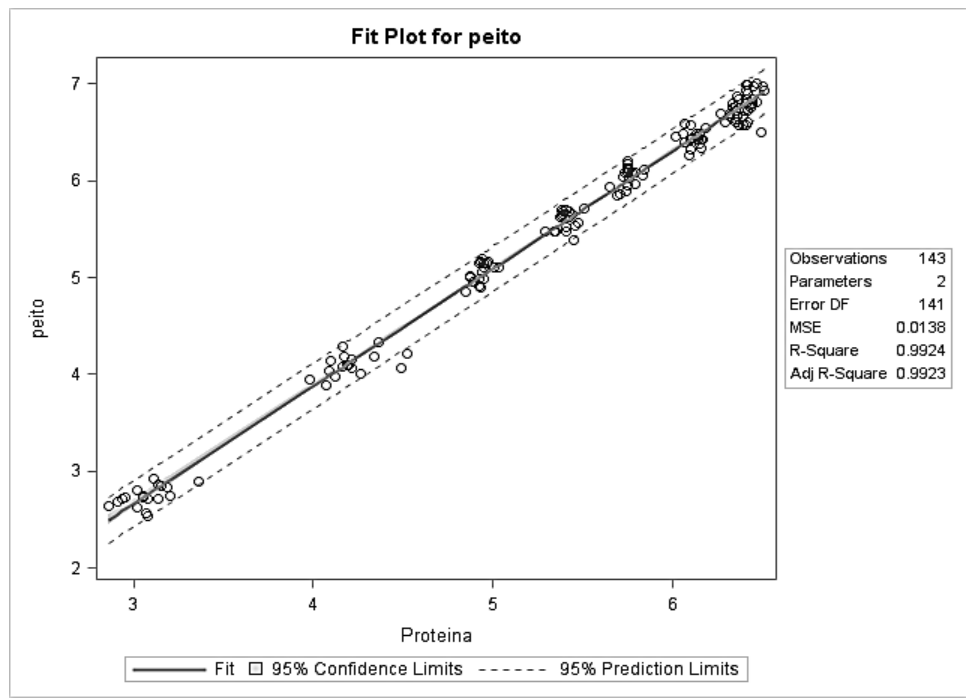

1b)

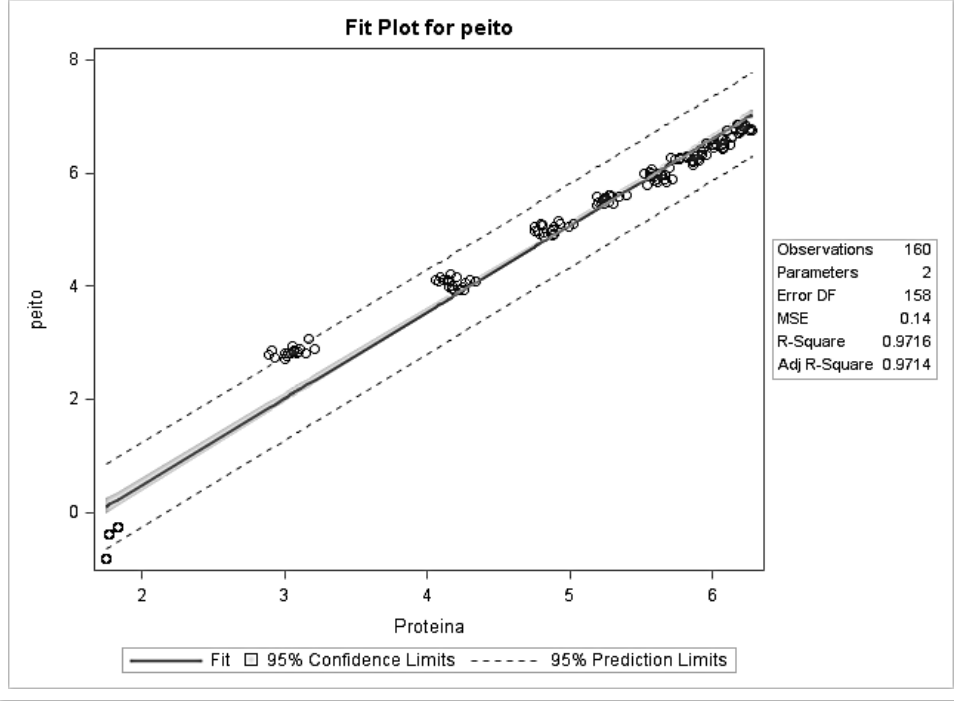

Fit Plot for peito

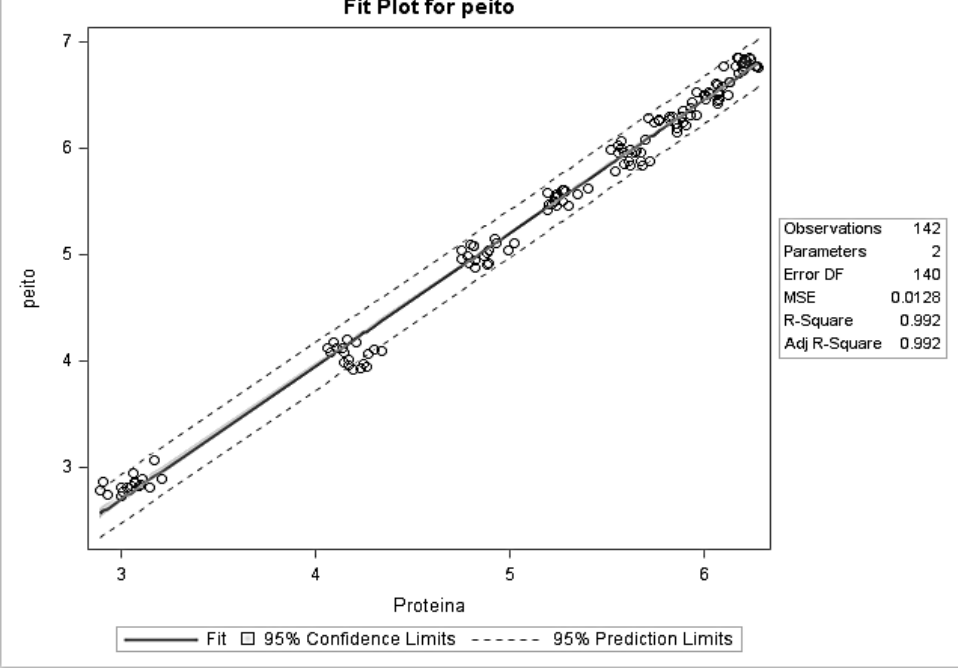


Apêndice $E$ - Alometria do peito com (1) e sem (2) $\circ 1^{\circ}$ dia de vida em relação ao peso corporal em jejum e depenado (PCJD) em machos (a) e fêmeas (b)

1a)

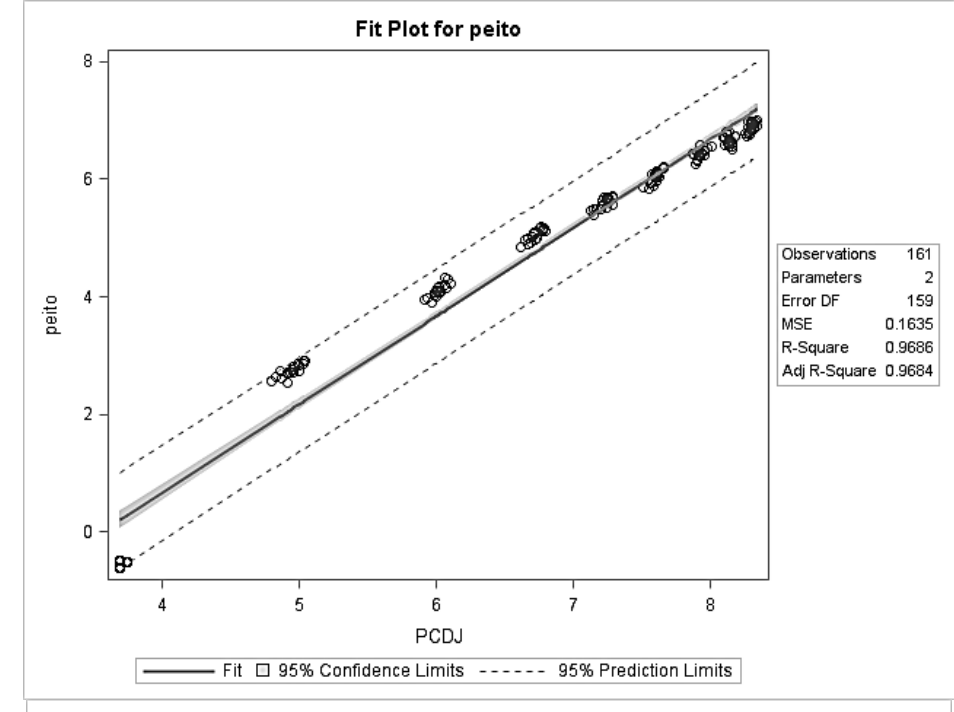

2a)

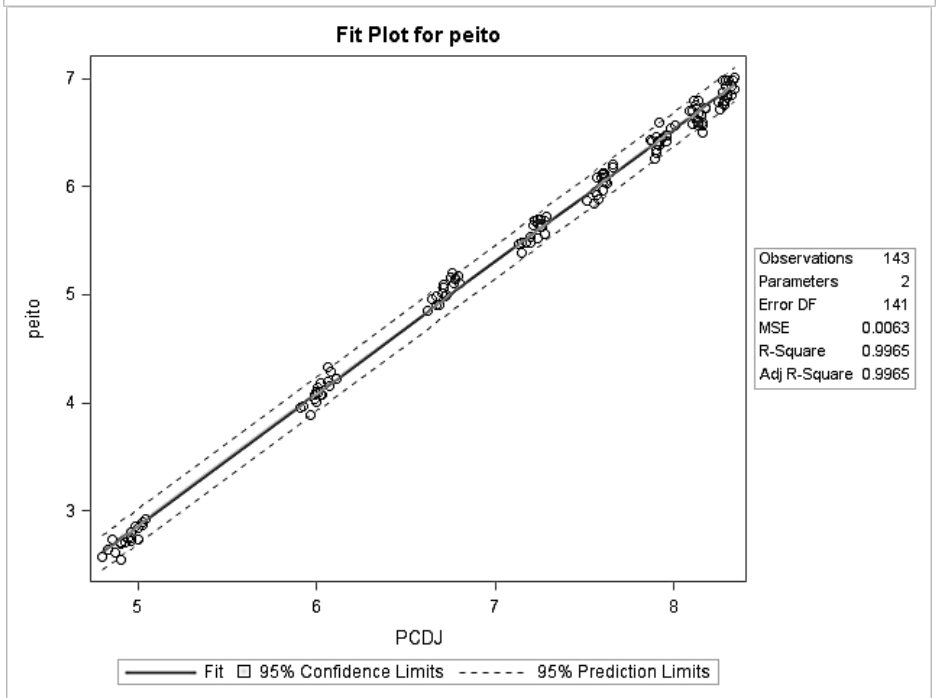

1b)
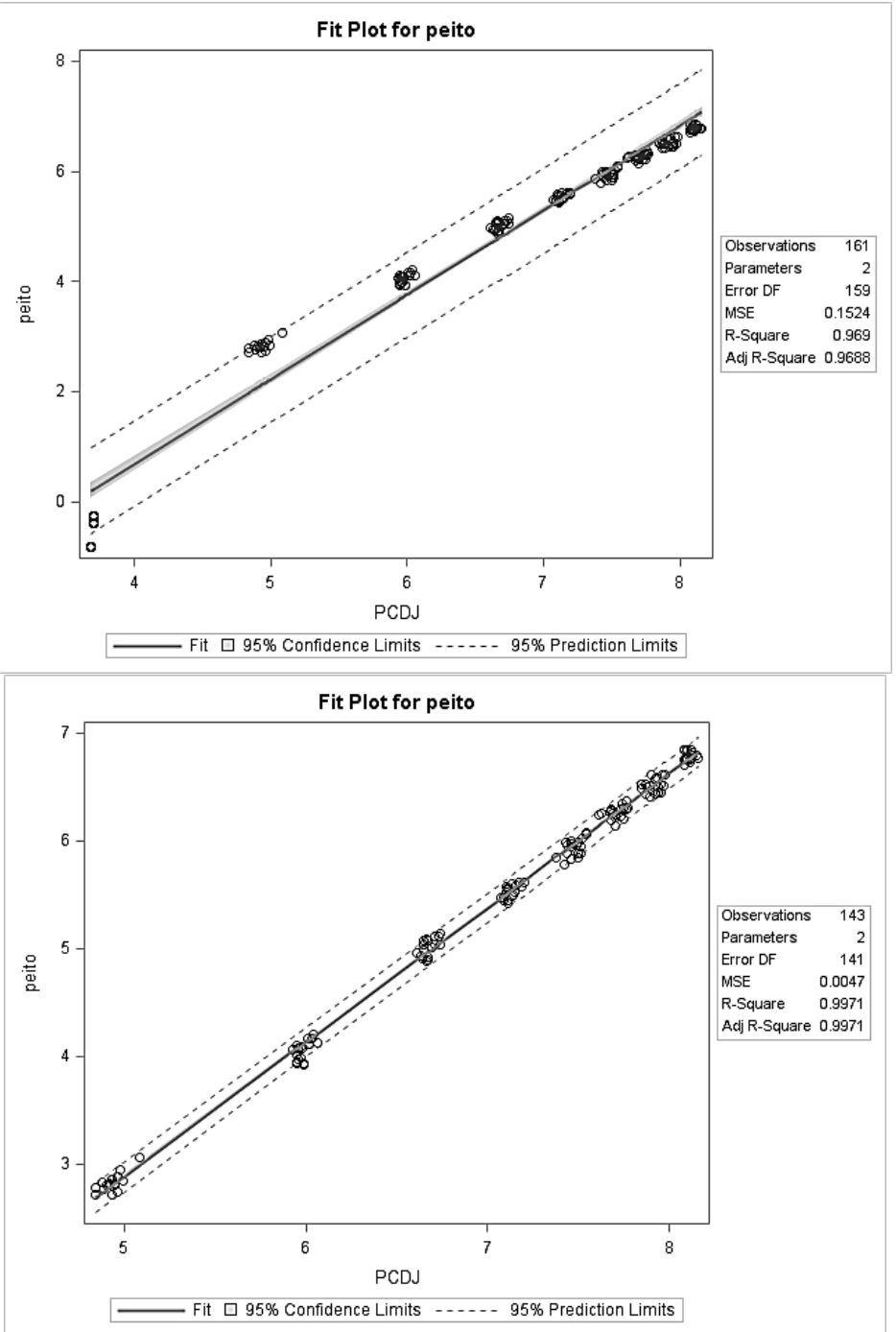
Apêndice F - Alometria da moela com (1) e sem (2) $01^{\circ}$ dia de vida das aves em relação ao peso corporal em jejum e depenado (PCJD) em machos (a) e fêmeas (b)

1a)

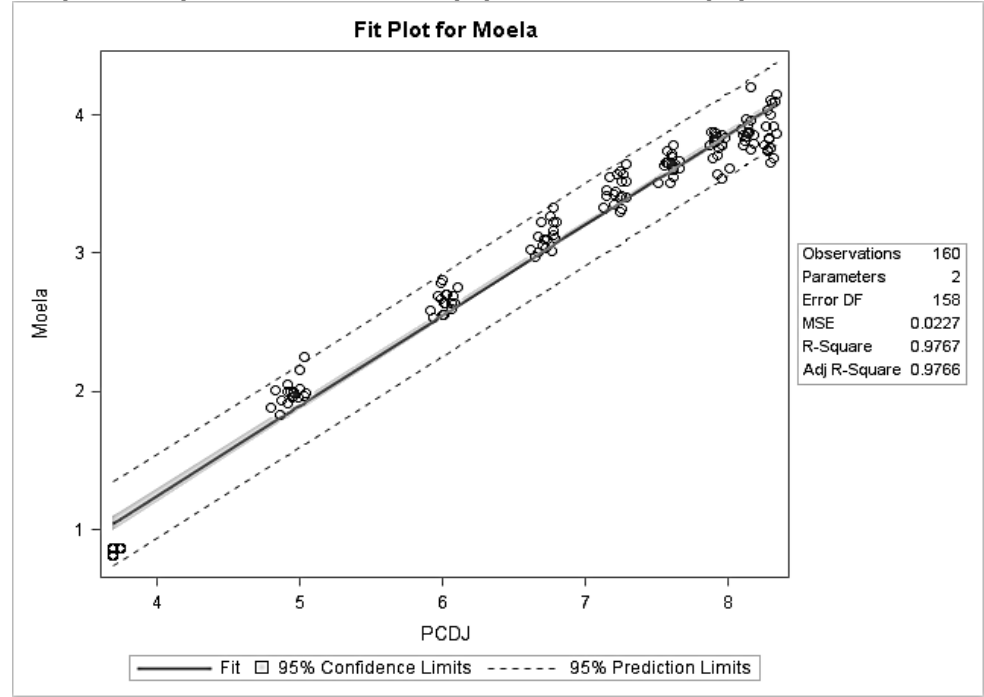

2a)

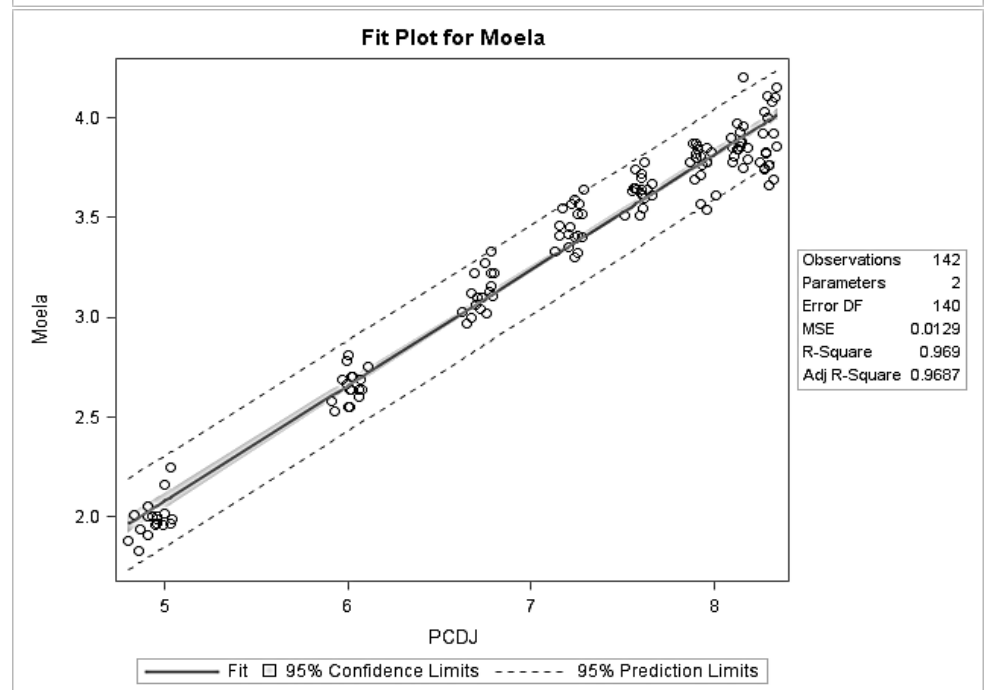

1b)

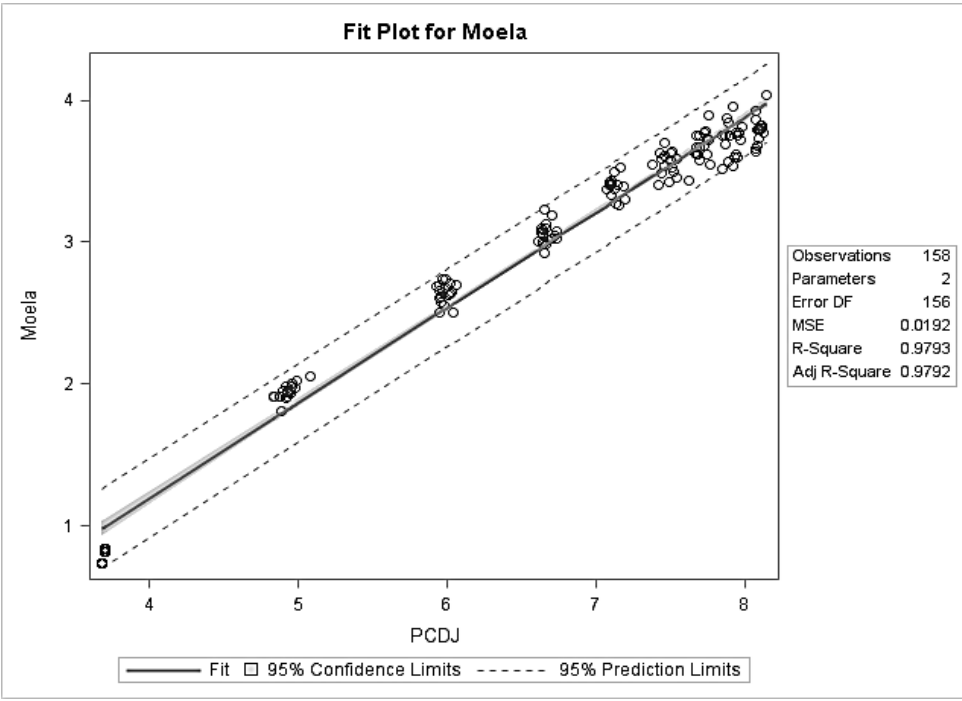

2b)

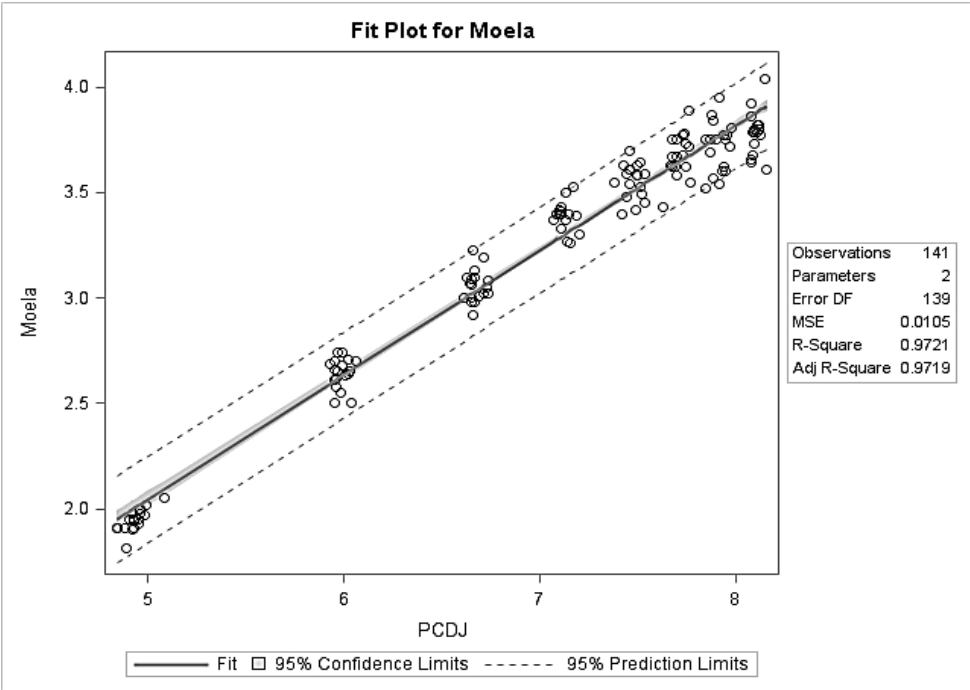

